\title{
When an eddy encounters shelf-slope topography
}

\author{
by \\ Deepak Abraham Cherian
}

B.Tech. (H), Indian Institute of Technology, Kharagpur (2010)

M.Tech., Indian Institute of Technology, Kharagpur (2010)

Submitted to the Joint Program in Physical Oceanography

in partial fulfillment of the requirements for the degree of

Doctor of Philosophy

at the

MASSACHUSETTS INSTITUTE OF TECHNOLOGY

and the

WOODS HOLE OCEANOGRAPHIC INSTITUTION

September 2016

(92016 Deepak A. Cherian.

All rights reserved.

The author hereby grants to MIT and WHOI permission to reproduce and to distribute publicly paper and electronic copies of this thesis document in whole or in part in any medium now known or hereafter created.

Author

Joint Program in Physical Oceanography Massachusetts Institute of Technology and Woods Hole Oceanographic Institution

July 27, 2016

Certified by

Kenneth H. Brink

Scientist Emeritus

Woods Hole Oceanographic Institution

Thesis Supervisor

Accepted by

Lawrence J. Pratt

Senior Scientist in Physical Oceanography

Woods Hole Oceanographic Institution

Chair, Joint Committee for Physical Oceanography 


\title{
When an eddy encounters shelf-slope topography
}

\author{
by \\ Deepak Abraham Cherian
}

\begin{abstract}
Submitted to the Joint Program in Physical Oceanography, Massachusetts Institute of Technology and Woods Hole Oceanographic Institution, on July 27, 2016, in partial fulfillment of the requirements for the degree of

Doctor of Philosophy in Physical Oceanography
\end{abstract}

\begin{abstract}
Eddies in the ocean move westwards. Those shed by western boundary currents must then interact with continental shelf-slope topography at the western boundary. The presence of other eddies and mean flows complicates this simple picture, yet satellite images show that mesoscale eddies translating near the shelfbreak routinely affect the continental shelves of the Mid-Atlantic Bight, the Gulf of Mexico etc. The consequent cross-shelfbreak transports are currently of unknown importance to shelf budgets of heat, salt and volume.

Thus motivated, this thesis uses idealized continuously stratified numerical experiments to explore eddy-slope interactions under four questions:

1. Can the continental slope prevent an eddy from reaching the shelfbreak?

2. What is the structure of the eddy-driven offshore flow?

3. How is the continental shelf affected by an eddy at the shelfbreak?

4. Given surface observations, can one estimate the volume of water transported across the shelfbreak?

The experiments show that the efficiency of Rossby wave radiation from the eddy controls whether it can cross isobaths: by radiating energy the eddy becomes shallow enough to move into shallower water. For wide continental slopes, relative to an eddy diameter, a slope can prevent an anticyclone from reaching the shelfbreak by shutting down such radiation. For narrow continental slopes, the interaction repeatedly produces dipoles, whose cyclonic halves contain shelf-slope water stacked over eddy water. The formation of such cyclones is explained. Then, the structure of shelf flows forced by the eddy are studied: their vertical structures are rationalized and scalings derived for their cross-isobath scales; for example, the extent to which the eddy influences the shelf. A recipe for estimating cross-isobath transports based on eddy surface properties is put forward. Finally, the findings are tested against observations in the Middle Atlantic Bight off the northeastern United States.
\end{abstract}

Thesis Supervisor: Kenneth H. Brink

Title: Scientist Emeritus

Woods Hole Oceanographic Institution 


\section{Acknowledgments}

What follows would not have been possible without the support, friendship and care of many people. My family has always been extremely supportive, encouraging, and understanding when I told them I wanted to move half the country away for my Bachelor's degree and then half the world away for graduate school. It is to them that this thesis is dedicated.

Ken has been the ideal guruji, patiently guiding me through many crests and troughs, consistently supportive, persistently encouraging and always patient. I shall miss our weekly wide-ranging conversations on oceanography, trains, history, hiking, politics, and much more. I look forward to many more such conversations in the future. I will particularly miss the many tales prompted by his eclectic office décor (includes one red herring, one pink flamingo and one bottle of tasteless water from Outhouse Springs among others). Steve Lentz will remain an inspiration: his reading was always rigorous, insight always enviable and patience always remarkable. His door has always remained open, despite Becca and I conspiring to chew up all his time. Much time spent in Glenn Flierl's office and classes have convinced me that he is the Zen master of physical oceanography - it is quite possible that fluid dynamical wisdom has never before been dispensed in such pithy form so persistently. It was a great honour to learn about eddies from him. Amala Mahadevan consistently encouraged me to think about my career path, vorticity, presenting my work to a larger audience and connecting my work to observations. In particular, she took me on an extremely educational and unforgettable cruise in the Bay of Bengal. Tom Farrar was always encouraging and helpful all six years. I look forward to our future collaboration. I have also learned an incredible amount from discussions with Joe Pedlosky, Joe LaCasce and Jamie Pringle.

Kate has been a constant companion, a special friend and bedrock. I owe a lot to my classmates and officemates - Dan, Melissa, Becca and Sophie - for advice, support and many fun times. Missy Issy made the office very cheerful; good accompaniment to Becca's recommended daily allowance servings of citrus and Dan's chocolate peddling. Rene and Kelsey were inordinately persistent at bringing cheer, roasted eggplant and ginger cookies. Arthur's practice of wearing a scarf indoors and his fondness for the Phoenix Landing and Californian wines provided lots of hilarity. I shall fondly remember Ben "Good Ben" Mandler for multiple wine tastings, a great Veggie Galaxy rant and many concerts; 
"Rough Steve" Messenger for many Steversations about Muddy flooring, politics and parking space-savers, and being a good sport and a great supportive friend; Joshua Giraffe for baiting Steve and helping me appreciate whiskey and Jay Z.; Princess Sophie for teaching me office dance moves; Sara Bosshart for being my Swiss chocolate dealer; Alex Bergan for being my homebrew dealer; Aimee for introducing me to podcasts, science radio shows and fun nights at Phoenix; Yodi for many nights of froyo and Seinfeld, for being my Eritrean food guide (shurro!) and for tolerating impromptu renditions of Skyfall (playing now) by Arthur, Ruel, Kinsley and I; Marie and Kinsley for an absolutely epic Muse concert; Papa Jaap for being ever-ridiculous in more ways than can be recounted here; Elena for humoring Papa Jaap and I being ridiculous (Röck Storagè), and her chicken soup for the grad-student soul; Ruel for his acerbic wit, many games of badminton and highbrow critical appreciation of Dwayne Johnson; Mike Sori for being a great cardboard cutout; Melissa for always making me try new things; Emily Zakem for many Souperbowl nights; Bryan and Fran for introducing me to Chicha; Cris for introducing me to Fulo; Kyrstin for Dinotopes; Andy and Dan for I-don't-know-how-many evenings spent chatting and cooking wonderful food.

Living with Dan \& Rene made WHOI housing infinitely more bearable. Brian Green classed up many evenings with fancy cocktails and literary chatter; grilling and being beardly with Nick Beaird is hard to top; Christopher Kinsley is a riot, as might be expected for Scots; Bram was funny and Eva was punny. Katie Pitz and Harriet were always fun to be around; Sarah Rosengard was somehow always a rainbow; Alec was an inspiring rollercoaster; Ben "Young BZ" Klein was always sobering until beer made an appearance; Gabi was always \m/; and Frank and Alex Evans were always unimaginably great. Vivek was always up for pool at Flat Top Johnny's, kebabs at Mann-o-Salwas and concerts everywhere; Sreeja always had good advice and a seemingly never-ending supply of photographs of exotic locations; and Srinath and Ved have been phundastic and phabulous friends for more than a decade now.

I must also acknowledge high-performance computing support from Yellowstone (ark:/85065/d7wd3xhc) provided by NCAR's Computational and Information Systems Laboratory, sponsored by the National Science Foundation. The research presented here was funded by National Science Foundation grants OCE-1059632 and OCE-1433953. Funding support from the Academic Programs Office, WHOI is also gratefully acknowledged. 


\section{Contents}

1 Introduction 9

1.1 The continental shelf and cross-shelfbreak exchange . . . . . . . . . 9

1.2 Energizing smaller-scale flow . . . . . . . . . . . . . . 13

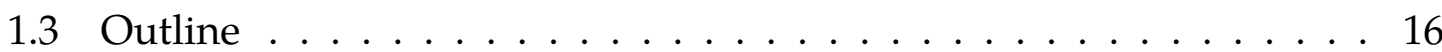

2 Problem formulation $\quad 19$

3 Diagnostics 23

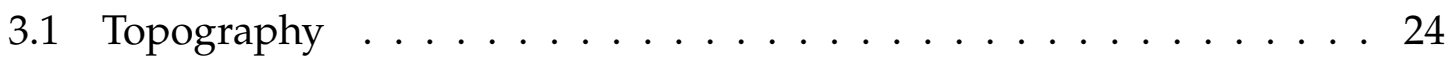

3.2 Eddy diagnostics . . . . . . . . . . . . . . . . 24

3.3 Calculating fluxes . . . . . . . . . . . . . . . 25

3.4 Resolution dependence . . . . . . . . . . . . . . . . . . . 28

4 Arresting an eddy's cross-isobath translation 29

4.1 Introduction . . . . . . . . . . . . . . . . . . . . . . 29

4.2 Additional diagnostics . . . . . . . . . . . . . . . . . 32

4.3 A typical simulation . . . . . . . . . . . . . . . . 32

4.4 Where the slope stops an eddy . . . . . . . . . . . . 33

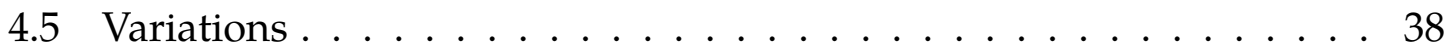

4.6 Summary and implications . . . . . . . . . . . . . . . . 40

4.7 Conclusion . . . . . . . . . . . . . . . . 42

5 An eddy encounters a steep narrow slope 51

5.1 Introduction . . . . . . . . . . . . . . . . . 51

5.2 A typical simulation . . . . . . . . . . . . . . . 52

5.3 Streamer flow over the slope . . . . . . . . . . . . . . . . . 55 
5.4 The fate of shelf-slope water . . . . . . . . . . . . . . . 64

5.5 Flow over a flat shelf $\ldots \ldots \ldots$. . . . . . . . . . 67

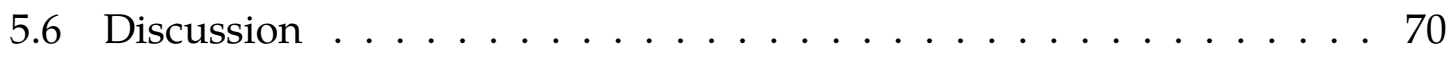

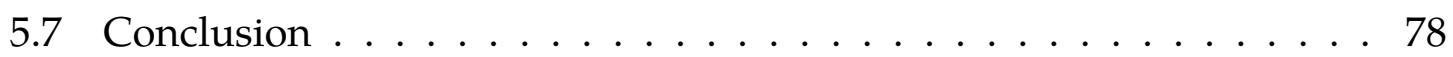

6 The forcing of sloping shelves by anticyclones at the shelfbreak $\quad 79$

6.1 Introduction . . . . . . . . . . . . . . . 79

6.2 Qualitative evolution . . . . . . . . . . . . . . . . . 79

6.3 Additional diagnostics . . . . . . . . . . . . . . 83

6.4 Flow over a sloping shelf . . . . . . . . . . . . . . . . . . 84

6.5 The effect of bottom friction $\ldots \ldots \ldots \ldots$

6.6 Summary . . . . . . . . . . . . . . . . . 99

$\begin{array}{lll}7 & \text { A recipe for cross-isobath fluxes } & 101\end{array}$

8 Discussion 107

8.1 Summary . . . . . . . . . . . . . . . . . . 107

8.2 Implications for the Middle Atlantic Bight . . . . . . . . . . . 108

8.3 Limitations and extensions . . . . . . . . . . . . . . . 114

$\begin{array}{ll}\text { A Simulation parameters } & 117\end{array}$

B When can an eddy cross the shelfbreak? 125

$\begin{array}{ll}\text { C ROMS configuration } & 127\end{array}$ 


\section{$1 \quad$ Introduction}

Mesoscale geostrophic eddies account for $90 \%$ of oceanic kinetic energy (Ferrari and Wunsch, 2009). They move dominantly westwards (Chelton et al., 2011) and eventually, interact with abrupt topographic features: seamounts, mid-ocean ridges, islands and continental margins. The ensuing interaction affects

the continental shelf through cross-shelfbreak fluxes of volume, heat and salt (for example, Lentz, 2010), and

the mesoscale eddy field by transferring energy to smaller scale flows that presumably eventually lead to dissipation (for example, Dewar and Hogg, 2010).

\subsection{The continental shelf and cross-shelfbreak exchange}

The coastal ocean is salty; much more so than an estuary. Since river inputs are fresh and surface fluxes $(E-P)$ can be unimportant (Lentz, 2010), there must exist an onshore salt flux across the shelfbreak; its importance to shelf budgets around the world being variable (Brink, 1998). Mesoscale deep-ocean eddies at the shelfbreak contribute to this flux by transporting fresh shelf water offshore and moving salty slope water onshore. Offshore fluxes are regularly observed in the Mid-Atlantic Bight off the north-eastern United States (for e.g. Joyce et al., 1992, and SST imagery) and in the Gulf of Mexico (Vukovich and Waddell, 1991; Frolov et al., 2004). The process might be important at other locations: along the East Australian shelf (Olson, 1991), the Gulf of Alaska (Okkonen et al., 2003; Ladd et al., 2007), the Mozambique channel (Roberts et al., 2014), off the Spanish coast (Peliz et al., 2004), in the Black 
Sea (Shapiro et al., 2010; Zhou et al., 2014), the Bering Sea (Mizobata et al., 2006), the Antarctic shelf (Stewart and Thompson, 2015), etc.

For example, the Gulf Stream is unstable, and frequently its meanders pinch off as large eddies, or rings, that are approximately $1000 \mathrm{~m}$ deep and $60-90 \mathrm{~km}$ in radius (Figure 1.1). Those that are not quickly reabsorbed by the Gulf Stream or its meanders move westward toward the shelfbreak off the northeastern United States. Upon encountering the shelfbreak, they move southwestward parallel to the shelfbreak until the Gulf Stream reabsorbs them at approximately $37^{\circ} \mathrm{N}$. During their southwestward transit, the rings transport cold shelf water offshore in filaments, termed 'streamers' (Joyce, 1984). In some cases, as in Figure 1.2, the interaction forms secondary cyclonic vortices of shelf water (Evans et al., 1985; Garfield and Evans, 1987; Kennelly et al., 1985). The shelf water is permanently exported: drifters deployed on the shelf and later entrained in a streamer eventually moved into the Gulf Stream (Bisagni, 1983). Rings also transport warm salty slope and eddy water onto the shelf to the southwest of the eddy center (Oey and Zhang, 2004; Lee and Brink, 2010; Zhang and Gawarkiewicz, 2015).

How important are such cross-shelfbreak fluxes to shelf budgets of volume, heat and salt? For the Mid-Atlantic Bight, Lentz (2010) found that an onshore salt flux of $0.7 \times 10^{-2} \mathrm{~kg} / \mathrm{m}^{2} / \mathrm{s}^{2}$ at the $100 \mathrm{~m}$ isobath ${ }^{1}$ - driven by time dependent flows is required to close the salt balance along the 50 - and $70-\mathrm{m}$ isobaths. The volume budget of Brink (1998) requires the offshore flux of shelf water to be 0.04-0.11 Sv. Various cross-frontal exchange processes are evidently responsible for these fluxes. Mesoscale eddy driven exchange could account for some of the unexplained salt flux in Lentz (2010) since on average, seven rings interact with the Mid-Atlantic Bight shelf south of George's Bank in a year (Figure 1.1 and Garfield and Evans, 1987). The episodic nature of eddy-driven exchange makes field observations of such exchange difficult, and the in-situ observational record is sparse. Only two estimates, viz. those of Joyce et al. (1992) and Lee and Brink (2010), use ADCPs to obtain direct velocity cross-sections. For the same salinity threshold, $S<33$, both estimates are of similar magnitude: 30 and $70 \mathrm{mSv}$.

Table 1.1 lists published estimates of these fluxes; most being extrapolations of sparsely sampled data. The use of different salinity thresholds to identify shelf water adds to the spread in estimates. Since satellite observations are currently the best record of these exchanges, it is of interest to use them to obtain estimates of

\footnotetext{
${ }^{1}$ approximately the shelfbreak
} 
cross-isobath fluxes - the primary motivation for this thesis.

In addition to transport magnitudes, the presence of large eddies at the shelfbreak raises several questions about how the eddies affect the continental shelf. For example, where, in the along-isobath direction, is the source of the exported shelf water? How far onshore of the shelfbreak can the eddy extract water? To what extent can eddy water penetrate on to the shelf? Is shelf water exported primarily from near the surface or from the bottom? Answering these questions requires that we understand the interaction of eddies with steeply sloping topography and the resulting flow field.

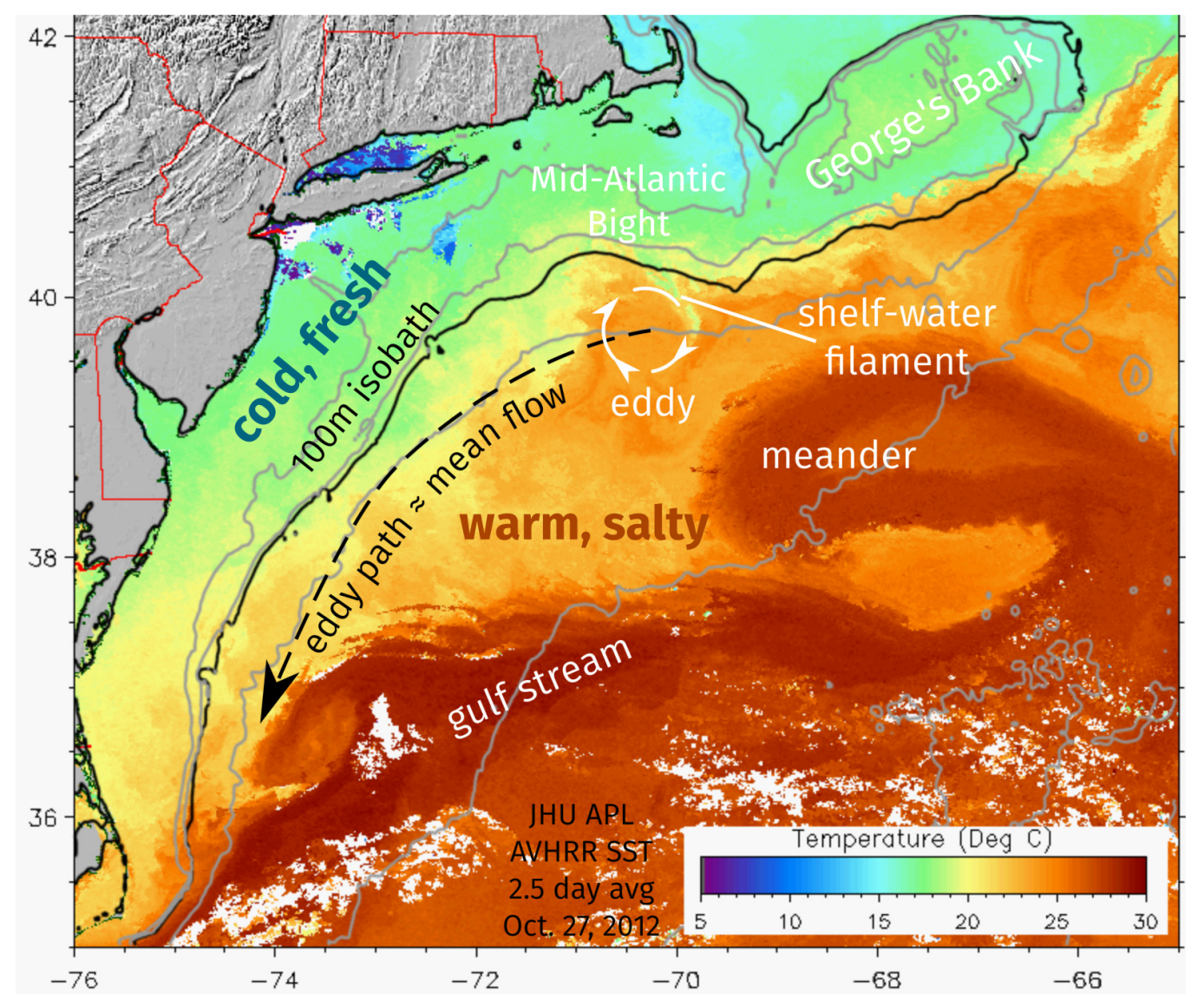

Figure 1.1: AVHRR SST image showing the Gulf Stream and a warm-core ring (WCR). The ring is drawing a cold streamer of shelf water across the shelfbreak into deep water. 




Copyright 2015 by the Ocean Remote Sensing Group, Johns Hopkins University Applied Physics Laboratory

Figure 1.2: A shelf-slope water cyclone formed when a Gulf-Stream warm-core ring is at the shelfbreak. 


\subsection{Energizing smaller-scale flow}

Eddy-topography interaction is also relevant to larger scale ocean circulation: the resulting flow features represent a transfer of energy to smaller scales. Ferrari and Wunsch (2009) identify the following as likely mechanisms that dissipate most of the mesoscale kinetic energy field:
(a) bottom drag,
(b) loss of balance,
(c) interactions with the internal wave field,
(d) continental margin scattering/absorption, and
(e) suppression by wind work.

The focus here is on (d), the scattering of energy into smaller scales catalyzed by eddies interacting with steep topography. The simplest limit is the interaction of eddies with vertical walls over a flat bottom.

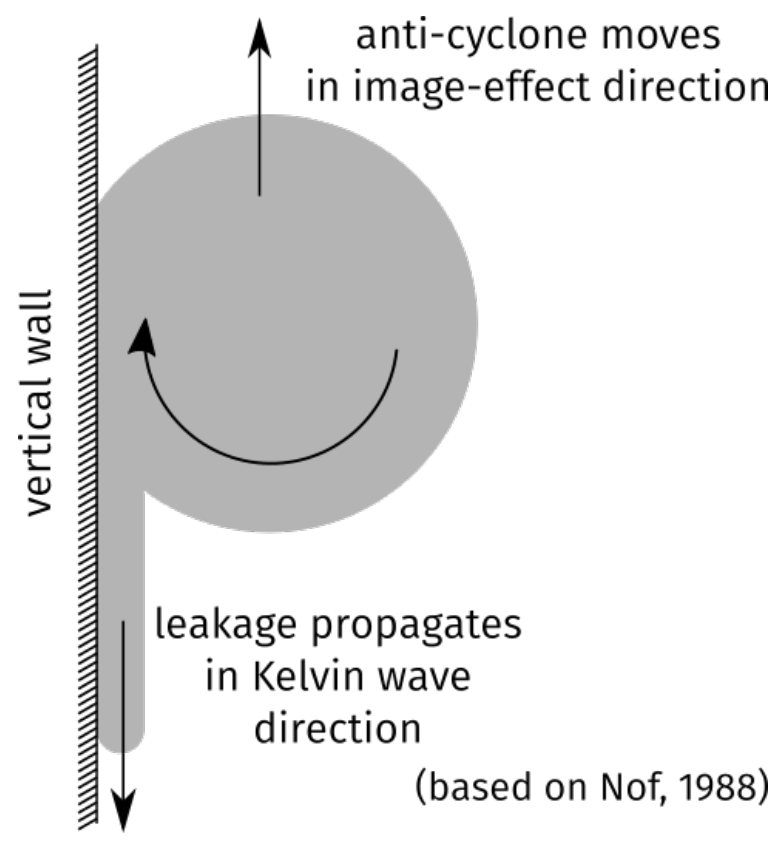

Figure 1.3: Schematic showing leakage from the eddy in the Kelvin wave direction based on Nof (1988) and succeeding work.

Nof (1988) was the first to show that in interacting with vertical walls, eddies leak fluid along the wall in the Kelvin wave direction (Figure 1.3). Just as for a 


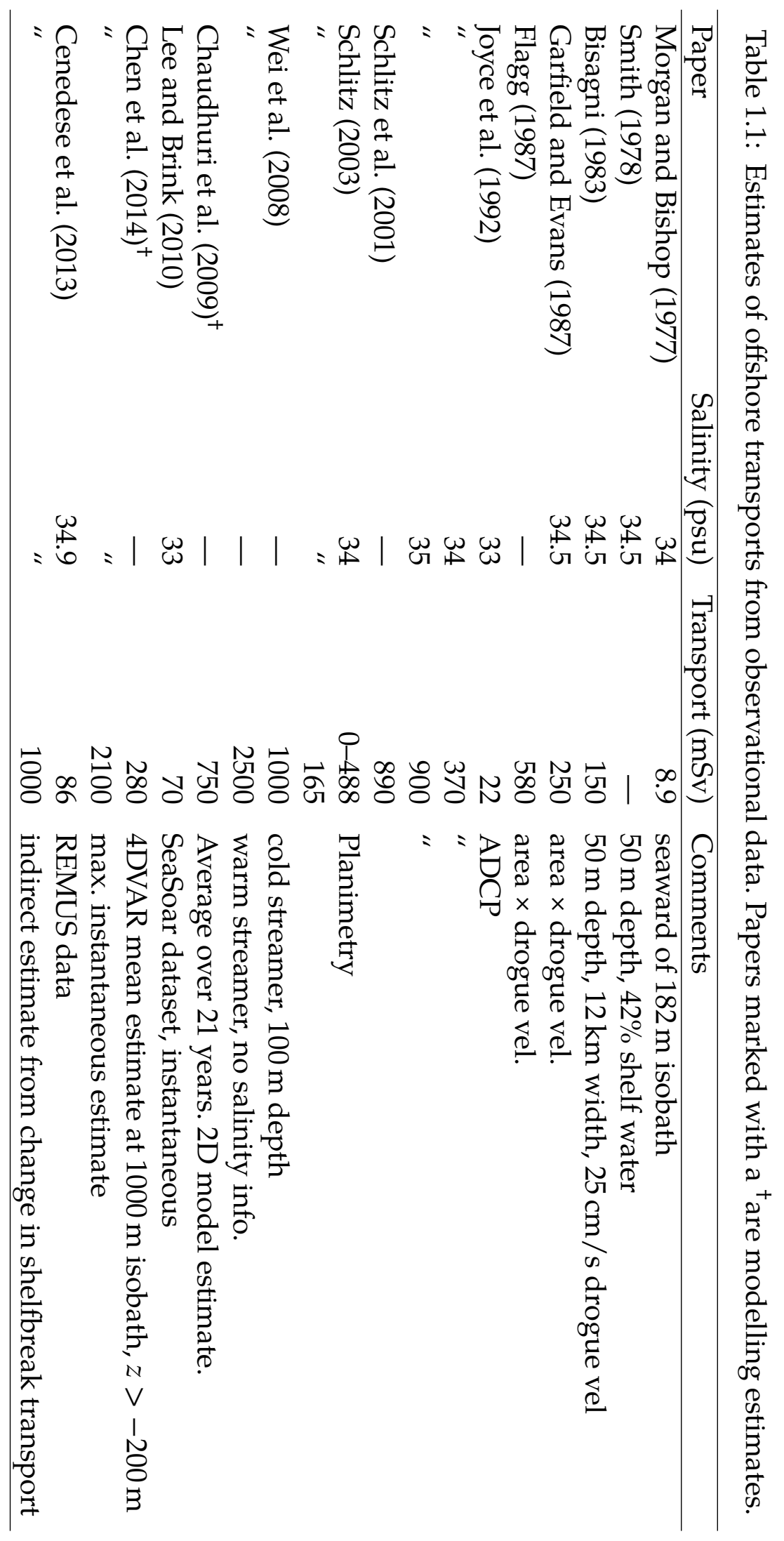


rocket, the leakage "pushes" the eddy along the wall in the opposite direction: hence termed "rocket effect". The rocket and image effects always propel the eddy in the same direction. Shi and Nof (1994) found that an initially circular eddy transformed into a D-like shape, termed "wodon"', as its streamlines adjusted to the presence of a wall: a quasi-geostrophic (QG) representation of the image effect. Eddies in the non-linear contour dynamics experiments of Shi and Nof (1993) exhibited similar, but more violent, behaviour. The leakage results from the growth of instability waves on the eddy's PV gradient. As the waves grow to finite amplitude, the eddy loses chunks of fluid, that propagate away from the eddy as smaller scale dipoles.

With the addition of shelf-slope-like topography, the evolution becomes more complicated (Chapters 5, 6). The advection of fluid across isobaths spins up secondary cyclones, in both near-surface and deep layers. These cyclones then interact with the original eddy, forming a dipolar system, resulting in a complicated looping trajectory. Investigators have also noted the excitation of topographic waves during the interactions; studied in more detail by Louis and Smith (1982) using theory and observations, and by Shaw and Divakar (1991) and Wang (1992) using numerical models.

Chapman and Brink (1987) used a superposition of linear waves to model the eddy as a linear, translating pressure disturbance. The eddy structure was not allowed to evolve in time. They found a bottom-intensified narrow jet along the shelfbreak directed downstream in the coastal trapped wave sense (i.e., moving such that shallow water is on the right in the northern hemisphere). Kelly and Chapman (1988) observed similar behaviour with a steady, linear and dissipative model. Wang (1992) described extensive barotropic and contour-dynamical numerical experiments of an anticyclone interacting with step topography. His findings, such as the spinup of secondary cyclones and the excitation of topographic waves, have held true for all subsequent studies.

Fewer studies have utilized continuously stratified models but in general, insights from simplified models like Wang (1992) and Shi and Nof (1993) appear to still apply. Oey and Zhang (2004) initialized their anticyclone over a slope. They observed a bottom-intensified slope jet similar to that in Chapman and Brink (1987) and secondary cyclones around the eddy. Their primary focus was on the effect of the bottom boundary layer associated with the leakage. Wei and Wang (2009)

\footnotetext{
${ }^{2}$ wall + modon
} 
started their eddies in deep water and described the subsequent evolution as the eddy interacted with the slope to the west. Again, the interaction resulted in the spin up of secondary cyclones and a bottom-intensified equatorward jet. Dewar and Hogg (2010) argued that mesoscale eddies in continuously stratified fluids arrest high mode topographic (or Kelvin) waves, leading to resonant transfer of energy from balanced motions to the unbalanced wave field. The data assimilative solution of Chen et al. (2014) also shows the formation of an equatorward leakage at the shelfbreak.

There exists some observational evidence for these smaller scale flow features. As part of the Warm Core Rings Experiment, Kennelly et al. (1985) reported observations of cyclonic 'ringlets' of approximately $20-30 \mathrm{~km}$ diameter, created in the northeast corner of the eddy, that are then advected around the eddy. They present hydrographic data showing a cyclone that contains shelf-slope water $(S<34)$ near the surface. Zhang and Gawarkiewicz (2015) recently reported glider and satellite observations of an equatorward leakage of ring water ${ }^{3}$ (in the Kelvin wave direction) at the Mid-Atlantic Bight. Lee and Brink (2010) also observed eddy water leaking on to the shelf and forming a small scale anticyclone.

In summary, there have been some attempts to examine the mechanisms underlying the creation of smaller-scale features, for which there exists some observational evidence. A majority of them have used simplified models: contour dynamics, two layer and quasigeostrophic models. Mechanistic insights from simplified models (for e.g., Shi and Nof, 1993) appear to still apply in primitive equation simulations (for e.g. Wei et al., 2008). However the structure of the smaller-scale features has not been examined in detail - a second motivation for this thesis.

\subsection{Outline}

So motivated, this thesis tackles four questions:

1. Can an eddy always get to the shelfbreak?

In the batrotropic limit, wide bottom slopes repel anticyclones to deeper water (Smith and O'Brien, 1983; LaCasce, 1998) ${ }^{4}$. It is possible that steep continental slopes prevent eddies from reaching the shelfbreak and so, influence their ability to effectively extract water from the shelf.

\footnotetext{
3termed "Pinnochio's Nose Intrusion" by them

${ }^{4}$ this bit of literature is summarized in Chapter 4
} 
2. What is the structure of the smaller scale flows energized during the interaction? For example, are shelf water cyclones always formed? What are the horizontal and vertical scales of these cyclones?

3. How is the shelf affected by an eddy at the shelfbreak? For example, from how far onshore can the eddy extract water? How much of the shelf is affected by the eddy driven flow?

4. Given surface observations, can we estimate the volume of water transported across the shelfbreak?

If possible, satellite-derived eddy properties may be used to estimate offshore flux magnitudes for a given anticyclonic eddy.

Given the sparsity of in-situ observations, an idealized numerical modeling approach is adopted, wherein a single anticyclonic eddy initialized in deep water on a planetary $\beta$-plane interacts with shelf-slope topography. There is no background flow - the presence of a shelfbreak front and mean flows over the slope are ignored even though both are present off the northeastern United States. The main elements of the problem viz., shelf-slope topography, anticyclonic eddy, and ambient stratification, are all reduced to the simplest possible form, so as to clearly isolate the eddy-topography interaction. As Section 8.3 points out, simulations with background flows, especially a shelfbreak frontal jet, are required to clarify the applicability of the presented results to the real ocean. 


\section{$2 \quad$ Problem formulation}

The model used throughout is an idealized configuration of the hydrostatic, primitive equation Regional Ocean Modeling System (Shchepetkin and McWilliams, 2005). It solves the equations ( $\rho \equiv \rho_{0}+\rho(x, y, z, t)$, subscripts represent differentiation, and $\left.\nabla=\partial_{x} \hat{i}+\partial_{y} \hat{j}\right)$ :

$$
\begin{aligned}
u_{t}+u u_{x}+v u_{y}+w u_{z}-f v=- & \frac{1}{\rho_{0}} p_{x}+\left(A_{v} u_{z}\right)_{z} \\
& \quad+\nabla \cdot\left(A_{H} \nabla u\right)+\underbrace{\nabla \cdot \sqrt{A_{B}} \nabla\left(\nabla \cdot \sqrt{A_{B}} \nabla u\right)}_{\text {biharmonic viscosity }} \\
v_{t}+u v_{x}+v v_{y}+w v_{z}+f u=- & \frac{1}{\rho_{0}} p_{y}+\left(A_{v} v_{z}\right)_{z} \\
& \quad+\nabla \cdot\left(A_{H} \nabla v\right)+\nabla \cdot \sqrt{A_{B}} \nabla\left(\nabla \cdot \sqrt{A_{B}} \nabla v\right) \\
0= & -p_{z}-\rho g \\
u_{x}+v_{y}+w_{z}= & 0 \quad\left(\kappa_{v} \rho_{z}\right)_{z}+\nabla \cdot\left(\kappa_{H} \nabla \rho\right)+\underbrace{\nabla \cdot \sqrt{\kappa_{B}} \nabla\left(\nabla \cdot \sqrt{\kappa_{B}} \nabla \rho\right)}_{\text {biharmonic diffusivity }}
\end{aligned}
$$

Here, $(x, y, z)$ define a right handed Cartesian coordinate system with $x$ generally along-isobath; $y$, generally cross-isobath and $z$ positive upwards. The model domain is a $\beta$-plane with $f=f_{0}+\beta y$. The topography is constructed using three straight lines in the cross-isobath plane representing the shelf, the continental slope and the deep ocean respectively (Figure 2.1). The deep ocean bottom is always flat. The term "shelfbreak" refers to the intersection of the shelf and continental slope; while "slopebreak" refers to the intersection of the continental slope and the flat bottomed deep ocean (Figure 2.1). A four-point running mean applied six times 


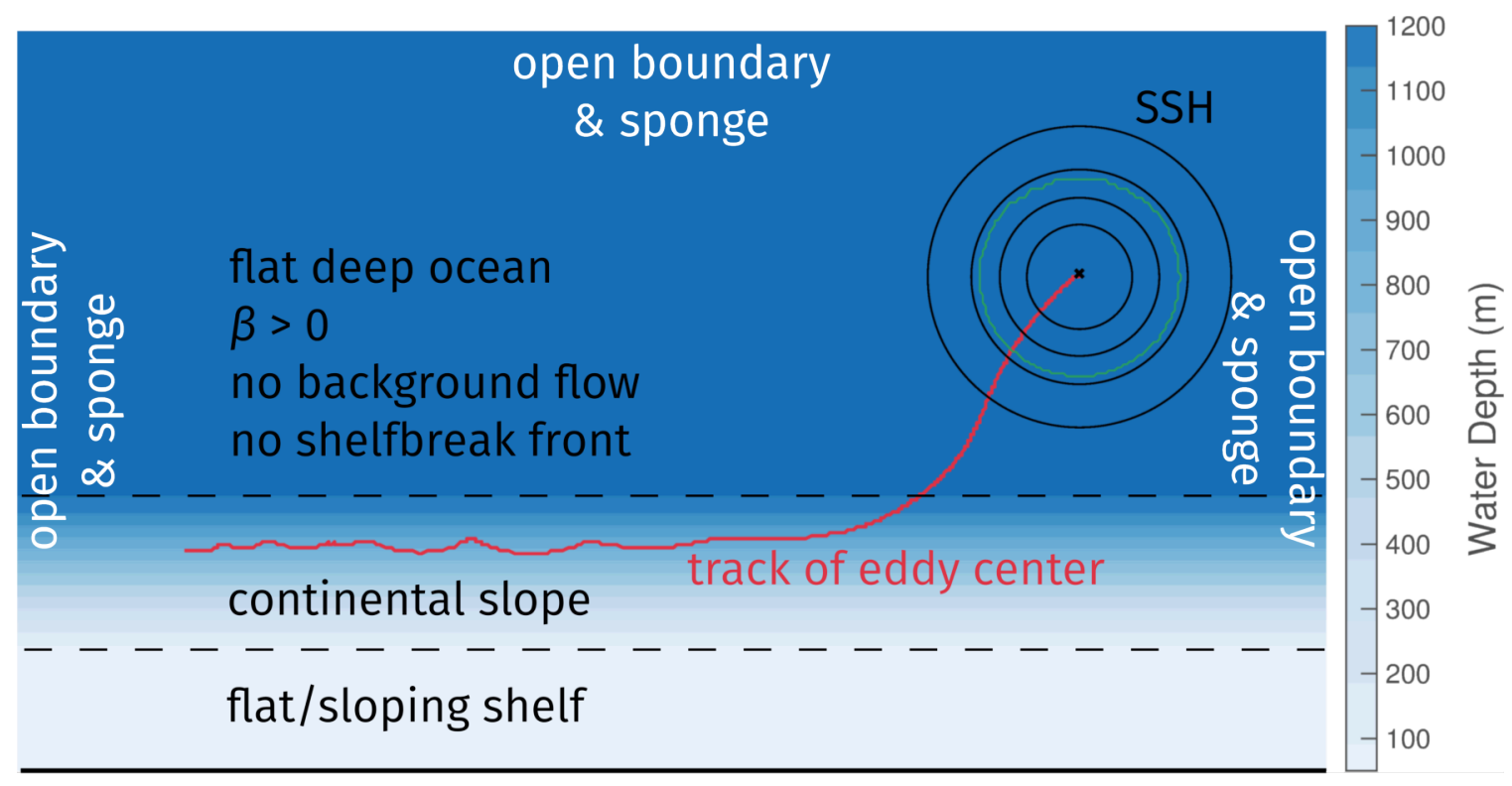

coastal wall

Figure 2.1: Model configuration with a southern coast. Water depth is in color with dashed black lines indicating the shelfbreak and slopebreak. The southern boundary is a coastal wall and the other three boundaries are open with $50 \mathrm{~km}$ sponge layers. The deep ocean is always flat. The eddy is initialized in the deep ocean as a Gaussian temperature anomaly. The solid black circular contours are SSH. The track of the eddy's center (SSH maximum) is shown in red. The green contour identifies the core of the eddy (Chapter 3).

smooths the bottom slope transitions at the shelfbreak and slopebreak.

The eddy is a radially symmetric, surface intensified, Gaussian temperature anomaly superimposed on background stratification $(\bar{\rho})$, as

$$
T_{\text {edd }}=T_{\mathrm{amp}} \exp \left[-(x / L)^{2}-(y / L)^{2}-\left(z / L^{z}\right)^{2}\right]
$$

The horizontal length scale $L$ is specified and the vertical scale is $L^{z}=\left(f_{0} L\right) /(N \sqrt{2})$, where $L / \sqrt{2}$ is the radius to maximum velocity. The density anomaly is balanced by a cyclo-geostrophic velocity field determined after prescribing zero velocity at the ocean's bottom. The ambient buoyancy frequency $N$ is constant for all simulations. To reduce model integration time, the eddy is generally started in deep water with its shoreward edge at the slopebreak (Figure 2.1). Its initial location is always at least 1.5 deformation radii away from the isobath of depth equal to its vertical scale. The eddy always starts in water deeper than its vertical scale i.e., it is "compensated" and has no deep flow initially. The eddy's initial evolution is similar to that 
over a flat bottomed ocean ${ }^{1}$ for at least the first 30 days. As in Wei et al. (2008), we let the eddy adjust to the $\beta$-plane in deep water before it impacts the slope, unlike previous $f$-plane studies (for e.g., Oey and Zhang, 2004) where the eddy starts on the slope.

Isolated anticyclonic eddies move southwestward on a $\beta$-plane (Mied and Lindemann, 1979; McWilliams and Flierl, 1979; Nof, 1983; Early et al., 2011). This tendency is used to move the eddy across isobaths without a cross-isobath background flow. The southwestward motion renders two coastal locations moot: for a coast at the north or east, the eddy will move away from the shelfbreak. The topography must be placed at either the western or southern boundary of the domain for the eddy to encounter it.

In the Mid-Atlantic Bight, the topography is present to the north and the west of the eddy, depending on location. The southwestward motion of an isolated eddy, means that one cannot use $\beta$ to move the isolated eddy towards a northern coast. Instead, most experiments described here use topography with a southern coast. With open eastern and western boundaries, this configuration allows Rossby waves radiated by the eddy to exit the domain (Mied and Lindemann, 1979; McWilliams and Flierl, 1979); allowing the eddy to interact with undisturbed shelf-slope waters. The latter is not true for a western coast because it traps Rossby wave momentum. Qualitatively, our results hold for both orientations because the secondary flow features that develop during the eddy-topography interaction are too small to be influenced by $\beta$. Once the eddy gets to the shelfbreak, the simulation is as if on an $f$-plane, and coastal orientation ceases to matter.

The coastal boundary is a free-slip wall. The other three boundaries are open. Boundary conditions used at these open boundaries are an explicit Chapman condition for the free-surface, a modified Flather condition for 2D momentum (Mason et al., 2010) and a combined radiation-nudging condition for tracers and 3D momentum (Marchesiello et al., 2001). Sponge layers are used to prevent noise at the open boundaries from contaminating the solution: $50 \mathrm{~km}$ (40 points) wide regions with lateral Laplacian viscosity $\left(A_{H}\right)$ linearly increasing from 0 to $50 \mathrm{~m}^{2} \mathrm{~s}^{-1}$ and lateral Laplacian diffusivity, $\kappa_{H}=0-5 \mathrm{~m}^{2} \mathrm{~s}^{-1}$.

For computational efficiency, a hyperbolic tangent function is used to stretch the horizontal grid spacing near the sponge layers at the open boundaries. Horizontal spacing ranges from $1 \mathrm{~km}$ to $2.5 \mathrm{~km}$. The results are insensitive to changes in grid

\footnotetext{
${ }^{1}$ verified using a flat bottom simulation
} 
spacing. In the vertical, 72 grid points are distributed such that vertical grid spacing is smallest near the surface and largest near the bottom $(0.6-25 \mathrm{~m})$. A density Jacobian based algorithm (Shchepetkin and McWilliams, 2003) reduces pressure gradient error ${ }^{2}$. Biharmonic lateral viscosity $\left(A_{B}=4.4 \times 10^{6}-3 \times 10^{8} \mathrm{~m}^{4} \mathrm{~s}^{-1}\right)$ and diffusivity $\left(\kappa_{B}=1.2 \times 10^{3}-8 \times 10^{4} \mathrm{~m}^{4} \mathrm{~s}^{-1}\right)$ along sloping vertical co-ordinate surfaces ${ }^{3}$ controls noise outside the sponge layers. The values scale with grid cell size. The Laplacian coefficients $A_{H}, \kappa_{H}$ are 0 outside the sponge layers. The bottom friction term is linear with coefficient $r_{f}$,

$$
\tau_{\mathrm{bot}}=\rho_{0}\left(-r_{f} u,-r_{f} v\right) .
$$

For simplicity, there is no shelfbreak front, so shelf and slope waters are indistinguishable in density. Instead, each water parcel is tagged with its initial latitude using a passive tracer termed the "cross-shelf dye". This dye traces "shelf water": water parcels that initially start south of the shelfbreak; and "slope water": parcels that are initially between the shelf- and slope-break. We use a second passive tracer to track "eddy water". This passive tracer is initialized with value 1 where the temperature anomaly (2.2) is greater than some small value. In practice, not all of the dye with value 1 is carried with the eddy, but this conservative initial distribution lets us identify an eddy core that transports mass over long spatial and time scales. The eddy also homogenizes the cross-shelf dye within it, letting us distinguish it from the surrounding water.

\footnotetext{
${ }^{2}$ ROMS option DJ_GRADPS

${ }^{3}$ s-surfaces in ROMS terminology
} 


\section{Diagnostics}

Table 3.1: Terminology used in this thesis.

\begin{tabular}{ll}
\hline Term & Definition \\
\hline$\left(L_{0}, L^{z}\right)$ & Gaussian horizontal and vertical scales of the eddy \\
$V_{0}$ & Maximum radial velocity in eddy \\
$H$ & Water depth \\
$H_{\mathrm{max}}$ & Maximum water depth \\
$H_{\mathrm{arr}}$ & Water depth when eddy is arrested \\
$H_{\mathrm{sb}}$ & Shelfbreak depth \\
$\lambda$ & $H_{\mathrm{sb}} / L^{z}$, non-dimensional shelfbreak depth \\
$f_{0}$ & Mean Coriolis frequency \\
$\beta$ & Planetary PV gradient, $\frac{\mathrm{d} f}{\mathrm{~d} y}$ \\
$\beta_{t}$ & Topographic PV gradient, $f_{0} \alpha_{\mathrm{sl}} / H_{\mathrm{max}}$ \\
$\zeta$ & Vertical vorticity, $v_{x}-u_{y}$ \\
$\alpha_{\mathrm{sh}}, \alpha_{\mathrm{sl}}$ & Bottom slope magnitude on shelf and slope \\
$S_{\mathrm{sh}}, S_{\mathrm{sl}}$ & $\frac{\alpha N}{f_{0}}$, Shelf and slope Burger numbers \\
$L_{\mathrm{sh}}, L_{\mathrm{sl}}$ & Shelf and slope widths \\
$L_{\beta}$ & $\sqrt{\frac{V}{\beta_{\mathrm{sh}}}}$, inertial length scale \\
$N$ & Buoyancy frequency \\
$Y_{\mathrm{sb}}$ & Shelfbreak location \\
Ro, Rh & Rossby, Rhines (using $\beta)$ numbers of the eddy \\
$r_{f}$ & Linear bottom drag coefficient $\left(\mathrm{m} \mathrm{s}{ }^{-1}\right)$ \\
$\left(u_{s}, u_{b}\right)$ & Surface and bottom velocity \\
$\mathrm{BC}$ & Measure of vertical shear in flow, $\left|u_{s}-u_{b}\right| /\left|u_{s}\right|$ \\
$\varphi_{o}$ & $H_{\mathrm{sb}} S_{\mathrm{sh}} N / V_{0}$ \\
$R$ & Distance of eddy center to shelfbreak \\
$y / R$ & Non-dimensional isobath \\
\hline &
\end{tabular}




\subsection{Topography}

In what follows, subscripts 'sh', 'sl', 'sb' refer to the shelf, the continental slope and the shelfbreak respectively. $H$ is water depth, $H_{\max }$ is the maximum water depth in the domain, and $\alpha$ is the bottom slope, $\mathrm{d} H / \mathrm{d} y$ if $y$ is the cross-isobath direction. $Y_{\mathrm{sb}}$ is the location of the shelfbreak.

Three parameters will be used to describe the topography in this thesis. One, topographic $\beta$ for the shelf and slope defined as $\beta_{\mathrm{sh}}=\alpha_{\mathrm{sh}} f_{0} / H_{\mathrm{sb}}$ and $\beta_{t}=\alpha_{\mathrm{s}} f_{0} / H_{\mathrm{max}}$ respectively. Two, a slope Burger number defined as $S=\alpha N / f_{0} . S_{\mathrm{sh}}$ and $S_{\mathrm{sl}}$ refer to the shelf and the continental slope respectively. Finally, $\lambda=H_{\mathrm{sb}} / L^{z}$ is a nondimensional measure of the shelf depth relative to the eddy's vertical scale.

\subsection{Eddy diagnostics}

The eddy is tracked using the method described in Chelton et al. (2011) with slight modifications. The method detects a simply connected region within a closed SSH contour containing a SSH maximum (or minimum for a cyclone). The density anomaly value (with respect to background stratification) associated with the contour of maximum speed, or zero relative vorticity, within the detected region at $t=0$ is used to identify the eddy's core in three dimensions at all times. As will be shown, the 3D density anomaly surface successfully tracks dyed water that is transported in the eddy throughout the simulation. The eddy's center is defined as the location of the SSH maximum within the detected region.

Time series of the eddy's velocity and length scales are obtained by assuming that the eddy always remains a Gaussian density structure in all dimensions. At the surface, the density field is $\left(\rho_{e} \exp \left[-\left(r / L_{0}\right)^{2}\right]\right) ; r$ being radial distance from the eddy's center. The corresponding balanced geostrophic velocity field, with maximum velocity $V_{0}$, is described by

$$
V=(\sqrt{2 e}) V_{0}\left(\frac{r}{L_{0}}\right) e^{-\left(r / L_{0}\right)^{2}}
$$

Equation (3.1) is fit to the eddy's surface velocity along a horizontal line in the along-isobath direction. The fit determines the eddy's maximum azimuthal velocity $V_{0}$ and its Gaussian length scale $L_{0}$ at the latitude of the eddy's center. A Gaussian fit, $\exp \left(-z / L^{z^{2}}\right)$, to the vertical profile of the temperature anomaly at the eddy's center is used to diagnose its vertical scale $L^{z}$. This agrees well with the 3D 
structure of the density anomaly contour described earlier ${ }^{1}$. The turnover time is defined as the ratio of the eddy's length and velocity scales, $L_{0} / V_{0}$.

The eddy's Rossby and Rhines numbers are defined as

$$
\mathrm{Ro}=\left\langle\frac{v_{x}-u_{y}}{f}\right\rangle, \quad \mathrm{Rh}=\frac{V_{0}}{\beta L_{0}^{2}},
$$

where, \langle\rangle represents an area average within the eddy's core at the surface, $f(y)$ is the Coriolis parameter; planetary $\beta=\mathrm{d} f / \mathrm{d} y$ and $V_{0}, L_{0}$ are the velocity and length scales of the eddy. Typical values for a Gulf Stream warm core ring are Ro $\sim 0.12$ (Olson, 1991) and Rh 13 (McWilliams and Flierl, 1979).

\subsection{Calculating fluxes}
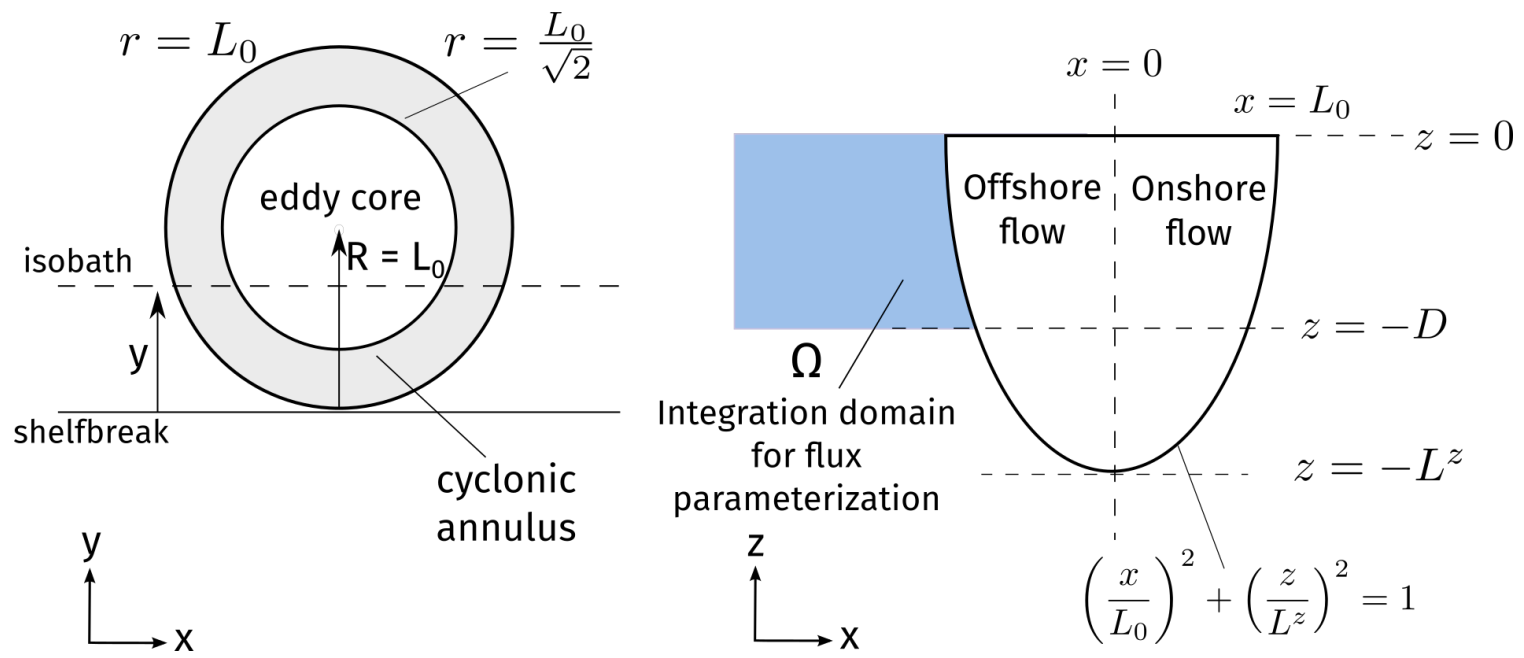

Figure 3.1: Schematics showing how the dye field is reconstructed to obtain a prediction for flux magnitude. (a) An idealized representation of the eddy as two concentric contours: the inner one is the radius to maximum velocity $r=L / \sqrt{2}$, and the outer is $r=L . z=-D$ is the depth to which the integration is conducted. $y, R$ are used to define a non-dimensional isobath value (Section 3.3), the flux across which will be compared across all runs. (b) In blue, the domain over which an idealized velocity field is integrated.

The instantaneous offshore flux is calculated as the integral of the cross-isobath velocity over the area containing water parcels that were initially inshore of the isobath; i.e., the advected water parcels have a cross-shelf dye value smaller than the ambient water at that isobath. In the vertical, the integration is between shelfbreak

\footnotetext{
${ }^{1}$ see Figure $4.2 \mathrm{~d}-\mathrm{f}$
} 


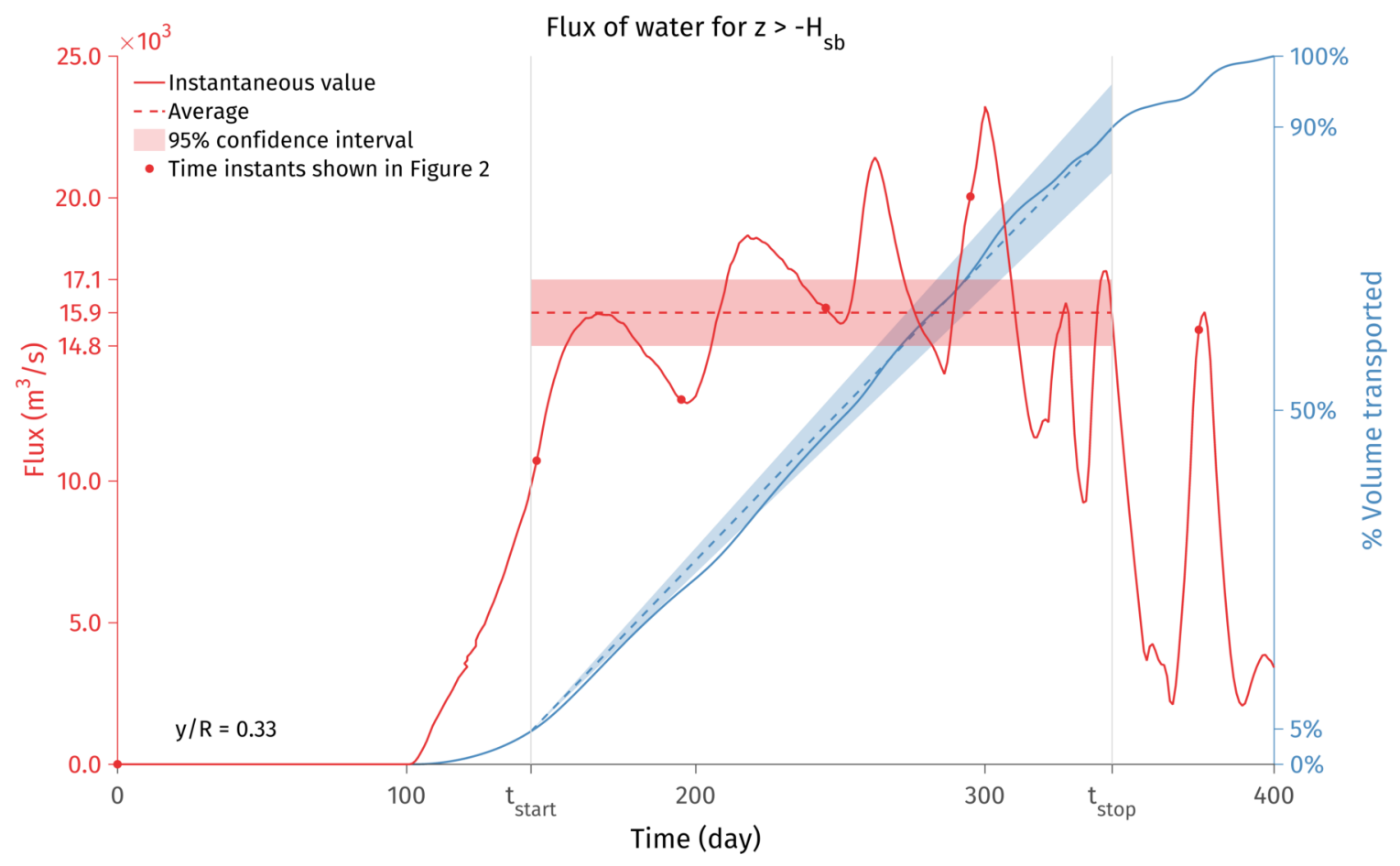

Figure 3.2: Flux diagnostics used in this thesis. The red solid line is a time series of the instantaneous offshore flux above $z=-H_{\mathrm{sb}}$ of water that originated inshore of non-dimensional isobath $y / R=1 / 3$, calculated at that isobath for the simulation in Figure 5.1. The blue solid line is the cumulative integral of this flux: the time series of the volume transported across that isobath. The average flux (dashed line) is calculated for the time interval starting when $5 \%$ of the total volume has been transported $\left(t_{\text {start }}\right)$ and ending when $90 \%$ of total volume has been transported $\left(t_{\text {stop }}\right)$. The interval $\left[t_{\text {start }}, t_{\text {stop }}\right]$ is indicated by the horizontal extent of the shaded regions. The vertical extent of the shading shows 95\% confidence bounds. Red dots indicate time instants of the snapshots in Figure 5.1.

depth and the surface. In the horizontal, the integration region is between the edge of the western sponge layer and the eddy's center with one exception. At the shelfbreak, we choose to integrate between the two sponge layers (justified in Section 5.5 and Figure 5.13).

A representative time series of instantaneous flux is shown in Figure 3.2 (red solid line). There is a ramp-up period as the eddy gets to the shelfbreak and later, a slow decrease in magnitude as the eddy translates along shore. The decrease is caused by the eddy slowly decaying as it loses mass to the leakage and energy to radiated waves (McWilliams and Flierl, 1979). The peaks and troughs in the time series are due to the eddy moving towards and then away from the shelfbreak, under the influence of smaller-scale secondary cyclones. 


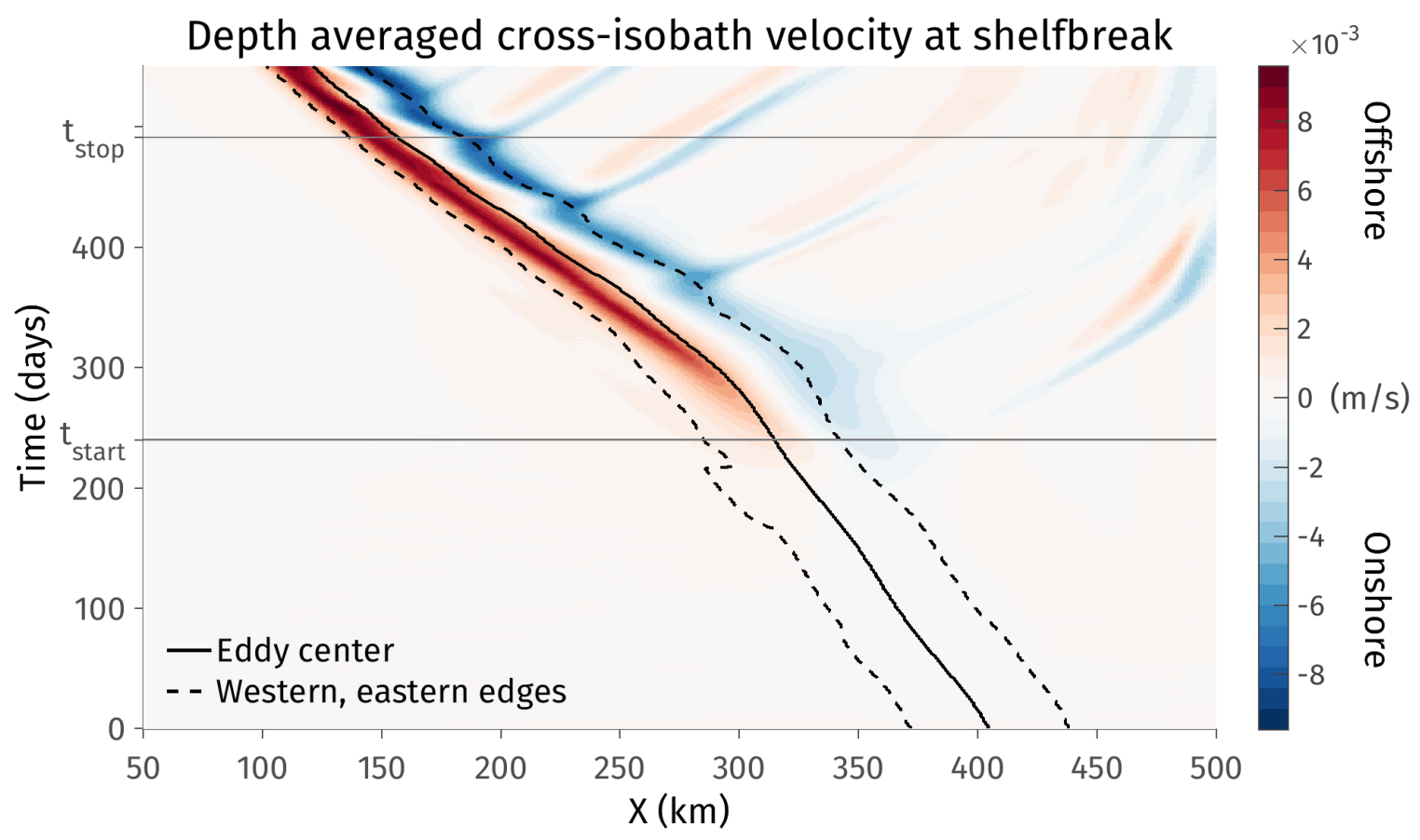

Figure 3.3: Representative Hovmöller diagram of depth-averaged cross-shelf velocity at the shelfbreak. Red is offshore flow and blue is onshore. The location of the eddy's center and its edges in the along-isobath direction are marked by the solid and dashed black lines respectively. The horizontal lines mark $\left[t_{\text {start }}, t_{\text {stop }}\right]$. Both the offshore and onshore flow are largest near the eddy. The along-isobath scale of both the outflow and the inflow is approximately an eddy radius. Small scale anticyclones formed by the instability of the eddy water leakage are seen propagating eastwards, downstream in the coastal trapped wave direction.

We seek to calculate an average flux across the isobath over a time interval that does not contain the ramp-up and decay phases. For this, we use the cumulative time integral of instantaneous flux: the total volume transported across the isobath up until that time (Figure 3.2, solid blue line). We choose the time interval $\left[t_{\text {start }}, t_{\text {stop }}\right]$, where $t_{\text {start }}$ is the time at which the cumulative volume transported is $5 \%$ of the total, and $t_{\text {stop }}$ is the time at which $90 \%$ of the total volume has been transported across the isobath. These thresholds were chosen to maximize length of the averaging time period while avoiding the ramp-up and decay phases. The average flux is calculated as the mean of the instantaneous flux in this time interval. The number of degrees of freedom is approximated by dividing the number of samples in $\left[t_{\text {start }}, t_{\text {stop }}\right]$ by an integral time scale estimate. The latter is the maximum time scale obtained by integrating the autocorrelation of the flux time series over successively larger lags (Talley et al., 2011). The vertical extent of the shaded region indicates the $95 \%$ confidence interval on the average flux estimate (Figure 3.2). Its 
horizontal extent shows the time interval, $\left[t_{\text {start }}, t_{\text {stop }}\right]$, over which the average is estimated.

A non-dimensional isobath location is used to compare flux estimates across different runs. It is defined as the ratio of $y$, the distance from the shelfbreak to the isobath, to $R$, distance from the shelfbreak to the eddy's center (Figure 3.1).

\subsection{Resolution dependence}

Experiments using a uniform $750 \mathrm{~m}$ grid compare favorably with those using a uniform $1 \mathrm{~km}$ grid. There are very slight differences in the track of the eddy. The average flux diagnostic differs only by $5 \%$ and the maximum flux increases by $15 \%$. Runs with and without horizontal grid stretching showed no difference in the diagnostics. 


\section{$4 \quad$ Arresting an eddy's cross-isobath translation}

\subsection{Introduction}

To maximize the cross-shelfbreak exchange in Figure 4.1a, an eddy must reach the shelfbreak i.e., the end of the continental slope. Is it possible for continental slopes to prevent eddies from reaching the shelfbreak?

Deep-ocean mesoscale eddies that originate in the deep ocean are influenced by planetary beta: $\beta=\mathrm{d} f / \mathrm{d} y \approx 2 \times 10^{-11} \mathrm{~m}^{-1} \mathrm{~s}^{-1}$ and $\beta L_{0} / f_{0} \approx \mathrm{O}\left(10^{-2}\right)$ (McWilliams and Flierl, 1979; Mied and Lindemann, 1979). Here, $f_{0}$ is the mean Coriolis frequency and $L_{0}$ is the radius to maximum velocity of the eddy. Sloping topography too provides a mean potential vorticity $(\mathrm{PV})$ gradient by forcing the stretching and compression of a water column when it crosses isobaths. Shallow water columns have higher PV than deeper water columns. The topographic PV gradient, or 'topographic beta' for the continental slope, is defined as $\beta_{t}=|\nabla H| f_{0} / H_{\max }, H_{\max }$ is the water depth of the bottom slope. For the continental slope off the Mid-Atlantic Bight, $\beta_{t} \approx 0.08 \mathrm{~m} \mathrm{~m}^{-1} \times 10^{-4} \mathrm{~s}^{-1} / 2000 \mathrm{~m} \approx O\left(10^{-9}\right) \mathrm{m}^{-1} \mathrm{~s}^{-1}$, two orders of magnitude larger than planetary $\beta$. The present question thus concerns the translation of eddies across PV gradients and the competition between planetary and topographic PV gradients especially with continuous stratification.

When placed on a PV gradient, eddies translate while radiating Rossby waves (for e.g., McWilliams and Flierl, 1979; Smith and O'Brien, 1983). Zonally, all eddies translate with high PV or shallower water to their right i.e., westwards on a sphere. Meridionally, anticyclones translate towards low PV: equatorward on a sphere or 
towards deeper water, while cyclones move towards high PV: poleward or towards shallower water. The governing parameter is $\mathrm{Rh} \sim V_{0} /\left(\beta L_{0}^{2}\right), V_{0}$ being the maximum velocity in the eddy. It measures eddy nonlinearity or wave steepness as the ratio of vorticity advection $(u \cdot \nabla \zeta)$ to planetary vorticity creation $(\beta v)$. The more non-linear an eddy (weaker $\beta$ ), the less it radiates energy as Rossby waves and vice versa.

Smith and O'Brien (1983) studied the eddy-topography problem with a two layer non-linear model. They suggest that the translation of barotropic vortices over topography on a $\beta$-plane can be predicted using the vector resultant of the translation tendencies of the eddy due to $\beta$ and $\beta_{t}$ individually. LaCasce (1998) explored the problem using a two layer $f$-plane quasi-geostrophic model with a sloping bottom. He found a dependence on an analogous steepness parameter: $\mathrm{Rh}_{2} \sim V_{2} /\left(\beta_{t} L^{2}\right)$, where $V_{2}$ is the lower layer velocity scale. Over gentle slopes (high $\mathrm{Rh}_{2}$ ), the anticyclonic eddy translated towards low $\mathrm{PV}$, whereas over steep slopes (low $\mathrm{Rh}_{2}$ ), the lower layer signal radiated away as topographic Rossby waves leaving behind an upper layer eddy insulated from the bottom. He concluded that the results of Smith and O'Brien (1983) held over gentle slopes, but not over steep ones (see LaCasce, 1996). Thierry and Morel (1999) used a two layer model to evaluate when reduced gravity models are appropriate. They found that this approximation worked well over steep slopes i.e., when the lower layer radiates away and the eddy is insulated from the bottom, as expected from LaCasce (1998).

Jacob et al. (2002) explored the problem using a two layer model studying four slope orientations (coasts at the north, south, east and west) and $\beta>0$. For "compensated" eddies with no deep flow, they found that the "evolution is minimally influenced by topography", agreeing with Smith and O'Brien (1983), Thierry and Morel (1999) and Kamenkovich et al. (1996). For "barotropically dominated" eddies with significant deep flow and $\mathrm{Rh} \sim \mathrm{O}(25)^{1}$, Jacob et al. (2002) concluded the following. If $\beta_{t}$ is in the same sense as that of $\beta$ (northern coast), then the eddy loses a large amount of energy to Rossby wave radiation and moves southwestward (geographically) towards low PV. If $\beta$ and $\beta_{t}$ oppose each other (southern coast, summarized in Figure 4.1b), they observed self-advection governed by the greater of $\beta$ and $\beta_{t}$, as predicted by Smith and O'Brien (1983). The wave radiation makes the eddy more baroclinic by weakening its deep flow and reducing its vertical scale, as in LaCasce (1998). When $\beta \approx-\beta_{t}$ (southern coast), the eddy moved westward along an isobath with little meridional motion and maintained its barotropic structure. Is

\footnotetext{
${ }^{1}$ the weak slope self-advection regime of LaCasce (1998)
} 
such behaviour possible in a continuously stratified fluid?

Consider a compensated eddy with no deep flow - initialized in water deeper than its vertical scale - moved by the planetary $\beta$-plane across a slope in a stratified fluid. Initially, the eddy is insulated from the bottom (LaCasce, 1998; Jacob et al., 2002). As the eddy moves into shallower water, its deep velocity signal increases. Eventually, it transitions from being compensated to barotropically dominated. Given that bottom velocities are generally smaller than surface velocities and that topographic $\beta$ is much larger than planetary $\beta$, one hypothesis is that $V / \beta_{t} L^{2}$ at the bottom always remains small, the slope is always non-dimensionally steep regardless of orientation, and the eddy always radiates energy effectively. The radiation spins down the eddy and insulates it from the topographic $\beta$ plane by weakening its deep flow as in LaCasce (1998). The planetary $\beta$-plane can then move the eddy into shallow water closer to the shelfbreak. The slope should not oppose the cross-isobath motion of the eddy but instead, actively assist it by enabling wave radiation. Then, the eddy will eventually reach the shelfbreak, driving significant transport across it. It is thus difficult to see how the along-isobath translation in the $\beta=-\beta_{t}$ limit of Jacob et al. (2002) is realized when a surface intensified eddy moves across isobaths in a continuously stratified fluid.

The fully non-linear, continuously stratified simulations presented here show that there is a regime, $10 \lesssim \mathrm{Rh} \lesssim 45$ and $\beta \beta_{t}<0$, where topography can arrest the cross-isobath motion of an eddy. It does so by shutting down the wave radiation from the eddy. For $\mathrm{Rh} \lesssim 5$, the planetary $\beta$-plane makes the eddy continuously radiate enough energy that it always reaches the shelfbreak. For Rh $\gtrsim 45$, wave radiation is so ineffective that the eddy cannot cross isobaths into shallower water. All simulations here are in the limit where the eddy's diameter is much smaller than the slope width - an approximation to the infinitely wide slope limit of LaCasce (1998). The case of narrower slopes, where the eddy always reaches the shelfbreak, is addressed in Chapter 5.

A suite of 28 simulations with varying eddy vertical scale $L_{z}, \beta$, topographic slope $\alpha_{\mathrm{sl}}$ and eddy Rossby number Ro were conducted to test the results for $5 \leq$ $\mathrm{Rh} \leq 40$, and another $10 \mathrm{in}$ total were conducted for $\mathrm{Rh} \leq 5$ and $\mathrm{Rh} \sim 60$ (Table A.1). The goal is to examine the $\beta=-\beta_{t}$ limit of Jacob et al. (2002). So, most experiments described here use topography with a southern coast. The more realistic case of a western coast is addressed in Section 4.5.2. 


\subsection{Additional diagnostics}

The eddy's potential and kinetic energies are calculated as

$$
\mathrm{PE}=\iiint(\rho-\bar{\rho}(z)) g z \mathrm{~d} V, \quad \mathrm{KE}=\iiint \frac{1}{2} \rho_{0}\left(u^{2}+v^{2}\right) \mathrm{d} V .
$$

The volume of integration is the 3D density anomaly contour that describes the core of the eddy: green contours in Figure 4.2.

The eddy's translation velocities are calculated as the $(x, y)$ translation velocities of the eddy's center $\left(V_{\mathrm{cen}}^{x}, V_{\mathrm{cen}}^{y}\right)$. Since the center (SSH maximum) can only change by grid point multiples, the velocity time series are noisy and so, are smoothed over ten days (Figure 4.3, lower panel). The $\times$ on each track in Figure 4.2 represents the location at which the eddy's cross-isobath translation has decreased significantly; to be used later to verify a proposed scaling. The eddy's cross-isobath translation velocity is assumed to decay as a Gaussian in time after attaining a maximum (black dashed line in Figure 4.3) viz.,

$$
V_{\text {cen }}^{y}=V_{\text {cen }}^{0} \exp \left[-\left(\frac{t-t_{\text {ref }}}{\tau}\right)^{2}\right]+V_{\text {cen }}^{1}
$$

The above Gaussian is fit to the cross-isobath translation velocity of the eddy's center after the velocity magnitude has reached its maximum value. $V_{\mathrm{cen}}^{0}$ and $V_{\mathrm{cen}}^{1}$ are constants determined by the curve fit. The position of the eddy at time $t-t_{\text {ref }}=\tau$, at which the cross-isobath motion has been considerably reduced, can then be consistently diagnosed for different simulations.

\subsection{A typical simulation}

The evolution of an eddy ${ }^{2}$ of radius $27 \mathrm{~km}$, vertical scale $310 \mathrm{~m}$, Rossby number Ro $\sim 0.1$ and Rhines number $\mathrm{Rh} \sim 21$ that starts in water $600 \mathrm{~m}$ deep is visualized in Figure 4.2 using maps of the dye fields at the surface. $\beta_{t}=7 \times 10^{-9} \mathrm{~m}^{-1} \mathrm{~s}^{-1} \cong 220 \beta$ for the continental slope and the shelf is flat. The slope width is $150 \mathrm{~km}$.

When the model is integrated, the anticyclonic eddy moves southwestward. Westward spreading of SSH contours in Figure $4.2 \mathrm{~b}$ indicate Rossby wave radiation (Flierl, 1984, 1994). There is a barotropic "wake cyclone" spun up to the northeast of the eddy (negative SSH in Figure 4.2b) that drives the eddy southwards. At $t \cong 60$ days, the eddy crosses the slopebreak ('o' in Figure 4.3) and interacts with

\footnotetext{
${ }^{2}$ ew $-64461-5$ in Table A.1
} 
the slope. The hypothesis of Section 1 is that for steep enough slopes, the lower layer signal will radiate away and the eddy should continually translate across isobaths while remaining surface-intensified. However, by $t=150$ days, the slope has arrested the eddy's cross-isobath motion and $V_{\text {cen }}^{y}$, the eddy's cross-isobath translation velocity, asymptotes to zero (Figure 4.3). The eddy is in direct contact with the bottom slope. It has not transported any water across the shelfbreak throughout the simulation (Figure 4.2c).

The eddy always moves westwards. At $t \cong 150$ days, it starts leaking water from its edge along-shelf — the "leakage" described in Shi and Nof (1993). The shedding of this water accelerates the eddy's along-isobath velocity $V_{\text {cen, }}^{x}$ presumably due to the rocket effect of Nof (1988). The leakage results in the eddy's horizontal scale decreasing for $t \gtrsim 150$ days (Figure 4.3). The time series of this particular eddy's kinetic and potential energies are highlighted in black in Figure 4.4. The initial Rossby wave radiation is apparent in the strong decay at the beginning. The rate of energy decay slows down significantly when the eddy's cross-isobath progress has been arrested (marked by $\times$ ). The slope has greatly reduced wave radiation from the eddy.

In Figure 4.2, the eddy's trajectory eventually follows an isobath nearly perfectly. This is not true for all simulations. In some, the eddy continues on to the shelfbreak but at a much slower cross-isobath velocity; approximately $10-15 \%$ of the maximum cross-isobath velocity for the inviscid, $r_{f}=0$, simulation in Figure 4.8. Such eddies that cross isobaths slowly are also considered to be arrested since the slope has dramatically slowed down the eddy's cross-isobath progress.

\subsection{Where the slope stops an eddy}

\subsubsection{Theory: the Flierl, Stern \& Whitehead theorem}

We need to understand when eddies radiate Rossby waves to explain how a wide slope reduces wave radiation from the eddy, and arrests its cross-isobath translation. The integrated angular momentum theorem of Flierl et al. (1983) addresses this question. If a spatially-confined structure (eddy) satisfies the theorem, it will remain isolated i.e., spatially confined, and slowly-varying: its structure will not change significantly because it radiates only a small amount of energy. If its structure is slowly varying, the eddy cannot cross into shallower water: for example, a $500 \mathrm{~m}$ deep eddy cannot cross into water $300 \mathrm{~m}$ deep without somehow losing some of its 
mass.

The short derivation below closely follows that in Flierl et al. (1983) and Flierl (1987). First, integrate the horizontal momentum and continuity equations in (2.1) between two material surfaces in the vertical $\left(\int_{z}\right)$, from $z=s_{0}(x, y, t)$ to $z=s_{1}(x, y, t)$. Second, integrate the momentum equations over the entire $x-y$ plane $\left(\iint_{x, y}\right)$, use the definition of a material surface ${ }^{3}$ and Leibniz's rule to get (Flierl, 1987)

$$
\begin{gathered}
\frac{\partial}{\partial t}\left(s_{1}-s_{0}\right)+\frac{\partial}{\partial x} \int_{z} u+\frac{\partial}{\partial y} \int_{z} v=0 \\
\iint_{x, y} \frac{\partial}{\partial t} \int_{z} u+\iint_{x, y} \frac{\partial}{\partial x} \int_{z} u^{2}+\iint_{x, y} \frac{\partial}{\partial y} \int_{z} u v-\iint_{x, y} f \int_{z} v=-\iint_{x, y} \frac{\partial}{\partial x} \int_{z} p+\iint_{x, y}\left(p_{1} s_{1 x}-p_{0} s_{0 x}\right), \\
\iint_{x, y} \frac{\partial}{\partial t} \int_{z} v+\iint_{x, y} \frac{\partial}{\partial x} \int_{z} u v+\iint_{x, y} \frac{\partial}{\partial y} \int_{z} v^{2}+\iint_{x, y} f \int_{z} u=-\iint_{x, y} \frac{\partial}{\partial y} \int_{z} p+\iint_{x, y}\left(p_{1} s_{1 y}-p_{0} s_{0 y}\right) .
\end{gathered}
$$

Aside from ignoring friction (addressed in Section 4.5.3), (4.3) contains no approximations and $p$ now includes the $1 / \rho_{0}$ term. A number of terms can be simplified using Gauss' theorem. For example,

$$
\iint_{x, y} \frac{\partial}{\partial y} \int_{z} p=\oint\left(\int_{z} p\right) \hat{y} \cdot \hat{n} \mathrm{~d} l
$$

where $\mathrm{d} l$ is along a bounding contour far away from the eddy, and $\hat{n}$ is the unit vector normal to that contour. For eddy-like isolated structures that do not radiate energy to this bounding contour, the RHS contour integral in (4.4) is zero. The same argument holds for the non-linear terms as well.

Choosing the material surfaces to be the upper and lower boundaries of the fluid and making the rigid lid approximation $\left(s_{1}=0, s_{0}=-H(x, y)\right)$ lets us define a transport streamfunction $\psi$ such that

$$
\int_{z} u=-\psi_{y} ; \quad \int_{z} v=\psi_{x}
$$

For an isolated eddy-like structure, $\psi$ must decay in the horizontal plane. Assuming that this decay is $\mathrm{O}\left(1 / r^{2}\right)$ means $\iint_{x, y} \psi_{y}=\oint \psi \cdot \hat{n} \mathrm{~d} l=0, r$ being radial distance

\footnotetext{
${ }^{3} w\left(x, y, s_{i}, t\right)=\left(\partial_{t}+u \partial_{x}+v \partial_{y}\right)_{z=s_{i}} s_{i}$
} 
from the eddy center. If the eddy's structure is slowly-varying, the time rate of change of the streamfunction field will be small far away from the eddy. Assuming that $\psi_{t}$ decays as $\mathrm{O}\left(1 / r^{2}\right),(4.3)$ simplifies to

$$
\begin{aligned}
0 & =\iint_{x, y} p_{0} \frac{\partial H}{\partial x} \\
\beta \iint_{x, y} \psi & =\iint_{x, y} p_{0} \frac{\partial H}{\partial y} .
\end{aligned}
$$

Equation (4.5) is a statement about the integrated forces on the system: eddy and topography. The first term in (4.5b), termed the $\beta$-force (Nof, 1983), arises because $f$ is different on the northern and southern sides of the eddy. If the vertically integrated volume transport in the eddy is equal on both sides, then the Coriolis force on the northern side is greater than that on the southern side. The net resul$\operatorname{tant}$ is $\beta \iint_{x, y} \psi$. The second term is the form stress on the bottom of the eddy i.e., the sloping bottom is pushing the anticyclone away. At no point have any assumptions about slope steepness, stratification or non-linearity been made.

Over a flat bottom, the original theorem put forward in Flierl et al. (1983) viz., $\beta \iint_{x, y} \psi=0$, is recovered. If $\beta \iint_{x, y} \psi \neq 0$, the $\beta$-force is unbalanced. Thus, any isolated structure that has net angular momentum initially - our anticyclone at $t=0-$ must radiate waves and set up motions at the domain boundaries to satisfy (4.3) as in Figure 4.2b (see Flierl, 1987).

As the eddy crosses the slope into shallower water, the bottom pressure anomaly increases. The topography opposes the cross-isobath motion of the eddy via an increasing form stress at the bottom of the eddy, decreasing the eddy's meridional translation velocity. As time progresses, the eddy's angular momentum slowly decreases due to radiation and the bottom pressure anomaly increases so that the $\beta$-force approximately balances the form stress. The radiation of energy from the eddy is significantly reduced, halting the spin-down of the eddy - it is now slowlyvarying $\left(\psi_{t}\right.$ decays as $\left.\mathrm{O}\left(1 / r^{2}\right)\right)$. The decay in the eddy's vertical scale is then arrested and its meridional velocity is reduced, preventing it from crossing isobaths.

The system need not evolve to a state where the $\beta$-force and form stress balance exactly. The eddy initially loses energy to Rossby waves prior to reaching this critical water depth. The contributions to the integrals in (4.3) from motions at the boundary are non-zero before the eddy's progress is arrested. Further, the generation of vorticity anomalies due to cross-slope advection of water and the leaked 
eddy water will also complicate the integrated momentum balance of the entire domain (for e.g., Wang, 1992; Oey and Zhang, 2004; Frolov et al., 2004). The argument here is that if the two terms in (4.5b) approximately balance each other, the eddy's core experiences little radiative energy loss. Flierl et al. (1983) derive an asymptotic series expansion for boundary signals set up by eddy radiation in a barotropic quasi-geostrophic fluid. The appropriate integral statement is $\beta \iint_{x, y} \psi=0$ for no wave radiation from the eddy over a flat bottom. The coefficient of the largest term in the asymptotic series is also $\beta \iint_{x, y} \psi$. Exactly satisfying the theorem zeroes out the largest term in the asymptotic series, reducing the rate of energy radiation but not to exactly zero ${ }^{4}$. When the theorem is only approximately satisfied, $\beta \iint_{x, y} \psi \approx 0$, the largest term in the expansion is small, as are the amplitudes of wave signals at the boundary. The eddy's structure is then slowly-varying. The eddy now crosses isobaths slowly because wave radiation cannot decrease its vertical scale quickly enough to reduce the opposing form stress.

Alternatively, studies have also shown that the eddy's meridional translation is intimately related to its ability to radiate Rossby waves. Both Flierl (1984) and Nycander (2001) derive analytical expressions for the eddy's steady-state meridional translation velocity as functions of the radiated Rossby wave field. The radiated wave field exerts a "wave drag" on the eddy, directed eastward opposing the eddy's westward motion. The westward Coriolis force on the southward moving mass of the eddy balances this wave drag in the steady-state integrated force balance (Flierl, 1984). In this framework, if there is no wave drag, the eddy cannot move meridionally assuming steady state physics.

\subsubsection{Scaling for arrest location}

Directly diagnosing the balance in (4.5b) is difficult; primarily because integrating to the domain boundary includes boundary signals set up by the initially radiated Rossby waves. Instead, assuming the balance holds, both terms in (4.5b) can be scaled to arrive at a testable relationship. For velocity scales $U_{s}$ (surface) and $U_{b}$ (bottom), vertical scale $L^{z}$, horizontal scale $R$ and assuming equal areas of integration at the surface and bottom $A$,

$$
\iint_{x, y} \beta \psi=\mathrm{O}\left(\beta\left(U_{s}-U_{b}\right) R L^{z} A\right) ; \quad \iint_{x, y} p_{\text {bot }} s_{0 y}=\mathrm{O}\left(\left|\frac{\partial H}{\partial y}\right| f_{0} U_{b} R A\right) .
$$

\footnotetext{
${ }^{4} \beta \iint_{x, y} \psi=0$ is necessary but not sufficient.
} 
Assuming that the eddy's density anomaly remains Gaussian throughout the evolution, thermal wind balance gives us an expression for the vertical profile of horizontal velocity in the eddy:

$$
U(z)=U_{s}\left[1-\operatorname{erf}\left(\frac{z}{L^{z}}\right)\right] \Rightarrow \frac{U_{b}}{U_{s}}=1-\operatorname{erf}\left(\frac{H}{L^{z}}\right),
$$

where $H$ is the water depth at the eddy center and $L^{z}$ is the eddy's vertical scale. Substituting (4.7) in (4.6) results in a relationship that predicts the 'critical' water depth, $H_{\text {arr }}$ at which the eddy should slow down significantly:

$$
1-\operatorname{erf}\left(\frac{H_{\text {arr }}}{L^{z}}\right) \approx \frac{\beta}{\beta_{z}+\beta}
$$

with $\beta_{z}=\left|\beta_{t}\right| H_{\max } / L^{z}=\alpha_{\mathrm{sl}} f_{0} / L^{z}$.

The scaling in (4.8) is tested using 28 simulations with varying $L^{z}, \beta$ and Ro (Figure 4.5, Table A.1). The balance in (4.8) should hold at a point in the eddy's trajectory where its cross-isobath translation velocity has been considerably reduced: the $\times$ in Figure 4.2, described in Section 3.2. $H_{\text {arr }}$ is the water depth at the locations marked by crosses in Figure 4.2. $L^{z}$ is chosen to be the mean of the eddy's vertical scale over $\left[0, t_{\mathrm{sl}}\right]$, where $t_{\mathrm{sl}}$ is the time instant when the eddy center crosses the slopebreak. This choice makes two simulations where the eddies stop at the same water depth (discussed later), overlap on the scatter plot (Os in Figure 4.5). The gray dashed lines are the least squares regression line and its confidence bounds at $95 \%$ significance:

$$
1-\operatorname{erf}\left(\frac{H_{\text {arr }}}{L^{z}}\right)=(1.84 \pm 0.18) \frac{\beta}{\beta_{z}+\beta}+(0.01 \pm 0.01)
$$

The correlation coefficient of the regression is 0.97 , illustrating that the shutdown of wave radiation from the eddy controls where its cross-isobath translation is arrested.

The time evolution of the eddy's integrated kinetic and potential energies for the simulations agrees with the hypothesis that the eddy's structure is slowly varying when arrest occurs (see (4.1) and Figure 4.4). Again, $\times$ indicates the time instant where the eddy's trajectory is arrested. There is a sharp change in slope close to this time instant - a large decrease in radiative energy loss from the eddy, consistent with the hypothesis. There is still small non-zero energy loss as expected from the caveats mentioned earlier. One, the hypothesized balance assumes that the flow field contains only the eddy. The presence of water leaked along-shore from the 
eddy in Figure 4.2 disproves this assumption. Two, the asymptotic expansion in Flierl et al. (1983) implies that the theorem is a necessary but not sufficient condition for the lack of wave radiation. Thus, the eddy should continue radiating at a much slower pace after the balance is approximately achieved. The leaking of eddy water along-shelf also reduces eddy energy. The sharp drops in energy at later times for some simulations in Figure 4.4 occurs when the eddy splits due to instability or gets close to the sponge layer.

For a given eddy vertical scale and topographic slope, (4.8) predicts a critical depth, $H_{\text {arr }}$ at which the eddy's progress is arrested. The prediction is tested using two simulations; the topography in one is $100 \mathrm{~m}$ deeper than the other everywhere. For $\mathrm{Rh} \sim 18$, the eddy stops at the same water depth in both simulations (Figure 4.6a, also true for $R h \sim 30$ ). For $R h \sim 60$, this is not true. These eddies are so nonlinear that wave radiation is not an important factor in the eddy's evolution: the vertical scale reduces only by approximately $5 \%$ as compared to $20 \%$ for the low $\mathrm{Rh}$ simulations. For $\mathrm{Rh} \sim 3$, the eddies radiate so much energy that the bottom pressure never becomes large enough for the terms in (4.8) to balance. These eddies always get to the shelfbreak.

Even though the theorem tells us when an eddy must radiate waves, it does not tell us how quickly the eddy's energy will radiate away. LaCasce (1998) found a dependence on a lower layer Rhines number $\left(V_{2} /\left(\beta_{2} L^{2}\right)\right)$ and Flierl (1984) derived a dependence on $\beta L / f_{0}$ for an eddy on a $\beta$-plane over a flat bottom. For an eddy to lose energy to radiation and so, cross isobaths, the flow field must not satisfy the theorem and the background PV gradient should be large enough to allow strong radiation. For Gulf Stream warm-core rings, Rh $\sim 10-20$, depending on choices (McWilliams and Flierl, 1979). Most of the simulations in Figure 4.5 are in this parameter range (Table A.1). They agree well with the theory and scaling presented (Figure 4.5).

\subsection{Variations}

\subsubsection{Narrow slopes: eddy scale $\gtrsim$ slope width}

In theory, the ideas of the previous section should also hold when the eddy's diameter is similar in magnitude or greater than the slope width. In practice, in this case, the eddy's edge always reaches the shelfbreak after which the eddy translates parallel to the shelfbreak, driving cross-shelfbreak exchange flows (Chapter 5). There 
is nothing dynamically special about the shelfbreak; it is the end of the slope and the eddy is too deep to cross on to the shelf.

\subsubsection{Western coast}

With a western coast $\left(H_{x} \neq 0, H_{y}=0\right),(4.5)$ results in two conditions (Flierl, 1987)

$$
\iint_{x, y} \psi=\iint_{x, y} p_{0}=0
$$

For the eddy to stop radiating, it would have to remain surface intensified, i.e. no bottom pressure signal, and spin up a cyclone of equal strength. Fulfilling the latter seems unlikely. So, the eddy should always get to the shelfbreak because it must always radiate energy. The eddy tracks in Figure 4.7 confirm this hypothesis for low Rh eddies. The only difference between the two panels is the orientation of the topography: coast at the south or west. Eddies that are arrested over a slope with a southern coast reach the shelfbreak for a western coast.

High Rh eddies are exceptions: these have $\mathrm{Rh} \sim 60$, while the rest have $\mathrm{Rh} \sim 12$. As in Section 4.4.2, large Rh simulations do not radiate much energy and their vertical scale changes only by approximately $5 \%$ over a 300 day integration, preventing them from crossing isobaths. Since Gulf Stream warm-core rings have $\mathrm{Rh} \sim 10-20$ (McWilliams and Flierl, 1979), the continental slope cannot prevent them from reaching the shelfbreak, even if the slope were wide enough.

\subsubsection{Bottom friction}

Non-zero linear bottom drag does not affect the theorem (Flierl et al., 1983). Integrating the horizontal stress term, $A_{v} v_{z z}$, in (2.1) between the two material surfaces, $s_{0}$ and $s_{1}$, and over the entire domain gives

$$
\iint_{x, y} \int_{z} \frac{\partial}{\partial z} A_{v} \frac{\partial v}{\partial z} \mathrm{~d} z \mathrm{~d} y \mathrm{~d} x=\iint_{x, y}\left(A_{v} \frac{\partial v}{\partial z}\right)_{s_{1}}-\left(A_{v} \frac{\partial v}{\partial z}\right)_{s_{0}}=-r_{f} \iint_{x, y} v_{\text {bot }} .
$$

Assuming that $v_{\text {bot }}$, the velocity right above the bottom boundary layer, is in geostrophic balance makes the RHS vanish just like the integrated pressure term in (4.4). Friction may spin down the eddy affecting both its angular momentum and its bottom pressure signal, but this doesn't affect the eddy's isolated nature, i.e. $\psi$ is still $\mathrm{O}\left(1 / r^{2}\right)$. Even with linear bottom friction, satisfying (4.5b) will shut down wave radiation from the eddy. Thus, non-zero bottom friction should not change much about the eddy's evolution as evidenced by Figure 4.8 for low Rh eddies. 
Visually, the eddy is arrested at nearly the same location in all three simulations, though the diagnosed locations (crosses) are slightly different (note scatter at $x=0.01$ in Figure 4.5). Varying the drag coefficient $r_{f}$ by a factor of 10, from $5 \times 10^{-4} \mathrm{~m} \mathrm{~s}^{-1}$ (a typical value) to $5 \times 10^{-3} \mathrm{~m} \mathrm{~s}^{-1}$ makes no difference to the eddy tracks. The eddy in the $r_{f}=0$ simulation continues on to the shelfbreak, but its cross-isobath progress is slow ( $15 \%$ of maximum cross-isobath velocity).

High Rh eddies are again exceptions, bottom friction makes a measurable impact on their translation. It does so by weakening the barotropic wake cyclone that drives the eddy southwards early in the simulation (Figure $4.2 \mathrm{~b}$ ). All the simulations in Figure $4.8 \mathrm{~b}$ stop at the same time instant, $t \approx 180$ days. Those with larger $r_{f}$ initially translate a smaller distance southward because of the weaker wake cyclone. The tracks thus indicate arrest at different isobaths. The two high Rh eddies in Figure $4.6 \mathrm{~b}$ are also arrested at the same time even though the $H_{\text {arr }}$ differs by $50 \mathrm{~m}$. A suitable explanation for this behaviour was not found.

\subsection{Summary and implications}

The translation of a surface-intensified eddy over a wide sloping bottom was studied using continuously stratified primitive equation model simulations. This chapter examined the two layer ideas of LaCasce (1996) and Jacob et al. (2002) in a system with continuous stratification. For topography with a southern or western coast, the eddy's progress across the slope can be arrested (Figure 4.9). The key physics is the eddy's tendency to radiate waves as diagnosed by these two questions:

- Is the background PV gradient strong enough to remove energy efficiently from the eddy i.e., how small is $\mathrm{Rh} \sim V /\left(\beta L^{2}\right)$ ?

- If not, can the system evolve to become isolated in the sense of the Flierl et al. (1983) theorem before the eddy reaches the end of the slope?

When radiation is not possible or can be shut down, the eddy's structure remains slowly-varying, preventing movement into water much shallower than the eddy's vertical scale (Section 4.4.1, Figure 4.9). Simulations with a southern coast illustrate the first point and those with a western coast illustrate the second (Sections 4.4.2 and 4.5.2 respectively). These two ideas also describe most of the previously observed behaviour over wide slopes, especially the two layer results of LaCasce (1998) and Jacob et al. (2002). 
Assuming that the lower layer is quasi-geostrophic, the two-layer version of the theorem is ( $\psi$ is streamfunction, subscripts identify layer, Flierl, 1994):

$$
\beta_{1} H_{1} \iint_{x, y} \psi_{1}+\beta_{2} H_{2} \iint_{x, y} \psi_{2}=0
$$

In one instance, Jacob et al. (2002) found that the eddy translated along-isobath westward and very slightly southward with very little radiation in their base case $\mathrm{e}^{5}$. For that simulation, $H_{1} / H_{2}=1 / 4, \beta=2 \times 10^{-11} \mathrm{~m}^{-1} \mathrm{~s}^{-1}, \beta_{t}=-2.5 \times 10^{-11} \mathrm{~m}^{-1} \mathrm{~s}^{-1}$ and $\psi_{1} / \psi_{2}=3$. When $\beta_{t}$ was halved, the eddy moved southward and when $\beta_{t}$ was doubled, the eddy moved northward (Figure 4.1). In all three cases, the theorem is not exactly satisfied. The differences can be interpreted using the ideas discussed earlier. Since this is the same eddy initialized in the same location, changing $\beta_{t}$ changes the initial form stress on the eddy. This explains the direction of motion i.e., northward when $\beta_{t}$ greater than $\beta$ because the form stress is greater than the $\beta$-force and pushes the eddy away; and vice versa. Further, when $\beta_{t}$ is doubled, Jacob et al. (2002) observed more radiation from the eddy. This can be explained using a lower layer Rhines number as in LaCasce (1998): when $\beta_{t}$ is doubled, the net lower layer PV gradient $\beta_{2}=\beta+\beta_{t}=-3 \times 10^{-11} \mathrm{~m}^{-1} \mathrm{~s}^{-1}$ and when it is halved, $\beta_{2}=0.75 \times 10^{-11} \mathrm{~m}^{-1} \mathrm{~s}^{-1}$. So, as observed, we expect less radiation in the latter case when compared to the former.

The framework used here, viz. that of wave radiation from eddies, does not explain the behaviour of high Rh eddies. Further progress requires that we understand the nature of wave radiation from eddies, particularly the rate of energy loss from the eddy as a function of Rh. Such a relation would enable parameterizing the time scale over which the eddy's trajectory is arrested, given an initial condition.

In the simulations presented here, the arrest time scale is long; generally on the order of a year due to the slow meridional (relative to PV gradient) translation velocity of the eddies. To expect oceanic eddies to evolve independently over such a long time is unrealistic. Observational evidence suggests that large mesoscale eddies like Aghulas rings and Gulf Stream warm-core rings have significant bottom pressure anomalies (for e.g. Kamenkovich et al., 1996; Baker-Yeboah et al., 2010). Such eddies might be arrested earlier, relative to more surface-intensified eddies. Even so, relative to the eddy's diameter, the $50 \mathrm{~km}$ wide continental slope is too narrow to arrest $100 \mathrm{~km}$ wide Gulf Stream warm-core rings in the real ocean.

\footnotetext{
${ }^{5}$ their simulation B4, Figure 18
} 
Wide shelves and abyssal slopes are two other locations where the arrest might be observed. However, mid-latitude shelf eddies, such as those created by baroclinic instability of up- and down-welling fronts, are too small for planetary $\beta$ to be influential i.e., $\beta L / f_{0}=\mathrm{O}\left(10^{-3}\right)$ for $L \approx 20 \mathrm{~km}$ (Brink and Seo, 2016). Instead, one can ask what the theorem of Flierl et al. (1983) says about such shelf eddies. For $\beta=0$, (4.5) implies that for shelf eddies to remain isolated (and live longer) they must have $\iint_{x, y} p_{\mathrm{bot}} \nabla H=0$. For a constant slope, long-lived shelf eddies must be surface-intensified i.e., have no integrated bottom pressure anomaly. This assertion neglects bottom friction and other non-linear effects such as vortex merger and instability.

The abyssal ocean might yield useful observations. But, cross-isobath, or meridional, translation velocities being much smaller than zonal translation velocities (McWilliams and Flierl, 1979), any eddy's meridional motion is likely strongly influenced by nearby flow features. One would need long-term observations of a large number of eddies to detect statistically significant meridional motion (or the lack of) as in Chelton et al. (2011). Such an observational dataset does not currently exist for the abyssal ocean.

\subsection{Conclusion}

The main result here is that continental slopes likely cannot prevent single isolated deep-water mesoscale anticyclones from reaching the shelfbreak. This is especially true for Gulf Stream warm-core rings at the Mid-Atlantic Bight where the continental slope is about half as wide as the ring. However, satellite observations indicate otherwise. That these rings are not always at the shelfbreak may be due to topographic variations, the northern location of the coast for part of the Mid-Atlantic Bight, and interactions with other flow features in the vicinity; viz., strong western boundary currents, other eddies and background mean flows (Cornillon et al., 1989). 
a) AVHRR SST for the Mid-Atlantic Bight, North-west Atlantic

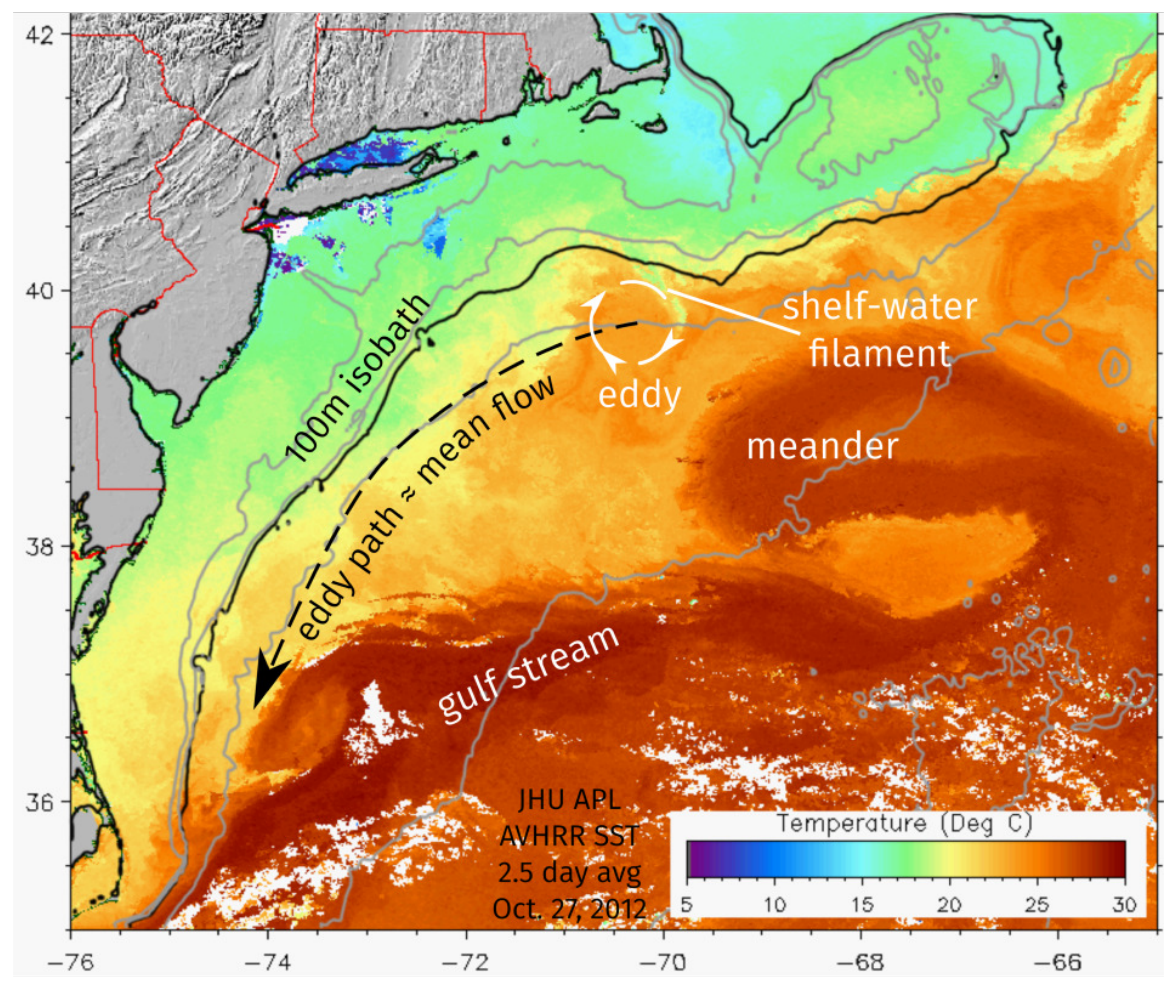

b) Summary of Jacob et al. (2002) for a southern coast

$\left(\beta>0, \beta_{t}<0\right)$

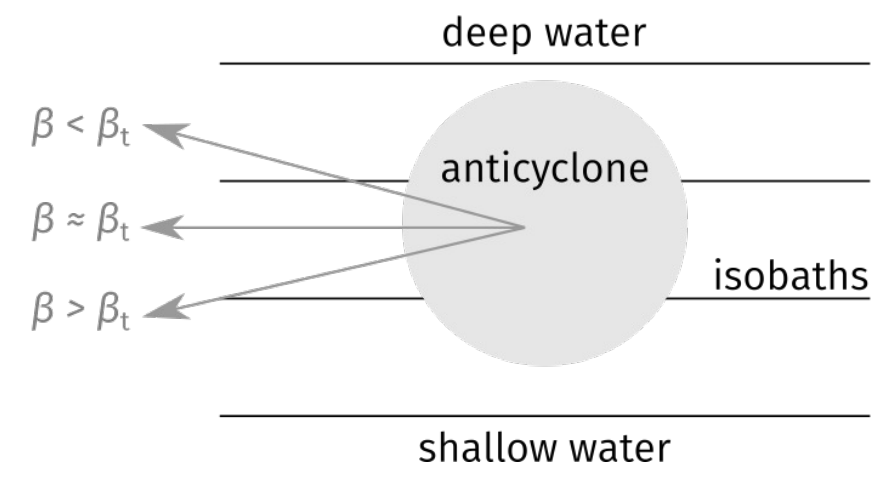

Figure 4.1: a) (Figure 1.1) The Gulf Stream and a warm-core ring in an AVHRR SST image from the Applied Physics Laboratory, Johns Hopkins University. The ring is drawing a cold streamer of shelf water across the shelfbreak into deep water. The solid black line is the $100 \mathrm{~m}$ isobath, generally considered the shelfbreak b) A schematic summarizing some of the results in Jacob et al. (2002). 


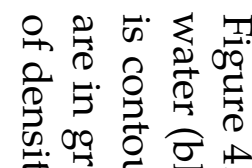

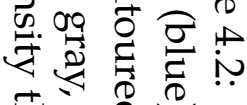

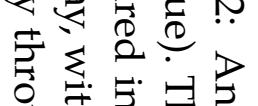

号

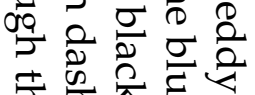

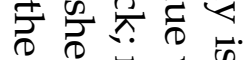

尺 $2 \sum_{0}$

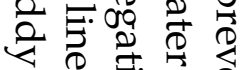

क क स

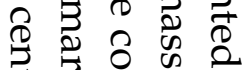

के

⿶凵

రे

哭告营告

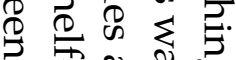

○ी

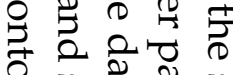

¿

F.

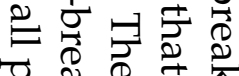

चृ

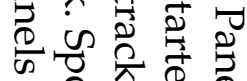

$30 \hat{2} \stackrel{0}{3}$

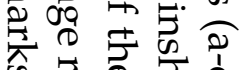

के ते के

穴哭

ล के है 0

常

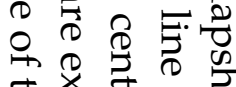

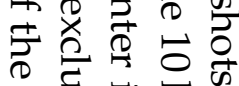

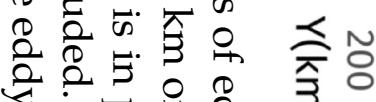

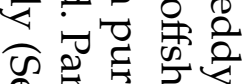

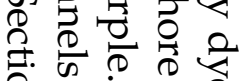

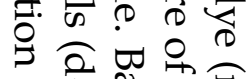

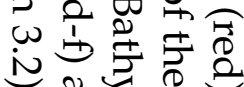
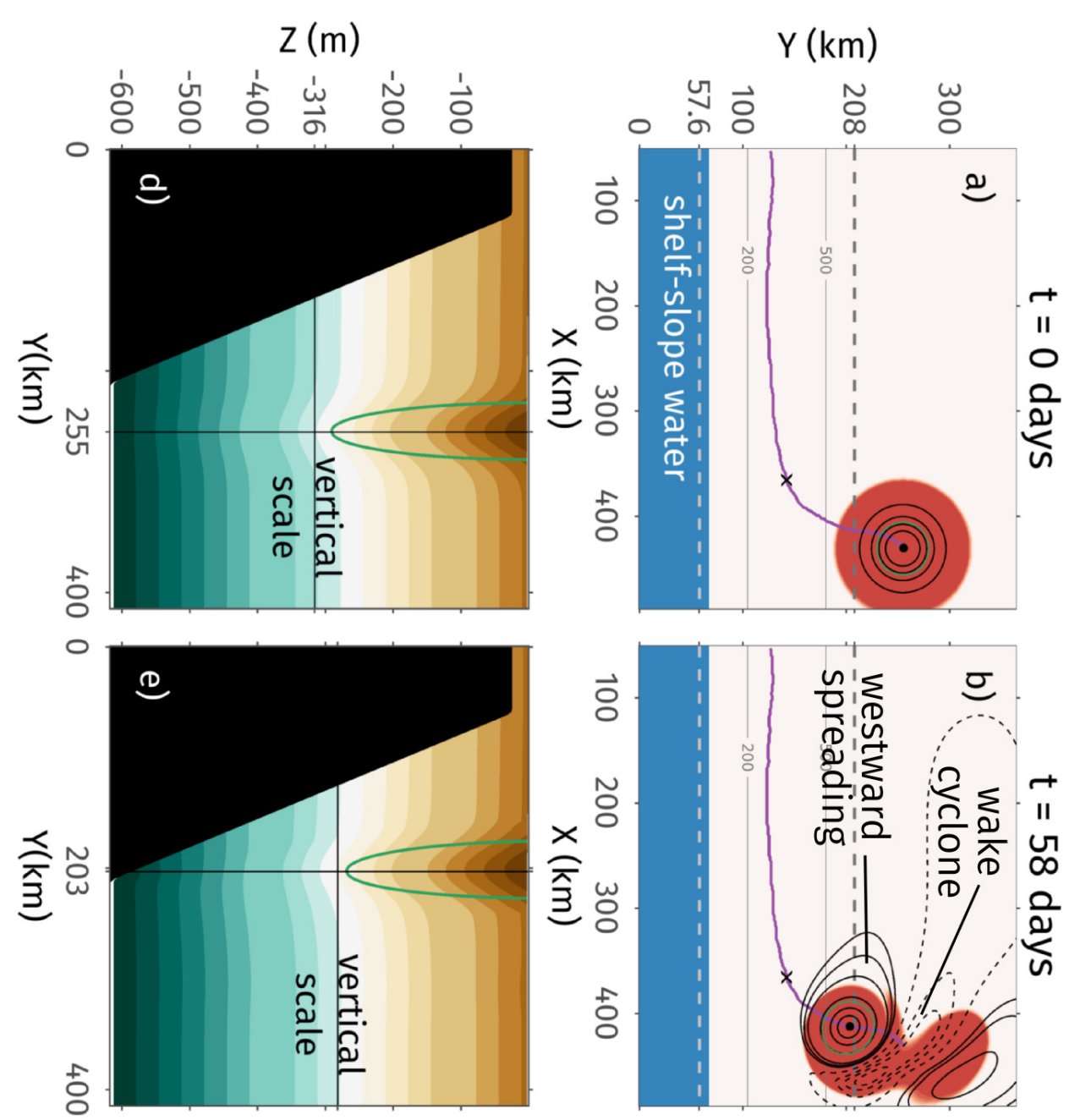

N

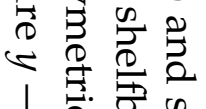

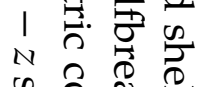

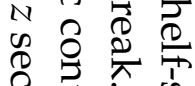

范苛
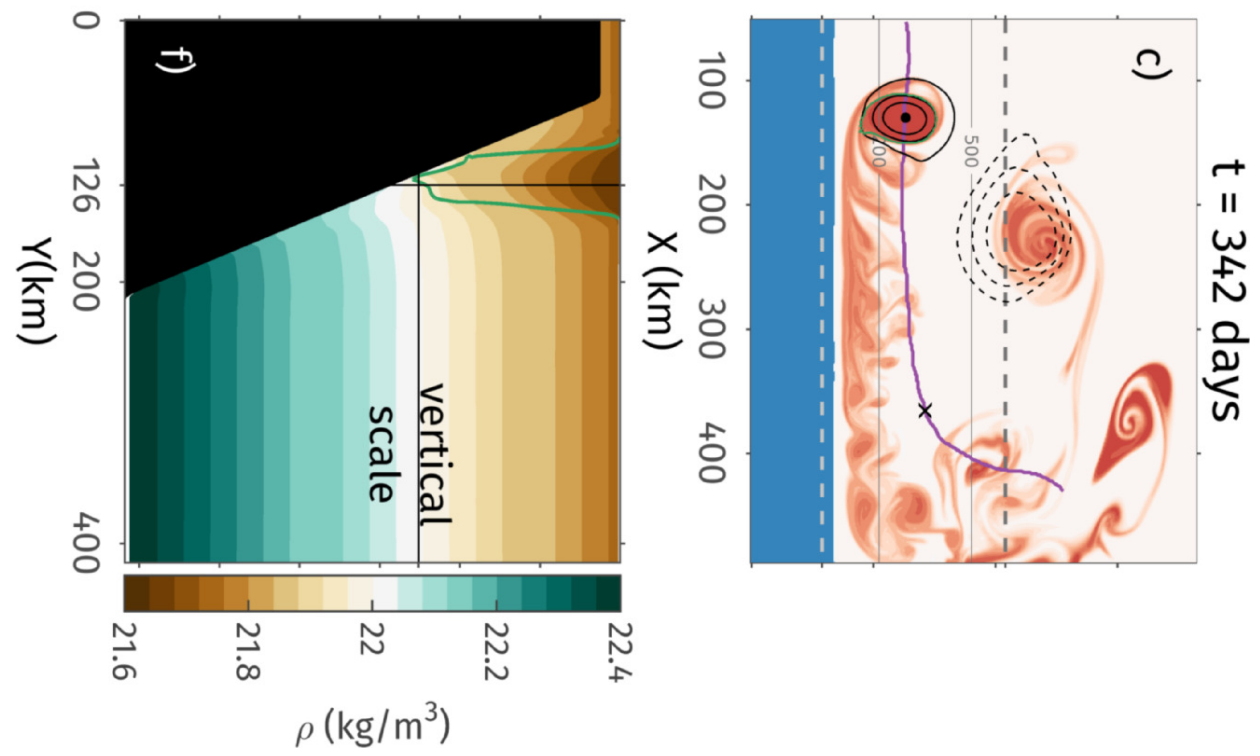


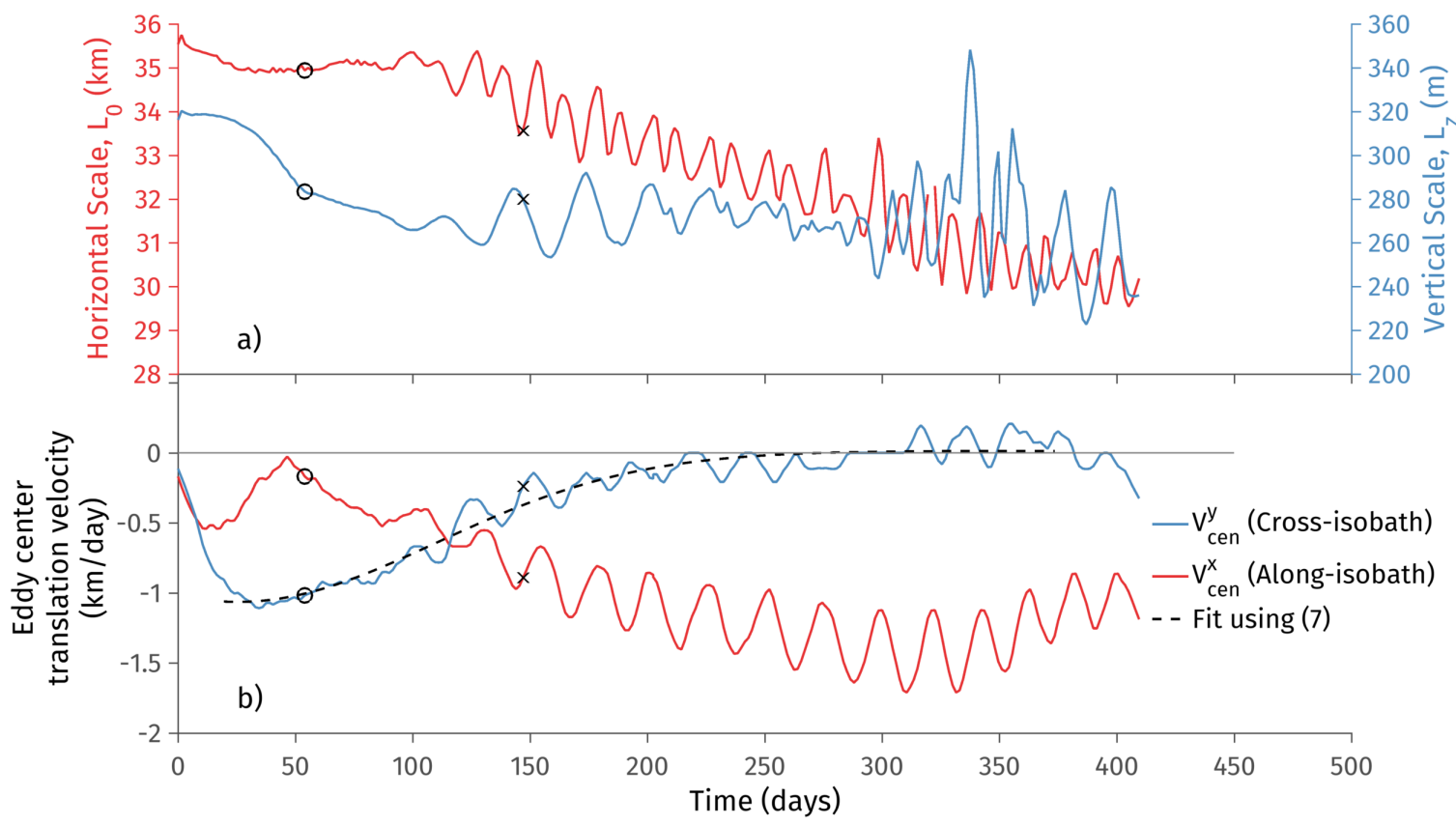

Figure 4.3: Time series of (a) eddy scales and (b) translation velocities for the eddy in Figure 4.2. The time instants at which the eddy crosses the slopebreak and when its cross-isobath translation velocity has reduced appreciably are marked by ' $O$ ' and ' $x$ ' respectively. The dashed line is the Gaussian fit in (4.2).
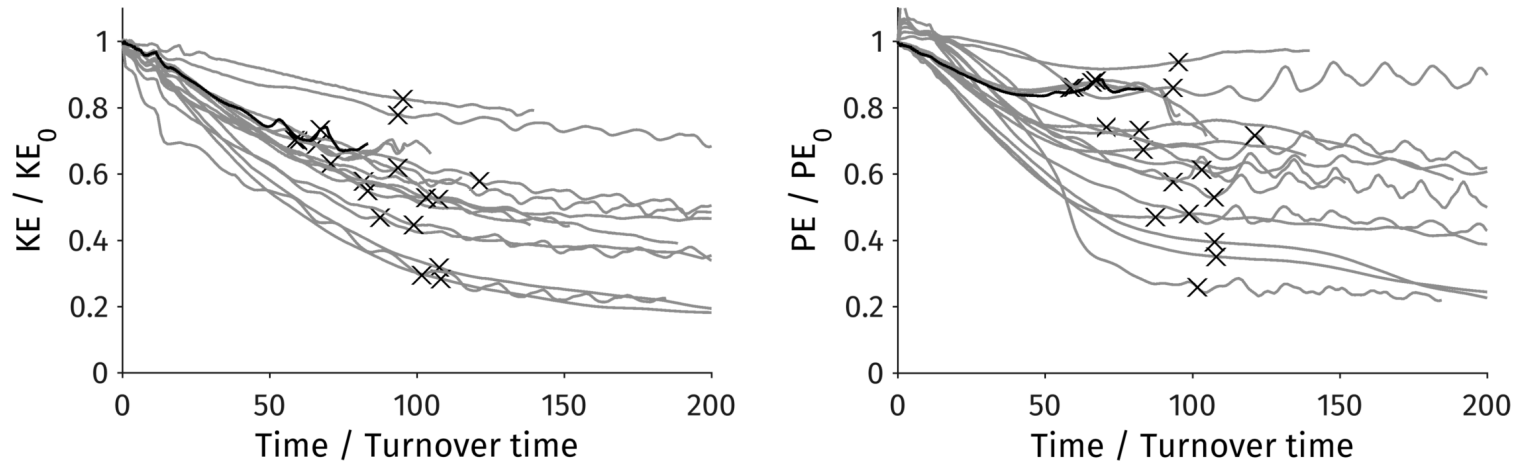

Figure 4.4: Integrated energy in the eddy as defined in (4.1). The ' $x$ ' marks the same time instant as those in Figure 4.2, i.e., the point at which cross-isobath translation is substantially reduced. This is at $t-t_{\text {ref }}=\tau$, where $\tau$ is defined using the Gaussian fit in (4.2). The topmost line is for a simulation with $\mathrm{Rh} \sim 65$ and the rest are for $\mathrm{Rh} \sim 12$. The simulation highlighted in black is the one in Figures 4.2 and 4.3. 


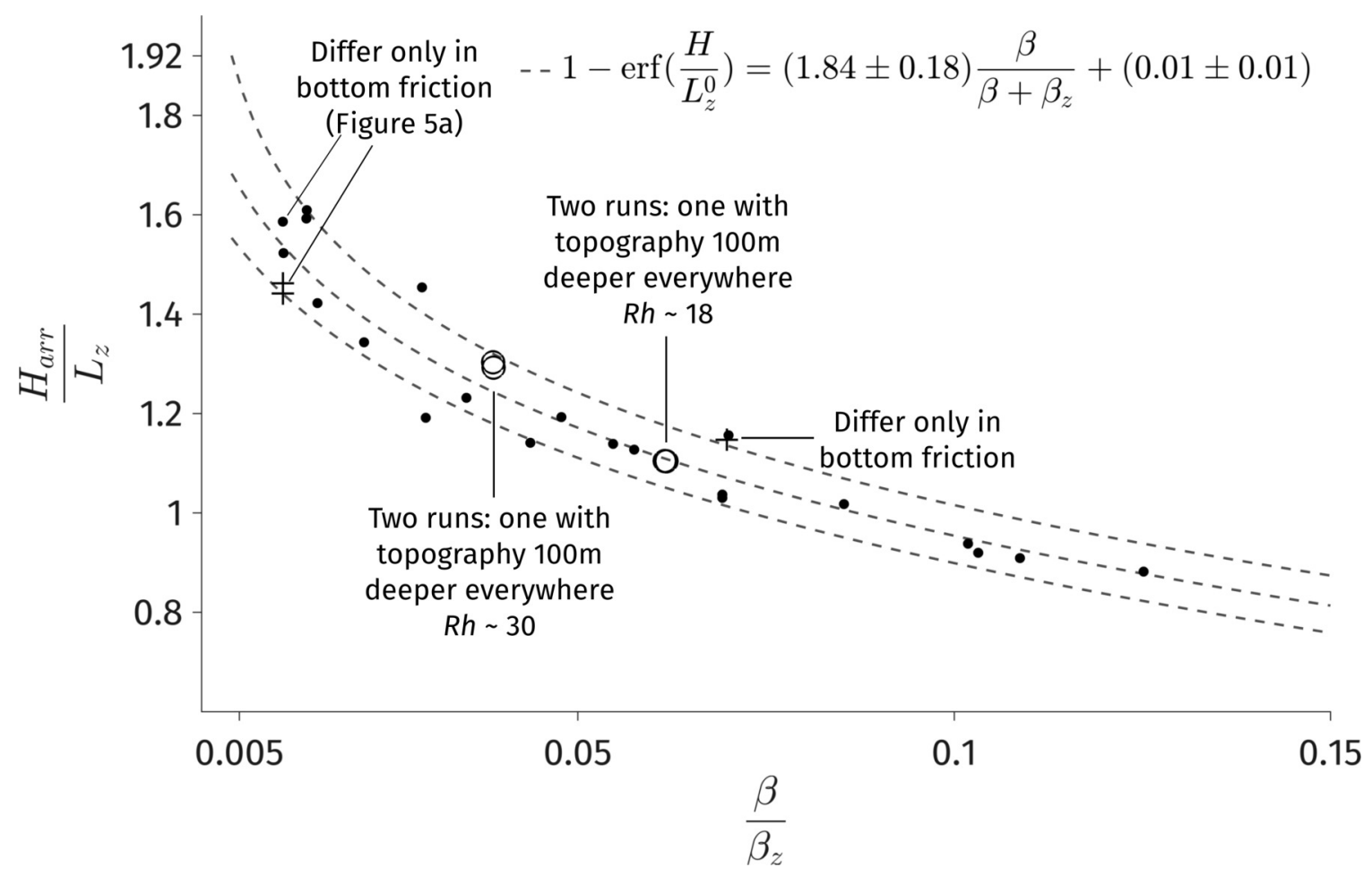

Figure 4.5: Flierl et al. (1983) based scaling for isobath $H_{\text {arr }}$ at which the eddy's crossisobath motion is appreciably reduced. The location is marked by $\mathrm{a} \times$ in Figures 4.2 and 4.7. All these simulations have (slope width) $>$ (eddy width) and $R h \leq 40$. The black dots are model simulations with anticyclones, constant $N^{2}$, no bottom friction and east-west isobaths. The ' + ' are simulations with bottom friction. Overlapping Os are two simulations that only differ in that one has topography $100 \mathrm{~m}$ deeper everywhere. There are two sets of such simulations. 
Water depth at eddy center

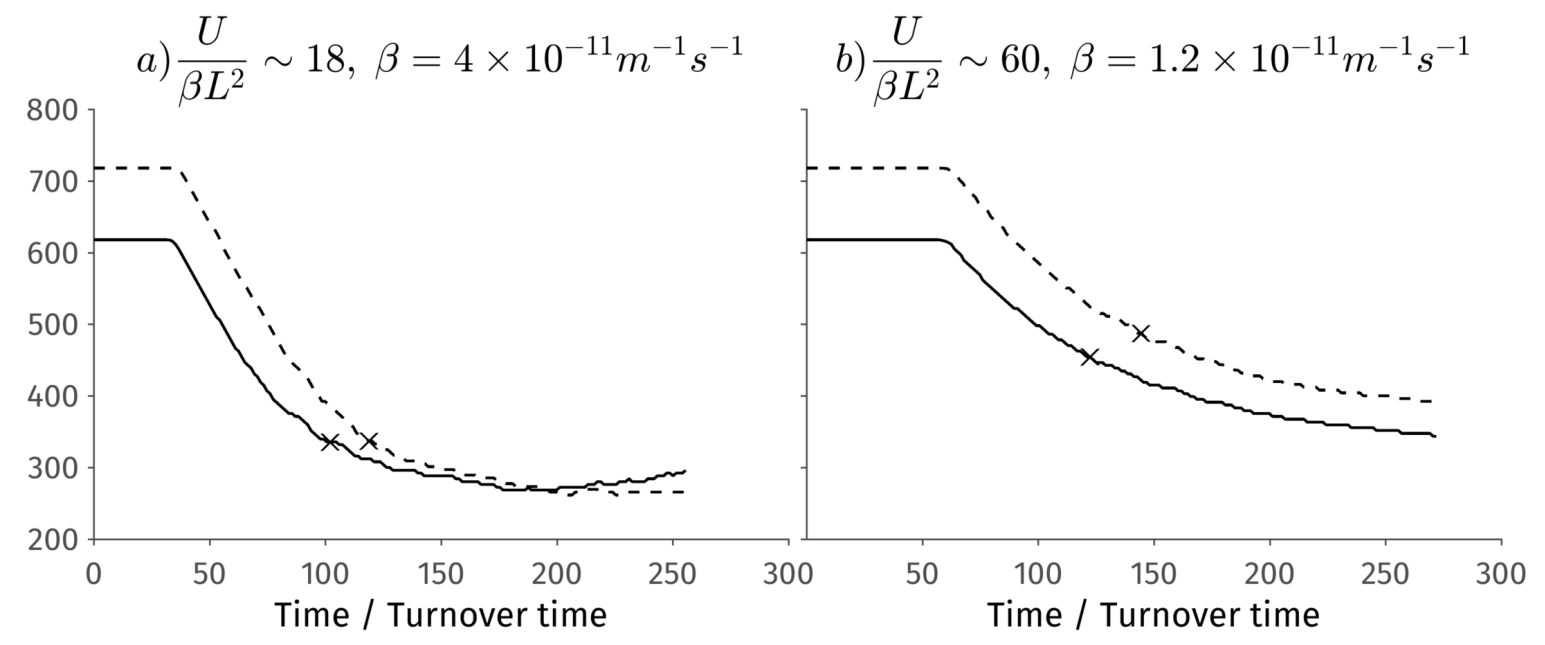

Figure 4.6: Time series of water depth at the eddy's center for two values of Rh. In each panel the only difference between two simulations is that in one, the topography is deeper by $100 \mathrm{~m}$. The panels differ only in the value of planetary $\beta$. (a) For low $\mathrm{Rh}$, the eddy stops at the same water depth for both simulations, indicating that a 'critical depth' exists. (b) For large Rh, this is not true. These eddies are so nonlinear that wave radiation is not an essential part of the eddy's evolution. The difference in water depth at the arrest locations in (b) is $50 \mathrm{~m}$. 

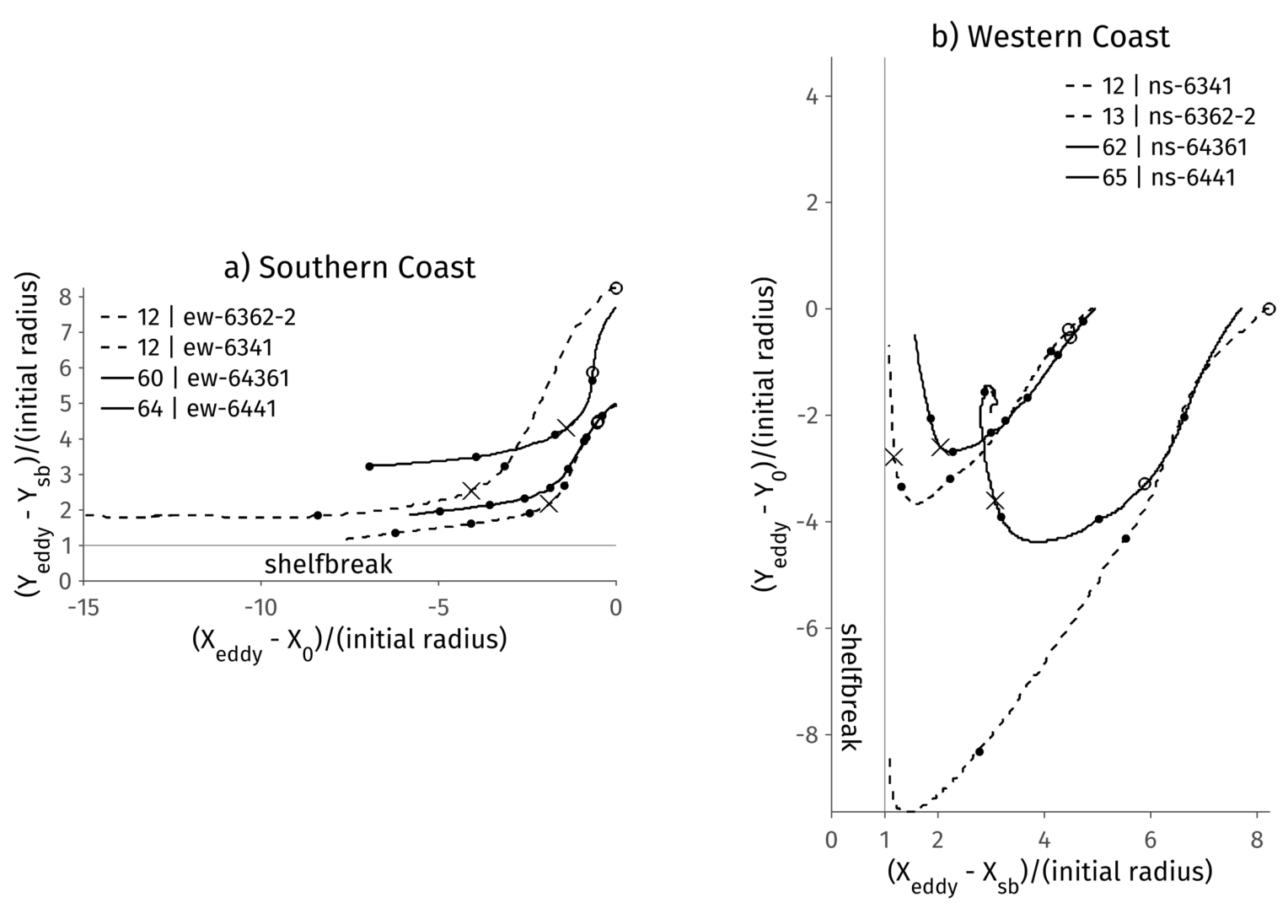

Figure 4.7: Isobath orientation matters only for low Rh eddies; shown by eddy center tracks for southern and western coasts when the slope width, $L_{s l}$, is much larger than eddy scale, $L_{0}$. Axes are relative to shelfbreak location in the cross-shelf direction and the eddy's initial location in the along-shelf direction. Both axes are normalized by the eddy's initial radius. Low Rh eddies (dashed lines) slow down significantly far away from the southern shelfbreak but reach the western shelfbreak (see 4.5.2). High Rh eddies (solid lines) stop far away from the shelfbreak in both cases 


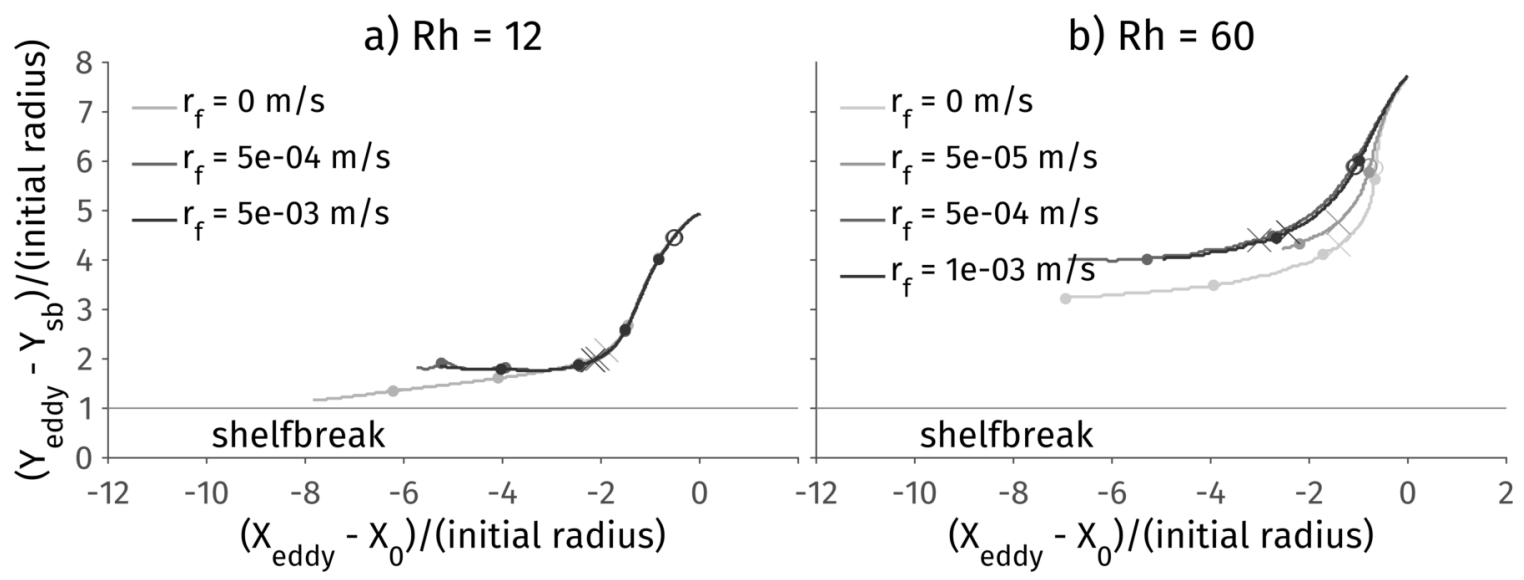

Figure 4.8: Does bottom friction make a difference? These are tracks of the eddy center for the same eddy and topography with different values of linear bottom drag coefficient, $r_{f}$. Darker lines have larger values of bottom friction. The solid dots indicate intervals of 100 days starting at $t=0$. For low Rh, bottom friction does not make a difference as predicted by the theorem. However, $r_{f}$ does matter for large Rh eddies.

topography cannot shut down radiation

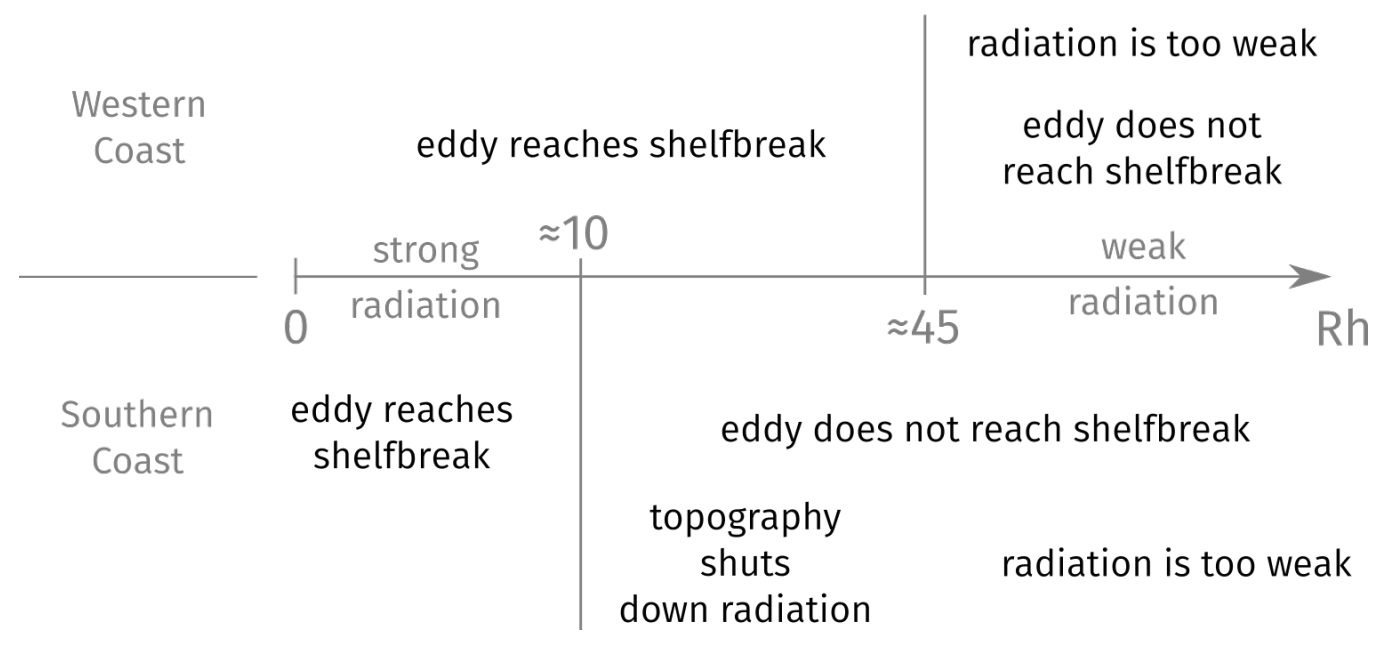

Figure 4.9: Regime diagram in $\mathrm{Rh}=V /\left(\beta L^{2}\right)$ for the anticyclone-topography interaction problem when the slope is much wider than the eddy's diameter. 


\section{$5 \quad$ An eddy encounters a steep narrow slope}

\subsection{Introduction}

(Portion of this chapter constitute an article accepted by the Journal of Physical Oceanography as "Cherian \& Brink (2016) Offshore transport of shelf water by deep-ocean eddies".)

The results in Chapter 4 show that narrow oceanic continental slopes likely cannot prevent deep-ocean eddies from reaching the shelfbreak. This chapter examines the evolution of eddies at the shelfbreak and the resulting offshore transport of shelf water.

We use idealized numerical simulations of a single eddy to examine the structure of the streamer transporting shelf-slope water offshore. This is a more in-depth parameter space exploration when compared to Wei and Wang (2009), and a primitive equation extension of the barotropic simulations of Wang (1992). Unlike Zhang et al. (2011), the coastline here is straight. On occasion, multiple eddies interact with the shelfbreak off the Mid-Atlantic Bight. Here, the presence of multiple eddies and mean flows is ignored for simplicity. We show that in every simulation the streamer appears to intrude into the eddy. The intrusion results in a subsurface maximum in offshore transport. We present a parameterization that, with some assumptions about the eddy's vertical structure, enables the use of available satellite-derived eddy properties (radius and azimuthal velocity) to estimate the amount of water crossing isobaths. For simplicity, there is no shelfbreak front in our simulations. 


\subsection{A typical simulation}

We conducted a series of simulations varying parameters such as velocity and length scales of the eddy, width and topographic slopes of the shelf and continental slope, shelfbreak depth $H_{\mathrm{sb}}, \beta$, bottom friction coefficient $r$, polarity of the eddy, geographic location of the coast and background stratification (Table A1). The evolution of a deformation-scale eddy (initially $25 \mathrm{~km}$ radius and $400 \mathrm{~m}$ depth) in a simulation with no bottom friction and a southern coast is shown in Figure 5.1 (ew-34 in Table A1, video in Supplementary Material). The eddy's initial Rossby number is 0.1 (Table 3.1). The $40 \mathrm{~km}$-wide shelf is flat. The water depth increases from $50 \mathrm{~m}$ at the shelfbreak to $1200 \mathrm{~m}$ in the deep water region. The slope is $50 \mathrm{~km}$ wide and has a slope Burger number of 1.5 (Table 3.1).

Initially, the anticyclonic eddy moves south-westward on the $\beta$-plane. While doing so, it radiates Rossby waves westward (Mied and Lindemann, 1979; McWilliams and Flierl, 1979). The radiated barotropic waves propagate westward faster than the eddy, and are evident in the westward spreading of SSH contours (Figure 5.1b). The eddy however moves faster than the baroclinic Rossby waves it radiates, leaving them behind (Mied and Lindemann, 1979; McWilliams and Flierl, 1979). In addition, a "wake cyclone" is spun up to the eddy's east by the advection of water parcels across the planetary PV gradient. This cyclone transports some slope water offshore in a filament visible at $x \sim 420 \mathrm{~km}$ in Figure $5.1 \mathrm{~b}$. There are also baroclinic Rossby waves left behind the eddy, a "Rossby wake" pattern, because the eddy moves faster than the baroclinic but slower than the barotropic Rossby waves (McWilliams and Flierl, 1979). The eddy's southward motion stops when it reaches the shelfbreak; after which, it translates westward along the shelfbreak, presumably due to the image effect. The evolution of the eddy strongly resembles the contour dynamics simulations of Shi and Nof (1993, Figures 3 and 5), wherein a vertical wall abruptly cuts off the circulation of an unstable eddy. As in their simulations, the eddy loses mass along the slope (wall), creating an along-shore jet moving away from the eddy; termed "leakage" by Shi and Nof (1993) and "Pinnochio's Nose Intrusion" by Zhang and Gawarkiewicz (2015). Oey and Zhang (2004) and Wei et al. (2008) observed similar along-slope or along-wall leakages in their modelling experiments, as did Chen et al. (2014) in their data assimilative solution. On encountering the slope, the eddy adjusts to the boundary condition by adopting an elliptical shape (termed "wodon" by Shi and Nof, 1994). The eddy continually revolves elliptically, as observed by Vukovich and Waddell (1991). 

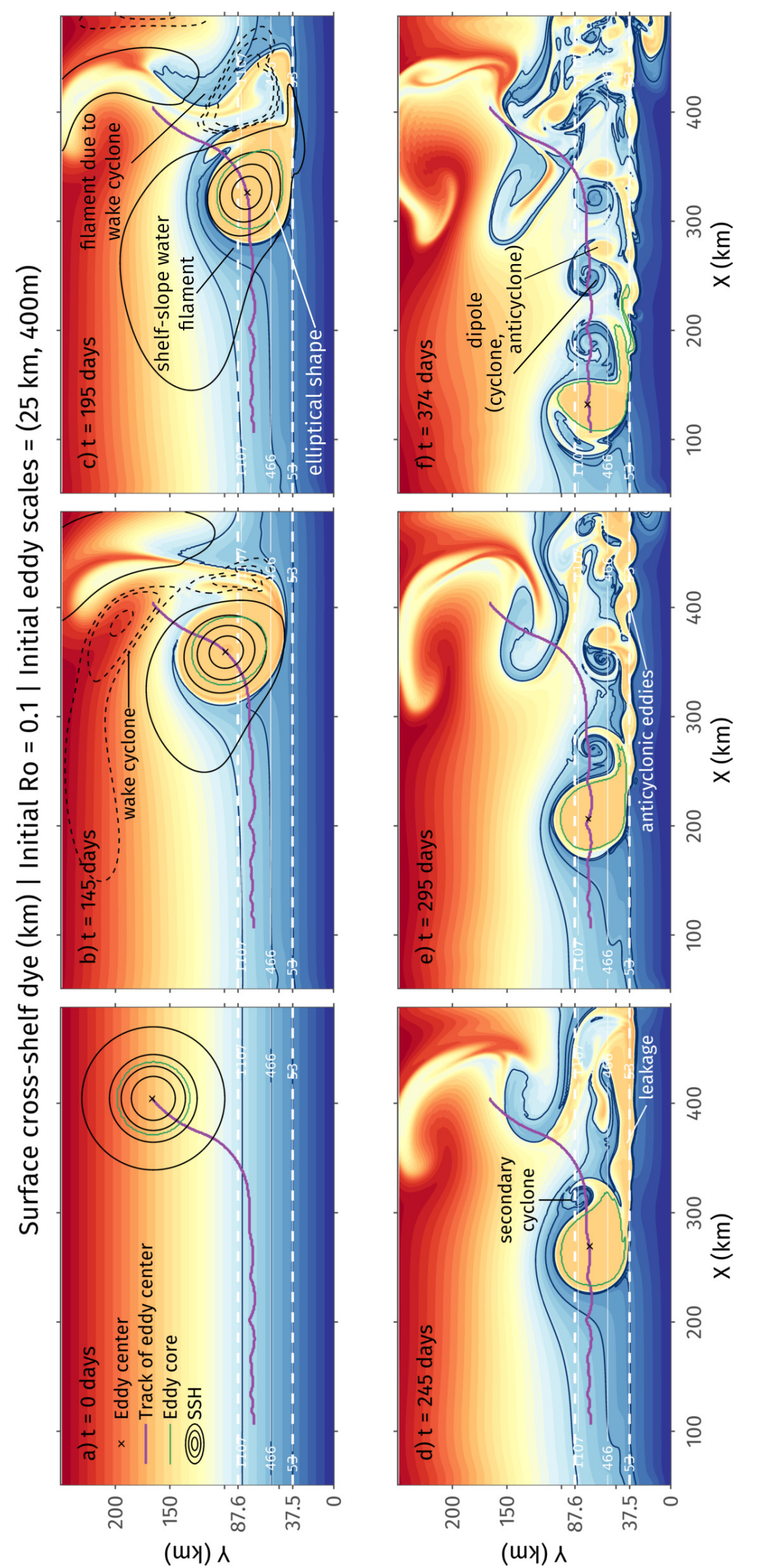

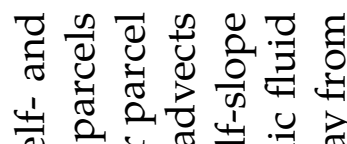

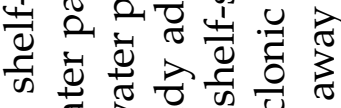
ङ3 3000 \& 屯ै कै

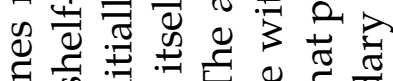

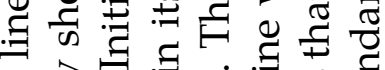

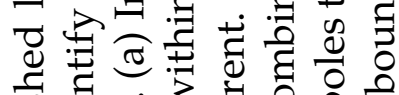

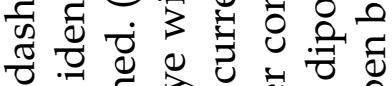

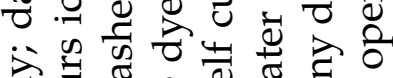

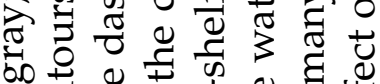

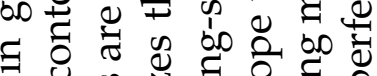

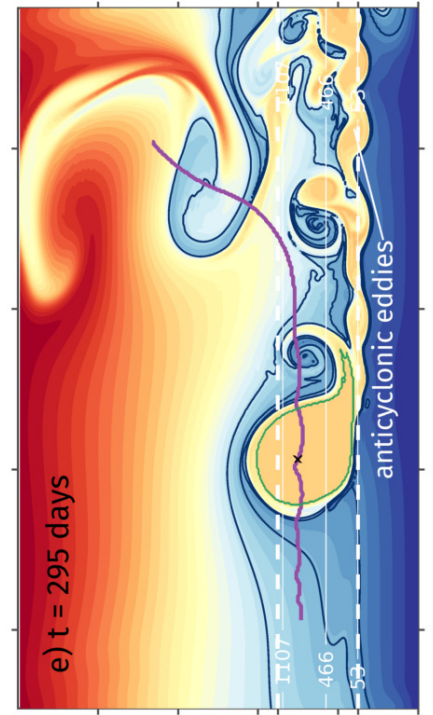

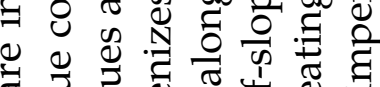

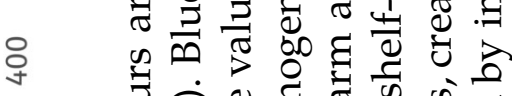

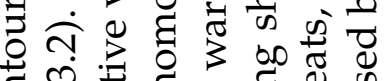

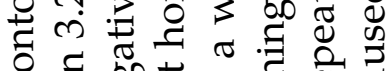
రิ

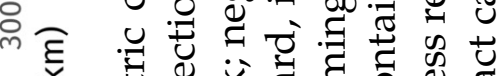
×

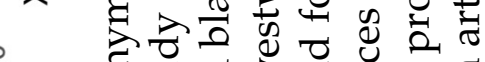

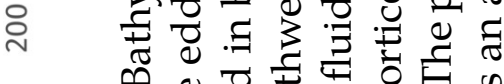

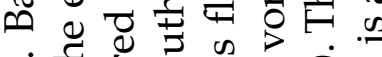
可声它 \& 0 क

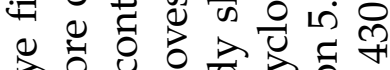

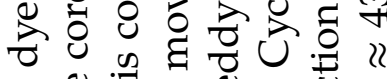
产

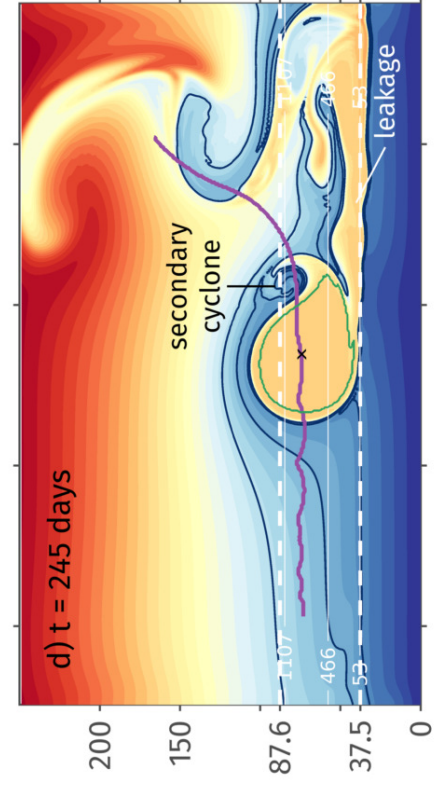

(u>|) $\wedge$

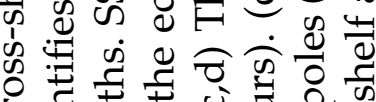

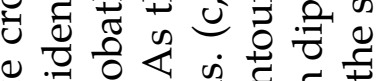
8.0 .

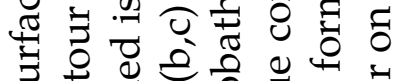

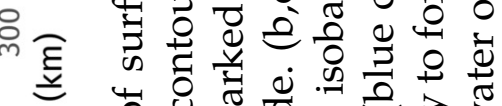
× 윰

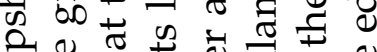

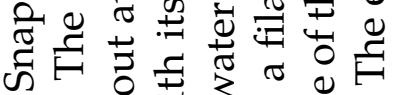

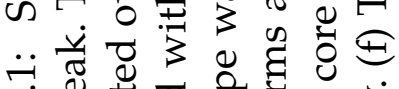

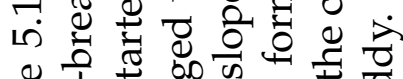
政

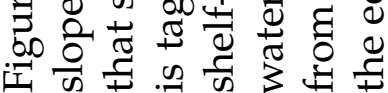


When at the shelfbreak, the anticyclonic eddy exports shelf water across the shelfbreak. Being an SSH high, the anticyclone raises the SSH at the shelfbreak, such that there is nearly-barotropic offshore flow of shelf water. An along-shelf jet, directed east to west, supplies the exported shelf water from downstream of the eddy (coastal-trapped wave sense). These aspects of the interaction are addressed in Section 5.5 for a flat shelf, and Chapter 6 for a sloping shelf. A recipe for predicting the magnitude of the offshore shelf water transport is described in Chapter 7. The advected shelf-slope water parcels initially have a filament-like structure (Figure 5.1c). Later on, the shelf-slope water parcels form smaller scale cyclones as they are advected around the eddy (panels $\mathrm{d}$ and $\mathrm{e}$ ). There is an advective feedback from these cyclones back on to the main eddy. They make the track of the eddy's center "loopy" later in the run, when it is weaker after losing mass and energy to the leakage and Rossby wave radiation. Once the cyclone reaches the slope on the eastern side of the eddy, it combines with anticyclonic eddy water, expelled from the edge of the eddy's core, to form a dipole that propagates eastward, away from the eddy (panel f). Not all of the expelled eddy water moves into the dipole. Instead, some eddy water propagates away from the eddy along the shelfbreak forming small anticyclonic eddies. The cycle then repeats, with the main eddy becoming smaller and smaller. The smaller-scale features created during the interacting are not influenced by planetary $\beta$; hence coastal orientation is irrelevant once the eddy reaches the shelfbreak. Observations indicate that Gulf Stream warm-core rings decay as they move along-isobath but not to the point that they disappear (Olson et al., 1985). Instead, they are reabsorbed by the Gulf Stream.

Surface maps of Ertel PV and relative vorticity display the same patterns present in the dye field (Figure 5.3). Both vorticity fields are filamentary. Once exported across the shelfbreak, shelf water parcels have cyclonic vorticity but low values of PV given their low-latitude origin. The anticyclonic eddy has a low PV core, reflecting the lower density stratification in the core of the eddy, surrounded by an cyclonic annulus of high PV fluid. This pattern is present when the eddy is initialized (not shown). PV has been homogenized to a large extent in the eddy core, though a small gradient is still present. The leakage, which contains water from the eddy's edge, dominantly contains high PV water. The rest of this thesis will focus on the dye field; being more straightforward to interpret than the filamentary vorticity fields.

In Figure 5.1, the leakage propagates away from the eddy in the coastal-trapped wave direction (coast, or higher $\mathrm{PV}$, to the wave's right) similar to the along-shore 
jet described in Chapman and Brink (1987). The agreement of directions is coincidental. Analogous simulations with a cyclone, moving northwards on a $\beta$-plane toward shelf-slope topography with a northern coast, show the leakage again moving eastwards - opposite to the coastal-trapped wave direction, but again away from the eddy (Nof, 1988, 1999; Shi and Nof, 1993). The leakage is caused by the eddy's circulation being interrupted by the slope or a vertical wall; a nonlinear interaction not represented by the linear wave physics of Chapman and Brink (1987). However, when compared with the anticyclone in Figure 5.1, the cyclone appears to leak a much lesser amount of water, and the leakage is less energetic (Figure 5.2). This dramatic difference is likely a result of the cyclone's leakage propagating eastward, opposite to the Kelvin-wave direction. Linear theory, as in Chapman and Brink (1987), indicates that information, i.e. mass and energy, propagates in the Kelvin-wave direction. Flow counter to this direction should be weak, as seen for the cyclone's leakage. Near the bottom, there is a thin layer of eddy water moving eastward and out through the open boundary. A dynamical explanation for such behaviour was not found.

\subsection{Streamer flow over the slope}

\subsubsection{The mean streamer field}

We now describe the mean offshore flow field experienced by shelf-slope water. We begin with a picture, Figure 5.4, of the cross-isobath flow field experienced by shelfslope water that originated inshore of isobath, $y / R=\frac{1}{2}$. It is representative of many simulations and all isobaths offshore of the shelfbreak. The color panel shows the time averaged cross-isobath velocity field, experienced by shelf-slope water, in a reference frame moving with the eddy whose center is at $x=0$. It is constructed using two pieces of information. One, at each time step, the instantaneous cross-isobath velocity field is interpolated to a coordinate system with the eddy's current center location as origin. Two, using the cross-shelf dye, we construct a mask identifying water parcels that started inshore of the chosen isobath i.e., (cross-shelf dye value) < (isobath location). We then average the product of these two fields over $\left[t_{\text {start }}, t_{\text {stop }}\right]$ (Section 3.3). The other two panels in Figure 5.4 show the along-isobath and vertical profile of the offshore flow obtained by integrating the averaged field (color panel) in $z$ and $x$ (up to eddy center, $x=0$ ) respectively.

The peak in onshore flow is smaller: there is net offshore export across this iso- 


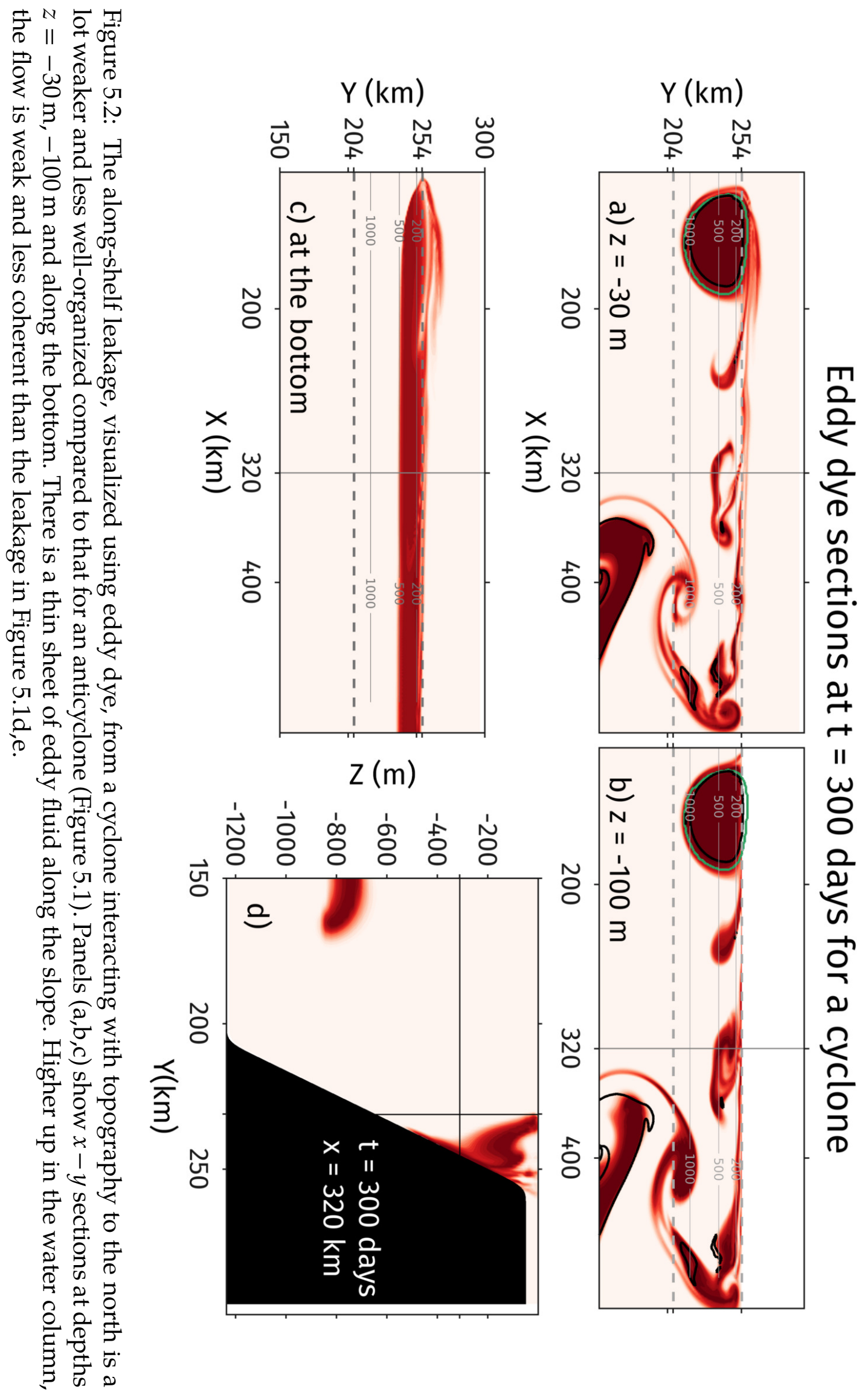




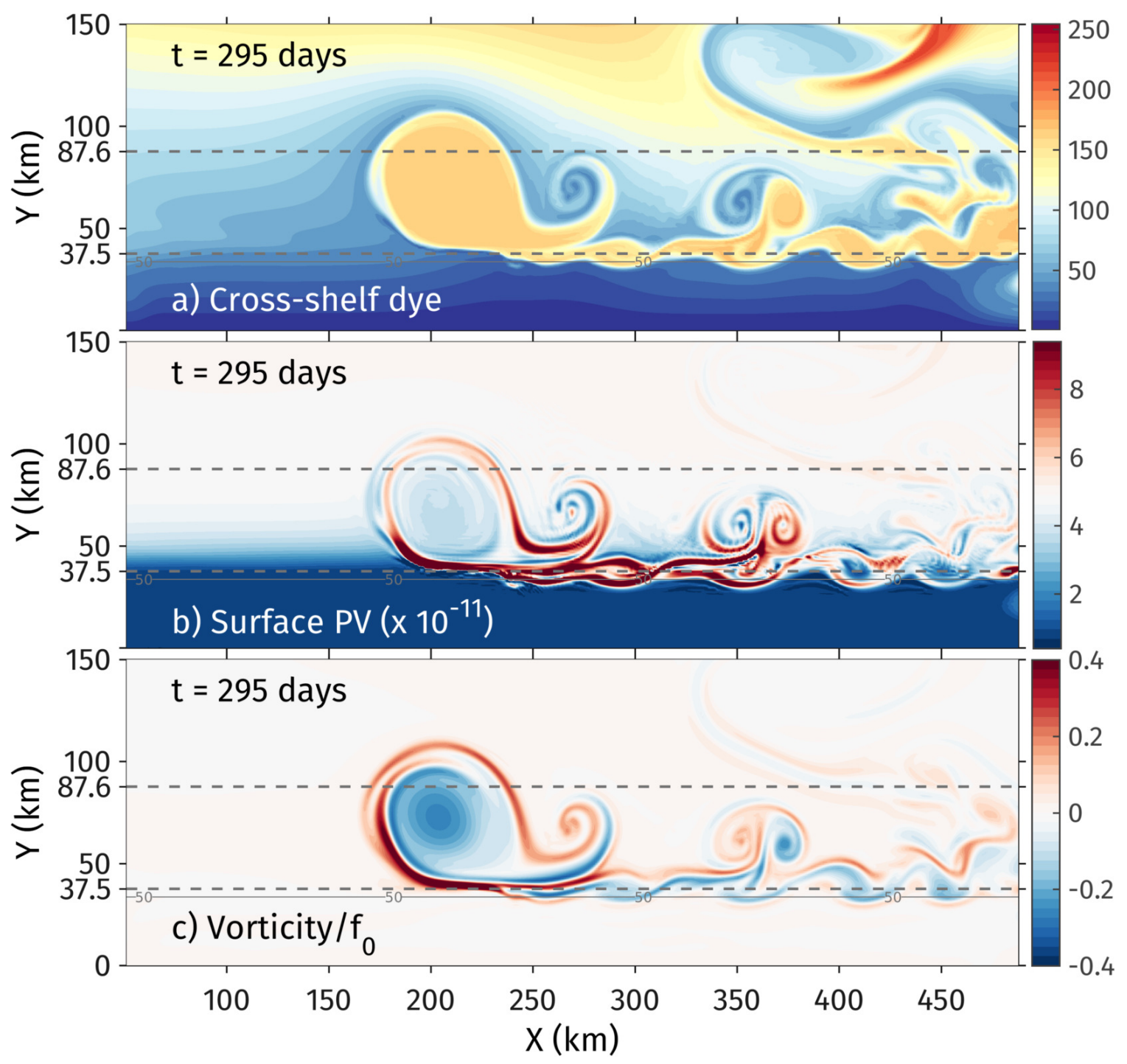

Figure 5.3: Cross-shelf dye, Ertel PV and relative vorticity (normalized by $f_{0}$ ) at $t=295$ days for the same simulation as in Figure 5.1.

bath. To the east of the eddy, the shelf-slope water mass is transported out the eastern boundary during the eddy's initial approach (Figure 5.1c), whereas to the west, the shelf-slope water mass is relatively undisturbed. Consequently, the water mass volume is permanently reduced on the east side whereas to the west, the undisturbed dye field is potentially an infinite source of the water mass. Additionally, some western water parcels mix as they move around the eddy, losing their identity by the time they reach the isobath of interest on the eastern side. Thus, larger offshore transport is accomplished during the simulation.

The along-isobath structure is as expected: there is a peak in offshore flow that decays away from the eddy (Figure 5.4). The vertical structure is surprising: there 


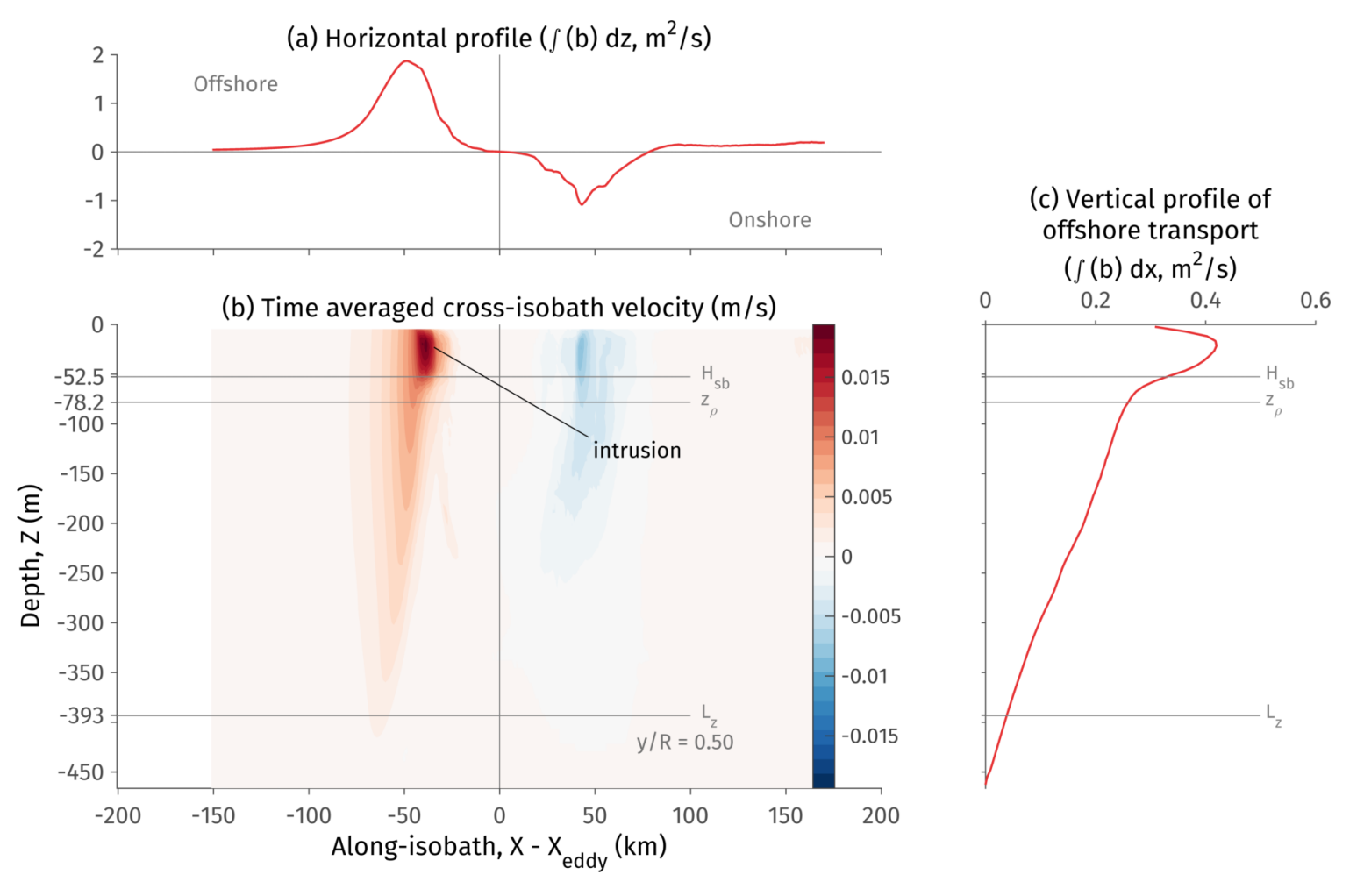

Figure 5.4: Averaged cross-isobath velocity field integrated to show both alongisobath and vertical structure. The instantaneous snapshots of cross-isobath velocity are averaged together in a reference frame with the eddy's center as origin. The average is over $\left[t_{\text {start }}, t_{\text {stop }}\right]$ (Section 3.3). $z_{\rho}$ is the predicted depth of the intrusion (Section 5.4).

is a pronounced subsurface peak in the offshore flow of shelf-slope water. The total instantaneous velocity field is always surface-intensified (see Figure 5.5), as expected since the eddy is initialized to be surface-intensified. The black contour in Figure 5.5 is the mask. It bounds the region containing shelf-slope water that started inshore of the isobath; i.e., the region over which we integrate the velocity field to obtain the instantaneous cross-isobath transport. The subsurface peak reflects an intrusion into the eddy, a kink in the black contour, at $z \approx-30 \mathrm{~m}$. The peak is a result of the larger horizontal extent of the integration domain at $z \approx-30 \mathrm{~m}$ and nearby depths. The peak is robust and exists for all runs conducted with anticyclonic eddies, so a general mechanism is at play.

\subsubsection{The intrusion mechanism}

Why is there a subsurface maximum in offshore transport, associated with an apparent intrusion of shelf water into the eddy? The gist is that the shelf-slope water 

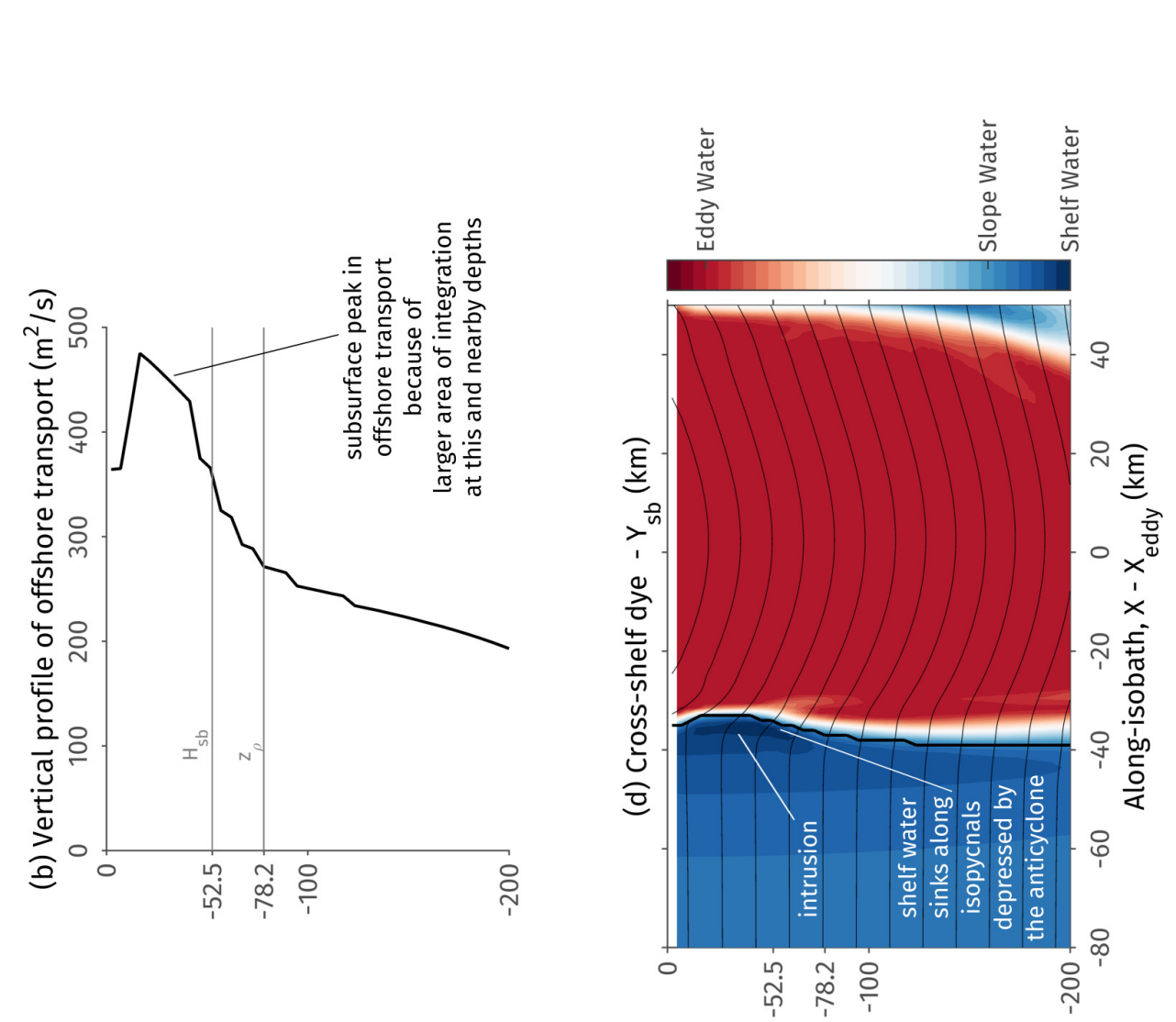

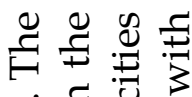

完寻

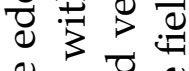

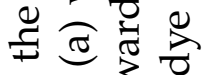

웜ㄹ⿺

둥

ज्ञ

号宁 导

ฮ 屯ี

च्ञ क्ष

를

此

त्ञा के

ర0

可

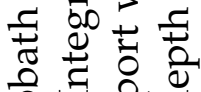

की है

के 屯ี

(w) पวdə0

उ 3

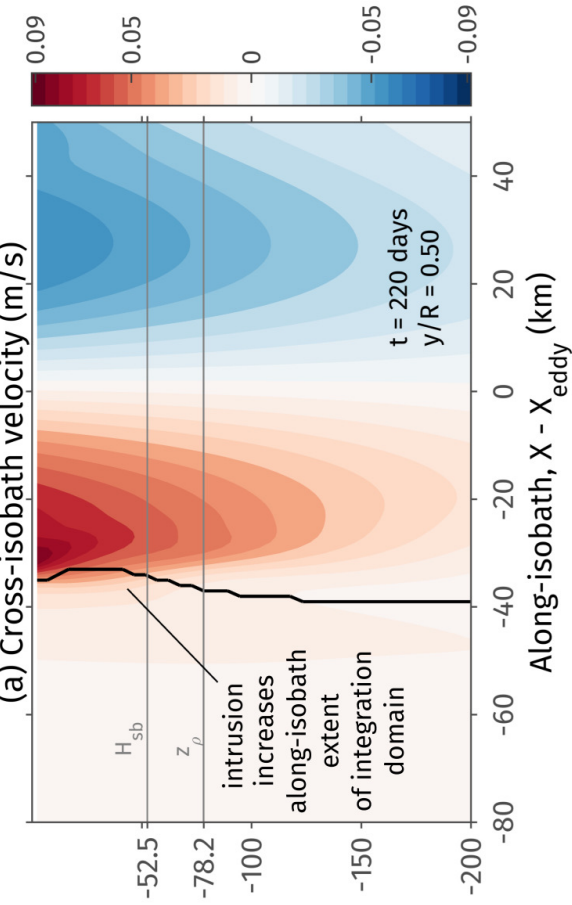

(m) प7də0

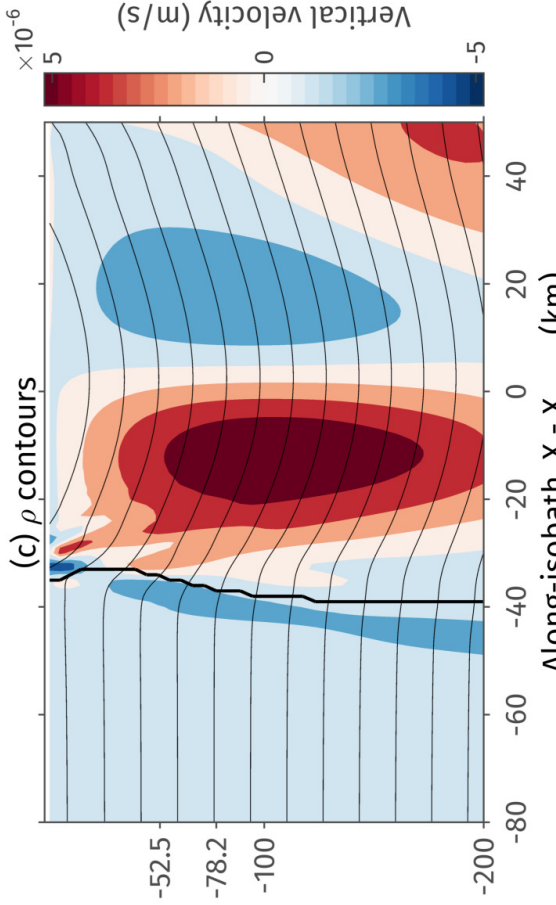

(ii) प7də0
馬造离

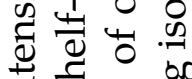

吉宁

Ð 륭 웅

तै

के 후의

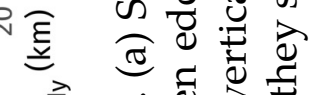
๖ं ¿ี

要

定产

N $\Xi$

के चे

号志 考

0 :

㐘

क्ञ 9.9

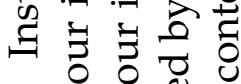

மั 윤

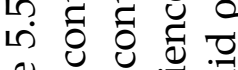

范

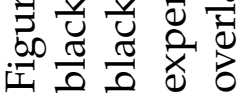




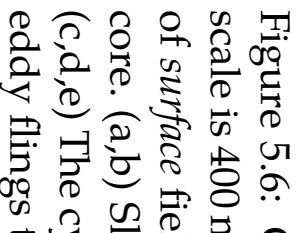

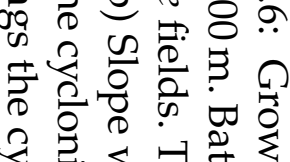

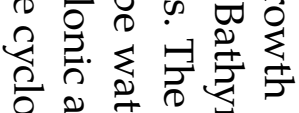

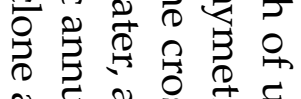

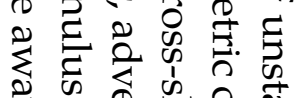

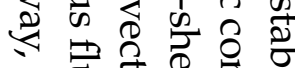

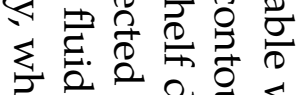
룽 뭉휴

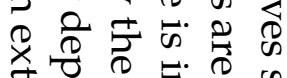
굴 至 क न 당

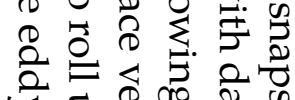
Q⿱宀女工 死 훙 탕 궁

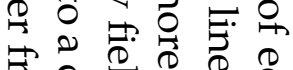

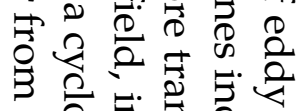
F 응 웅

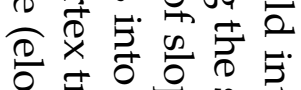

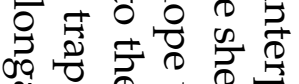

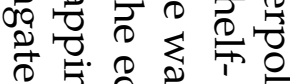

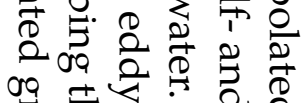

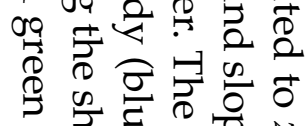
2 잉

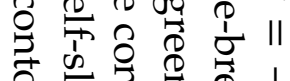

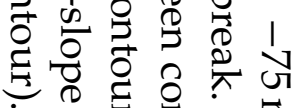

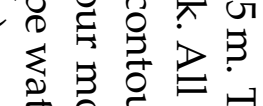
尊 \% क ठ
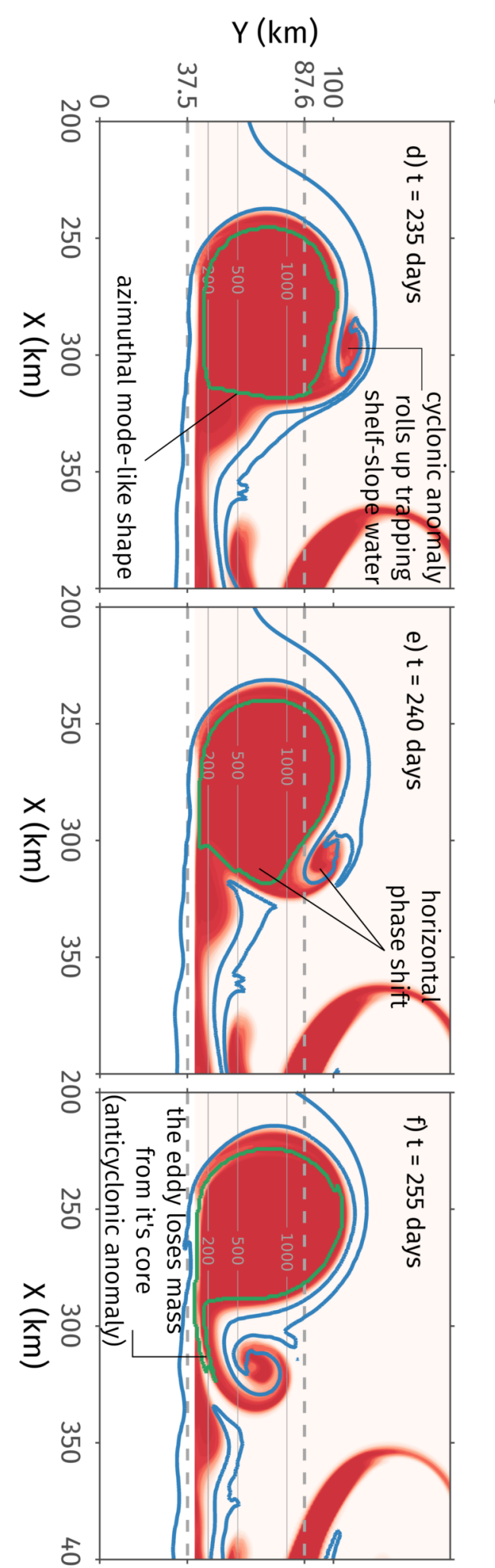

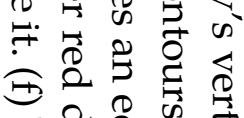

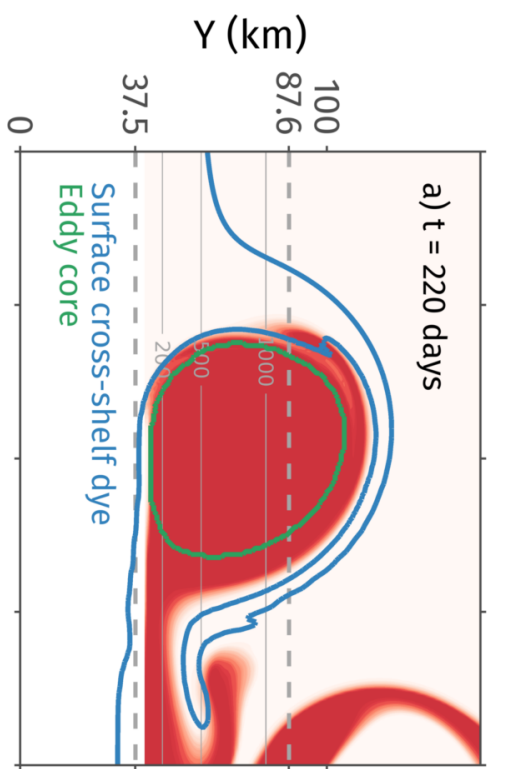

$\frac{m}{2}$

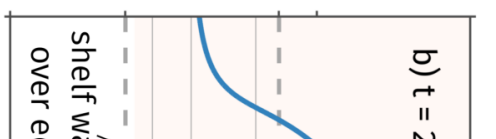

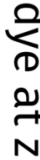

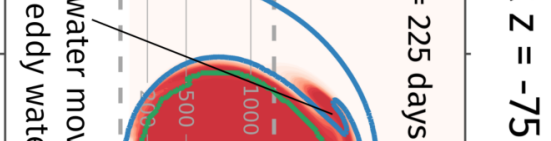

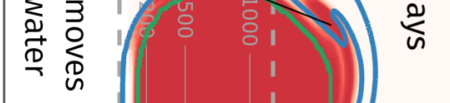

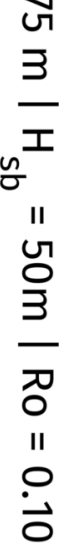

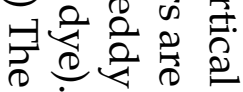


does not intrude into the eddy. Instead, the eddy bulges out below shelfbreak depth for two reasons:

(a) below shelfbreak depth, the eddy adjusts to the boundary condition imposed by the slope by compressing itself in the cross-isobath direction and squeezing out in the along-shelf direction (Shi and Nof, 1994); and

(b) a cyclonic vorticity anomaly propagating on the eddy's PV gradient appears as an additional propagating bulge on the eddy's side.

Near the surface, the eddy advects shelf-slope water over the bulge in its deep structure, making it appear as if shelf-slope water is intruding into the eddy (Figure 5.5).

The formation of apparent intrusions and eventually, dipoles is described using two figures. Figure 5.6 shows $x-y$ slices of the eddy dye field (in red) at $z=-75 \mathrm{~m}=$ $1.5 \times H_{\mathrm{sb}}$. The blue contour indicates the location of a single value of cross-shelf dye at the surface and the green contour identifies the core of the eddy defined using a density anomaly criterion, again, at the surface (Section 3). Figure 5.7 shows a three dimensional summary of the process again using passive tracers: the red surface identifies the edge of the eddy and the blue surfaces visualizes shelf-slope water. In what follows, it is useful to idealize the eddy as two concentric contours following Shi and Nof (1993) — one being the radius to maximum velocity containing the anticyclonic core of the eddy; and the other, indicating the boundary of the eddy fluid (Figure 3.1). Between the two contours, lies an annular region of cyclonic relative vorticity where the velocity of the eddy decays from its maximum value to nearly zero. For the idealized Gaussian eddy, these contours are $r=1 / \sqrt{2}$ and roughly, $r=1$.

The sequence of events is:

1. As the eddy approaches from the north, the slope interrupts its circulation below shelfbreak depth by imposing a no-normal flow boundary condition.

a) Because the slope is steep compared to the eddy, this is effectively a lateral boundary condition on the eddy. Above shelfbreak depth, there is no such imposition. The difference is key: below shelfbreak depth, the eddy responds as described in Shi and Nof (1994) by bulging out and adopting a more elliptical shape (Figure 5.7c). 
b) Below shelfbreak depth, the slope also diverts some eddy water alongshore away from the eddy. This can be visualized as a nonlinear jet of water splitting into two upon hitting a wall (Oey and Zhang, 2004; Whitehead, 1985). Above shelfbreak depth, where there is no boundary, some eddy water spills onto the shelf and spreads alongshore away from the eddy. The water currently in the leakage is lost from the eddy's cyclonic annulus - the gap between the green and blue contours in Figure $5.6-$ as in Shi and Nof (1993) and Zhang and Gawarkiewicz (2015).

2. The eddy advects shelf-slope water parcels over the bulge that exists in its structure below shelfbreak depth (blue filament in Figure 5.7c). The advected shelf/slope water (blue contour in Figure 5.6) takes the place of the eddy's lost annulus fluid. In the cross-section, it appears as if the shelf-slope water is intruding into the eddy (Figure 5.7c).

3. Simultaneously at depth, to the west of the eddy center, cyclonic vorticity is generated at the slope. This may happen for two reasons. First, bottom friction at the slope (if present) generates cyclonic vorticity by retarding the alongisobath velocity. Second, hydraulic arrest of topographic waves by the eddy's flow can create vorticity of sign opposite to that of the main eddy (Dewar et al., 2011).

4. Propagating vorticity anomalies, both cyclonic and anticyclonic, are now excited on the PV gradient of the eddy. They are identified as such following Shi and Nof (1993) who show a cyclonic anomaly propagating on the outer PV contour and an anticyclonic anomaly propagating on the inner contour (Shi and Nof, 1993, Figure 3). These anomalies are likely a result of the slope interrupting the circulation of the baroclinically unstable eddy and perturbations due to cyclonic vorticity being generated at the slope. The anomalies are seen in Figure 5.6 (c-e) as a bulge in the red eddy dye field at the outer edge of the eddy (cyclonic), and in the azimuthal mode-like shapes seen in the eddy core (anticyclonic, green contour).

5. The apparent intrusion highlighted in Figure 5.5 is a result of the shelf-slope water being advected over the bulge in the eddy's shape below the shelfbreak depth (Figure 5.7). The fate of the shelf water is now tied to that of the cyclonic anomaly. 
6. The anomalies phase-lock, mutually amplify and ultimately grow to finite amplitude as they propagate around the eddy, as in Shi and Nof (1993). The peaks in the cross-isobath flux time series in Figure 3.2 correspond to the cyclonic anomaly crossing that isobath. Unambiguously determining the nature of the instability is difficult. There is a horizontal phase shift between two anomalies (Figures 5.6e and 5.7c). The eddy and shelf-slope water filament might be undergoing a barotropic instability as in Shi and Nof (1993). However, if one were to consider eddy water alone, the cyclonic anomaly only exists below shelfbreak depth while the anticyclonic anomaly is visible at the surface - there is some baroclinic character to the evolution.

7. As the cyclonic anomaly amplifies and rolls up into a vortex at depth, it traps the shelf-slope water above it (Figure 5.7). The cyclonic anomaly now has a "stacked" vertical structure that is preserved through the rest of its evolution. Below shelfbreak depth (roughly), the water column contains eddy water, while above it, there is shelf-slope water that has taken the place of the shed annulus fluid (Figure 5.6d-f; Figure 5.8 and Section 5.4).

8. When the phase-locked finite amplitude anomalies reach the slope on the eastern side of the eddy, they break off as a dipolar chunk of water (Figure 5.6f). The cyclonic anomaly is now a vortex, whereas the anticyclonic anomaly is expelled from the eddy's core as a filament of fluid. The two then eventually form a dipole that propagates away. Not all of the eddy water expelled from the main eddy is in the dipole; some of it is deposited at the shelfbreak where it then forms small, surface-intensified anticyclonic eddies that translate along the shelfbreak (Figure 5.1d-f).

9. This process repeats itself, with the eddy continually losing mass. The eddy is ultimately destroyed if the model is integrated for long enough.

Even though the eddy is always surface-intensified, the vertical profile of average cross-isobath transport has a subsurface maximum always (Figures 5.4 and 5.5). The maximum is a result of the larger horizontal extent of the integration region where shelf water appears to intrude into the eddy (Figure 5.5). We have argued that the shelf water is not intruding into the eddy; instead, it is advected over a bulge in the eddy's shape below shelfbreak depth. The bulge exists for two reasons: the eddy adjusts to the boundary condition imposed by the continental slope, and cyclonic anomalies propagate on the eddy's PV gradient (Figure 5.7a,c). The propagating 
cyclonic anomaly traps near-surface shelf-slope water as it rolls up into a cyclone (Figure 5.7c,d). Finally, the stacked cyclone forms a dipole with water expelled from the eddy's core. The process is dissipative in that it acts to transfer energy from the main eddy to smaller-scale features.

\subsection{The fate of shelf-slope water}

The shelf-slope water is permanently exported in dipoles that propagate eastward away from the eddy i.e., downstream in the coastal trapped wave, or Kelvin wave, sense. The dipoles then interact with the leakage and other flow features that haven't escaped the domain. Vertical profiles of cross-shelf dye at different stages in the formation of the dipole show that the cyclone's stacked structure is preserved throughout (Figure 5.8b). The boundary between the two water masses in the cyclone is the depth, $z_{\rho}$, of the isopycnal surface of same density as the densest shelf water. The shelf-water stretches and sinks to this surface as it moves offshore (Figure 5.5d), and the eddy water upwells from depth so that the isopycnals pinch together at $z_{\rho}$, associated with a subsurface peak in PV (Figure 5.8d). $z_{\rho}$, marked in Figure 5.8, is determined by comparing the initial density profile on the shelf to that one eddy radius away from the eddy center in the along-shelf direction. It is also the width of the peak in offshore transport (Figures 5.4 and 5.5b).

The sinking of shelf-slope water along isopycnals creates negative density anomalies in the cyclones around $H_{\mathrm{sb}}$ (Figure 5.8c). Closer to the surface, the density signal is complicated by the surface boundary layer forced by the no-flux condition on temperature at the surface. This particular run is long enough that the boundary layer depth reaches $30 \mathrm{~m}$ with background vertical mixing. Figure 5.9 shows vertical profiles at $t=79$ days for three locations through the secondary cyclone for a different run with shelfbreak depth of $100 \mathrm{~m}$. The density anomaly profile, relative to $H_{\mathrm{sb}}$, is similar to that in Figure 5.8c, indicating upwelling of deep eddy water (denser than ambient) and sinking/stretching of shelf water (lighter than ambient).

In the dipole, the anticyclonic vortex is stacked too: it contains eddy water to roughly shelfbreak depth, and shelf-slope water underneath (reddish-orange profiles in Figure 5.8a). The shelf-slope water appears to be trapped after the anticyclone is expelled form the eddy core. The density anomaly in the anticyclonic anomaly is not as negative as at the eddy's center because the eddy expels fluid from its annular edge (Shi and Nof, 1993; Zhang and Gawarkiewicz, 2015). Despite the complex water mass structure, relative vorticity does not change sign with 

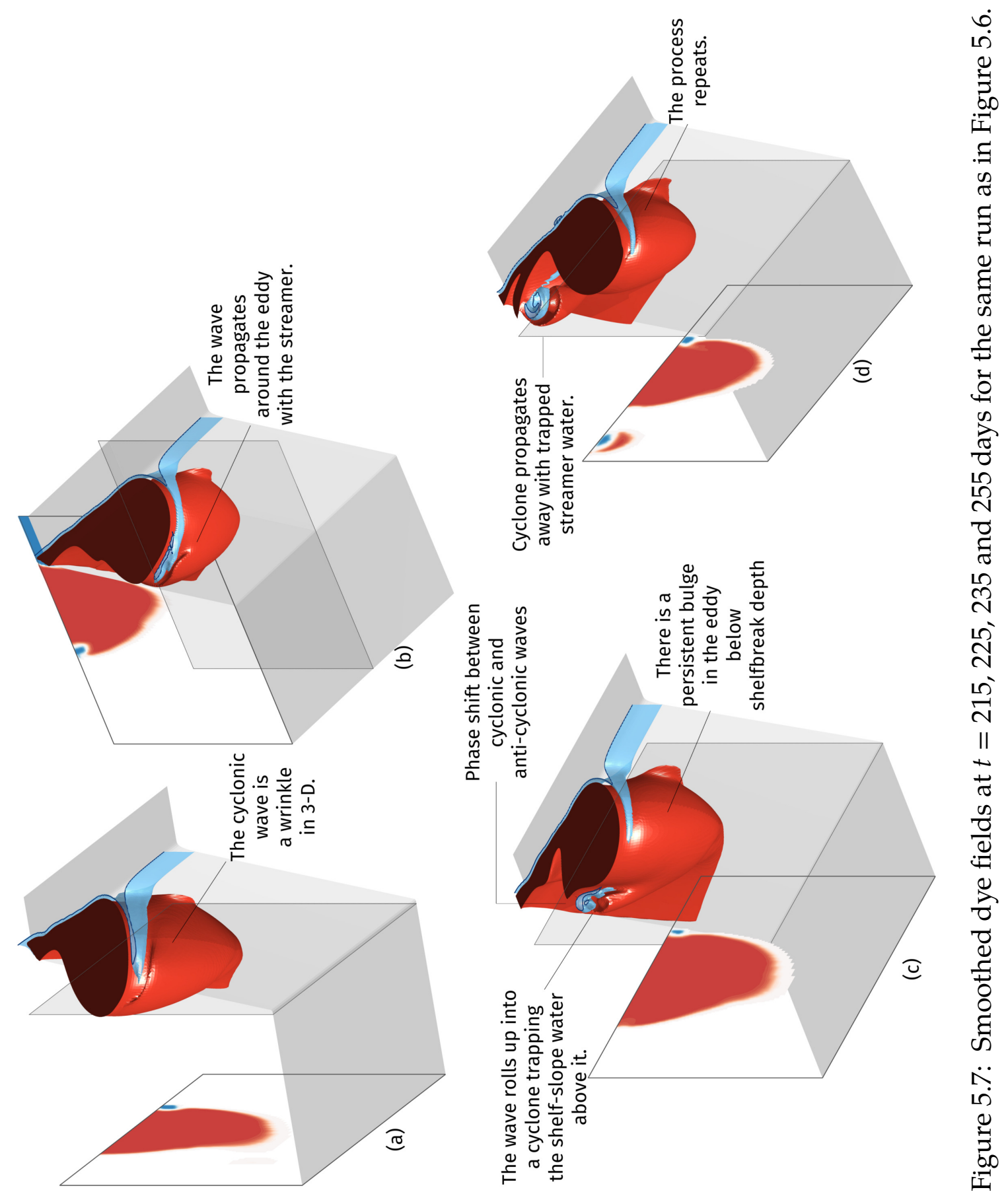


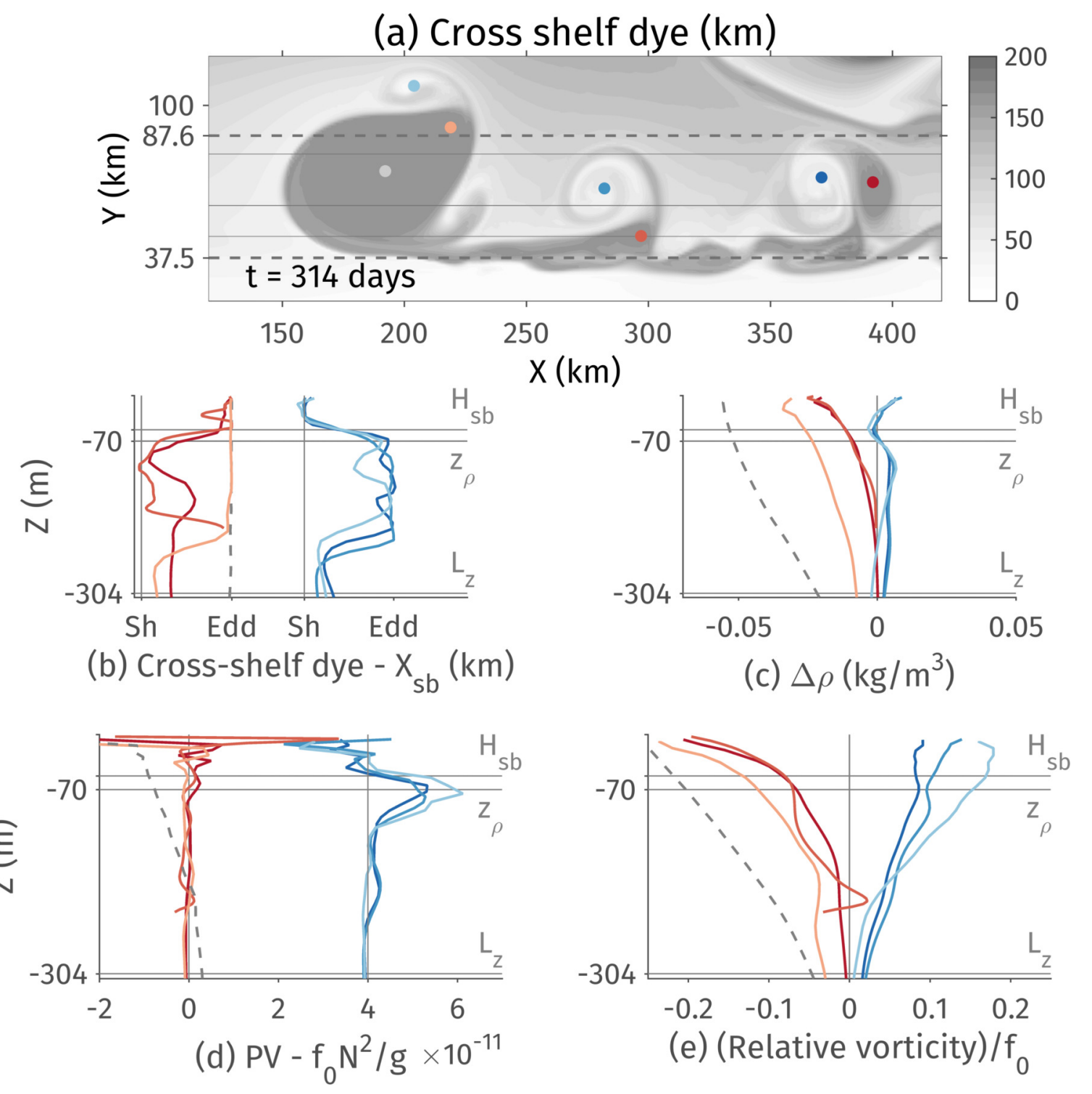

Figure 5.8: Vertical profiles at the dots illustrating the transition from an unstable wave to a dipole. The red profiles, on the left in each panel, are in locations with anticyclonic vorticity and vice versa. The gray dashed profile is at the eddy center providing a reference value for the fields. In (b) and (d), the lines on the right are displaced to make them easier to see. $z_{\rho}$ is the predicted depth to which shelf water sinks, determined using the initial density field (see text). (b) Water masses as identified by cross-shelf dye: "Sh" is shelf-slope water and "Edd" is eddy water. (c) Profiles of the density anomaly. The anticyclones are always lighter than ambient water. The cyclones have the stacked structure explained in Section 5.4. (d) Profiles of PV anomaly: the cyclones have a subsurface peak corresponding to the interface between shelf and eddy water (see a). (e) Normalized relative vorticity whose sign doesn't change with depth. 


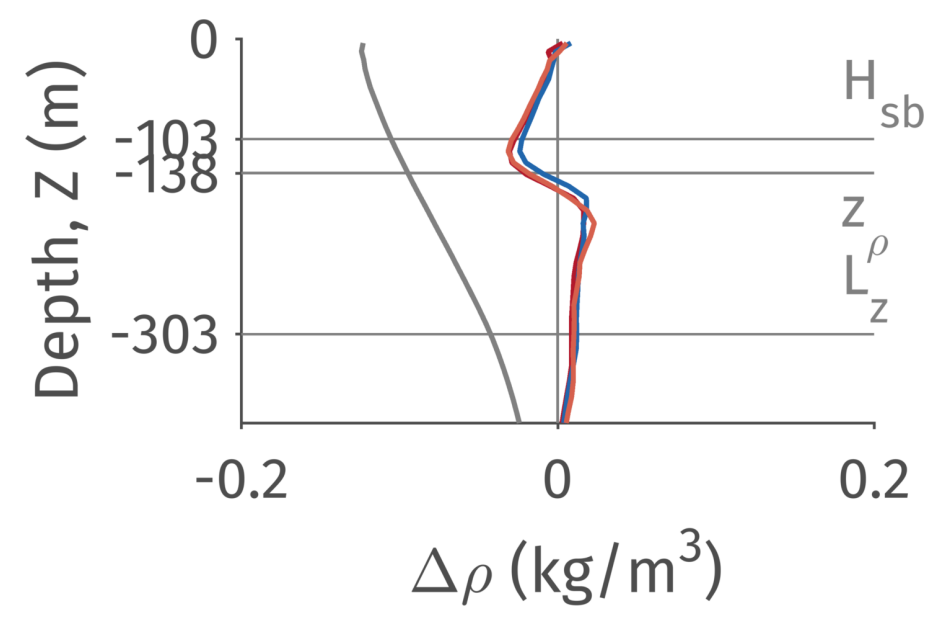

Figure 5.9: Vertical profiles of density anomaly with respect to background stratification through the secondary cyclone for a run with shelfbreak depth of $100 \mathrm{~m}$. Colored profiles are at locations in the secondary cyclone and the gray profile is at the eddy center ( $\Delta \rho$ is always negative). The density anomaly is negative above shelfbreak depth, indicating stretching and sinking of shelf water. Below it is positive, indicating upwelling and rising of denser eddy water from depth.

depth for all profiles in Figure 5.8e.

\subsection{Flow over a flat shelf}

At the shelfbreak, the offshore flow structure is less complicated - it is barotropic and occurs on both sides of the eddy center (Figure 5.10) even with bottom friction. As the eddy's horizontal scale is much larger than the shelf's internal deformation radius, the forcing at the shelfbreak is barotropic and it drives a barotropic export of shelf water. An along-shelf flow over the entire shelf supplies the outflow (Figure 5.11). With a sloping shelf, there is a limit to the cross-shore extent of the eddy's influence. This will be addressed in a future paper. That export occurs even to the east of the eddy's center $\left(X-X_{\text {eddy }}>0\right.$ in Figure 5.10) can be explained as follows.

When the eddy reaches the shelfbreak, on the eastern side and below shelfbreak depth, the slope diverts some of the eddy's incoming flow to the east - the leakage. Above the shelfbreak, some of the eddy's flow is also diverted, but this fluid can return to the main eddy while spilling onto the shelf (Figure 5.11, top panel, $x=$ $250 \mathrm{~km}$ ). The leaked eddy water raises the SSH at the shelfbreak. There is then a SSH gradient in both along-shelf and cross-shelf directions, forcing both an alongshelf westward flow on the shelf and a cross-shelfbreak offshore flow to the east of the eddy center (Figure 5.11). Eventually, the leaked eddy water breaks off and 

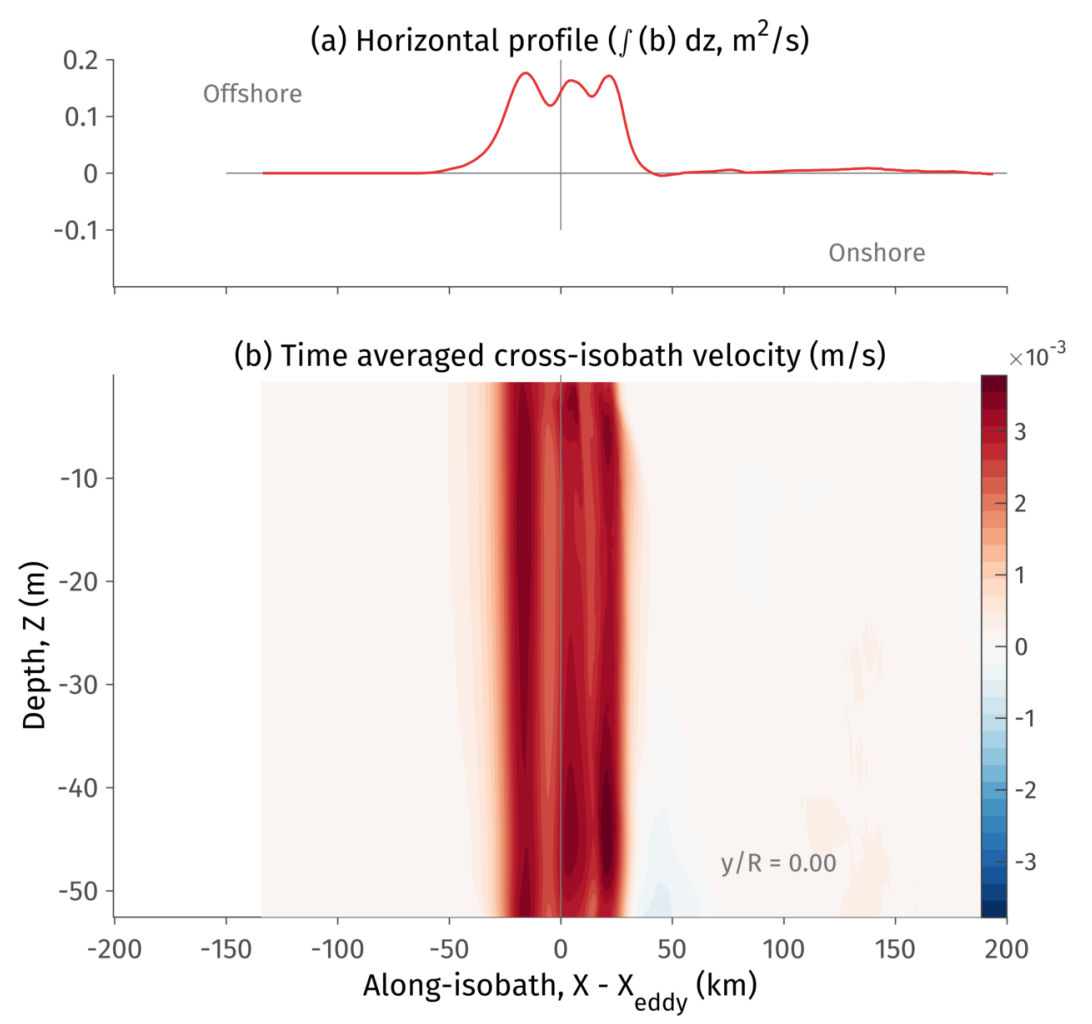

(c) Vertical profile of offshore transport ( $\left.\int(b) \mathrm{dx}, \mathrm{m}^{2} / \mathrm{s}\right)$

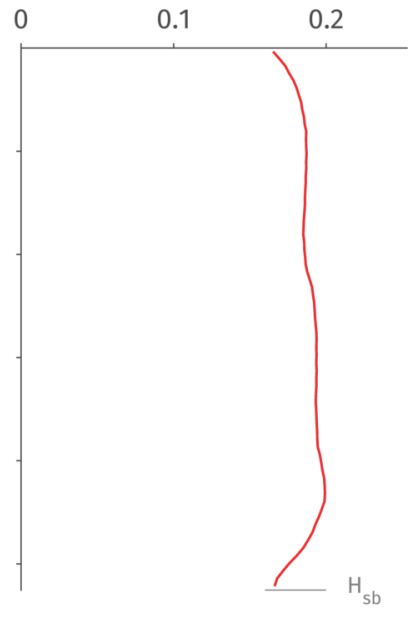

Figure 5.10: Averaged cross-isobath velocity field integrated to show both alongisobath and vertical structure at the shelfbreak for a flat shelf. To obtain this image, instantaneous snapshots of cross-isobath velocity are averaged together in a reference frame based on the eddy's center as origin. The average is over the time interval $\left[t_{\text {start }}, t_{\text {stop }}\right]$ (Section 3.3). There is offshore transport both to the east and west of the eddy's center; its vertical structure is barotropic.

propagates along-shelf away from the main eddy. The cycle then repeats.

When the dipole is formed, it does not comprise all of the water expelled from the eddy core. Some eddy water is deposited at the shelfbreak; while the dipole moves northward away from the shelfbreak (Figure 5.11, top panel, $x=350 \mathrm{~km}$ ). Farther downstream away from the eddy (Kelvin or coastal-trapped wave sense), the leaked water rolls up into small surface-intensified anticyclonic vortices at the shelfbreak (Figure 5.11 at $x=350$ and $400 \mathrm{~km}$, Figure $5.1 \mathrm{e}$ at $x \approx 400 \mathrm{~km}$ ). These vortices transport shelf water both onshore and offshore near the bottom while translating along the shelfbreak away from the eddy. The offshore-onshore transport is seen far away from the eddy center in the lower panels of Figure 5.13. There is very little sign of it in the average cross-isobath velocity field (Figure 5.10). So, integrating over the entire length of the shelfbreak to estimate a flux magnitude is not a bad choice because the small scale vortices accomplish little net transport. 


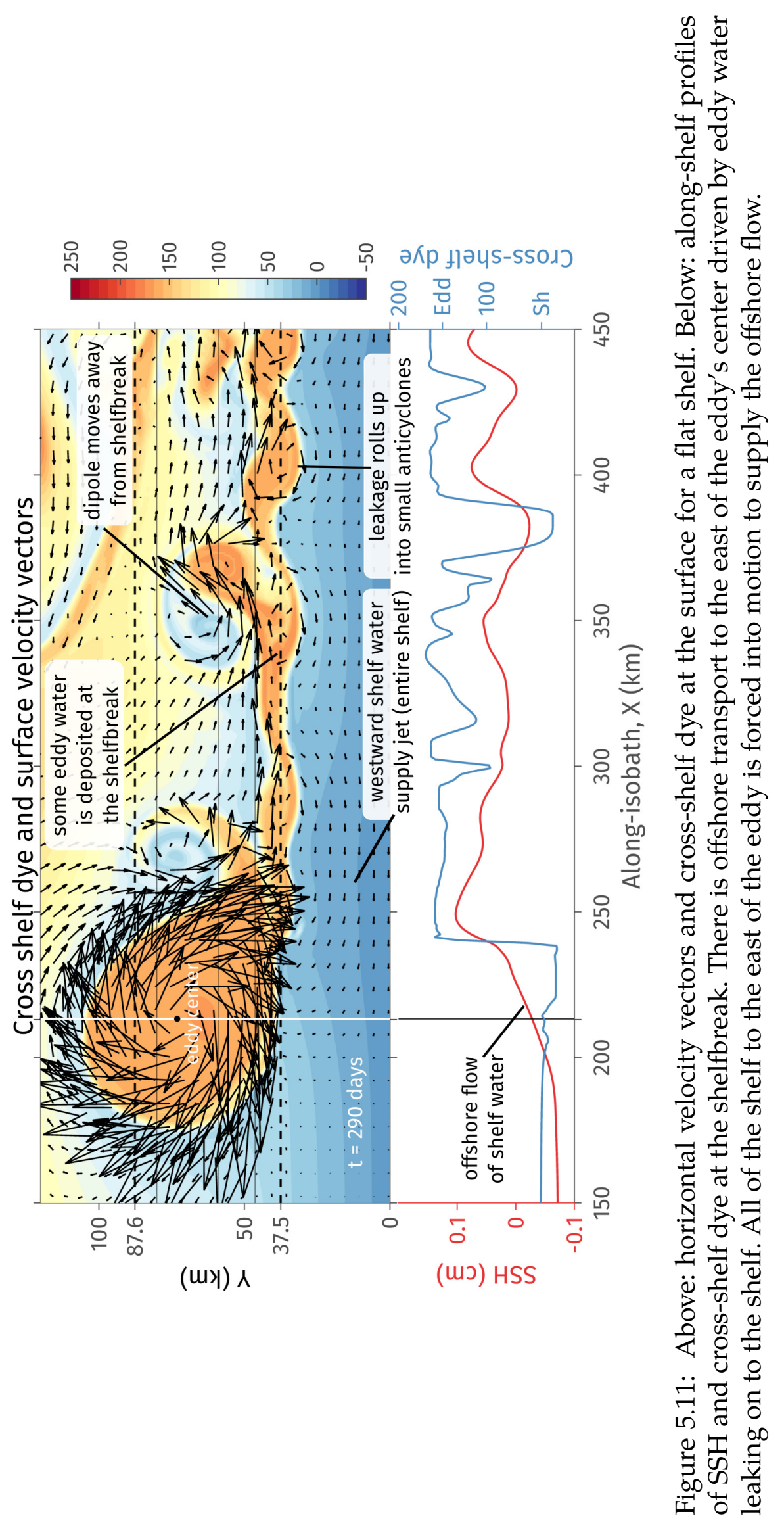




\subsection{Discussion}

\subsubsection{Variations}

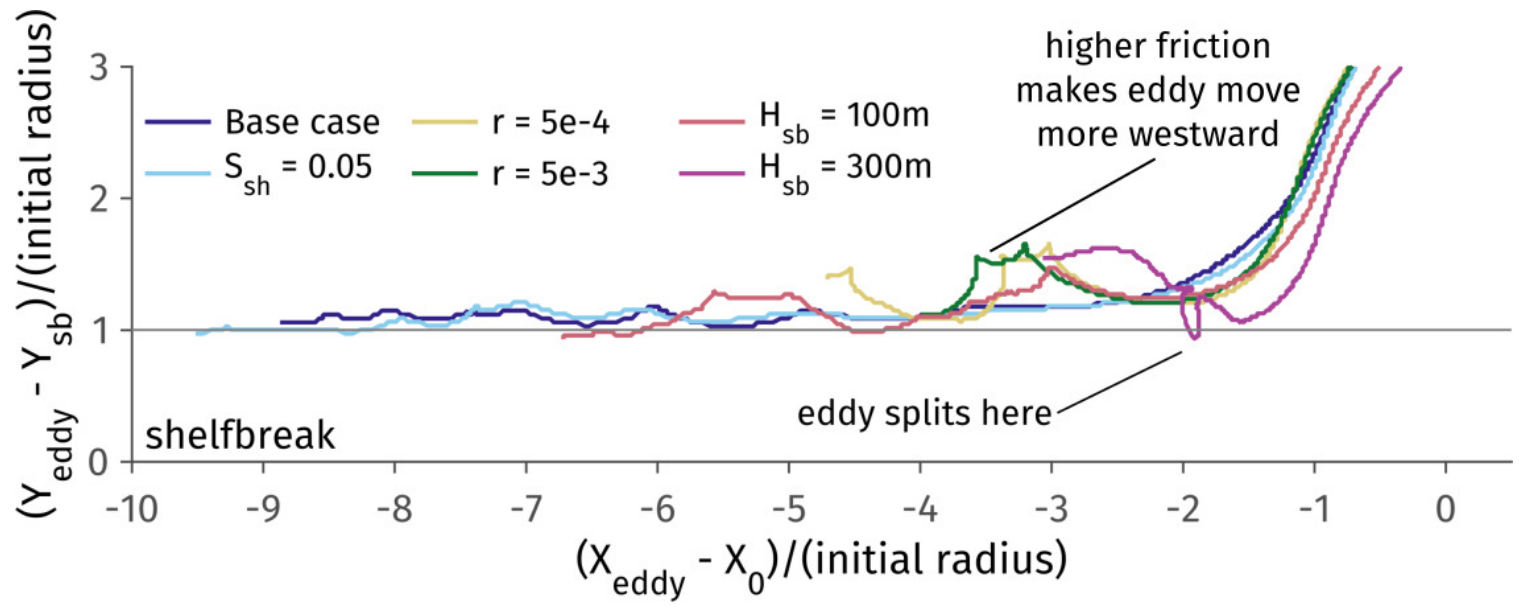

Figure 5.12: Tracks of the eddy center ( $\mathrm{SSH}$ maxima). All simulations have an eddy of $25 \mathrm{~km}$ radius, $400 \mathrm{~m}$ vertical scale and Ro $\sim 0.1$. The $x, y$ axes show location of the eddy center relative to the shelfbreak in $y$ and the eddy's initial location in $x$. Both axes are normalized by initial radius of the eddy. All but one track (dark magenta, $H_{s b}=300 \mathrm{~m}$ ) asymptote to $y=1$, indicating that the eddy's southern edge is at the shelfbreak and cannot cross onto the shelf. The base case has no bottom friction $(r=0)$ and a flat shelf $\left(S_{\mathrm{sh}}=0\right)$ with a shelfbreak depth of $50 \mathrm{~m}$. Addition of bottom friction results in generation of stronger cyclonic vorticity at the slope and greater meridional motion of the eddy (Section 5.3.2). Similar behavior occurs when increasing shelfbreak depth, resulting in greater stretching of shelf water and stronger cyclonic vortices. As the shelf gets deeper $(300 \mathrm{~m})$, the track gets complicated with the eddy splitting across the shelfbreak (dip in dark magenta track). A sloping shelf does not change the trajectory at all.

The evolution of the eddies remains qualitatively similar for different parameter values, as indicated by the eddy center tracks in Figure 5.12.

Bottom friction $(r \neq 0)$ generates vorticity at the slope, creating stronger secondary cyclones when compared to inviscid runs, making the eddy's track loopier. For larger values of bottom friction, stronger secondary cyclones are generated. The stronger cyclone advects the eddy more westward as it traverses around the eddy (Figure 5.12). Both friction and hydraulic arrest contribute to the generation of cyclonic vorticity at the slope.

The most influential parameter is $\lambda=H_{\mathrm{sb}} / L^{z}$, the ratio of shelfbreak depth to the eddy's vertical scale (Figure 5.13). So far, we have focused on the range $0.1 \lesssim \lambda \lesssim 0.4$ (middle panels), where the cross-shelfbreak flow has the filament/vortex character 


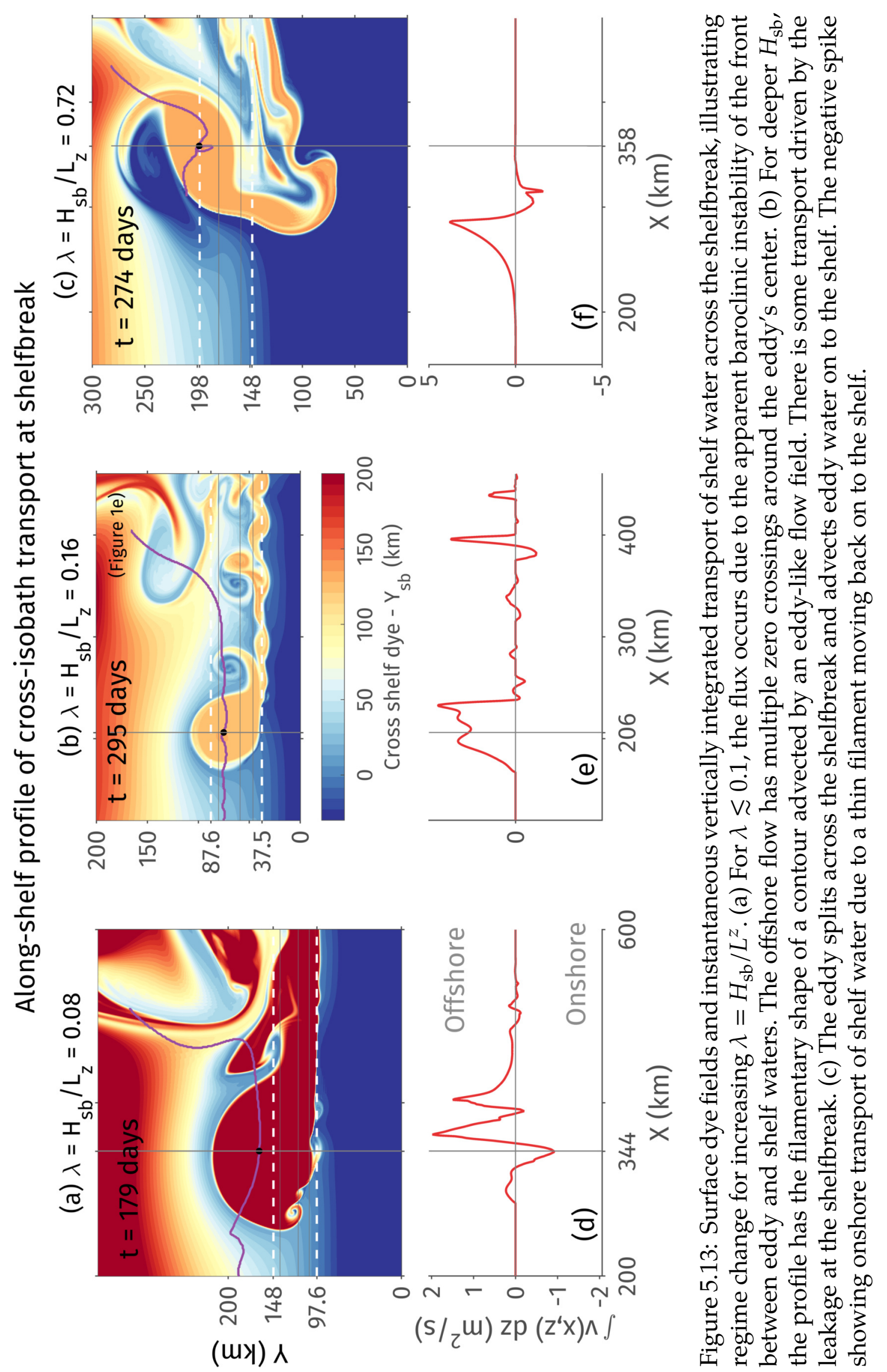


observed in some satellite images. Stronger shelf-slope water vortices are formed with deeper shelves and stronger eddies. Away from the eddy, there is some transport associated with the eddying leakage. For $\lambda \lesssim 0.1$, the export of shelf water across the shelfbreak is dominated by an apparent instability at the ring's edge. The instability makes the vertically integrated instantaneous cross-shore velocity change sign frequently around the eddy's center (lower panels). The change in sign is also present in the time-averaged offshore flow (not shown). One plausible explanation is that reducing the water depth changes the mean PV gradient ${ }^{1}$, which in turn reduces the wavelength of the most unstable mode. For $0.4 \lesssim \lambda \lesssim 1$, the interaction resembles that of an eddy with a ridge, and the eddy splits across the shelfbreak. The sharp dip in the $H_{\mathrm{sb}}=300 \mathrm{~m}$ track in Figure 5.12 is when that eddy starts to split across the shelfbreak (see Figure 5.13). When $\lambda \sim 1$, the eddy continues across the shelfbreak on to the shelf almost unimpeded (not shown).

All experiments described so far have had a coast at the south. With a western coast, the slope blocks both the radiated Rossby waves and the wake cyclone of the eddy (negative SSH contours in Figure 5.1c). In the initial stages, the faster moving barotropic Rossby waves break on the slope but eventually, the slower moving baroclinic Rossby waves meet the same fate. With a southern coast, the western boundary is open and these waves slowly disperse away from the eddy. The eddy, being more nonlinear than the wake cyclone, has greater meridional velocity and moves away from the cyclone. Eventually, the interaction is that of an "isolated" eddy and the topography (contrast the dyed slope fluid in Figure 5.1 and Figure 5.14). With a western coast, the slope blocks both the waves and the wake cyclone, and the two together act to transport slope water across isobaths (blue filament at $y=250 \mathrm{~km}$ ). Upon reaching the coast, the anticyclone moves northwards ${ }^{2}$ towards these flow features. While doing so, it experiences a ring edge instability similar to Figure 5.13a, and spins up a cyclone that advects it away from the slope. The eddy and topography are the same as in Figure 5.13b. Because of its greater crossisobath velocity, here westward instead of southward, the eddy reaches the slope earlier. It radiates less energy and is deeper when compared to a simulation with a southern coast. $\lambda=H_{\mathrm{sb}} / L^{z}$ is thus smaller. The eddy and the secondary cyclone then seem to form a modon-like structure that propagates southward at considerable distance from the shelfbreak. Experiments looking at $\lambda \lesssim 0.1$ will again help understand the eddy's evolution in this case. The waves spin up a cyclonic flow

\footnotetext{
${ }^{1}$ by increasing the topographic PV gradient, $f_{0} / H_{\mathrm{sb}} \nabla H$

${ }^{2}$ image effect
} 


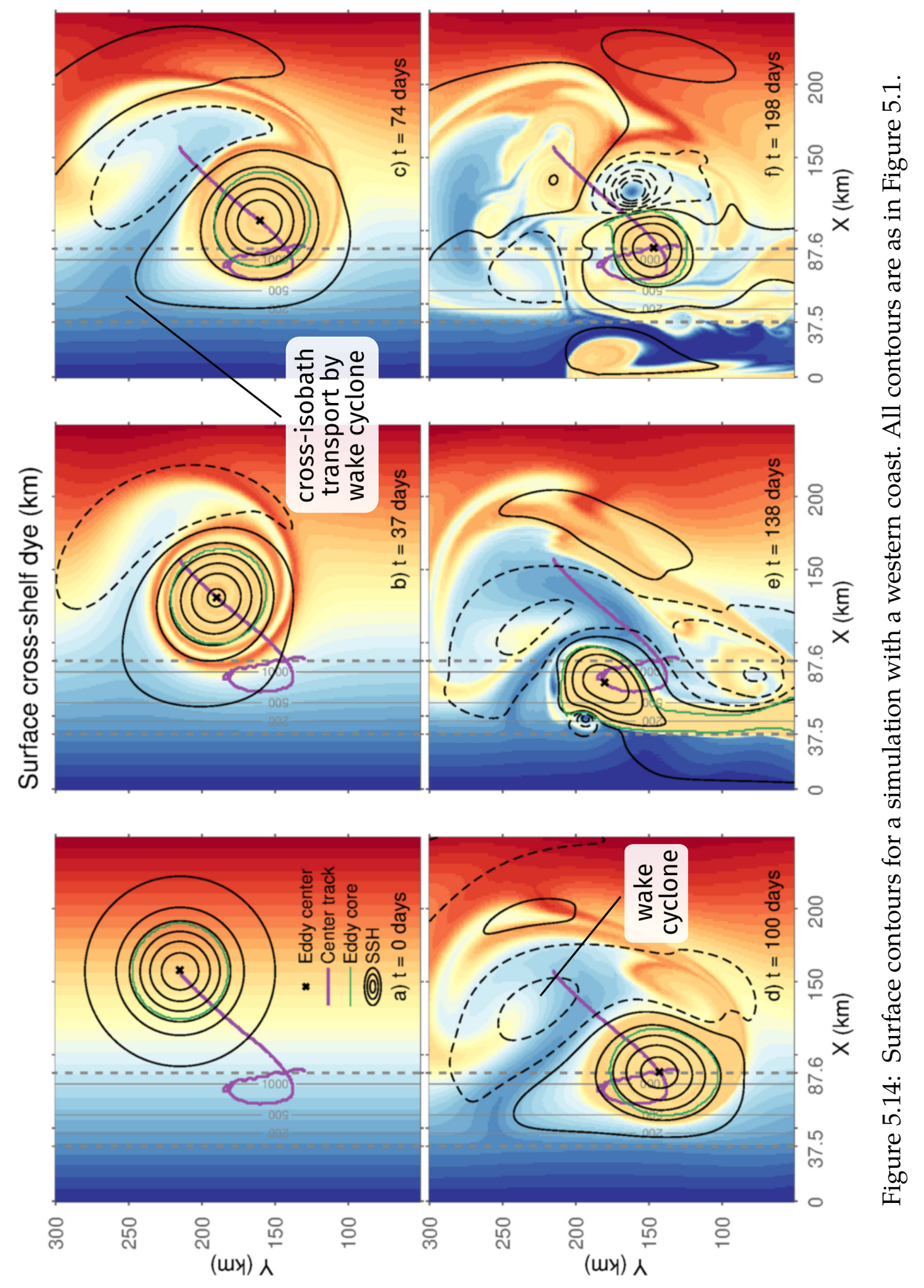


field over the slope that transports slope water across isobaths. Further, the anticyclonic eddy translates northwards towards these flow features due to the image and rocket effects (Nof, 1999). Unlike with a southern coast, the eddy isn't interacting with undisturbed slope fluid. However, the evolution remains similar. The mechanism of Section 5.3.2 still results in shelf water "intruding" into the eddy creating a subsurface maximum in offshore transport. The exported shelf water originates from south of the eddy, i.e., downstream in the coastal trapped wave sense, just as for a southern coast. There is also an along-shelf leakage jet containing eddy water that moves southward (downstream in the coastal-trapped wave sense). Thus, qualitatively, the results described earlier still hold.
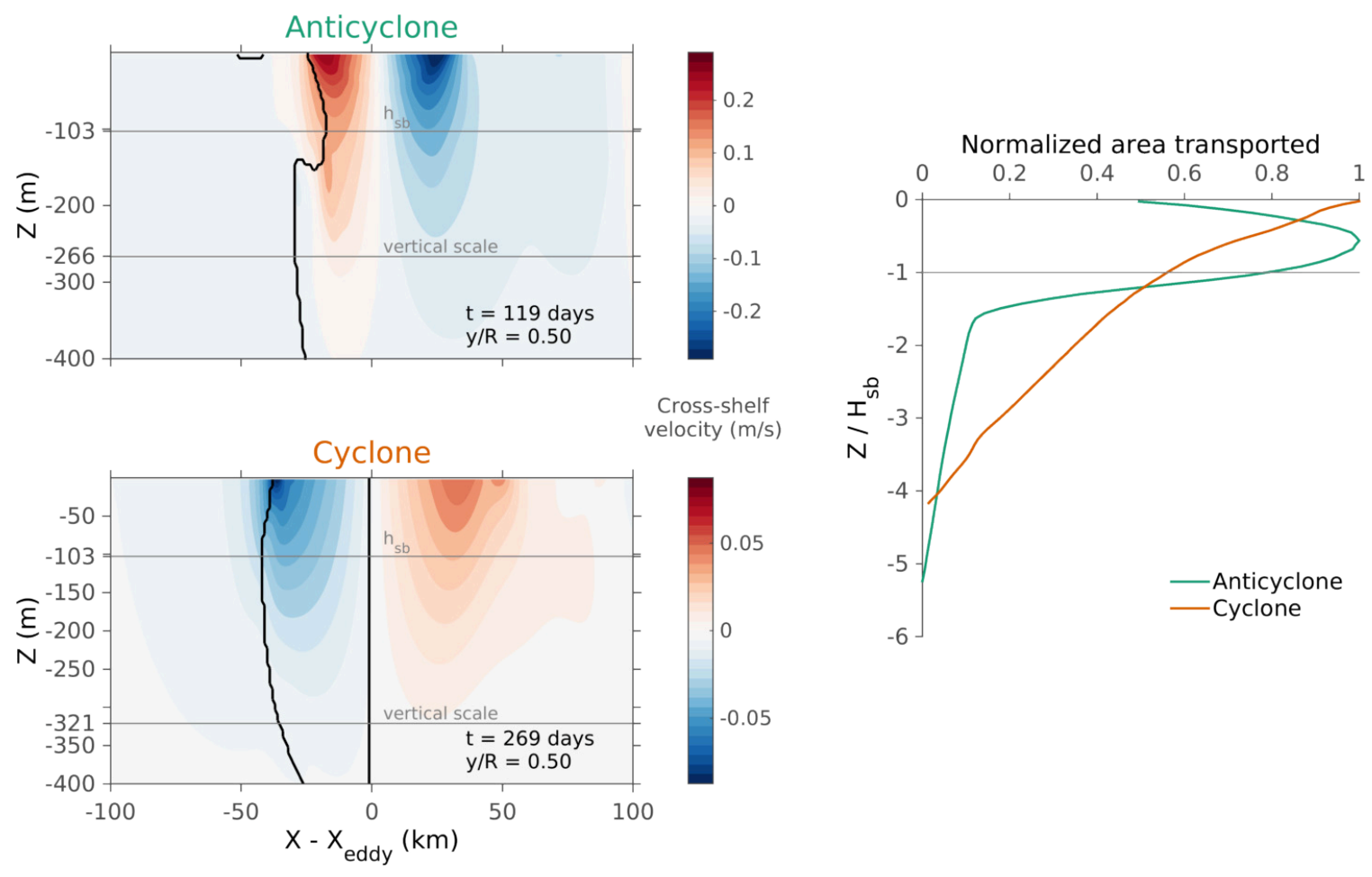

Figure 5.15: Cyclones do not show a subsurface peak in offshore flow. The color panels show instantaneous cross-isobath velocity for an anticyclone and a cyclone. The black contour is the boundary between shelf-slope water and eddy water. In the former, shelf water is denser than eddy water and so, sinks underneath it resulting in a "intrusion" in the side of the eddy. In the latter, the shelf water is lighter and rises over the eddy water. The lines are the integrated (over $\left[t_{\text {start }}, t_{\text {stop }}\right]$ ) area transported $\left(\mathrm{m}^{\wedge} 2\right)$ as a function of depth with both axes normalized. Integrating this line in $z$ and renormalizing would give the total volume transported. No subsurface peak is seen for the cyclone.

When a cyclone interacts with shelf-slope topography to the north, the crossisobath transport is surface-intensified (Figure 5.15). The difference is that the cyclone 

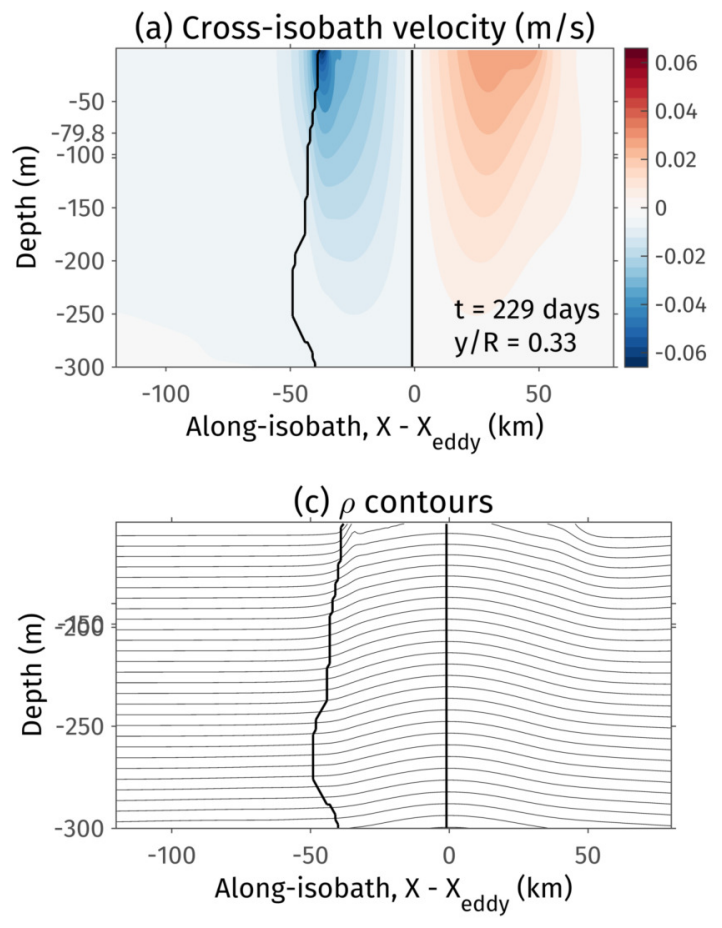

(b) Vertical profile of offshore transport $\left(\mathrm{m}^{2} / \mathrm{s}\right)$

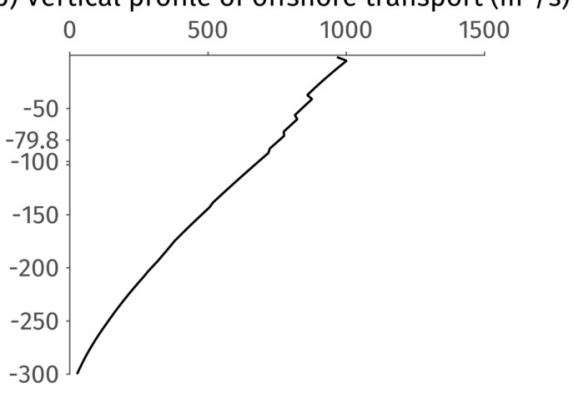

(d) Cross-shelf dye $-Y_{s b}(k m)$

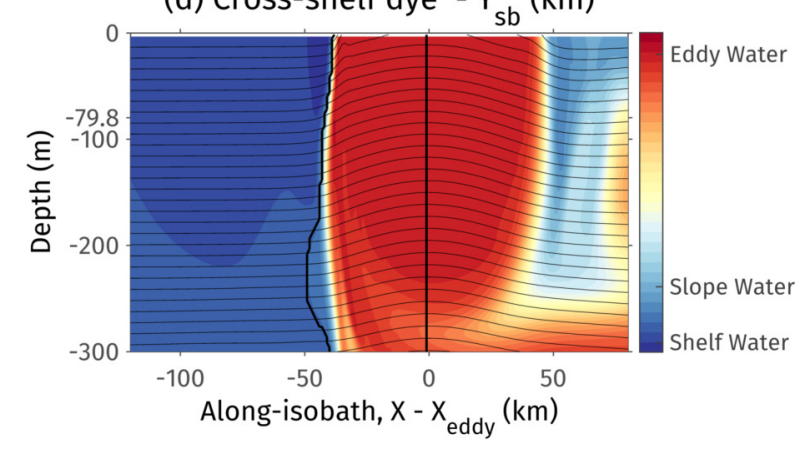

Figure 5.16: Instantaneous along-shelf sections similar to Figure 5.5, but for a cyclone. The cyclone raises isopycnals and so, the shelf water upwells and is squeezed as it moved offshore. The vertical profile of offshore transport is thus, surfaceintensified.

is a dense water anomaly that raises isopycnals near itself. Anticyclones make a shelf-slope water parcel sink along depressed isopycnals as it moves offshore over the unstable cyclonic wave. This creates an apparent intrusion at depth (Figure 5.15). On the other hand, when cyclones advect a shelf-slope water parcel offshore, it rises along uplifted isopycnals over the near-surface eddy water (Figure 5.16c). The shelf-slope water intrusion, now, is at the surface, resulting in a surface-intensified transport profile (Figures 5.15).

\subsubsection{Observational evidence}

There are three features common to every simulation with both western and southern coasts: one, a subsurface peak in offshore transport of shelf-slope water at every isobath offshore of the shelfbreak; two, the leakage of eddy water as an along-shelf jet and three, intrusions of shelf-slope water into the eddy that eventually form stacked cyclones and dipoles. Are there observations of such behavior?

Only two observational papers use ADCPs to directly estimate the offshore 
transport viz., Joyce et al. (1992) and Lee and Brink (2010). In the former, it is unclear whether integrating the velocity field over shelf-slope water would result in a subsurface peak. The ADCP data of Lee and Brink (2010) show a surface intensified velocity field with a slight subsurface maximum. Both observations suffer from being single snapshots of an unsteady flow field. Lee and Brink (2010), in particular, measured velocities right as the ring separated from the Gulf Stream. At the time of observation, it is likely that offshore transport was still filamentary as in the initial panels of Figure 5.1.

The along-shelf leakage has received the least attention of the three. Oey and Zhang (2004) discussed observations of a bottom-intensified along-slope jet near a Loop Current ring at an oil industry site in the Gulf of Mexico. Lee and Brink (2010) observed a growing warm saline intrusion that appears to break off into a small warm eddy at the $100 \mathrm{~m}$ isobath on George's Bank (Figure 1.1). Such evolution appears to be similar to that which forms the warm eddies propagating along the shelfbreak in Figure 5.1e and 5.1f. High-salinity intrusions on George's Bank are commonly, but not always, associated with Gulf Stream warm-core rings near the shelfbreak (Mountain et al., 1989; Churchill et al., 2003). Ullman et al. (2014) observed an anomalous near-bottom warm saline water mass at the 30- and 50$\mathrm{m}$ isobaths in Rhode Island Sound, roughly $100 \mathrm{~km}$ from the shelfbreak. Its water properties were similar to a water mass observed a month earlier on the continental slope after a Gulf Stream warm core ring had hit the shelfbreak. Presumably, the leakage rolled up into an eddy, as in Lee and Brink (2010), that penetrated far on to the shelf. The leakage is also present in the lab experiments of Andres and Cenedese (2013) and Cenedese et al. (2013). Recently, Zhang and Gawarkiewicz (2015) reported glider observations and SST images of the leakage at the Mid-Atlantic Bight shelfbreak. Their adjoint model analysis showed that water in the leakage originated in the edge of the eddy, i.e. the annulus, as in Shi and Nof (1993) and agrees with our model results.

There are two discrepancies between our results and typical SST images of the north-west Atlantic (for e.g. Figure 1.1). In our simulations, all eddies eventually start creating shelf water cyclones. Simultaneously, in the model, there is always leakage of eddy water along the shelfbreak. Both features are not always observed in SST data. They require that the sloping bottom impose a lateral boundary condition, boundary-normal velocity $\approx 0$, that diverts the eddy's flow causing the loss of annulus fluid. In the Mid-Atlantic Bight, there exists shelf water offshore of the 
shelfbreak $^{3}$. Thus, offshore transport of shelf water does not require that the eddy be at the shelfbreak.

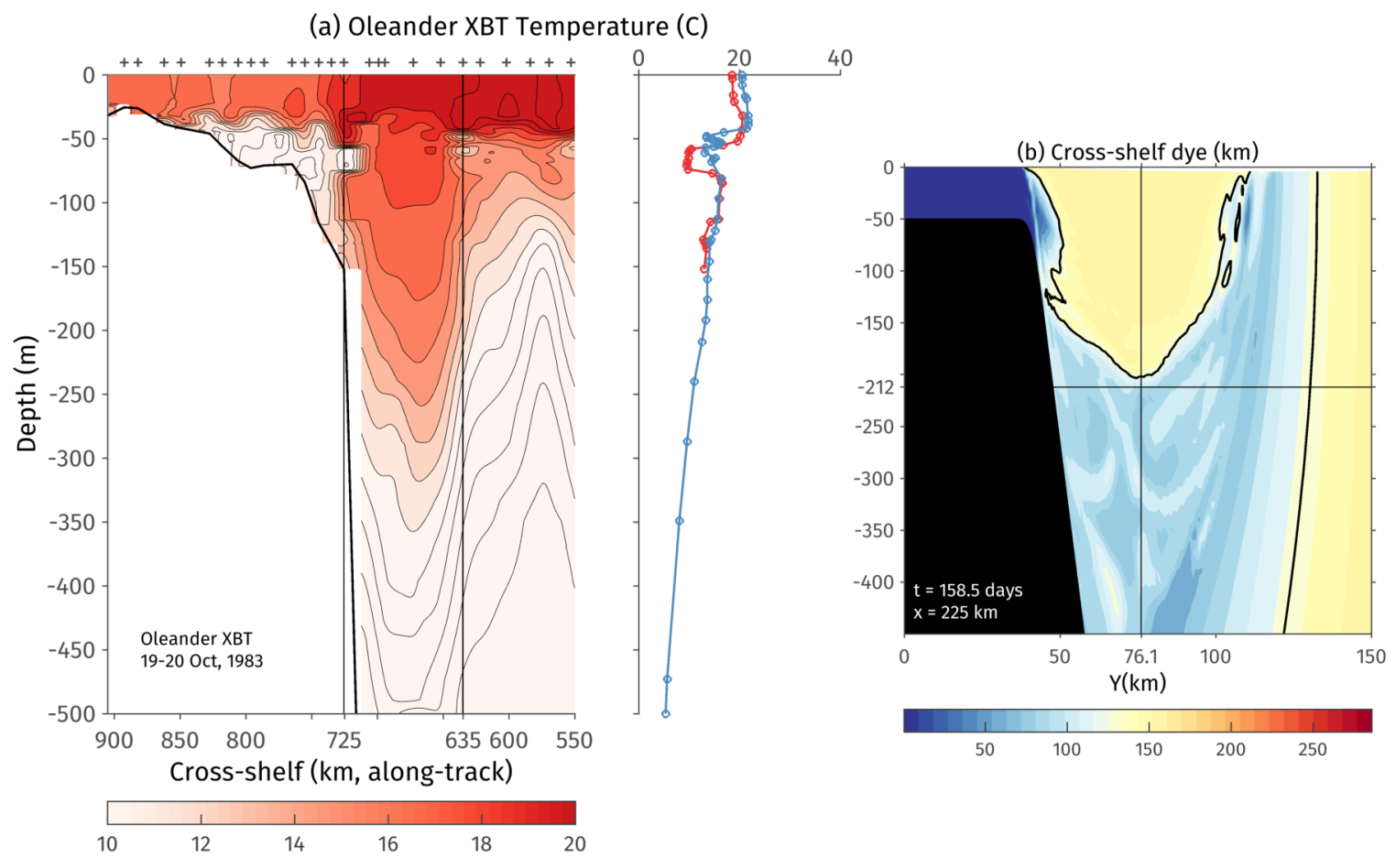

Figure 5.17: (a) Temperature section from Oleander XBT data showing shelf water intrusions in a warm core ring (after Churchill et al., 1986). The $10^{\circ} \mathrm{C}$ water is likely near-bottom "cold pool" water on the Mid-Atlantic Bight shelf (see $x=50 \mathrm{~km}$ and Houghton et al. (1982)). A similar intrusive feature appears on the other side of the ring, but with higher temperature. The two lines are vertical profiles of temperature through the two intrusions. (b) Model $y-z$ section of cross-self dye through the eddy center showing shelf-slope water intrusions on either side of the eddy.

If the eddy is not close enough to the slope, then it will not shed much fluid. Instead, it will wrap the shelf water around itself as a filament, like the ambient water swirled around in the first three panels of Figure 5.1. This would explain the subsurface cores of near bottom "cold pool" water (Houghton et al., 1982): 32 psu, $10^{\circ} \mathrm{C}$ water parcels in observations of the shelf water filament (Nelson et al., 1985; Tang et al., 1985; Ramp et al., 1983; Garfield and Evans, 1987). These cores are outside the eddy. If the subsurface core is embedded in the eddy as in Churchill et al. (1986, Figure 8), recreated in Figure 5.17a, then the mechanism of Section 5.3 is likely responsible. Figure 5.17a compares favorably with a $y-z$ section of eddy dye in Figure 5.17b. Note that the warm core ring is in direct contact with the upper slope, between the 100-m and 150-m isobaths.

\footnotetext{
${ }^{3}$ Because the shelfbreak front tilts and outcrops offshore of the shelfbreak
} 
The way our experiments are set up, the $\beta$-plane continuously forces the eddy into the topography, the eddy always gets to the shelfbreak, and the eddy-slope interaction is always severe. In the real ocean, this does not happen. The presence of other rings and a meandering Gulf Stream makes the trajectory of actual warm core rings far more complicated than that solely determined by $\beta$-plane translation (Cornillon et al., 1989). Thus, we do not expect the mechanism of Section 5.3 to always occur; explaining why the subsidiary cyclones observed by Kennelly et al. (1985) are not stacked. There seem to be no observations of stacked cyclones or dipoles between the shelfbreak and Gulf Stream.

The episodic, unpredictable nature of ring-slope interaction makes it a hard process to observe. The integral time scale for the flux time series in Figure 3.2 is roughly 1.3-1.4 times the eddy turnover time scale (the ratio of length scale to velocity scale) and the turnover time scale for warm core rings is approximately 2$2.5 \mathrm{~d}$. Thus, for statistically independent snapshots of the flow field for averaging, an along-isobath transect would need to be repeated with approximately four day separation.

\subsection{Conclusion}

Using idealized numerical simulations, we have shown that for $0.1 \lesssim H_{\mathrm{sb}} / L_{z} \lesssim 0.4$, the interaction of a eddy with shelf-slope topography is very similar to its interaction with a vertical wall described in Shi and Nof (1993). In doing so, the eddy moves along-shelf in the image-effect direction and develops apparent intrusions of shelf-slope water (Figure 5.7). The apparent intrusions are quite similar to Oleander XBT observations that show a shelf water parcel embedded in a Gulf Stream warm core ring (Churchill et al., 1986). They result from shelf-slope water being advected over an unstable cyclonic wave propagating on the eddy at depth. The intrusions have two consequences: one, the vertical profile of offshore transport has a subsurface maximum (Figure 5.4); and two, shelf-slope water is trapped in stacked cyclones that contain shelf-slope water down to shelfbreak depth (roughly) and eddy water below (Figure 5.8). These cyclones combine with water extracted from the eddy's core to form dipoles that then move away from the shelfbreak (Figure 5.1). The shelf water is thus permanently exported, agreeing with the drifter tracks in Bisagni (1983). Next, I focus on flow over a sloping shelf. 


\section{The forcing of sloping shelves by anticyclones at the shelfbreak}

\subsection{Introduction}

As mentioned in Chapter 1, the presence of large eddies at the shelfbreak raises several questions about how the eddies affect the shelf. For example, where, in the along-isobath direction, is the source of the exported shelf water? Is it exported primarily from near the surface, near the bottom or throughout the water column? From how far onshore of the shelfbreak can the eddy extract water? To what extent can eddy water penetrate on to the shelf?

This chapter explores the above questions using a series of idealized primitive equation numerical simulations in which an anticyclonic eddy initialized in deep water moves toward and interacts with shelf-slope topography to the south. The parameters varied include shelf slope, eddy Rossby number, shelfbreak depth, bottom friction coefficient and planetary $\beta$ (Table A.5).

\subsection{Qualitative evolution}

The evolution of an anticyclone of radius $25 \mathrm{~km}$, vertical scale $400 \mathrm{~m}$ and Rossby number 0.1 is visualized using the cross-shelf dye field in Figure 6.1. The slope Burger number for the continental slope is 1 and that of the shelf is 0.05 . The shelfbreak depth is $50 \mathrm{~m}$ and there is no bottom friction. 
The eddy evolves in a manner similar to that described in Chapter 5 for simulations with a flat shelf. The eddy moves southwestward while radiating Rossby waves, evident in the westward spreading of SSH contours in Figure 6.1b. When its edge reaches the shelfbreak, the eddy translates westward along an isobath. There, it leaks mass as an along-shore jet (Figure 6.1c-f), termed the "leakage" by Shi and Nof (1993) and "Pinocchio's Nose Intrusion" by Zhang and Gawarkiewicz (2015). A cross-section at $t=298$ days (Figure $6.1 \mathrm{e}$ ) and $x=350 \mathrm{~km}$ shows the leakage to be surface intensified (Figure 6.2). There is a deep bottom-trapped slope jet of eddy water, previously studied by Oey and Zhang (2004). The eddy exports shelf water across the shelfbreak - the "outflow" - while advecting slope and eddy waters on to the shelf - the "inflow". The offshore export of shelf water is accomplished by the eddy raising the SSH at the shelfbreak (Figure 6.3), such that there is nearlybarotropic offshore flow of shelf water. Initially, the shelf water is exported as a filament, termed a "streamer". Later, the exported shelf water forms cyclones that then combine with eddy water in the leakage to form dipoles (Figure 6.1e,f). Chapter 5 described the formation mechanism and vertical structure of these cyclones. Here, the focus is the flow field on the shelf.

The influence of a sloping shelf is evident when comparing a snapshot of the surface dye field and surface velocity vectors to an analogous snapshot from a simulation with a flat shelf (Figure 6.3). Regardless of shelf slope, a westward along-shelf jet on the shelf supplies the shelf water that is advected offshore. The shelf water originates from downstream of the eddy, in the coastal trapped wave sense ${ }^{1}$, as seen in Figure 6.3. The net volume flux across the shelfbreak is compensated by an alongshelf input to the shelf at the eastern boundary - solid and dashed black lines nearly balance in the shelf volume budget (Figure 6.4). Simulations with a western coast exhibit analogous behaviour: an along-shelf jet supplies shelf water from downstream (south) of the eddy. Over a flat shelf, the supply jet exists across the whole shelf (Figure 6.3a). The sloping shelf reduces the supply jet's cross-isobath length scale. It will be shown that this cross-isobath scale is roughly an inertial length scale: $L_{\beta}=\sqrt{V_{0} / \beta_{\mathrm{sh}}}$ (Section 6.4.2), $V_{0}$ being an eddy velocity scale and $\beta_{\mathrm{sh}}=f_{0} / H_{\mathrm{sb}} \alpha_{\mathrm{sh}}$, topographic beta for the shelf.

The sloping shelf also reduces the magnitude of offshore transport of shelf water (Figures 6.3,lower panel and 6.9). At the shelfbreak, the eddy raises the sea surface by nearly the same amount in both flat and sloping shelves in Figure 6.5. In that figure, the instantaneous SSH field at the shelfbreak is time-averaged over $\left[t_{\text {start }}, t_{\text {stop }}\right]$

\footnotetext{
${ }^{1}$ i.e., Kelvin wave sense
} 

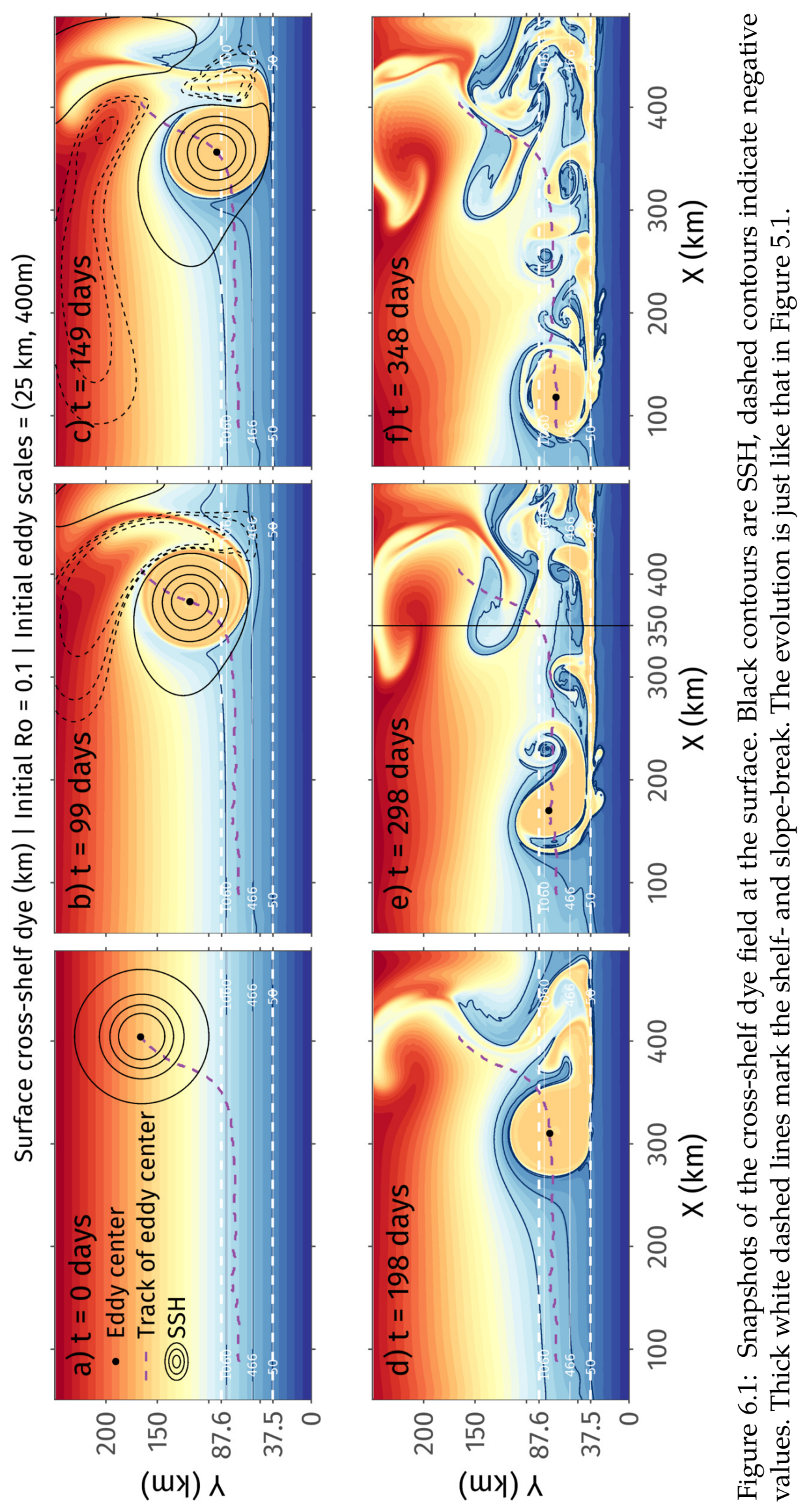


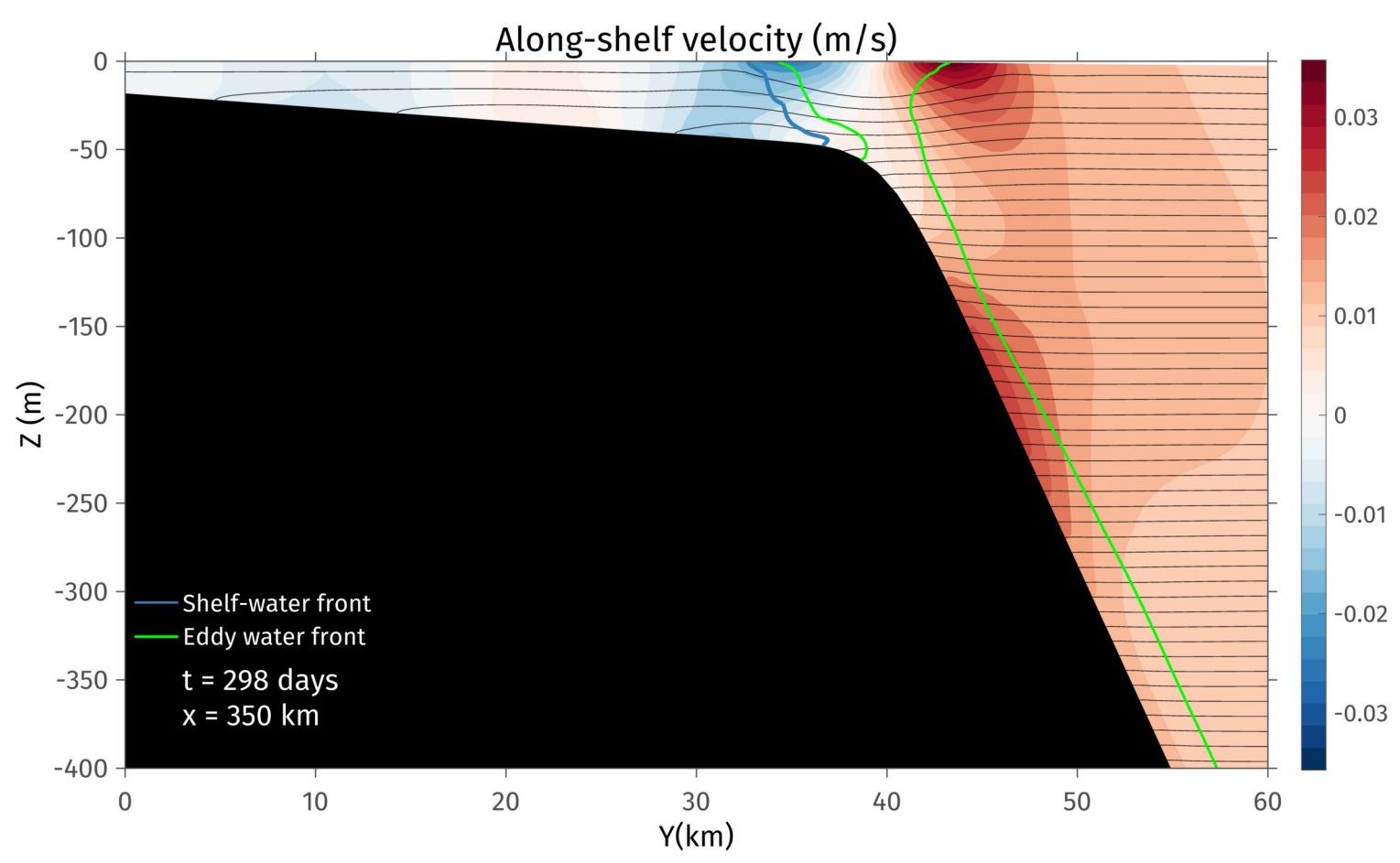

Figure 6.2: Instantaneous cross-shelf section of along-shelf velocity $u$ in color and density in black contours at $t=298$ days and $x=350 \mathrm{~km}$ for the simulation in Figure 6.1. The thick blue contour is the cross-shelf dye front between shelf and nonshelf waters. The thick green contour marks the outline of eddy water determined using the eddy dye field. The along-shelf leakage is surface intensified. There is an additional bottom intensified slope jet of eddy water at $z \approx-200 \mathrm{~m}$, previously studied in Oey and Zhang (2004).

with the along-shelf axis referenced to the eddy's center. For a barotropic outflow at the shelfbreak, the net geostrophic transport is

$$
-f \iint v \mathrm{~d} x \mathrm{~d} z=-g H_{\mathrm{sb}} \int_{-\infty}^{\infty} \eta_{x} \mathrm{~d} x=-g \Delta \eta,
$$

$\Delta \eta$ being the net jump in SSH in the along-shelf direction at the shelfbreak. The time-averaged SSH perturbation experienced by shelf water over a sloping shelf is $25 \%$ smaller when compared to that over a flat shelf (thick portion of the lines in Figure 6.5). The geostrophic balance in (6.1) then indicates that the transport magnitude, and cross-shelfbreak velocity in Figure 6.3, is smaller. In summary, the addition of a shelf slope reduces the offshore flux of shelf water and the cross-isobath extent to which the eddy can affect water parcels on the shelf. 


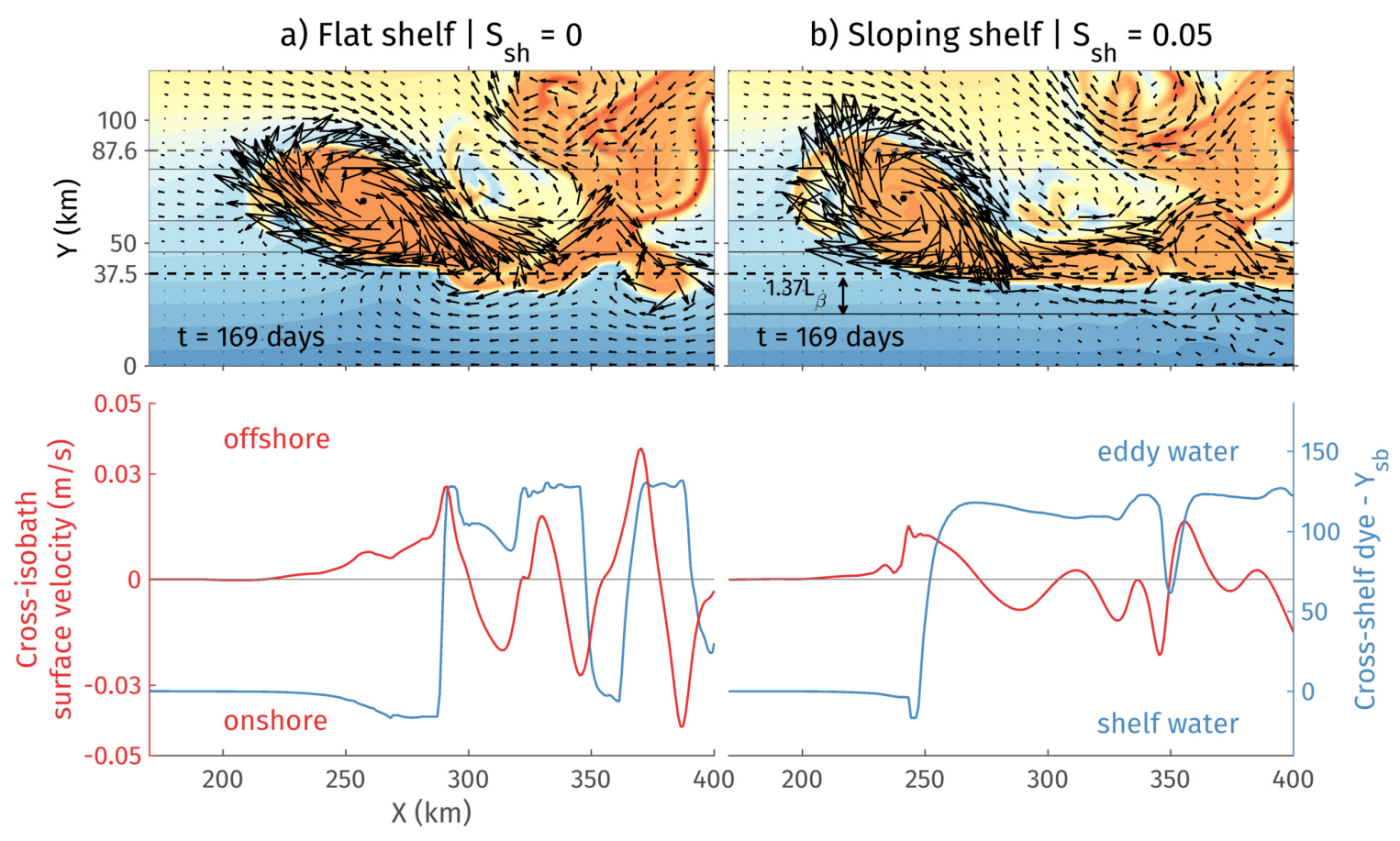

Figure 6.3: Horizontal velocity vectors and cross-shelf dye at the surface for a flat shelf and a sloping shelf simulation. There is offshore transport to the east of the eddy's center driven by eddy water leaking on to the shelf. With a flat shelf, all of the shelf is forced into motion to supply the offshore flow at the shelfbreak. With a sloping shelf, there is a limit to the extent of the eddy's influence on the shelf. This limit is a Rhines scale. Wave activity on the sloping shelf is also apparent.

\subsection{Additional diagnostics}

The non-dimensional parameter BC quantifies the extent to which a velocity field is vertically sheared i.e., baroclinic:

$$
\mathrm{BC}=\operatorname{median}\left\{\frac{\left|u_{s}-u_{b}\right|}{\left|u_{s}\right|}\right\}
$$

Here, $u_{s}$ and $u_{b}$ are velocities at the surface and 10 points off the bottom respectively. Defining $u_{b}$ in this way prevents BC from being influenced by the bottom boundary layer in simulations with bottom friction. The median is computed over $\left[t_{\text {start }}, t_{\text {stop }}\right]$ in grid cells on the shelf that contain shelf water. To avoid contamination by points where $\left|u_{s}\right|$ is small, we restrict the calculation to cells with $\left|u_{s}\right| \geq 0.2 \max \left\{\left|u_{s}\right|\right\}$, where the maximum is calculated at each time instant. For barotropic flows, $u_{s}=u_{b}$, $\mathrm{BC}=0$ whereas for more baroclinic flows, $u_{s} u_{b}<0$ or $u_{b}=0, \mathrm{BC} \geq 1$. 


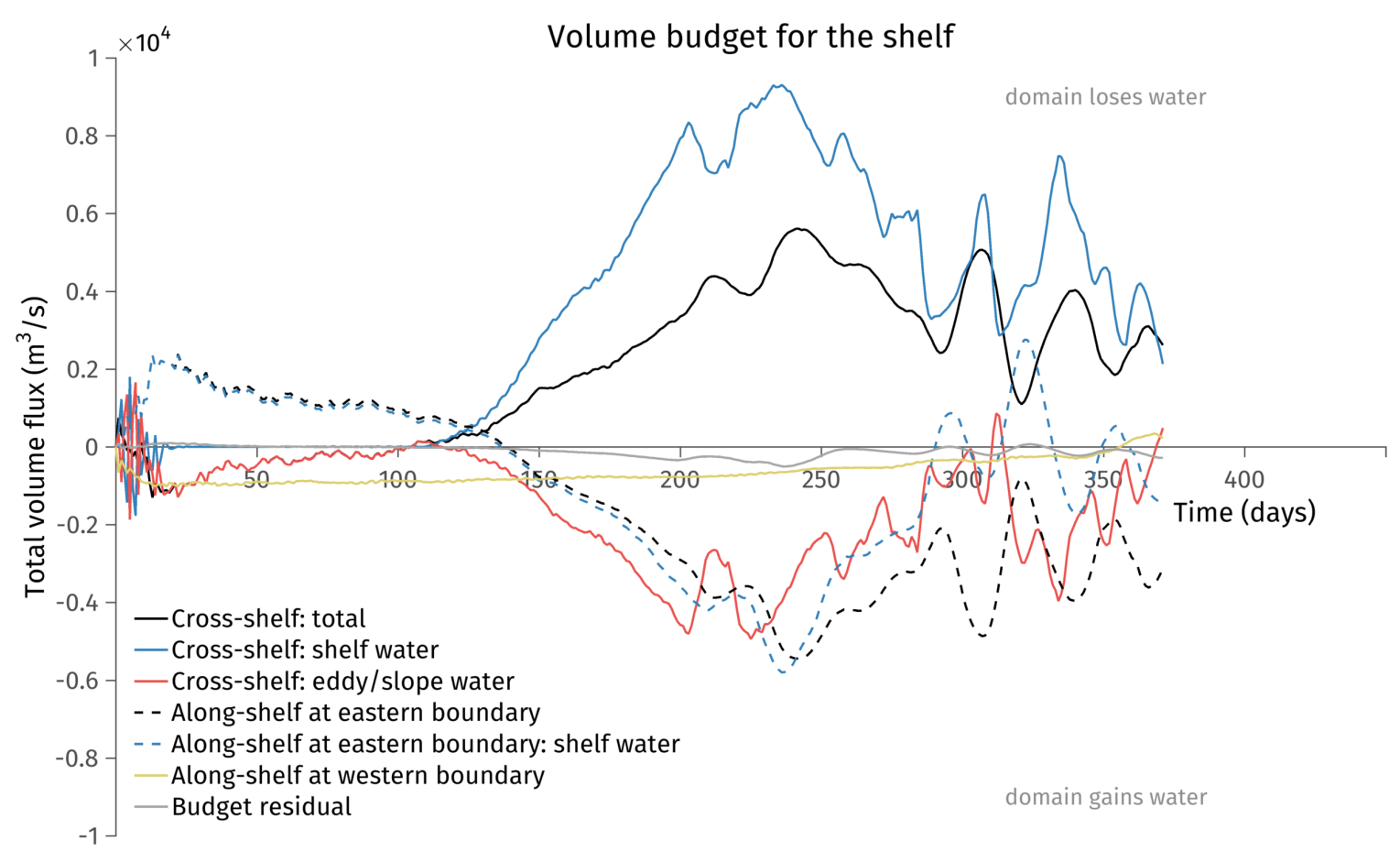

Figure 6.4: Volume budget for the shelf: defined as a volume bounded by the two sponges, the coastal wall and the shelfbreak. The shelf water outflow is compensated by an along-shelf jet moving water from the open eastern boundary into the domain. The solid blue line is the volume flux of shelf water across the shelfbreak, plotted in red in Figure 3.2.

\subsection{Flow over a sloping shelf}

\subsubsection{Cross-shelfbreak flow}

The along-isobath scale of both the offshore and onshore flow is an eddy radius. This is evident in Figure 6.6: the Hovmöller diagram of depth-averaged cross-isobath flow at the shelfbreak. Figure 6.6 does not distinguish between eddy and shelf waters. The solid black line is the eddy center and the dashed lines are the eddy's western and eastern edges.

The average vertical structure of the onshelf "inflow" of non-shelf water and offshelf "outflow" of shelf-water across the shelfbreak is calculated using the instantaneous cross-isobath velocity field, appropriately masked using the dye field. The masked velocity field is integrated in the along-isobath direction $x$ and over $\left[t_{\text {start }}, t_{\text {stop }}\right]$ to obtain a vertical profile, plotted in Figure 6.7 for a set of inviscid simulations (Table A.5). The parameters varied include shelf slope, eddy velocity and length scales, and shelfbreak depth. The non-shelf water inflow is vertically sheared 


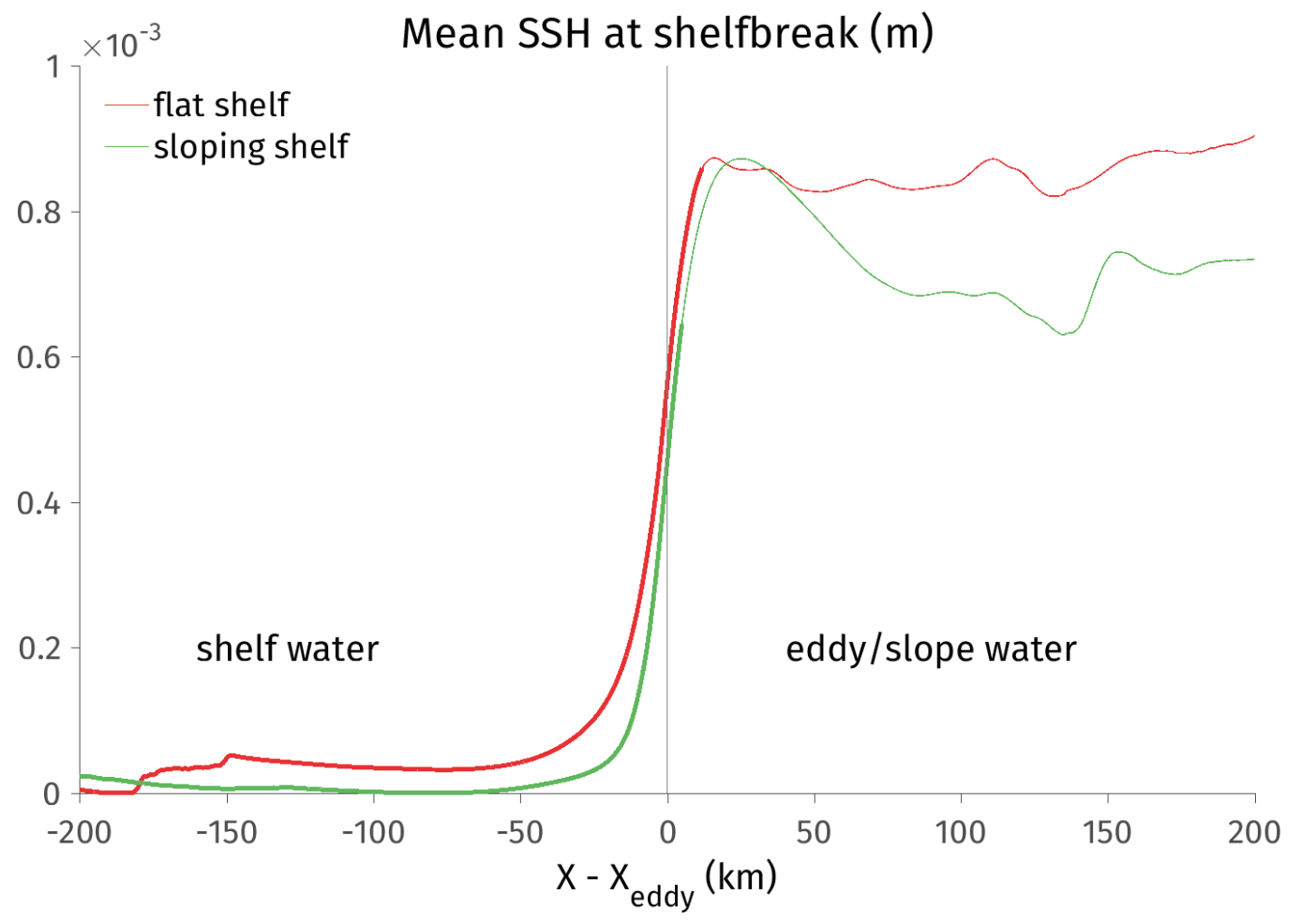

Figure 6.5: Along-shelf profiles of time-averaged SSH at the shelfbreak for two simulations: one with a flat shelf and one with a sloping shelf. The time average is over $\left[t_{\text {start }}, t_{\text {stop }}\right]$. The along-shelf axis has its origin at the eddy center. Line thickness indicates water mass identified using the time-averaged cross-shelf dye field: shelf water is thick and eddy water is thin. Shelf water in the sloping shelf run experiences a smaller SSH perturbation. The offshore transport is thus smaller.

(baroclinic) for all simulations, whereas the shelf water outflow is generally vertically uniform (barotropic) with a few exceptions. Notably, differences in vertical structure are seen even when the ratio $\lambda=H_{\mathrm{sb}} / L^{z}$, shelfbreak depth to eddy vertical scale, is unchanged. The horizontal and vertical structures of the outflow and inflow are now addressed separately.

\subsubsection{Shelf water flow}

\section{Shelf water supply jet}

For most simulations, the along-shelf supply jet is dominantly barotropic as diagnosed by the parameter BC: BC $\lesssim 0.4$ for most inviscid simulations in Figure 6.8a. The dependence of $\mathrm{BC}$ on the as yet undefined parameter $\varphi_{o}$ will be rationalized later. For now, the low values of BC justify idealizing the supply jet as dominantly barotropic. The jet's dynamics should be controlled by the equation for vertical rel- 


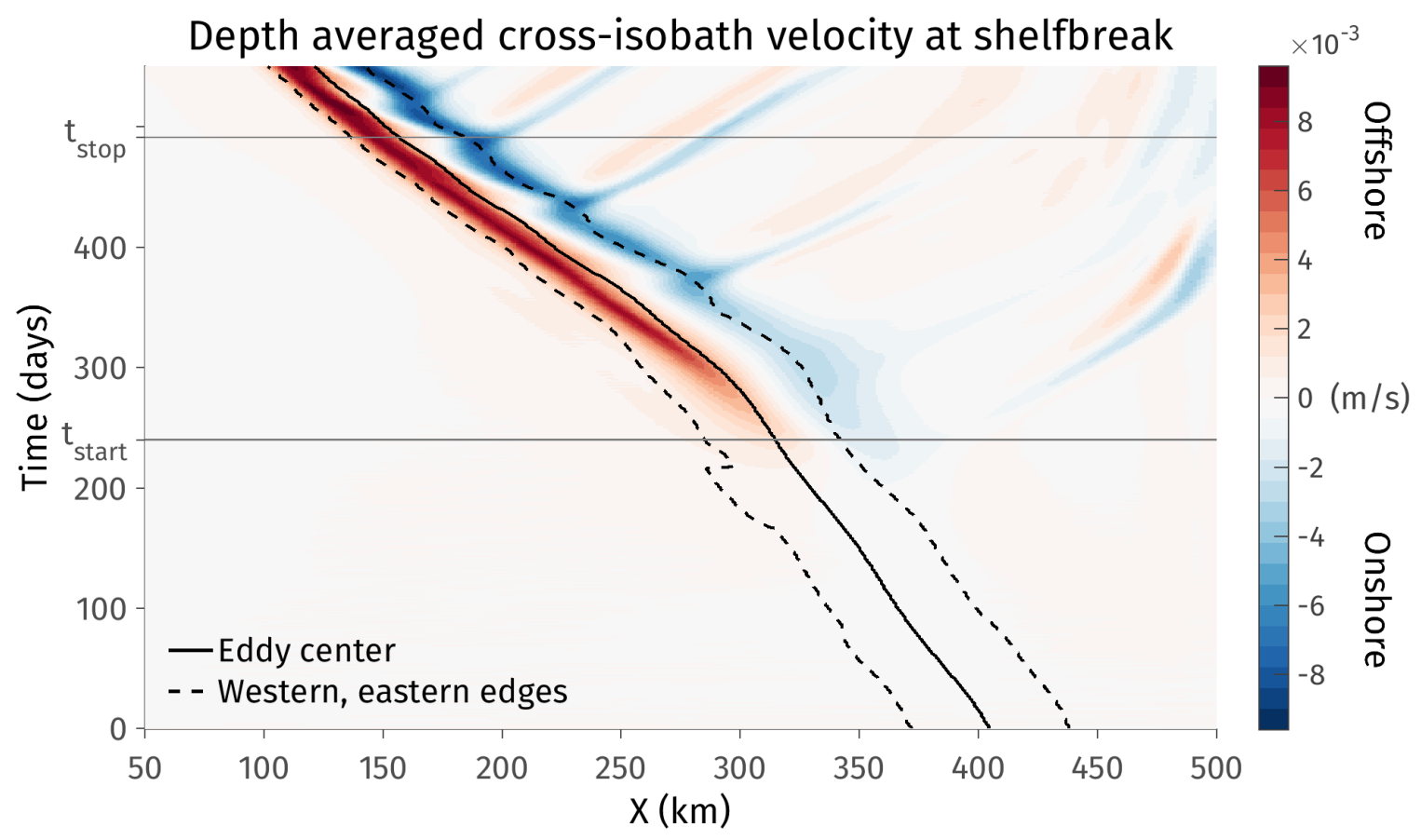

Figure 6.6: Hovmöller diagram of depth-averaged cross-shelf velocity at the shelfbreak. Red is offshore flow and blue is onshore. The location of the eddy's center and its edges in the along-isobath direction are marked by the sloid and dashed black lines respectively. The horizontal lines mark $\left[t_{\text {start }}, t_{\text {stop }}\right]$. Both the offshore and onshore flow are largest near the eddy. The along-isobath scale of both the outflow and the inflow is approximately an eddy radius. Small scale anticyclones formed by the instability of the eddy water leakage are seen propagating eastwards, downstream in the coastal trapped wave direction.

ative vorticity, $\zeta=v_{x}-u_{y}$ :

$$
\frac{\mathrm{D}}{\mathrm{D} t}(f+\zeta)=(f+\zeta) \frac{\partial w}{\partial z}+\text { tilting terms. }
$$

If vertically uniform, (6.3) can be integrated vertically between the surface and bottom to obtain (ignoring tilting terms):

$$
\int_{-H}^{0} \frac{\mathrm{D}}{\mathrm{D} t}(f+\zeta)=(f+\zeta) \alpha_{\mathrm{sh}} v_{\text {bottom }} .
$$

Balancing the two terms, $\int u \cdot \nabla(f+\zeta)$ and $(f+\zeta) \alpha_{\text {sh }} v_{\text {bottom, }}$ yields a horizontal length scale for the supply jet,

$$
L_{\beta}=\sqrt{\frac{V_{0}}{\beta_{\mathrm{sh}}}},
$$

i.e., the advection of relative vorticity balances the stretching caused by shelf water parcels moving across isobaths as they cross the shelfbreak. The eddy velocity scale 

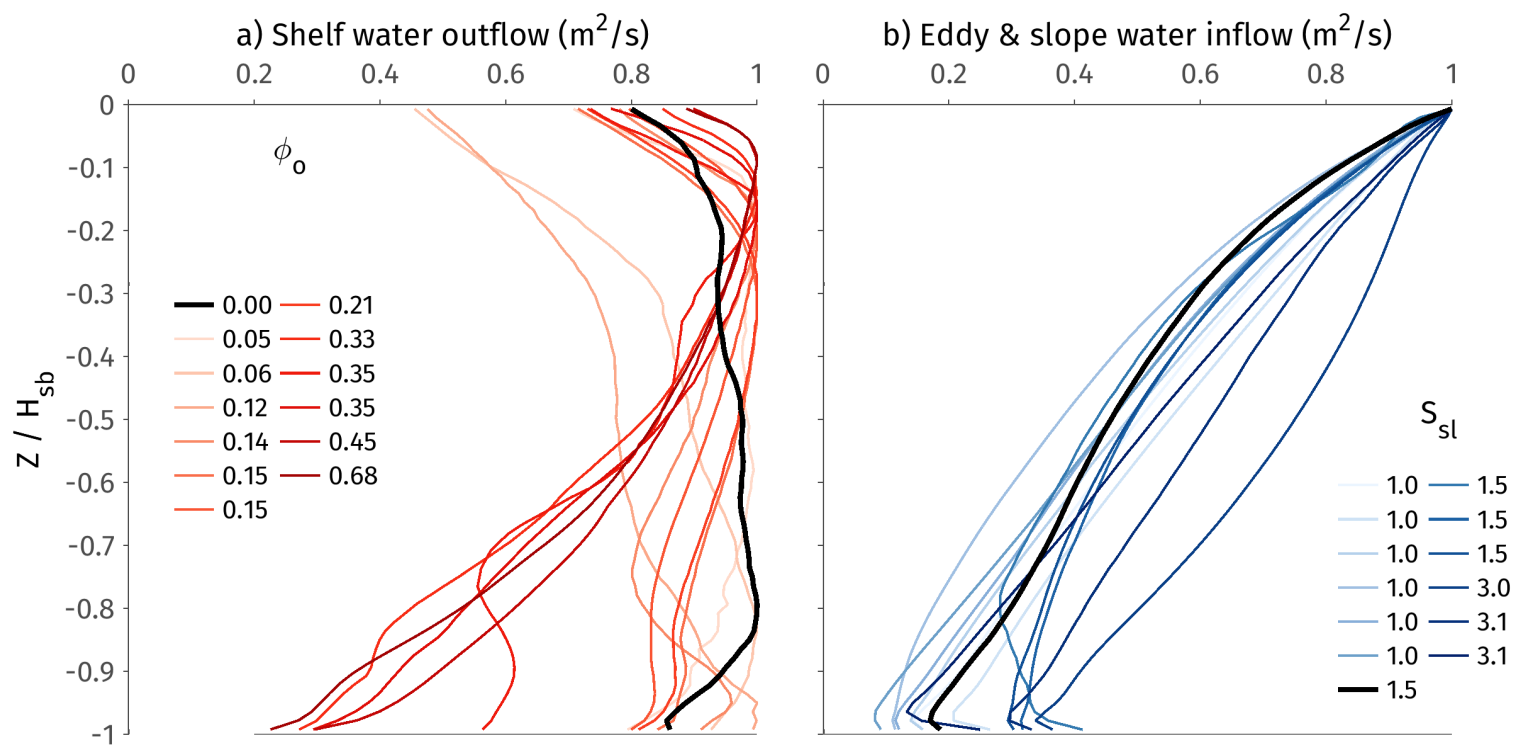

Figure 6.7: Vertical profiles of the time-averaged shelf water outflow and non-shelf water inflow at the shelfbreak. The time average is over $\left[t_{\text {start }}, t_{\text {stop }}\right]$. The thick black lines are for a simulation with a flat shelf. The inflow is always baroclinic while the outflow is only sometimes baroclinic (see Sections 6.4.3 and 6.4.2). Values are normalized such that the maximum value in each profile is 1 .
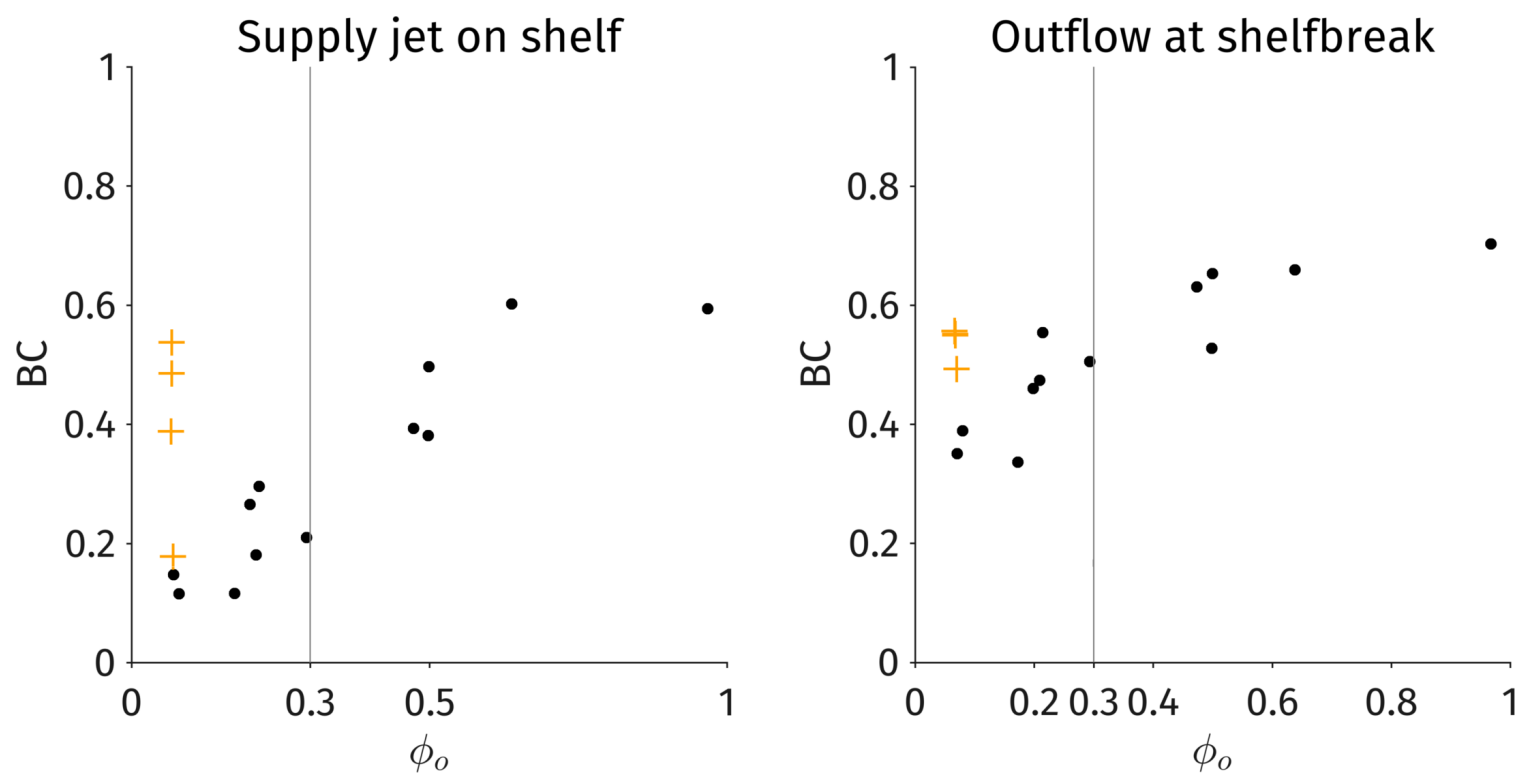

Figure 6.8: The shelf water supply jet is more baroclinic, as measured by $B C$, for larger values of non-dimensional parameter $\varphi_{o}$ (Section 6.4.2). Orange points are simulations with bottom friction. They appear to be more baroclinic than the corresponding inviscid simulation, but a more detailed examination shows this to be false (Section 6.5). 
$V_{0}$ is assumed to be a good scale for the depth-averaged along-shelf velocity. The hypothesis is tested using simulations for which $\lambda=H_{\mathrm{sb}} / L^{z}<0.35$ (Table A.5). For the remaining simulations, the shelfbreak is deep enough that a substantial portion of the eddy crosses onto the shelf (Chapter 4). The eddy can then extract shelf water from distance larger than $L_{\beta}$ from the shelfbreak (see Figure 6.10). Such simulations are not examined further.

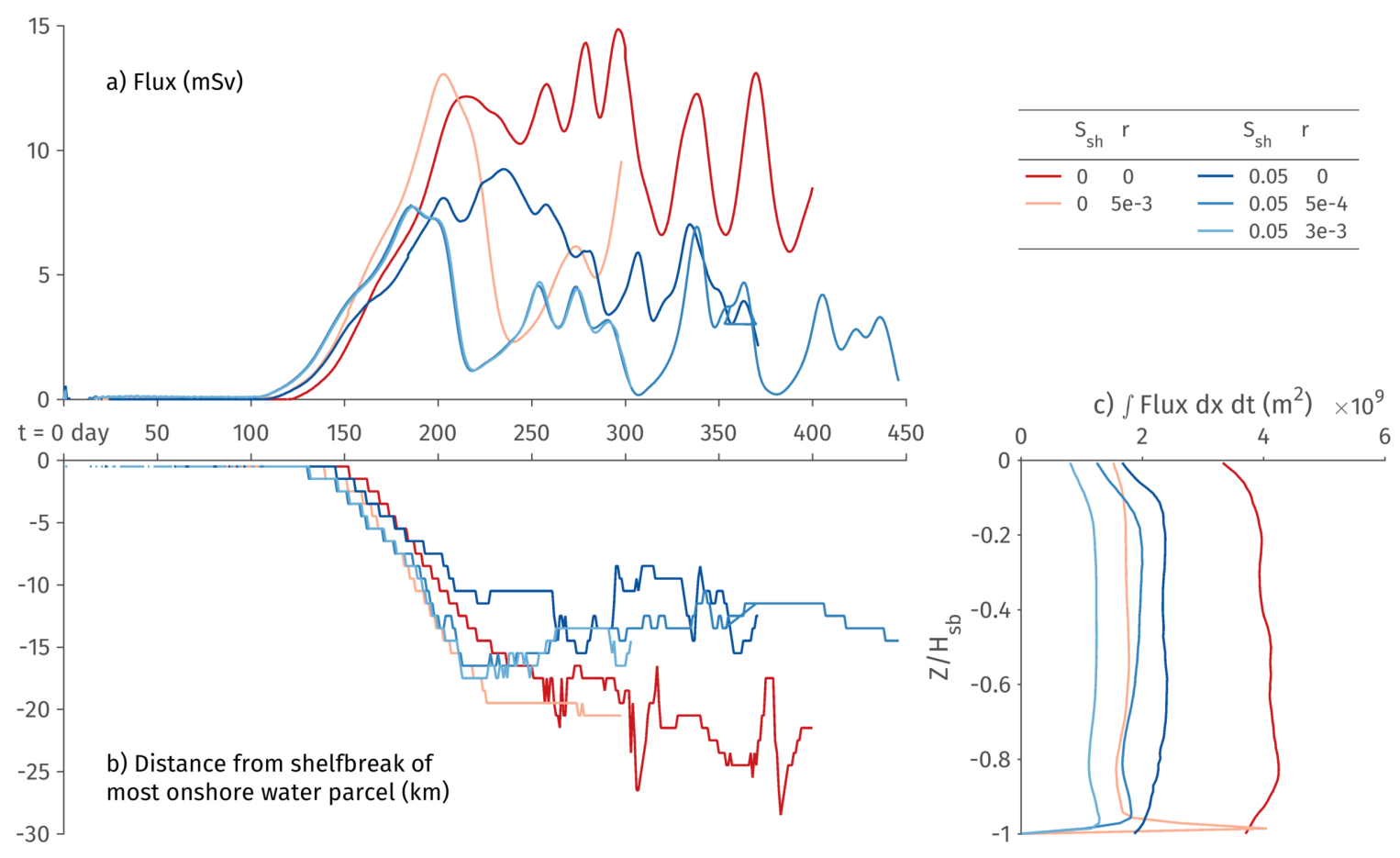

Figure 6.9: Offshore flow at the shelfbreak is strongly influenced by a shelf slope and not much influenced by friction. The reddish lines are for a flat shelf, and the bluish lines are for a sloping shelf. $S_{\mathrm{sh}}$ is the slope Burger number for the shelf and $r_{f}$, the linear bottom drag coefficient in $\mathrm{m} / \mathrm{s}$. (a) Time series of offshore flux at the shelfbreak. The addition of friction results in stronger secondary vortices that pull the eddy away from the shelfbreak, causing a drop in flux magnitude. (b) Lowest value of cross-shelf dye crossing the shelfbreak at that instant; i.e., a time series of the extent to which the eddy can extract water off the shelf. Adding a slope reduces the cross-shelf scale while increasing friction with a slope does not change much. (c) Vertical structure of the outflow.

To quantify the cross-shelf distance over which the eddy can extract shelf water, we use a time series of the lowest value of cross-shelf dye crossing the shelfbreak (for e.g., Figure 6.9b). This time series identifies the origin of the most onshore water parcel crossing the shelfbreak at that time instant, indicating the extent to which the eddy's influence penetrates on the shelf. With a flat bottom (dark red), there is no dynamical limit and the value slowly increases with time. The function, 
$y_{1}+y_{0} \tanh \left[\left(t-t_{0}\right) / T\right]$, is fit to this time series, with $y_{0}, y_{1}, t_{0}, T$ being constants determined by the fit. The width of the supply jet is estimated as $y_{0}+y_{1}$.

The diagnosed width of the shelf water supply jet scales with the length scale $L_{\beta}$ (Equation 6.5 and Figure 6.11a). On average, the eddy can extract a water parcel that starts a distance of roughly $L_{\beta}$ away from the shelfbreak. A balanced jet of horizontal scale $L_{\beta}$ has vertical scale $f L_{\beta} / N$. One can then compare that vertical scale to a shelfbreak depth to define

$$
\varphi_{o}=\left(\frac{H_{\mathrm{sb}}}{f_{0} L_{\beta} / N}\right)^{2}=\left(\frac{N H_{\mathrm{sb}} / f_{0}}{L_{\beta}}\right)^{2} .
$$

$\varphi_{o}$ indicates whether the balanced along-isobath jet of width $L_{\beta}$ appears baroclinic over the shelf. Alternatively, $\varphi_{o}$ is a Burger number that compares the supply jet length scale $L_{\beta}$ to the shelf deformation radius. Over all simulations, the level of baroclinicity of the along-shelf flow, BC defined in (6.2), varies approximately linearly with $\varphi_{o}$ for $\varphi_{o} \lesssim 0.35$ (Figure 6.8). The shelf supply jet becomes increasingly sheared in the vertical as $\varphi_{0}$ increases.

\section{Cross-shelfbreak outflow}

The cross-shelfbreak outflow of shelf water also displays increased vertical shear for larger values of $\varphi_{o}$ (Figure 6.7a). For the cross-shelfbreak flow, BC is calculated using the cross-shelf velocity $v$ at the shelfbreak instead (Figure 6.8b). Again, there is an approximately linear dependence with $\varphi_{o}$, but the values of $\mathrm{BC}$ are higher than those in Figure 6.8a. The increased shear is a result of near-bottom density anomalies.

When a flow with a cross-isobath component interacts with a sloping bottom, it must move either up- or down-slope, constrained by the kinematic bottom boundary condition, $w=u \cdot \nabla H$. In doing so, the flow advects the background density field and creates near-bottom density anomalies (Figure 6.12). These density anomalies must be balanced by a geostrophic velocity field through the thermal wind equation. Thus, the slope is expected to modify the vertical shear of any cross-isobath current.

The density equation can be written in terms of buoyancy, $b=-g \rho / \rho_{0}$ as

$$
\frac{\mathrm{D} b}{\mathrm{D} t}+w \mathrm{~N}^{2}=0, \quad z=-H
$$

Assuming a steady outflow,

$$
u b_{x}+v b_{y}=-\alpha_{\mathrm{sh}} v N^{2}, \quad z=-H
$$




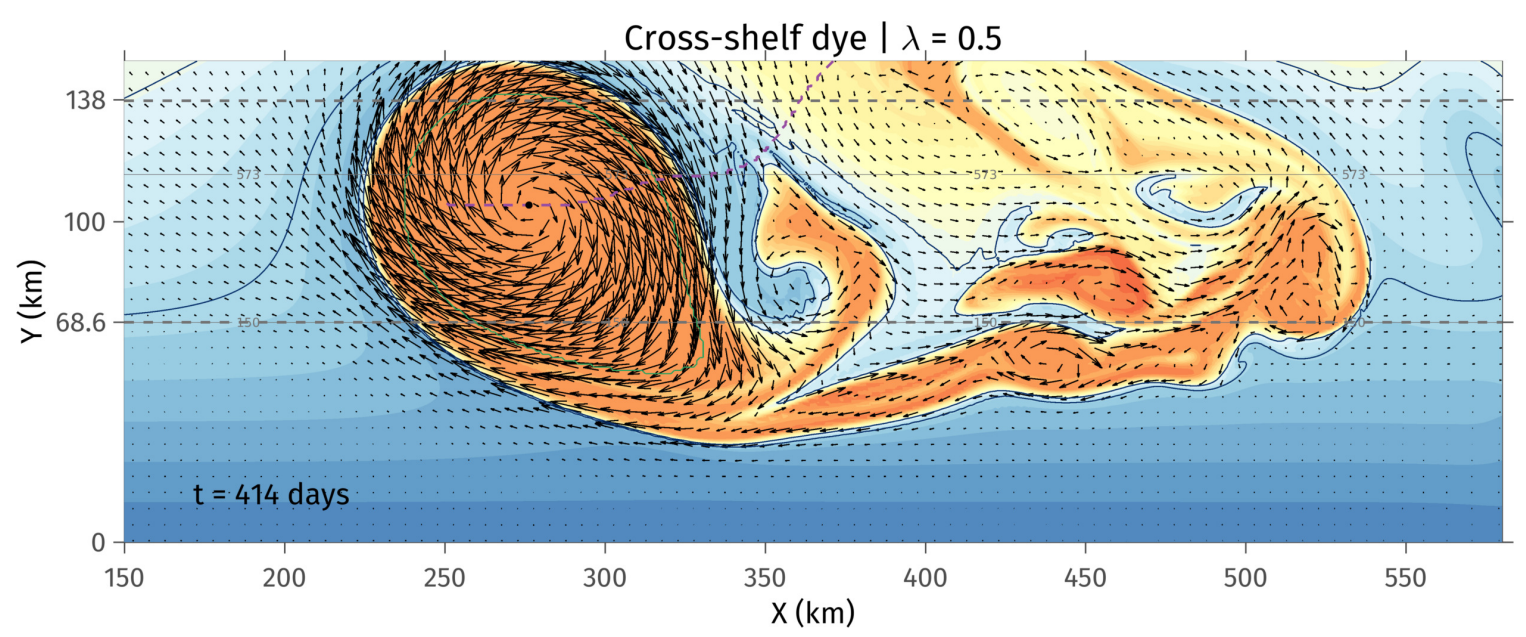

Figure 6.10: For $\lambda=H_{\mathrm{sb}} / L^{z}=0.5$, a substantial portion of the eddy's core crosses onto the shelf. The velocity vectors indicate that the eddy can now extract shelf water from a distance larger than $L_{\beta}$. Such simulations are excluded from Figure 6.11a. They are not excluded from Figure $6.11 \mathrm{~b}$ where the width of the eddy leakage on shelf, as measured far downstream at $x=450 \mathrm{~km}$ for this simulation, correlates well with the shelf Rossby radius.
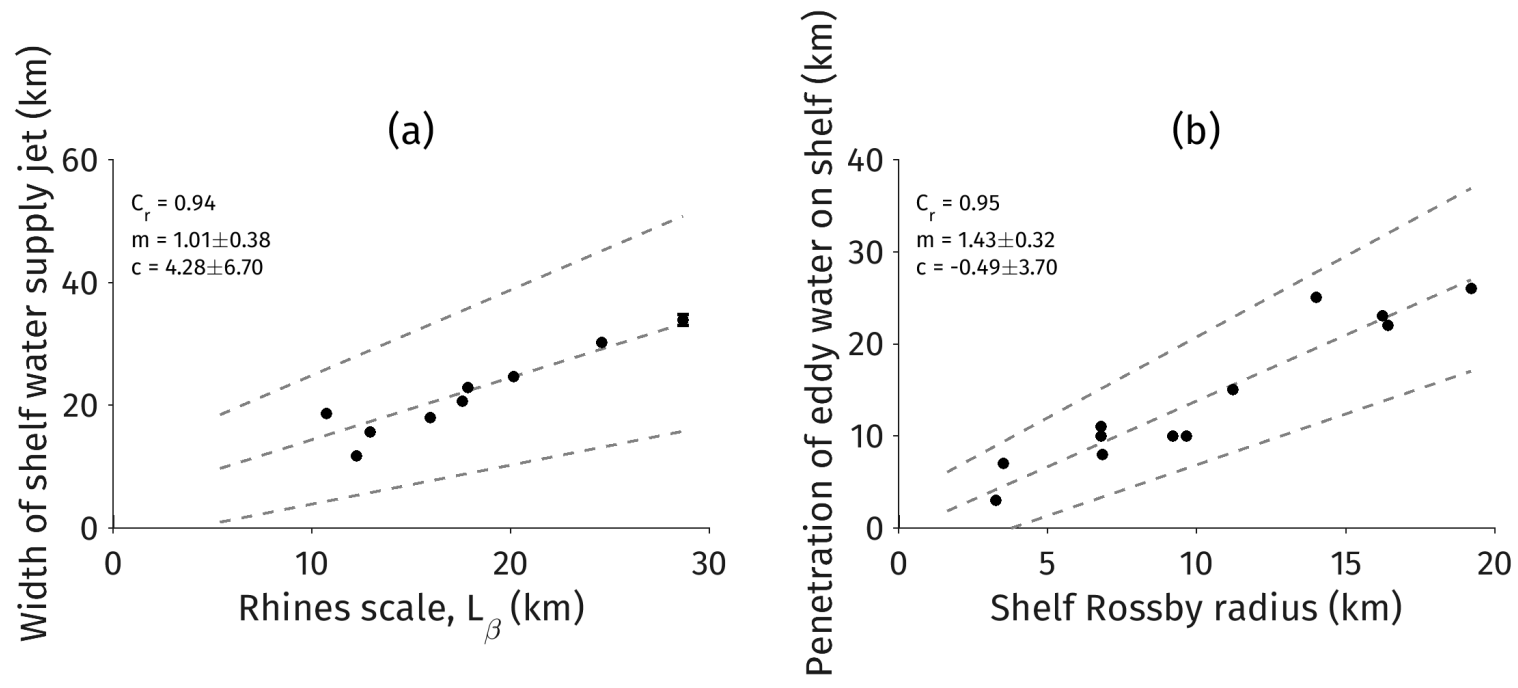

Figure 6.11: Parameterizations for the extent to which the eddy can extract water from and push water onto the shelf. The dashed lines are regression lines of slope $m$ and $y$-intercept $c$ and their $95 \%$ confidence bounds. $C_{r}$ is the correlation coefficient. 
after applying the bottom boundary condition $w=-\alpha_{\mathrm{sh}} v$ for a sloping shelf with southern coast.

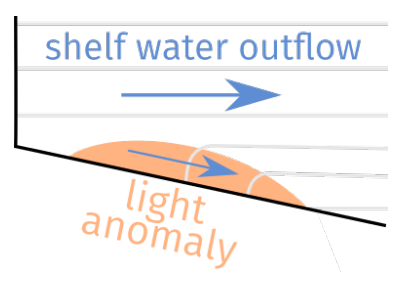

Figure 6.12: The kinematic bottom boundary condition imposed by the bottom slope on a cross-isobath flow forces the creation of density anomalies. These anomalies modify the vertical shear of the velocity field through the thermal wind equation.

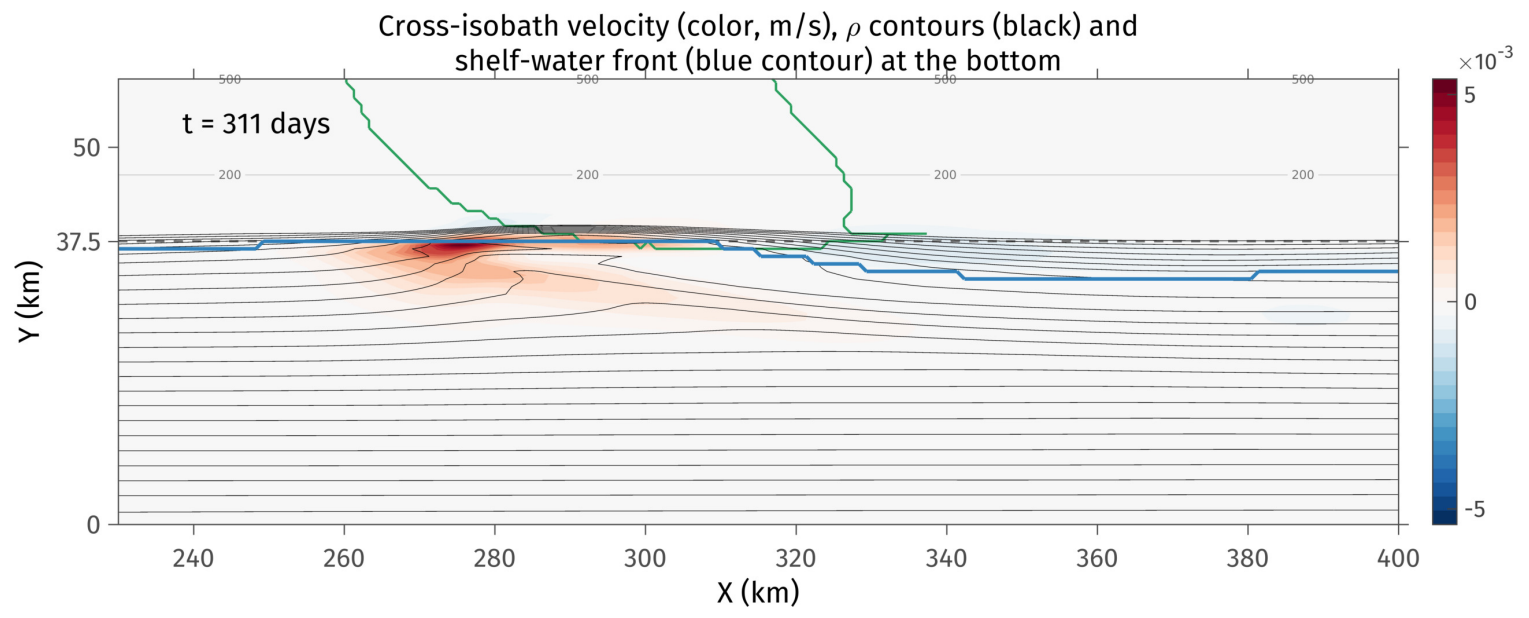

Figure 6.13: Instantaneous cross-isobath velocity in color and density contours at the bottom for an simulation with $\varphi_{o}=0.35$, i.e. the outflow is baroclinic. For clarity, only density contours over the shelf are shown. The cross-isobath flow creates a bottom density anomaly where the shelf water supply jet starts crossing isobaths. The along-isobath density gradient intensifies as the cross-isobath velocity increases at $x=270 \mathrm{~km}$. It then modifies the vertical shear of the outflow.

The density anomaly created by $w N^{2}=-\alpha_{\mathrm{sh}} v N^{2}$ spreads out in the alongisobath direction (Figure 6.13). Assuming a steady flow field, the density anomaly is geostrophically balanced by a vertically sheared anomalous along- and crossisobath velocity fields $\left(u^{\prime}, v^{\prime}\right): f_{0} v^{\prime} z=b_{x}$ and $-f_{0} u^{\prime} z=b_{y}$.

$$
u f_{0} v_{z}^{\prime}-v f_{0} u_{z}^{\prime}=\alpha_{\mathrm{sh}} v N^{2}, \quad z=-H
$$

Here, primes indicate velocities associated with the near bottom density anomaly and unprimed velocities are associated with the "background" jet. (6.9) can then 
be divided by $u v$ and rewritten as

$$
\frac{v_{z}^{\prime} H_{\mathrm{sb}}}{v}-\frac{u_{z}^{\prime} H_{\mathrm{sb}}}{u}=\frac{\alpha_{\mathrm{sh}} N^{2} H_{\mathrm{sb}}}{f_{0} u}, \quad z=-H
$$

If the background velocity $(u, v)$ is vertically uniform, the LHS is an expression for the effectiveness of the anomalous bottom-induced vertical shear over the shelfbreak depth. The idea is similar to that of frictional bottom boundary layers on bottom slopes modifying the shear of background currents (Trowbridge and Lentz, 1991). There, the combination of an along-isobath flow and bottom friction drives an along-slope buoyancy flux. Here, the background current has a cross-isobath component that drives an along-slope buoyancy flux. The consequence of the flux is to generate buoyancy anomalies that are balanced by a vertically sheared velocity.

Assuming that the along-shelf supply jet velocity, here $u$, scales like the eddy velocity scale $V_{0}$, the term on the right

$$
\frac{\alpha_{\mathrm{sh}} N^{2} H_{\mathrm{sb}}}{f_{0} u} \sim \frac{\alpha_{\mathrm{sh}} N^{2} H_{\mathrm{sb}}}{f_{0} V_{0}}=\left(\frac{H_{\mathrm{sb}}}{f L_{\beta} / N}\right)^{2}=\varphi_{0} .
$$

The extra shear in (6.10) created by near bottom density anomalies is thus of the same order of magnitude as that in the along-shelf supply jet, $\varphi_{0}$. As the along-shelf flow turns to move offshore near the eddy, it crosses isobaths creating near-bottom density anomalies that intensify the flow's shear, explaining the larger values of BC in Figure 6.8b.

To summarize, the volume transported across the shelfbreak is compensated by an along-shelf flow that supplies shelf water from downstream of the eddy, in the coastal-trapped wave, or Kelvin wave, sense. This supply flow is generally barotropic with a cross-shelf length-scale of $L_{\beta}$ (Figures 6.3 and 6.11). On reaching the eddy, the flow is directed offshore and becomes increasing baroclinic as it approaches the shelfbreak (Figures 6.8 and 6.7a).

\subsubsection{Eddy water on the shelf}

The vertical structure of the eddy water inflow onto the shelf is significantly sheared in Figure 6.7b. The density anomaly-based reasoning of the previous section does not apply in this case because the appropriate bottom slope, that of the continental slope, is quite steep. The kinematic bottom boundary condition imposes $w=u$. $\nabla H=\alpha v$ at the bottom, $v$ being cross-isobath velocity and $\alpha$ bottom slope. For small 


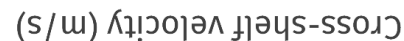

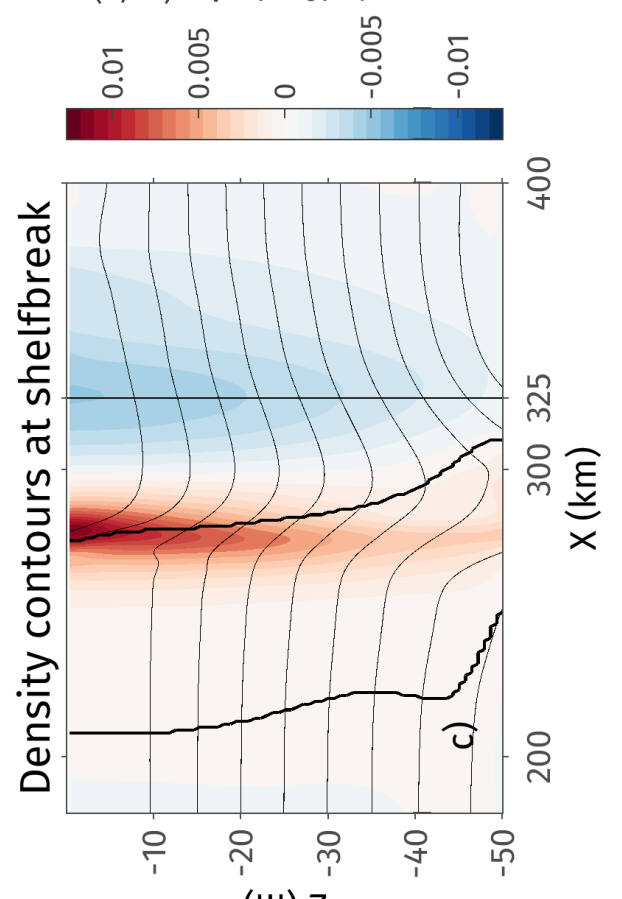

(u) $\mathrm{Z}$
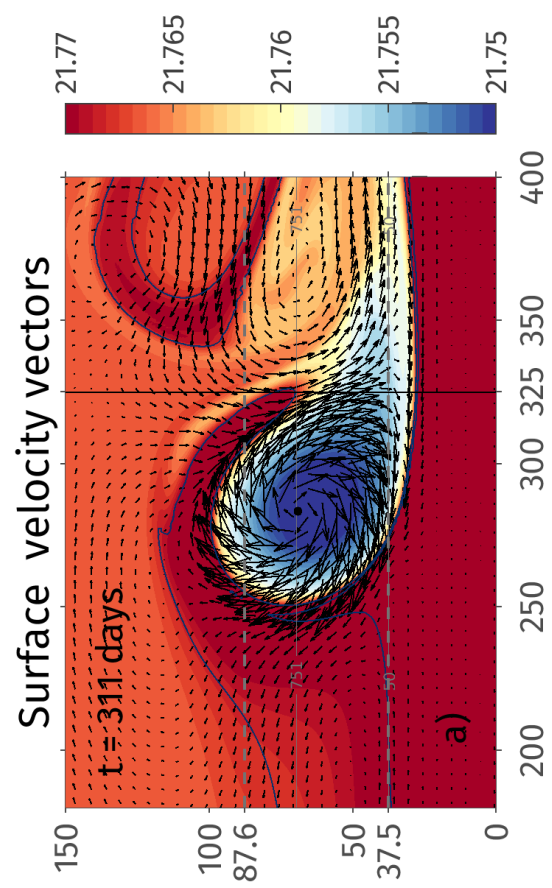

(u>|) ᄉ

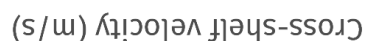
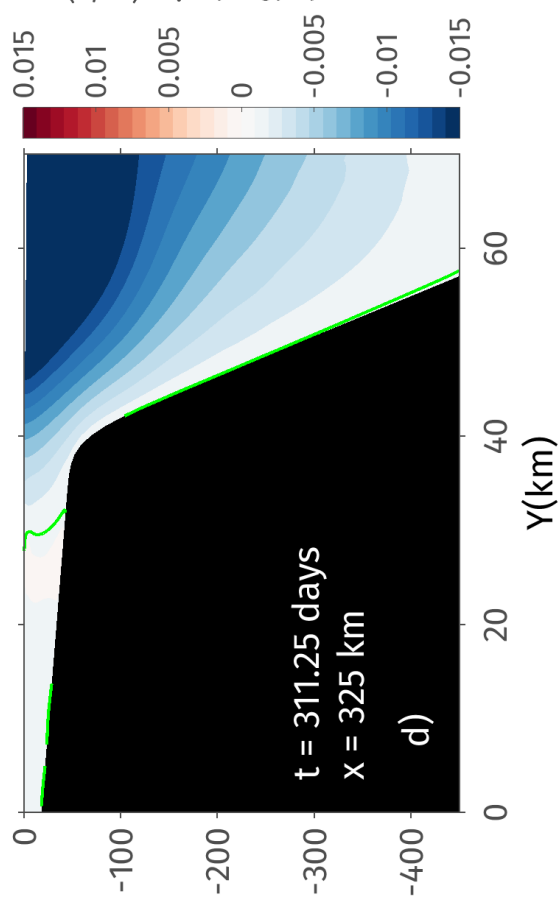

(w) Z
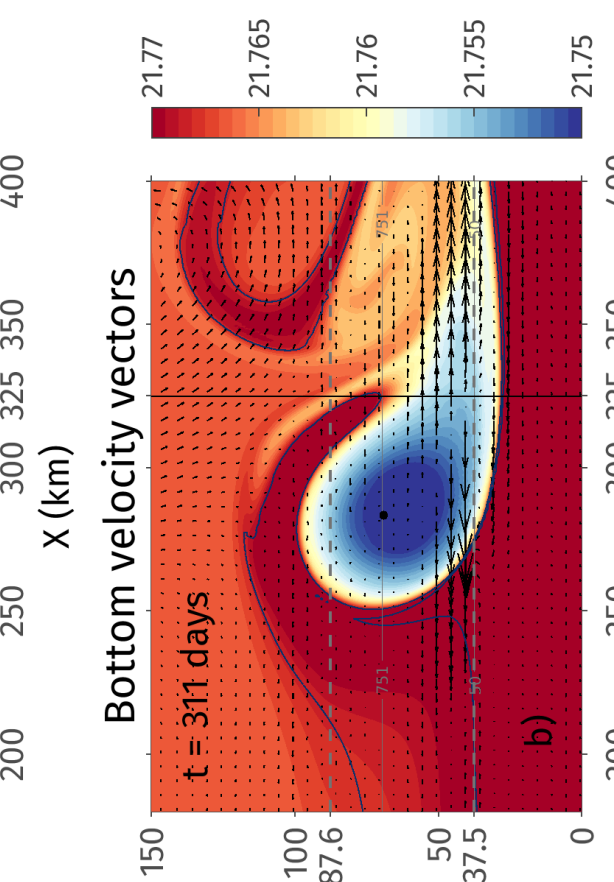

옴

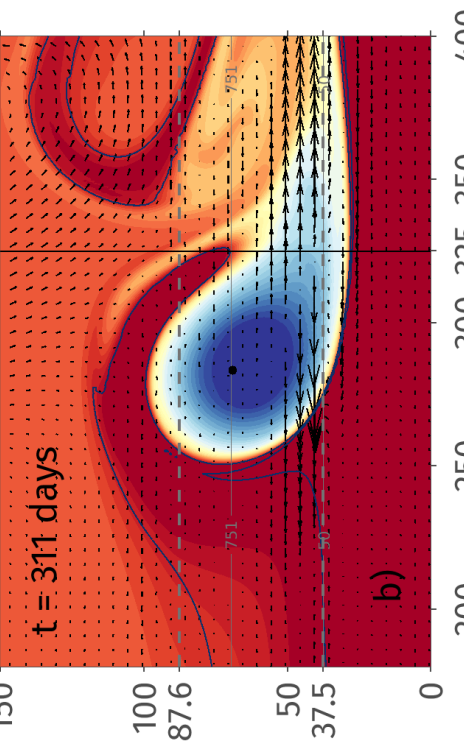

$(u>\mid) \wedge$
苞莞

का एै

声范

른

$\exists$ क

至至

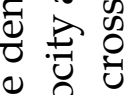

¿ $\frac{0}{0}$

क 岕芯

ลำ

त) की क्षे

กุं पु चु

0 己

110

๙

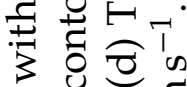

$m>\dot{ }$

부유

常高

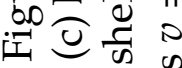

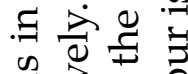

。

ธี ญे ठ

坖 की

छे $\cong$ का

के च

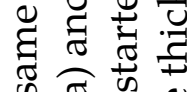

क त क क

로 Ð

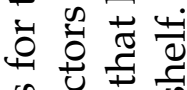

क ष

宅氙芒

की.

के 월

计

붕

○े

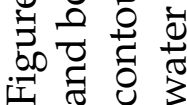


$\alpha$, the sloping bottom deflects the flow either up- or down-slope. For infinite slope $\alpha$, i.e. a vertical wall, the appropriate boundary condition is $v=0$. For increasing bottom slope $\alpha$, there must be a transition from a regime where the appropriate boundary condition is $w=\alpha v$ to one where $v=0$, i.e. as $\alpha \rightarrow \infty, v \rightarrow 0$ so that $\mathrm{w} \$$ is bounded. The upper bound on $w$ is set by the continuity equation which imposes $w \leq \mathrm{O}(V D / L)$, where $V$ is the cross-isobath velocity scale and $D, L$ are appropriate vertical and horizontal scales.

Combining the two constraints, viz. the bottom boundary condition and the continuity equation, and using $D=\mathrm{O}(f L / N)$ then results in

$$
w=\alpha v \lesssim \mathrm{O}(V D / L) \Rightarrow S_{\mathrm{sl}}=\frac{\alpha_{\mathrm{sl}} N}{f} \leq \mathrm{O}(1) .
$$

When (6.12) is satisfied, the slope is gentle and the cross-isobath flow is deflected either up- or down-slope i.e. $v_{y} \approx-w_{z}$ and the flow is approximately two-dimensional in the $y-z$ plane. When (6.12) is not satisfied, the slope is steep and acts like a vertical wall that deflects the near-bottom cross-isobath flow in the along-isobath direction. Now, $u_{x} \approx-v_{y}$ and the flow is approximately two-dimensional in the horizontal $x-y$ plane (Figure 6.14b).

Over the shelf where $S_{\mathrm{sh}} \leq 0.2,(6.12)$ is satisfied and the slope forces vertical motion with the consequences described in Section 6.4.2. For the continental slope however, $S_{\mathrm{sl}} \geq 1$ and the slope is expected to force $v \approx 0$ as in Figure $6.14 \mathrm{~d}$. The thick green contour is $v=10^{-4} \mathrm{~m} \mathrm{~s}^{-1}$, a tenth of the peak surface cross-isobath velocity. At the surface, the eddy forces a small but non-zero cross-isobath velocity $v$. Below shelfbreak depth, the slope forces $v \approx 0$, pinching the velocity contours in Figure $6.14 \mathrm{~d}$. The horizontal scale over which the eddy's flow is diverted is roughly an eddy radius, $L_{0}$. The associated balanced flow vertical scale is the eddy's vertical scale $L^{z}=f L_{0} / N$. For most runs, $\lambda=H_{\mathrm{sb}} / L^{z} \leq 0.3$. So the entire water column at the shelfbreak must reflect adjustment to the $v \approx 0$ condition at depth, resulting in strong vertical shear between the surface and shelfbreak depth (Figure 6.7b).

The inflow of eddy and slope waters rotates to follow isobaths after it crosses the shelfbreak. Being strongly sheared i.e. baroclinic, the cross-isobath scale of the balanced along-shelf flow should scale with the shelf deformation radius, $N H_{\mathrm{sb}} / f$. This hypothesis is tested using multiple simulations (Table A.5). The width of the eddy water leakage on the shelf is identified by using depth and time-averaged (over $\left[t_{\text {start }}, t_{\text {stop }}\right]$ ) cross-shelf dye field $C_{\text {mean }}$ at a location far downstream ${ }^{2}$ near the

\footnotetext{
${ }^{2}$ in the coastal trapped wave sense
} 
eastern sponge.

The cross-shelf dye field $C$, being undisturbed until the eddy reaches the shelfbreak, is used to identify shelf water parcels as $C<Y_{\mathrm{sb}}{ }^{3}$. The width of the leakage on the shelf is defined as the location where $C_{\text {mean }}>Y_{\text {sb }}$; the time- and depthaveraged location of the front between shelf and non-shelf waters (thick black contour in Figure 6.2). The diagnosed location of the front compares favourably with the shelf deformation radius in Figure 6.11b.

\subsection{The effect of bottom friction}

With the addition of bottom friction, the picture remains qualitatively similar. The most visible difference is the spin up of a stronger secondary cyclone that pulls the eddy away from the shelfbreak (Figure 6.15, Chapter 5). The value of bottom drag, $r_{f}$, for the simulation in Figure $6.15 \mathrm{c}$, d is large: $3 \times 10^{-3} \mathrm{~m} \mathrm{~s}^{-1}$, relative to a representative value for the real ocean, $5 \times 10^{-4} \mathrm{~m} \mathrm{~s}^{-1}$. Despite the large difference in these values, the flow evolution is relatively unaffected. The presence of friction is more important than its magnitude, as will be described below.

When the eddy is pulled away, the SSH forcing at the shelfbreak and over the shelf is reduced. There is a drop in cross-shelfbreak flux magnitude (Figure 6.15e) and the along-shelf flow over the shelf is weakened (Figure 6.15d). The only significant shelf water velocities are near the leakage at the shelfbreak, where the alongshelf flow balances the density gradient between the ambient shelf water and eddy water leaked onto the shelf.

That the along-shelf flow is localized to near the shelfbreak is apparent in its cross-isobath extent relative to the shelfbreak (Figure 6.16). The extent is measured as the distance over which the along-shelf depth-averaged velocity drops to $30 \%$ of its value at the shelfbreak. The localized along-shelf flow at the leakage is responsible for the much larger value of $\mathrm{BC}$ at $t=230$ days. Prior to this time, the value of BC and the cross-isobath scale in Figure 6.16 are both comparable to that of the inviscid simulation. Using the median to summarize the time-series of BC in Figure $6.15 \mathrm{~d}$, as in (6.2), thus overestimates the baroclinicity of the shelf flow for the frictional runs in Figure 6.8 (orange points).

Bottom friction might affect the along-isobath supply jet in three ways:

\footnotetext{
${ }^{3} Y_{\mathrm{sb}}$ being the location of the shelfbreak in the cross-isobath direction, here $y$
} 


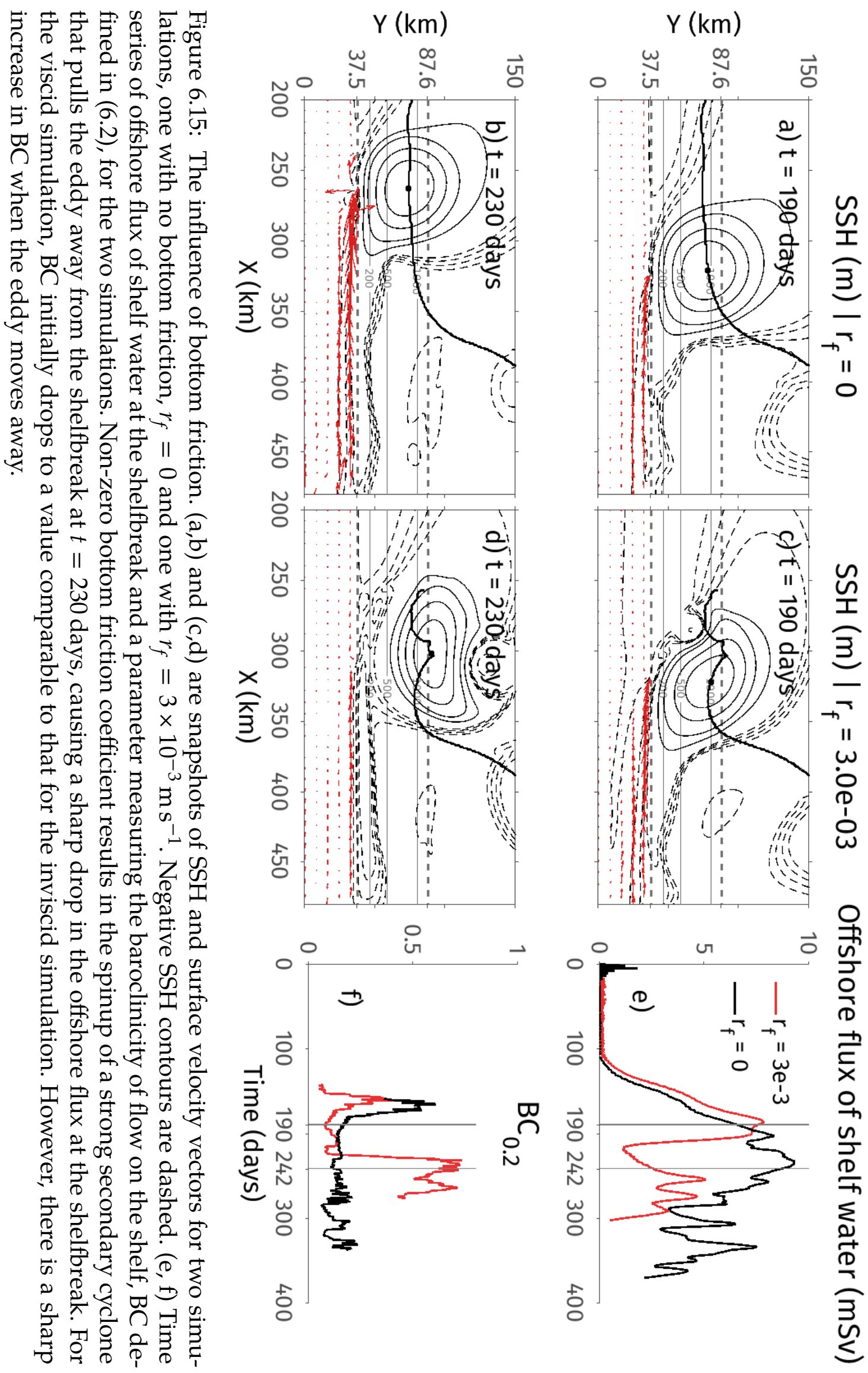




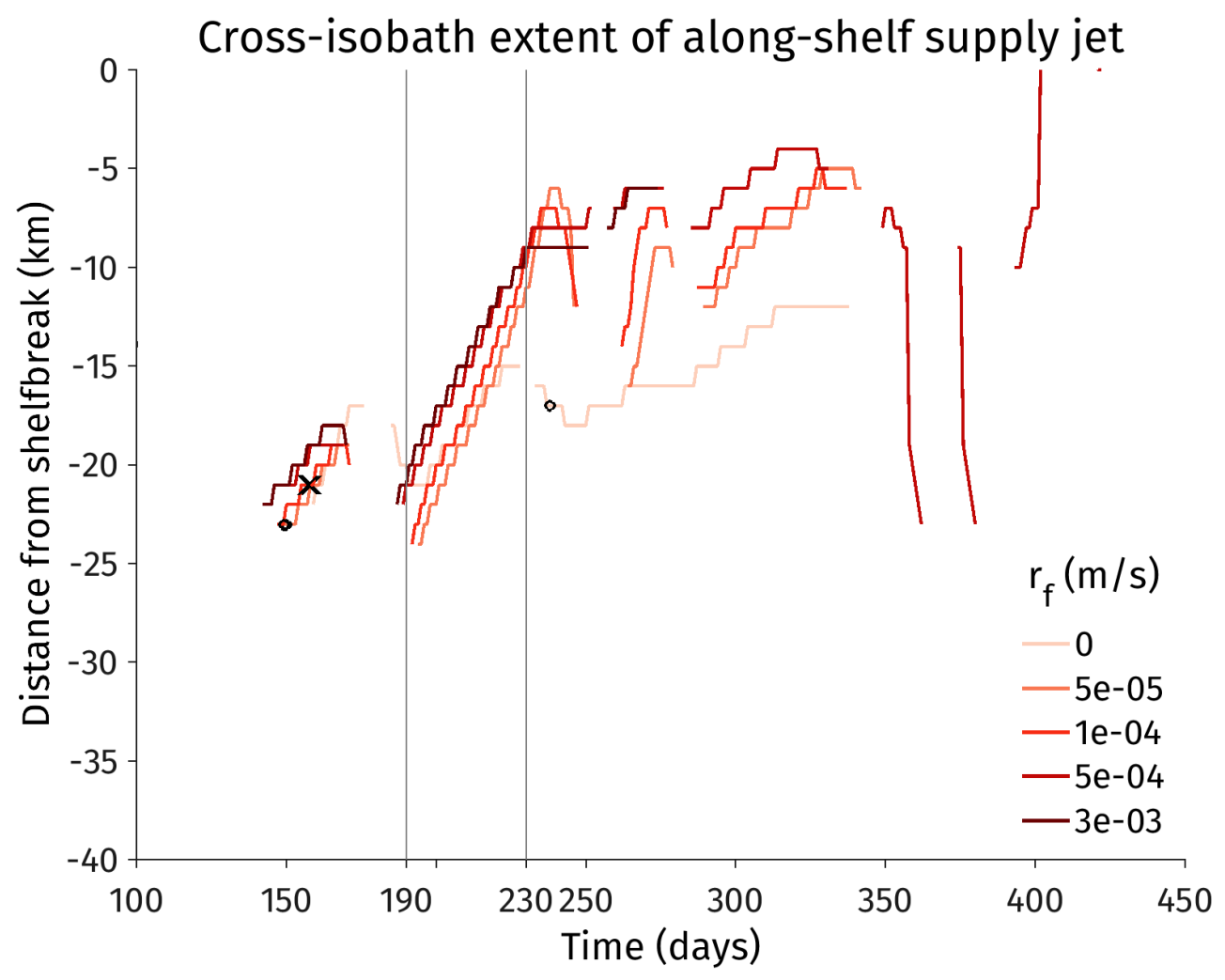

Figure 6.16: Cross-isobath scale of along-shelf flow. No distinction is made between shelf and non-shelf waters. The $y$-axis is the distance at which the depth-averaged along-shelf velocity drops to $30 \%$ of its maximum value on the shelf. All viscid runs behave in exactly the same manner: the cross-isobath scale drops when the eddy moves away (Figure 6.15).

1. Buoyancy arrest might limit the jet's cross-isobath extent (Brink, 2012),

2. Stratified spindown might make the jet more baroclinic (Holton, 1965) and

3. Arrested topographic wave physics could make the jet wider farther downstream of the eddy (Csanady, 1978).

However, bottom friction appears to have little effect on the maximum crossisobath extent of the supply jet despite the large variation in $r_{f}$ values used (Figures $6.15 \mathrm{~b}$ and 6.16). Buoyancy arrest can be ruled out: for barotropic flows, the expressions of Brink (2012) predict an along-isobath adjustment scale of at least a $1000 \mathrm{~km}$ for buoyancy arrest to influence the cross-isobath scale of the supply jet.

The time scale of stratified spin-down is $\mathrm{O}$ (few days), much smaller that the characteristic time scale of the flux time series in Figure 6.15e. However, stratified spindown is expected to act over a vertical scale $\sim \mathrm{O}(f L / N)$. For this particular 
simulation, the jet is barotropic with approximate cross-isobath scale $L_{\beta}=\sqrt{V_{0} / \beta_{\mathrm{sh}}}$. Its vertical scale $f L_{\beta} / N \approx 4 H_{\mathrm{sb}}$, so the spin-down should equally affect the entire water column at all depths above the bottom Ekman layer. BC, being calculated above the bottom Ekman layer, is thus unaffected by the spindown (Figure 6.15d). Vertical profiles of the outflow are also barotropic with a shallow Ekman layer near the bottom where velocity drops to zero (Figure 6.9c).

With bottom friction, a steady PV conserving barotropic flow will cross isobaths in response to Ekman pumping in the bottom boundary layer, termed an "arrested topographic wave" (Csanady, 1978). The governing equation for SSH $\eta$ is

$$
\frac{\partial^{2} \eta}{\partial y^{2}}+\alpha_{\operatorname{sh}} \frac{f}{r} \frac{\partial \eta}{\partial x}=0
$$

This equation can be viewed as a diffusive equation i.e., the along-shelf flow is expected to diffuse and become wider as one moves in the coastal trapped wave, or Kelvin wave, direction. Here, the along-shelf supply jet is expected to widen near the eastern boundary. (6.13) can be scaled to obtain an along-shelf length scale, $L_{\mathrm{atw}}$ over which the along-shelf supply jet spreads to cover the whole shelf.

$$
L_{\mathrm{atw}}=L_{\mathrm{sh}}^{2}\left(\frac{f \alpha_{\mathrm{sh}}}{r}\right)
$$

For the simulation with $r_{f}=3 \times 10^{-3} \mathrm{~m} \mathrm{~s}^{-1}, L_{\mathrm{atw}}=20 \mathrm{~km}$ (Table A.5), so the along-shelf jet should cover the entire shelf within $20 \mathrm{~km}$ of the eddy. Figures $6.15 \mathrm{~b}$ and 6.16 indicate otherwise. A suitable explanation for this behaviour was not found. For the remaining viscous simulations with lower values of $r_{f}, L_{\text {atw }}$ is either similar to or greater than the distance between the outflow and the sponge, so one does not expect to see widening of the jet. Bottom friction on the continental slope appears to have a greater effect on the eddy-shelf interaction than bottom friction on the shelf.

The drop in cross-shelfbreak shelf water flux magnitude at $t=200$ days in Figure 6.9a for the viscous simulations is similar to that seen for a flat shelf. Regardless of shelf slope, simulations with bottom friction attain the same maximum flux as the corresponding inviscid simulation. The time averaged flux magnitude is reduced because the eddy moves away from the shelfbreak frequently as in Figure $6.15 \mathrm{~d}$. Changing $r_{f}$ from $5 \times 10^{-4} \mathrm{~m} \mathrm{~s}^{-1}$ to $3 \times 10^{-3} \mathrm{~m} \mathrm{~s}^{-1}$ does not change the flux magnitude time series. 


\subsection{Summary}

This chapter examined the nature of shelf flows forced by an anticyclonic eddy at the shelfbreak, summarized in Figure 6.17.

The shelf water exported across the shelfbreak is supplied by an along-shelf jet that supplies shelf water from downstream of the eddy, in the coastal-trapped or Kelvin wave sense, as expected from Chapman and Brink (1987). For a sloping shelf, the along-shelf jet is of limited cross-shore extent: distance $L_{\beta}$ from the shelfbreak on average. This along-shelf supply jet is dominantly barotropic: its vertical shear depends on parameter $\varphi_{o}$, which may be interpreted as a Burger number comparing the jet width $L_{\beta}$ to the shelf Rossby radius. The eddy also transports eddy and slope waters onto the shelf. These waters persist on the shelf within a region of width, on average, a shelf Rossby radius from the shelfbreak.Most notably, the vertical structure of the shelf water outflow and eddy water inflow can be different. In the simulations here, the former is generally barotropic while the latter is generally baroclinic (vertically sheared, Figure 6.7). These results do not depend on linear bottom friction.

There still remain a few unresolved questions viz., the mechanism by which a sloping shelf reduces the magnitude of cross-isobath flow, the inability of bottom friction to affect the along-shelf supply jet and its effect in simulations with more baroclinic outflows. Using the presented results, Chapter 8.2 discusses the implications of Chapters 4-6 for the Mid-Atlantic Bight.

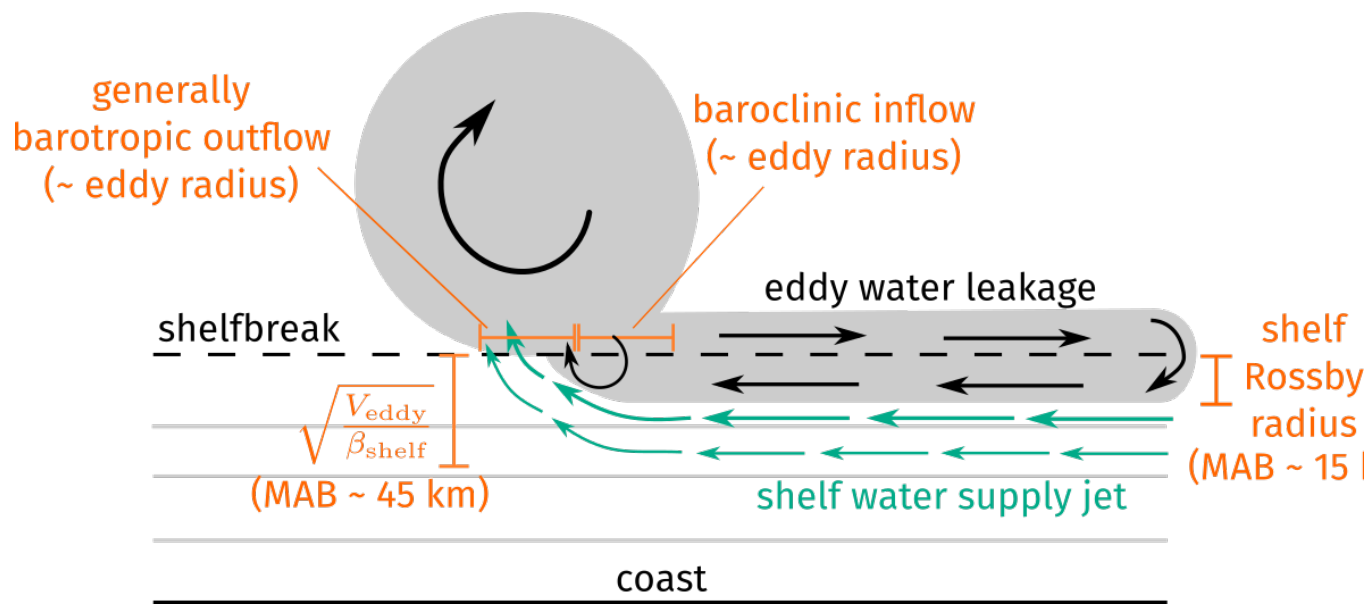

Figure 6.17: Shelf and slope flows forced by an eddy at the shelfbreak. 


\section{$7 \quad$ A recipe for cross-isobath fluxes}

(Most of this material is currently in review at the Journal of Physical Oceanography as "Cherian \& Brink (2016) Offshore transport of shelf water by deep-ocean eddies").
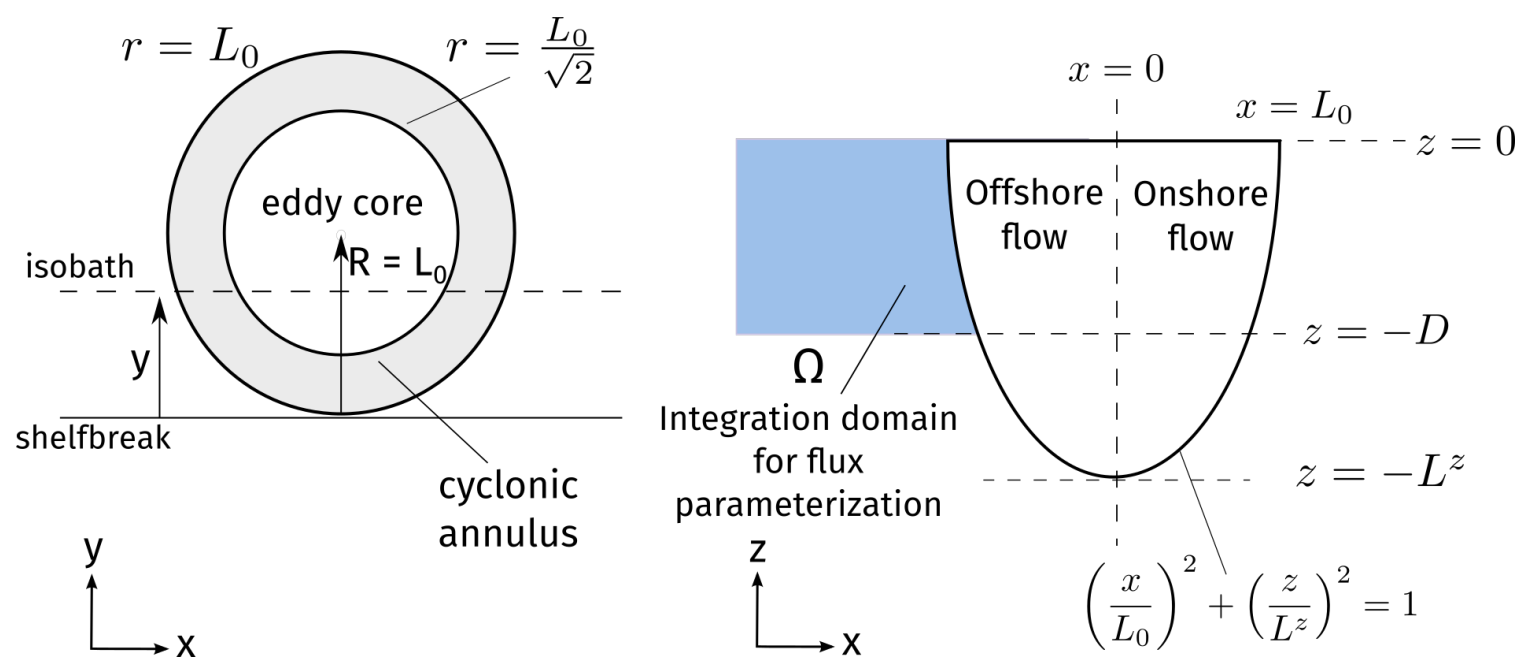

Figure 7.1: Schematics showing how the dye field is reconstructed to obtain a prediction for flux magnitude. (a) An idealized representation of the eddy as two concentric contours: the inner one is the radius to maximum velocity $r=L / \sqrt{2}$, and the outer is $r=L . y, L_{0}$ are used to define a non-dimensional isobath value (Section 3.3), the flux across which will be compared across all runs. (b) In blue, the domain over which an idealized velocity field is integrated.

A parameterization is now developed to predict the average offshore transport between $\left[t_{\text {start }}, t_{\text {stop }}\right]$; to be used with satellite data for estimates of real world trans- 

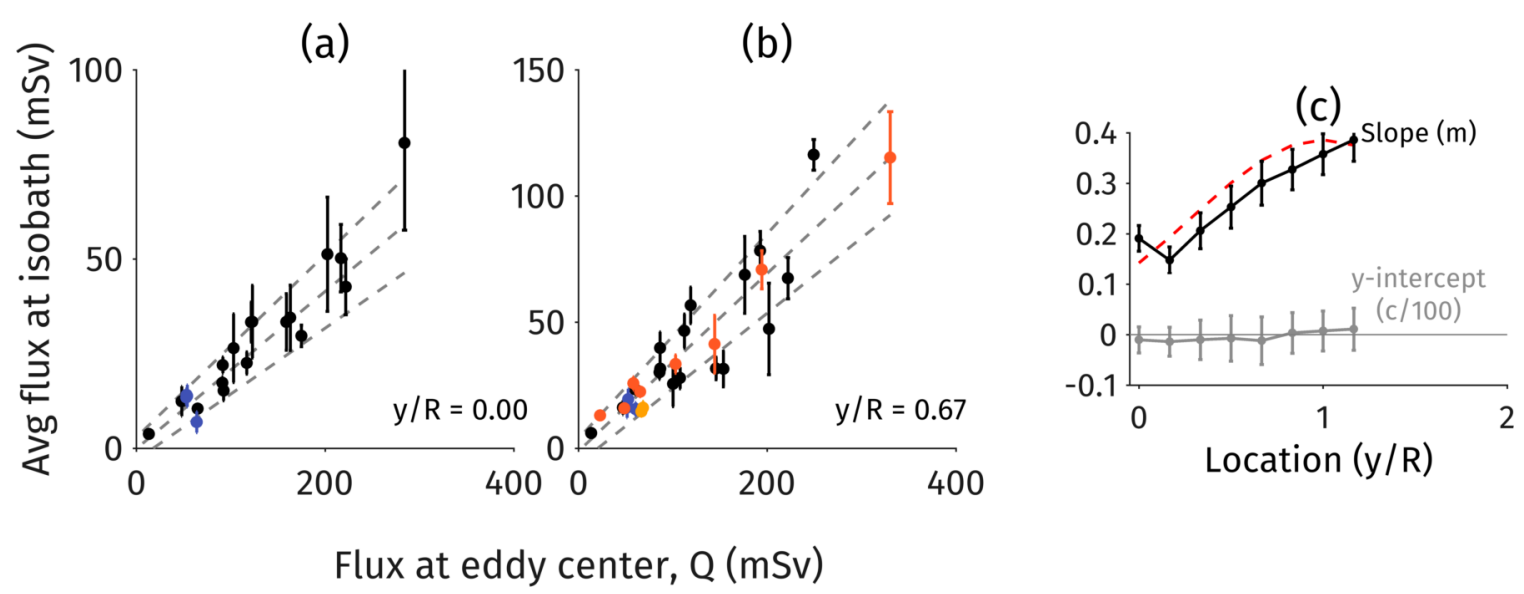

Figure 7.2: Parameterization for average flux at an isobath (flat shelf). Panels (a) and (b) are for particular isobaths: $y / R=0,0.67$. Regression lines, diagnosed flux $=m Q+c$, are obtained using weighted least squares with weights being the inverse of the standard error. The black points are inviscid runs, blue points are viscid and red points are runs with a sloping shelf. Panel (c) shows the isobath dependence of the regression slope $m$ and $y$-intercept $c$ (Table 7.1). The red dashed curve is a Gaussian centered at the eddy center $y / R=1$.

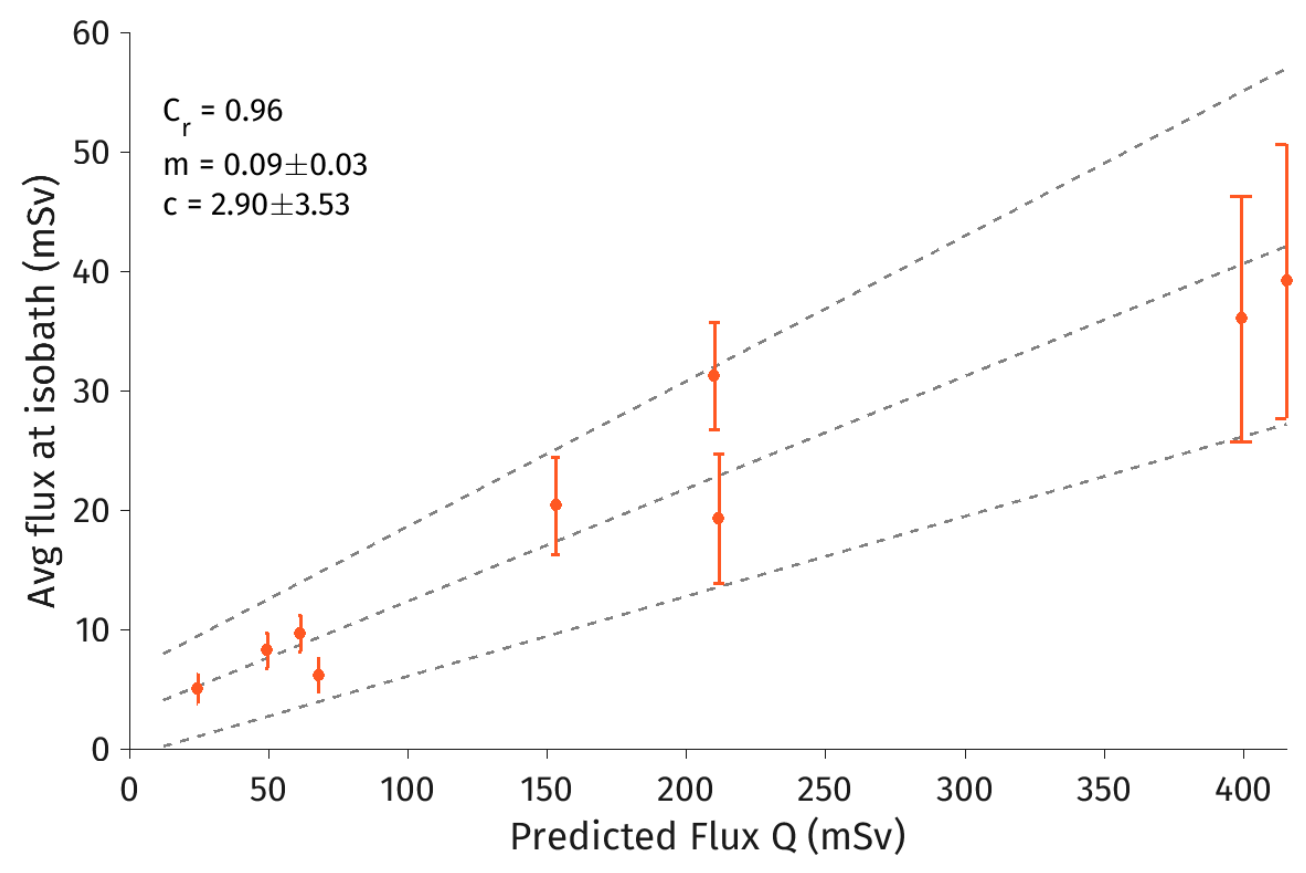

Figure 7.3: Parameterization for average flux at the shelfbreak for a sloping shelf. Regression lines, diagnosed flux $=m Q+c$, are obtained using weighted least squares with weights being the inverse of the standard error on the flux estimate. 
Table 7.1: Regression slopes at all isobaths for the average flux parameterization.

\begin{tabular}{cccccc}
\hline$y / R$ & 0 (sloping shelf) & 0 (flat shelf) & 0.16 & 0.33 & 0.5 \\
$m$ & $0.09 \pm 0.03$ & $0.19 \pm 0.03$ & $0.15 \pm 0.03$ & $0.21 \pm 0.04$ & $0.25 \pm 0.04$ \\
\hline$y / R$ & & 0.67 & 0.83 & 1 & 1.17 \\
$m$ & & $0.30 \pm 0.04$ & $0.33 \pm 0.04$ & $0.36 \pm 0.04$ & $0.39 \pm 0.04$ \\
\hline
\end{tabular}

ports. The water mass of interest here comprises parcels that originate onshore of a specified isobath. We make four assumptions:

a. The eddy's structure is well approximated by a Gaussian density anomaly in $(x, z) ; x$ being the along-isobath direction. In $y$, generally cross-isobath, the eddy's structure is complicated by the eddy adjusting to the slope - its form is determined later by regression.

b. Thermal wind balance is an accurate estimate of the vertical structure of the cross-shelf velocity field.

c. The eddy's core is bounded by the contour, $\left(x / L_{0}\right)^{2}+\left(z / L^{z}\right)^{2}=1$.

d. The eddy's center is always a radius away from the shelfbreak, radius being the Gaussian length scale $L_{0}$ (Section 3.2), so that $R=L_{0}$ in Figure 7.1. We ignore "loopiness" in the eddy tracks.

Our approach is to approximate velocity and dye fields similar to Figure 5.4 and integrate over them numerically. The steps are as follows:

1. Determine the eddy scales, $V_{0}, L_{0}, L^{z}$ when the eddy is at the shelfbreak (defined in Section 3.2). The time series of eddy scales can be noisy, particularly in $\left[t_{\text {start }}, t_{\text {stop }}\right]$. So, we choose to use the time average of $V_{0}, L_{0}, L^{z}$ over $t=\left[0, t_{\text {start }}\right]$.

2. Assuming that the eddy always remains Gaussian in the along-isobath plane, reconstruct the cross-isobath velocity field $V$ at $y=y_{0}$ using thermal wind balance (assumptions $\mathrm{a}, \mathrm{b}$ ):

$$
V\left(x, y_{0}, z\right)=(\sqrt{2 e}) V_{0} Y_{v}\left(y_{0}\right) \frac{x}{L_{0}} e^{-\left(x / L_{0}\right)^{2}}\left[1-\operatorname{erf}\left(-\frac{z}{L^{z}}\right)\right] .
$$

The eddy's center is at $(x, y)=(0,0)$. If the eddy was Gaussian in $y, Y_{v}=$ $e^{-\left(y_{0} / L_{0}\right)^{2}}$. However, the cross-isobath structure of the velocity field is modified by eddy being squeezed against the slope and spilling onto the shelf. We 
obtain best results by not assuming the Gaussian form for $Y_{v}$, which is left undetermined for now.

3. Construct a region $\Omega$ over which to integrate the assumed velocity field: the blue region in Figure 3.1. In the vertical, integrate from the desired depth, $z=-D$, to the surface. Further, assume that shelf water is only present outside the eddy's core and integrate over $\left(x / L_{0}\right)^{2}+\left(z / L^{z}\right)^{2} \geq 1$ (assumption c). Accounting for the "intrusion" in the eddy's side (Figure 5.5) does not improve the estimate.

$$
\Omega=\left\{(x, z) \mid-D \leq z \leq 0,\left(x / L_{0}\right)^{2}+\left(z / L^{z}\right)^{2} \geq 1\right\} .
$$

4. Numerically integrate the assumed velocity field over $\Omega$ to get a transport estimate, $T$ :

$$
\begin{aligned}
T\left(y_{0}\right) & =Y_{v}\left(y_{0}\right) Q\left(y_{0}\right) \\
& =Y_{v}\left(y_{0}\right)(\sqrt{2 e}) V_{0} \iint_{\Omega} \frac{x}{L_{0}} e^{-\left(x / L_{0}\right)^{2}}\left[1-\operatorname{erf}\left(-\frac{z}{L^{z}}\right)\right] \mathrm{d} x \mathrm{~d} z .
\end{aligned}
$$

$Q$ is the volume flux within $\Omega$, the blue region in Figure 3.1, at the latitude (cross-isobath location) of the eddy's center. $Q$ must be scaled down by $Y_{v}$ to obtain the actual transport $T$ at the desired latitude.

$Y_{v}\left(y_{0}\right)$ is determined empirically using 30 simulations with $0.1 \lesssim H_{\mathrm{sb}} / L^{z} \lesssim 0.4$ (Table A1). To do so, we regress the diagnosed transport above $z=-D=-H_{\mathrm{sb}}$, the "true" value of $T\left(y_{0}\right)$, against the overestimate, $Q\left(y_{0}\right)$, at different non-dimensional isobaths $y / R$. A weighted least squares regression determines the best fit and its 95\% confidence bounds:

$$
\text { diagnosed flux, } T=m Q+c .
$$

The weights used are the standard error of each average estimate. At all isobaths, the $y$-intercept of the regression line, $c$, includes 0 within its error bounds. Thus, $Y_{v}\left(y_{0}\right) \equiv m(y / R)$ by comparing (7.3) and (7.4). Now, $Y_{v}$ also includes errors associated with the choice of bounding contour for the eddy core, errors in the estimate of eddy scales and those associated with ignoring the apparent intrusion into the eddy. Thus $Y_{v}$ is not 1 at the latitude of the eddy's center. In Figure 7.2, the predicted overestimate $Q$ is compared against the diagnosed average transport at two non-dimensional isobaths: the shelfbreak $y / R=0$ and offshore of it, $y / R=0.67$. The latter is typical of all isobaths offshore of the shelfbreak. 
The variation of the regression slope $m\left(\equiv Y_{v}\right)$ with isobath $y / R$ reflects the shape of the eddy in the cross-isobath direction, decaying with distance away from the eddy's center (Figure 7.2c). The red dashed line in Figure 7.2c is a perfect Gaussian curve centered at $y / R=1$, the eddy center, and amplitude equal to the maximum value of $m$. The Gaussian decay captures much of the variation in $m$ - the eddy is very nearly Gaussian in the cross-isobath direction. However, the monotonic decrease of $m$ away from the eddy's center is interrupted at the shelfbreak. We have assumed that the eddy's center is one radius away from the shelfbreak (assumption d). This assumption is violated by the eddy spilling onto the shelf. $m(y / R)$ changes by less than $10 \%$ when changing the integration depth $D$.

For larger values of flux, the points are more uncertain and farther away from the line. These simulations have deeper shelves $(\lambda \sim 0.3)$ and /or stronger eddies (Ro $\sim 0.25)$ that spin up stronger cyclones. These cyclones advect the eddy away and toward the shelfbreak, making the flux time series noisier. For warm core rings, $\lambda \sim 0.1$ and Ro $\sim 0.15$ which places them near the center of each panel. Offshore of the shelfbreak, the presence of a shelf slope makes no difference, so those simulations are included in the appropriate panels (orange points). At all isobaths (not shown here), correlation coefficient $C_{r}$ between the diagnosed average flux and $Q$ is in the range $0.9-0.94$, significantly different from 0 at $99 \%$ confidence, and percentage errors are typically $10-25 \%$. 


\section{$8 \quad$ Discussion}

\subsection{Summary}

Wide continental slopes can prevent an eddy from reaching the shelfbreak (Figure 4.9 and Chapter 4). The governing constraint is the radiation of Rossby waves from the eddy. If efficient radiation is possible, the eddy can move into shallower water by radiating energy and reducing its vertical scale. If not, the eddy cannot reach the shelfbreak. For low-nonlinearity eddies, $R h=V_{0} /\left(\beta L^{2}\right) \lesssim 45$, only wide southern slopes ${ }^{1}$ can arrest an eddy's cross-isobath motion. Chapter 4 used the theorem of Flierl et al. (1983) to derive a scaling for the water depth at which the eddy's progress is arrested (equation 4.8). For high-nonlinearity eddies, $\mathrm{Rh} \gtrsim 45$, both western and southern coasts can arrest the eddy. These eddies are nonlinear enough that they do not radiate much energy and the reasoning that leads to (4.8) does not apply.

With narrow slopes, (slope width) $\lesssim$ (eddy diameter), the eddy always reaches the shelfbreak and strongly influences the shelf (Chapter 5). The anticylone raises SSH at shelfbreak setting up a generally barotropic offshore flow of shelf water, and a generally baroclinic onshore flow of eddy and slope waters (Figure 6.7). The crossshelfbreak flow have a horizontal scale of approximately an eddy radius. The exported shelf water originates from downstream of the eddy, in the coastal-trapped or Kelvin wave sense. It is supplied by an along-shelf gesotrophically balanced and dominantly barotropic jet of limited cross-shelf extent over the shelf (Figure 6.17 and 6.4). When at the shelfbreak, unstable waves are excited on the eddy's PV gradient as has been observed in eddy-wall interactions (Shi and Nof, 1993). There

\footnotetext{
${ }^{1}$ coast to the south
} 
are two waves: a cyclonic perturbation on the eddy's annulus and an anticyclonic perturbation on the eddy's core. The two are phase shifted in the horizontal so that they mutually amplify each other. The presence of shelf-slope topography introduces vertical structure because the bottom boundary condition is effectively a lateral boundary condition only below shelfbreak depth. The exported shelf water is advected over an unstable cyclonic perturbation on the eddy that exists below shelfbreak depth (Figure 5.7). As noted by Shi and Nof (1993), the unstable waves mutually amplify and grow to finite amplitude. The cyclonic perturbation then rolls up into a "stacked" cyclone with shelf water stacked over eddy water. The stacked cyclone then combines with water expelled from the eddy's core (the anticyclonic perturbation) to form dipoles. This process repeats forming a stream of dipoles behind the eddy (Figure 6.17).

Most notably, this thesis illustrates how results from greatly simplified models, such as those of McWilliams and Flierl (1979), LaCasce (1998) and Shi and Nof (1993), apply to a continuously stratified ocean with shelf-slope topography. Next, I address the implications of the presented results for the Mid-Atlantic Bight.

\subsection{Implications for the Middle Atlantic Bight}

\subsubsection{Interactions with the slope}

In the Mid-Atlantic Bight, the slope width is roughly $50 \mathrm{~km}$, smaller than a Gulf Stream warm-core ring diameter $(100 \mathrm{~km})$, and the coast is either to the north or to the west of the eddy. Where the coast is to the north, $\beta$-plane translation and the mean southwestward background flow move warm-core rings away from the coast. Where the coast is to the west, warm-core rings are always expected to get to the shelfbreak and move northward parallel to the shelfbreak (Chapter 4). Satellite images, such as Figure 1.1, make it clear that warm-core rings generally translate southwestward after they are spawned. The southwestward translation persists even when the ring's edge is quite close to the shelfbreak. Such behaviour is contrary to that seen in all simulations, where the eddy always moves in the "imageeffect direction" viz., northward for a western coast and westward for a southern coast. The southwestward motion is likely indicative of a general southwestward mean flow off the Mid-Atlantic Bight advecting the eddies as in Cornillon et al. (1989).

In the experiments here, the $\beta$-plane continuously forces the eddy into the to- 
pography, the eddy always gets to the shelfbreak, and the eddy-slope interaction is always severe. In the real ocean, such severe interaction need not happen for two reasons. One, a substantial part of the Mid-Atlantic Bight has a coast to the north, meaning warm-core rings are likely to move away from the coast. Two, the presence of other rings, background mean flows and a meandering Gulf Stream makes the trajectory of actual warm core rings far more complicated than that solely determined by $\beta$-plane translation (Cornillon et al., 1989). Thus the presented scalings for length scales and transports are likely over-estimates. Indeed, offshore transport of shelf water persisted only for 6 days in the data assimilative solution of Chen et al. (2014). In the experiments here, the timescale is $\mathrm{O}$ (50 days) for the simulations with bottom friction (Figure 6.15). The difference is likely due to external influences on the ring's trajectory (Cornillon et al., 1989). For example, moorings deployed during the Nantucket Shoals Flux Experiment (Beardsley et al., 1985) ${ }^{2}$ sampled three warm-core rings passing near or through the moored array. The rings forced substantial velocities at the $200 \mathrm{~m}$ isobath i.e., the upper slope. No such influence was observed at moorings inshore of the shelfbreak. Presumably, the ring was too far offshore of the shelfbreak to affect the shelf.

Chapter 5 studied eddy-slope interaction for the parameter range $0.14 \leq \lambda=$ $H_{\mathrm{sb}} / L^{z} \leq 0.4$. Depending on choices, $\lambda$ for Gulf Stream warm-core rings at the MidAtlantic Bight seems to be between 0.1 and 0.2 . For $\lambda \lesssim 0.1$, the eddy develops small scale instability waves at its edge that later develop into multiple secondary cyclones (Figures 5.13a and 8.2). Such behaviour does occur in the real ocean. Ramp et al. (1983) studied what appear to be instability waves, similar to those in Figure 5.13a, in SST images and attributed them to the barotropic instability resulting from the enhanced shear between the ring flow and the shelfbreak front jet. Two small scale cyclones are present at a ring's edge in the top-right corner of Figure 8.1, similar to those in Figure 8.2. Further work is required to clarify the nature of the instability, whether the presence of a shelfbreak front affects the instability, and parameterize the cross-shelfbreak transport in such cases. The simulations still exhibit a subsurface peak in offshore transport of shelf water for $\lambda \lesssim 0.1$, so one still expects to observe the formation of stacked cyclones off the Mid-Atlantic Bight. However, there aren't any reported observations of stacked cyclones or dipoles over the continental slope even though multiple such dipoles are formed in every simulation. Again, the simulations describe severe interaction between the eddy and topography that is likely rare, due to external influences on the ring's trajectory.

\footnotetext{
${ }^{2}$ a cross-shelf line south of Nantucket island (approximately $70^{\circ} \mathrm{W}$ )
} 


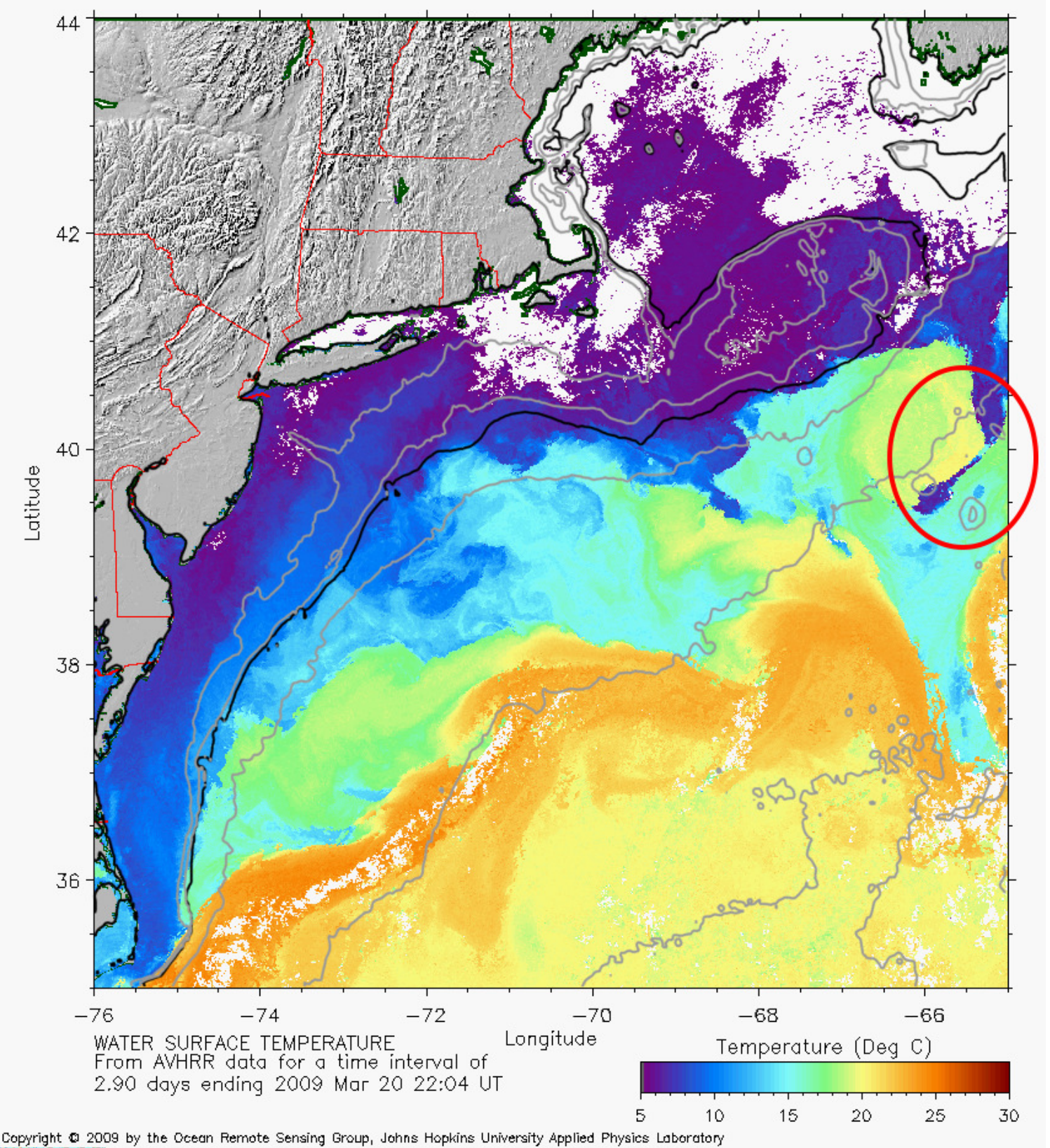

Copyright 2009 by the Ocean Remote Sensing Group, Johns Hopkins University Applied Physics Laboratory

Figure 8.1: Instability waves on the eddy (top right) in an AVHRR image from JHU APL, modified to include topographic contours. The waves appear similar to those in Figure 8.2 for $\lambda \sim 0.1$. 


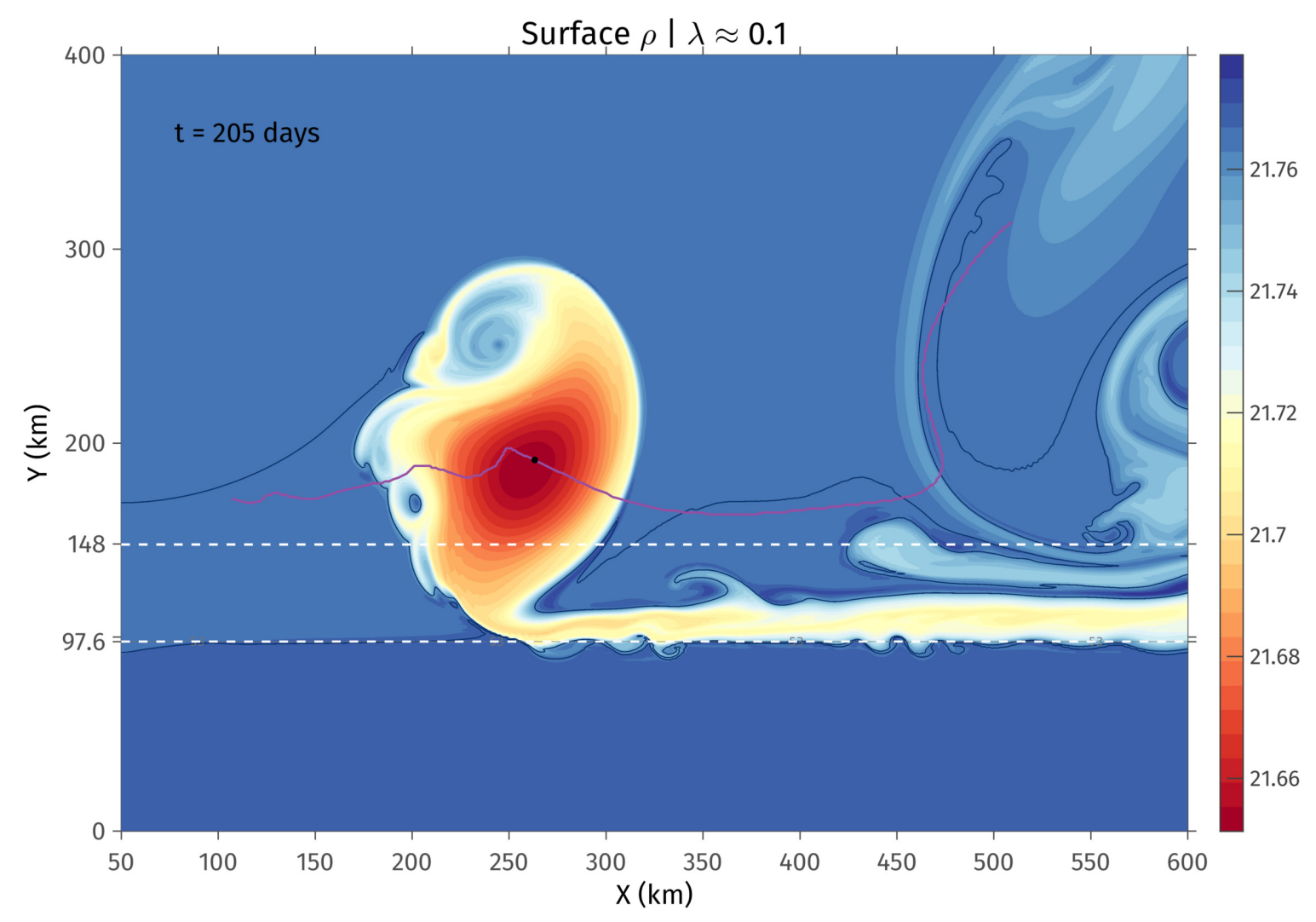

Figure 8.2: Multiple wavelengths of a finite amplitude instability wave on an eddy visible in a snapshot of surface density. The simulation is the same as the one in Figure 5.13a. Compare to the SST image in Figure 8.1.

\subsubsection{Shelf flows and cross-shelfbreak fluxes}

In the Mid-Atlantic Bight shelf, $\alpha_{\mathrm{sh}} \approx 10^{-3} \mathrm{~m} \mathrm{~m}^{-1}, N \approx 10^{-2} \mathrm{~s}^{-1}$ and $H_{\mathrm{sb}} \approx 100 \mathrm{~m}$. A typical warm-core ring velocity is $\mathrm{O}\left(2 \mathrm{~m} \mathrm{~s}^{-1}\right)$. With these choices, $L_{\beta}$ is approximately $45 \mathrm{~km}$ and the eddy water inflow is expected to penetrate approximately $1.4 \mathrm{NH}_{\mathrm{sb}} / f_{0} \approx 14 \mathrm{~km}$ inshore of the shelfbreak. These length scales are an average estimate. Further,

$$
\varphi_{o}=\frac{S_{\mathrm{sh}} N H_{\mathrm{sb}}}{V_{0}}=\frac{0.1 \times 10^{-2} \times 100}{1.5} \approx 0.06 .
$$

The estimated $\varphi_{o}$ predicts that shelf water outflow should be barotropic and that the shelf water supply jet should scale like $L_{\beta} \approx 45 \mathrm{~km}$.

The drifter observations of Brink et al. (2003) indicate that shelf water between the surface and at least $40 \mathrm{~m}$ depth is exported by warm-core rings at the shelfbreak off George's Bank (Figure 1.1). The most onshore drifter that crossed the 
shelfbreak started at the $60 \mathrm{~m}$ isobath, roughly $50 \mathrm{~km}$ inshore of the shelfbreak. Lee and Brink (2010) observed that the ring managed to affect the entire shelf water column, $\leq 100 \mathrm{~m}$ deep. The warm eddy water intrusion on to the shelf extends nearly to the bottom in some places and the associated velocity field was surface intensified "with little or no flow near the bottom". The latter is as expected since $S_{\mathrm{sl}}>1$ for the continental slope off the Mid-Atlantic Bight. Lee and Brink (2010) also show a filament of ring water that appears to have penetrated roughly $25-40 \mathrm{~km}$ inshore of the $100 \mathrm{~m}$ isobath, much larger than the predicted estimate of $14 \mathrm{~km}$ based on the shelf Rossby radius. One cannot however rule out external influences: wind driven Ekman transport, shelfbreak front instabilities etc. More recently, Zhang and Gawarkiewicz (2015) observed warm-core ring water intruding approximately $20 \mathrm{~km}$ inshore of the $100 \mathrm{~m}$ isobath. Waters with ring density extend nearly to the bottom just as in Figure 6.2 and Lee and Brink (2010). With the exception of Lee and Brink (2010)'s observation of eddy water at the $60 \mathrm{~m}$ isobath, the observations are generally consistent with the predictions based on the results in Section 6.4. The most dramatic prediction is that the vertical structure of the outflow and inflow at the Mid-Atlantic Bight shelfbreak are quite different: a barotropic outflow and a baroclinic inflow. Though some observational evidence exists, the predictions need to tested with repeated along-shelf sections at the Mid-Atlantic Bight shelfbreak.

Using the ADCP observations of warm-core ring 99C in Wei et al. (2008), $V_{0}=$ $1.2 \mathrm{~m} \mathrm{~s}^{-1}$ and a radius to maximum velocity of $45 \mathrm{~km}$. The recipe of Chapter 7 requires a Gaussian length scale $L_{0}$ (Section 3.2). For a Gaussian density anomaly, the radius to maximum velocity is $L_{0} / \sqrt{2}$, so we use $L_{0}=45 \sqrt{2} \mathrm{~km} \approx 65 \mathrm{~km}$. We assume $L_{z}$ to be $1000 \mathrm{~m}$ based on observations in Joyce (1984, Figure 10). With these choices, the parameterization in (7.3) predicts an average offshore transport of $0.3 \mathrm{~Sv}$ across the shelfbreak, if the ring is at the shelfbreak (Chapter 7). Joyce and Kennelly (1985) report $V_{0}=1.8 \mathrm{~m} \mathrm{~s}^{-1}$ and $L_{0}=100 \mathrm{~km}$. Equation (7.3) then predicts an offshore flux of $0.7 \mathrm{~Sv}$. These values are approximately the same magnitude or much larger than the mean along-isobath flow on the shelf (less than $0.5 \mathrm{~Sv}$ onshore of the shelfbreak, Lentz, 2008) and the mean transport in the shelfbreak front (0.24-0.45 Sv, Linder and Gawarkiewicz, 1998). So, if a ring is at the shelfbreak, there should be a large perturbation to the shelf flow near the shelfbreak.

This thesis has ignored the presence of a shelfbreak front, a major flow feature in the Mid-Atlantic Bight. Because the shelfbreak front tilts and outcrops offshore of the shelfbreak, there is shelf water offshore of the shelf. A ring need not be at the shelfbreak for it to transport shelf water (Figure 1.1). The value of $0.3 \mathrm{~Sv}$ or 
$0.7 \mathrm{~Sv}$ is thus an over-estimate of average cross-shelfbreak transport. Given the much larger velocity and vorticity signatures of the eddy, it is likely that the front is not a substantial barrier to the offshore flow imposed by the eddy. Indeed, Cenedese et al. (2013) observed that the jet associated with the shelfbreak front had both reversed direction and increased transport magnitude from $0.29 \mathrm{~Sv}$ to $0.39 \mathrm{~Sv}$ during a period of ring interaction. Their lab experiments too showed that strong eddies, those with a velocity scale larger than that of the shelfbreak jet (e.g. Gulf Stream warm-core rings), extracted water from inshore of the shelfbreak jet maximum. Thus one still expects to see a subsurface maximum in offshore transport of shelf water, because the mechanism responsible is triggered by the eddy-topography interaction.

At the Mid-Atlantic Bight, existing observations (for e.g., Gawarkiewicz et al., 2001; Zhang and Gawarkiewicz, 2015) do indicate that the front moves inshore where the eddy forces an inflow. The front apparently does not prevent eddy water from crossing on to the shelf, so our results should still be applicable at least when the eddy is at the shelfbreak. Whether the onshore transport of eddy water matters to shelf water ${ }^{3}$ budgets depends on whether the leaked eddy water can break through the front. This hypothesis will need to be checked with higher resolution $(200-500 \mathrm{~m})$ model runs that are capable of resolving the baroclinic instability of the front.

The volume budget of Brink (1998) for the Mid-Atlantic Bight requires an offshore flux of shelf water in the range of $0.04-0.11 \mathrm{~Sv}$. Over a year, this exports a volume of $1.3 \times 10^{12}-3.5 \times 10^{12} \mathrm{~m}^{3}$ corresponding to 50 to 130 days of ring interaction with the shelf, assuming again, that the eddy is right at the shelfbreak and transports on average $0.3 \mathrm{~Sv}$ of water throughout the interaction. Halliwell and Mooers (1979) estimated that an average of 3-5 eddies affected the shelfbreak front every year with a residence time of 2-3 weeks, which is at most a 100 days of eddy-front interaction. On the other hand, Garfield and Evans (1987), using 7 years of SST imagery, estimate that streamers are observed $70 \%$ of the time, roughly 250 days a year. All this reinforces that the $0.3 \mathrm{~Sv}$ estimate is likely an overestimate and that identifying a shelf water streamer in satellite observations does not require that the ring significantly interact with the shelf (Figure 1.1 and Beardsley et al., 1985)

\footnotetext{
${ }^{3}$ defined as a density class and not as water inshore of the shelfbreak
} 


\subsection{Limitations and extensions}

A lot remains to be done. Some particular areas that have been highlighted are:

Radiation of waves from highly nonlinear eddies: The behaviour of high Rh eddies in Chapter 4 needs to be rationalized.

Ring edge instability waves: Shi and Nof (1993) attribute the spin up of secondary cyclones to unstable waves on the eddy's PV gradient while Dewar and Hogg (2010) attribute it to hydraulic arrest of topographic wave modes. The relation between the two needs to be clarified. The dependence of instability wavelength on $\lambda$ might explain the presence of small-scale waves at the ring's edge (Figures 5.13a, 8.1 and Ramp et al. 1983).

Shelfbreak fronts: High resolution simulations capable of resolving the instability of shelfbreak fronts are needed to clarify the extent to which the results of this thesis are still applicable in the presence of such unstable fronts and their associated eddies (Garvine et al., 1989; Gawarkiewicz et al., 2001).

Flux timescale: A major feature of the conducted simulations is that eddies can spend large amounts of time, $\mathrm{O}$ (50 days), at the shelfbreak in the absence of external factors. This is in stark contrast to the approximately 6 day timescale in Chen et al. (2014). For the coastal oceanographer, an appropriate next step would be to run idealized numerical experiments with an actively unstable offshore current that spawns eddies as in Zhang (2009) and Stewart and Thompson (2015). Such experiments, though computationally expensive, would help constrain the magnitude and timescale of the cross-shelfbreak flux under a less severe set of assumptions. By accounting for one source of variability in the ocean, they will also help assess the relevance of the single eddy simulations to the real ocean.

Section 8.2 attempted to reconcile predictions and the limited set of existing observations for the Mid-Atlantic Bight. Such analysis should be conducted for other parts of the world ocean, assuming that relevant observations exist. Indeed, the low number of observations is currently the biggest hurdle to further progress.

One striking prediction of these simulations is the existence of stacked cyclones and dipoles over the continental slope and in the deep ocean. It might be fruitful to search through the historical hydrographic database and Argo data for profiles 
with shelf water (salinity $S<32$ ) near surface and ring water below $(S>35.5)$ at depth. However, these datasets will not indicate whether the profiles are associated with coherent cyclonic structures. One expects to see dipoles in satellite imagery, yet no such reports exist. Again, this might be connected to external influences on the eddy's trajectory reducing the severity of the eddy-slope interaction. Another avenue for observational testing might be to look at historical mooring deployments on the shelf. The simulations predict a major perturbation to shelf flows when a ring is present. Such perturbations should be visible in moorings downstream (coastal trapped wave sense) of the eddy.

Fully verifying the results presented here requires an extensive field campaign similar to the Warm Core Rings Experiment of 1983, now more than thirty years old. Despite the subject's unpredictable nature and associated logistical difficulties, a successor seems fully warranted. 
A Simulation parameters 


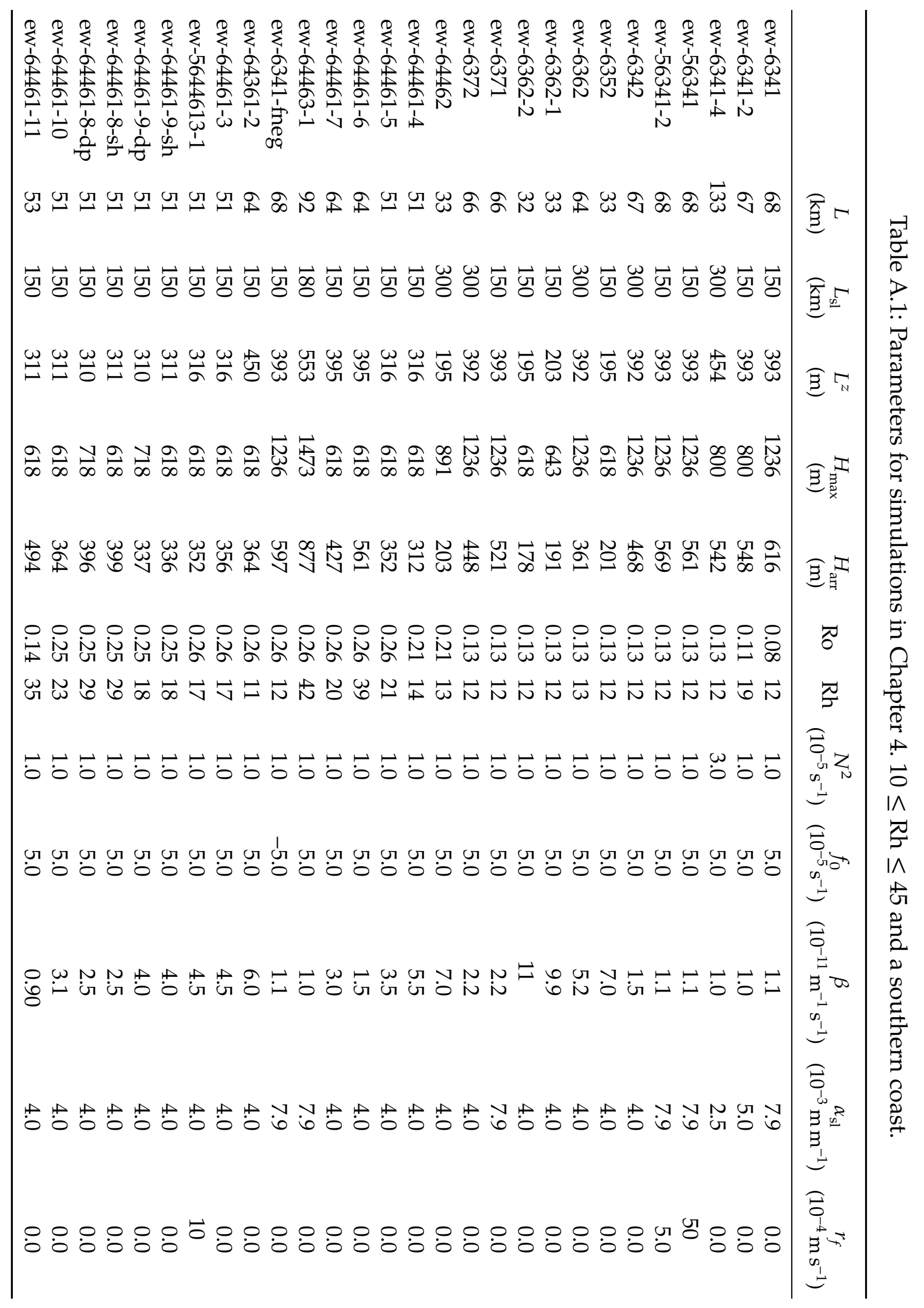




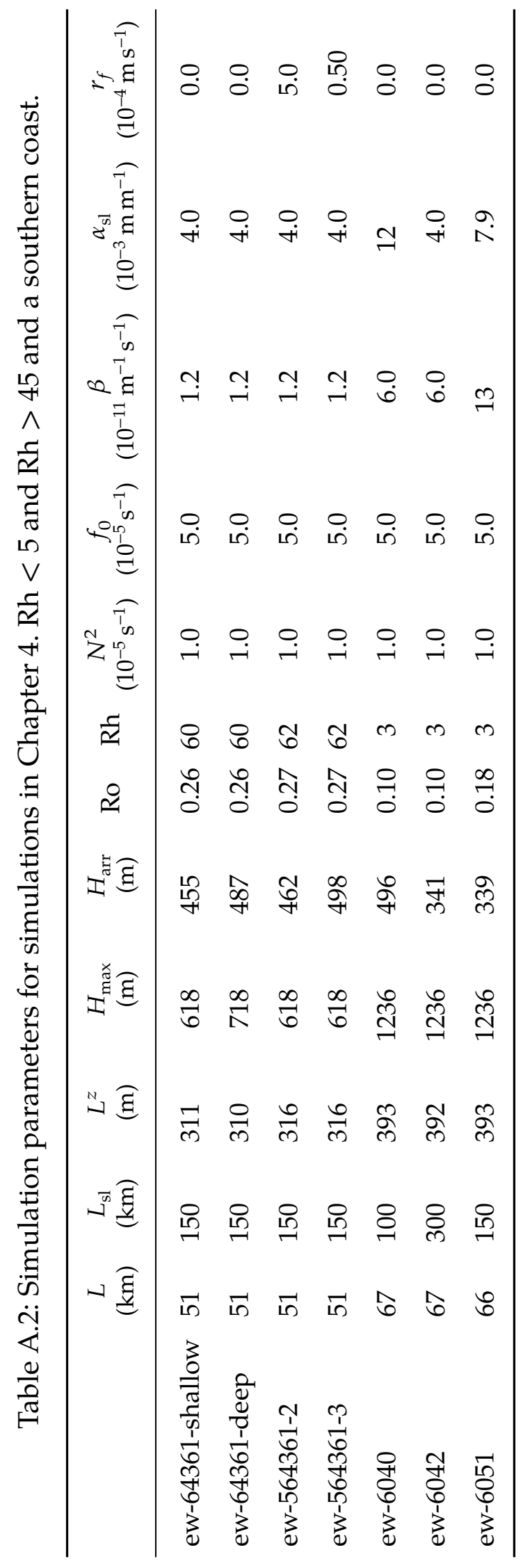




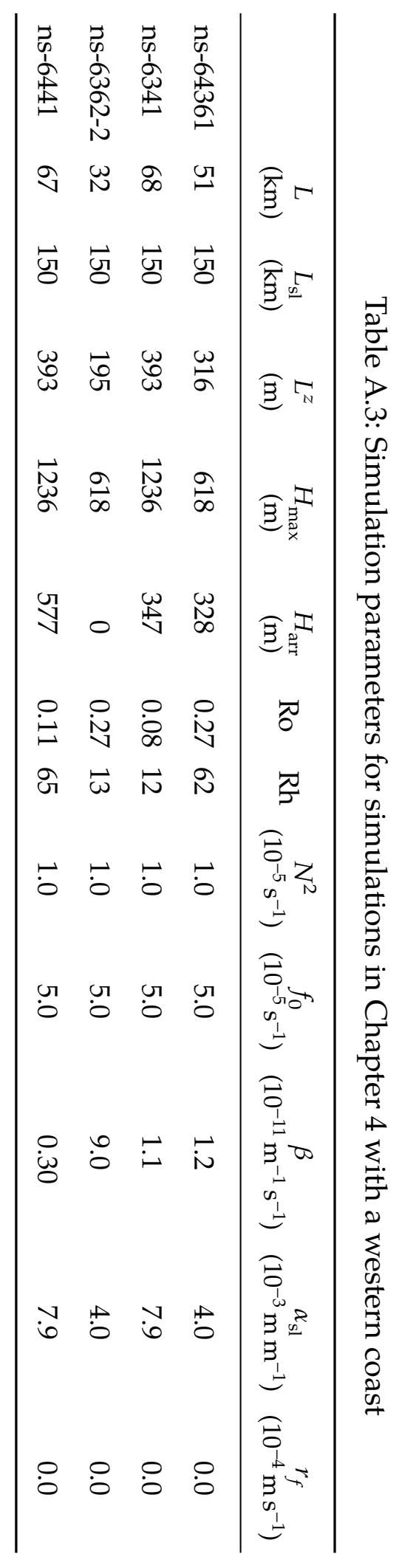


Table A.4: Simulation parameters for Chapter 5.

\begin{tabular}{|c|c|c|c|c|c|c|c|c|c|c|c|c|}
\hline & $\begin{array}{c}L \\
(\mathrm{~km})\end{array}$ & $\begin{array}{l}L_{z} \\
(\mathrm{~m})\end{array}$ & Ro & $\lambda$ & $\begin{array}{c}L_{\mathrm{sh}} \\
(\mathrm{km})\end{array}$ & $\begin{array}{c}L_{\mathrm{sl}} \\
(\mathrm{km})\end{array}$ & $S_{\mathrm{sh}}$ & $S_{\mathrm{sl}}$ & $\begin{array}{c}N^{2} \\
\left(10^{-5} \mathrm{~s}^{-1}\right)\end{array}$ & $\begin{array}{c}f_{0} \\
\left(10^{-5} \mathrm{~s}^{-1}\right)\end{array}$ & $\begin{array}{c}\beta \\
\left(10^{-11} \mathrm{~m}^{-1} \mathrm{~s}^{-1}\right)\end{array}$ & $\begin{array}{c}r \\
\left(10^{-4} \mathrm{~m} \mathrm{~s}^{-1}\right)\end{array}$ \\
\hline ew-04 & 82 & 261 & 0.10 & 0.20 & 40 & 50 & 0.00 & 1.50 & 1.0 & 5.0 & 6.0 & 0.0 \\
\hline ew-05 & 81 & 292 & 0.18 & 0.18 & 40 & 50 & 0.00 & 1.50 & 1.0 & 5.0 & 6.0 & 0.0 \\
\hline ew-06 & 81 & 300 & 0.26 & 0.18 & 40 & 50 & 0.00 & 1.50 & 1.0 & 5.0 & 6.0 & 0.0 \\
\hline ew-34 & 76 & 344 & 0.10 & 0.15 & 40 & 50 & 0.00 & 1.50 & 1.0 & 5.0 & 1.5 & 0.0 \\
\hline ew-35 & 73 & 334 & 0.19 & 0.16 & 40 & 50 & 0.00 & 1.50 & 1.0 & 5.0 & 3.0 & 0.0 \\
\hline ew-36 & 72 & 321 & 0.27 & 0.16 & 40 & 50 & 0.00 & 1.50 & 1.0 & 5.0 & 5.0 & 0.0 \\
\hline ew-37 & 69 & 343 & 0.14 & 0.15 & 40 & 50 & 0.00 & 1.50 & 1.0 & 5.0 & 2.2 & 0.0 \\
\hline ew-6370 & 73 & 343 & 0.15 & 0.15 & 40 & 50 & 0.00 & 0.75 & 1.0 & 5.0 & 2.2 & 0.0 \\
\hline ew-2340 & 75 & 356 & 0.10 & 0.29 & 40 & 50 & 0.00 & 1.50 & 1.0 & 5.0 & 1.5 & 0.0 \\
\hline ew-2345 & 76 & 346 & 0.10 & 0.22 & 40 & 50 & 0.00 & 1.50 & 1.0 & 5.0 & 1.5 & 0.0 \\
\hline ew-2360 & 72 & 349 & 0.24 & 0.30 & 150 & 50 & 0.00 & 1.50 & 1.0 & 5.0 & 5.0 & 0.0 \\
\hline ew-2365 & 67 & 330 & 0.26 & 0.24 & 75 & 50 & 0.00 & 1.50 & 1.0 & 5.0 & 5.0 & 0.0 \\
\hline ew-23340 & 96 & 485 & 0.10 & 0.15 & 40 & 70 & 0.00 & 1.50 & 1.0 & 5.0 & 1.0 & 0.0 \\
\hline ew-24340 & 86 & 432 & 0.11 & 0.19 & 75 & 50 & 0.00 & 1.50 & 1.0 & 5.0 & 1.0 & 0.0 \\
\hline ew-4040 & 92 & 340 & 0.10 & 0.15 & 40 & 50 & 0.00 & 1.50 & 1.0 & 5.0 & 4.0 & 0.0 \\
\hline ew-4050 & 136 & 376 & 0.17 & 0.14 & 40 & 50 & 0.00 & 1.50 & 1.0 & 5.0 & 4.0 & 0.0 \\
\hline ew-4343 & 41 & 165 & 0.00 & 0.32 & 40 & 50 & 0.00 & 1.50 & 1.0 & 5.0 & 2.9 & 0.0 \\
\hline ew-5341 & 72 & 340 & 0.10 & 0.15 & 40 & 50 & 0.00 & 1.50 & 1.0 & 5.0 & 1.5 & 50 \\
\hline ew-5343 & 70 & 339 & 0.10 & 0.15 & 40 & 50 & 0.00 & 1.50 & 1.0 & 5.0 & 1.5 & 5.0 \\
\hline ew-5040 & 93 & 259 & 0.10 & 0.20 & 40 & 50 & 0.00 & 1.50 & 1.0 & 5.0 & 6.0 & 10 \\
\hline
\end{tabular}


Continued from previous page

\begin{tabular}{|c|c|c|c|c|c|c|c|c|c|c|c|c|}
\hline & $\begin{array}{c}L \\
(\mathrm{~km})\end{array}$ & $\begin{array}{l}L_{z} \\
(\mathrm{~m})\end{array}$ & Ro & $\lambda$ & $\begin{array}{c}L_{\mathrm{sh}} \\
(\mathrm{km})\end{array}$ & $\begin{array}{c}L_{\mathrm{sl}} \\
(\mathrm{km})\end{array}$ & $S_{\text {sh }}$ & $S_{\mathrm{sl}}$ & $\begin{array}{c}N^{2} \\
\left(10^{-5} \mathrm{~s}^{-1}\right)\end{array}$ & $\begin{array}{c}f_{0} \\
\left(10^{-5} \mathrm{~s}^{-1}\right)\end{array}$ & $\begin{array}{c}\beta \\
\left(10^{-11} \mathrm{~m}^{-1} \mathrm{~s}^{-1}\right)\end{array}$ & $\begin{array}{c}r \\
\left(10^{-4} \mathrm{~m} \mathrm{~s}^{-1}\right)\end{array}$ \\
\hline ew-5041 & 92 & 260 & 0.10 & 0.20 & 40 & 50 & 0.00 & 1.50 & 1.0 & 5.0 & 6.0 & 50 \\
\hline ew-8041 & 79 & 270 & 0.10 & 0.19 & 40 & 50 & 0.05 & 1.50 & 1.0 & 5.0 & 6.0 & 0.0 \\
\hline ew-8042 & 154 & 274 & 0.10 & 0.18 & 40 & 100 & 0.10 & 1.50 & 4.0 & 5.0 & 3.0 & 0.0 \\
\hline ew-8352 & 134 & 245 & 0.15 & 0.28 & 70 & 70 & 0.10 & 1.00 & 1.0 & 2.0 & 0.35 & 0.0 \\
\hline ew-583411 & 68 & 344 & 0.11 & 0.15 & 40 & 50 & 0.05 & 1.50 & 1.0 & 5.0 & 1.5 & 30 \\
\hline ew-583413 & 69 & 344 & 0.11 & 0.15 & 40 & 50 & 0.05 & 1.50 & 1.0 & 5.0 & 1.5 & 5.0 \\
\hline ew-8383 & 180 & 350 & 0.12 & 0.37 & 70 & 70 & 0.15 & 1.00 & 1.0 & 3.0 & 0.50 & 0.0 \\
\hline
\end{tabular}




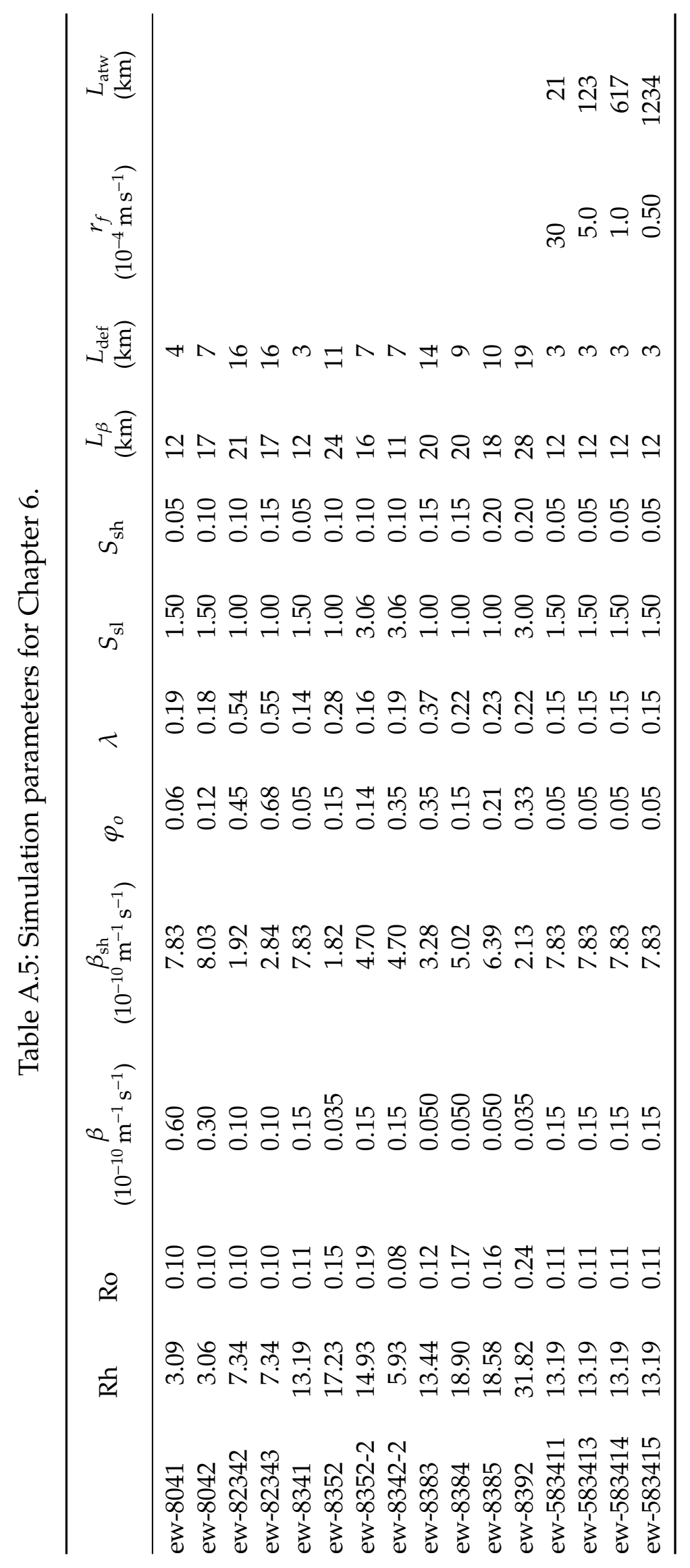




\section{B When can an eddy cross the shelfbreak?}

A few simluations were conducted to examine when an eddy can cross the shelfbreak and onto the shelf. They are similar to those in Kamenkovich et al. (1996) and Beismann et al. (1999). Motivated by Aghulas eddies interacting with Walvis Ridge off Namibia, those papers studied whether eddies could cross a subsurface ridge. Both studies indicated that the controlling parameter is the vertical scale of the eddy relative to the height of the ridge. So, here the parameter varied is $\lambda=H_{\mathrm{sb}} / L^{z}$.

To avoid interactions with the coastal wall, the shelf is a lot wider $(150 \mathrm{~km} \sim$ $2 \times$ eddy radius) in these runs. Only the shelfbreak depth is varied and the slopes are kept narrow ( $\sim$ eddy radius). Upon changing $\lambda$, the nature of the interaction changes dramatically (Figure B.1):

- when $\lambda \sim 0.25$, the eddy leaks fluid as an along-shelf jet,

- when $\lambda \sim 0.36$ or 0.65 , the eddy splits into two across the "ridge", and

- when $\lambda \sim 1$, the eddy crosses the shelfbreak without any major splitting and a slight deviation in track.

As one might have expected, an eddy can only completely cross on to the shelf when the shelf is deeper than the eddy's vertical scale. In other cases, the eddy splits across the shelfbreak or leaks water along-shelf. 


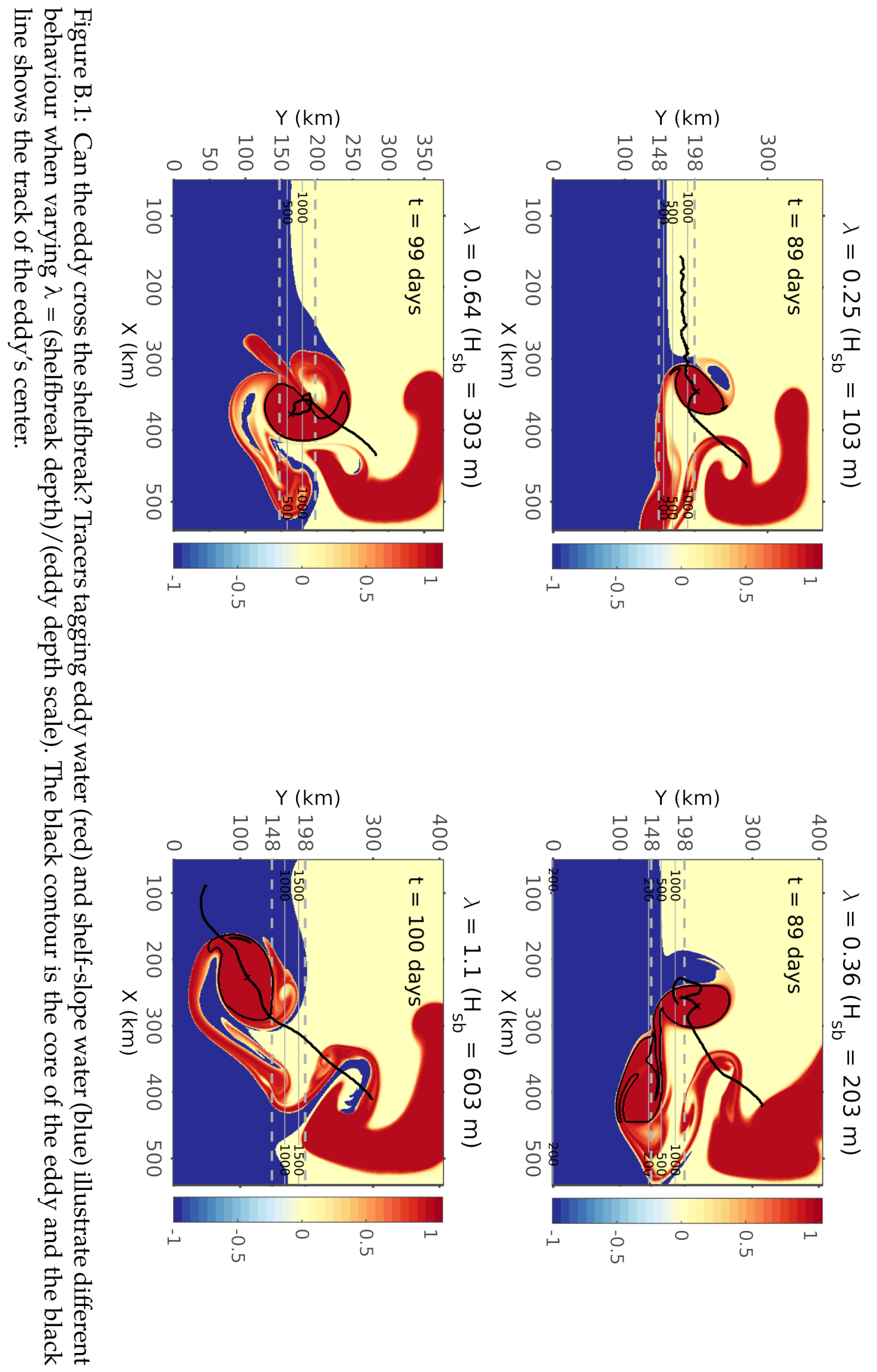




\section{ROMS configuration}

The ROMS model was modified to allow the use of harmonic and biharmonic mixing at the same time. The code is available upon request.

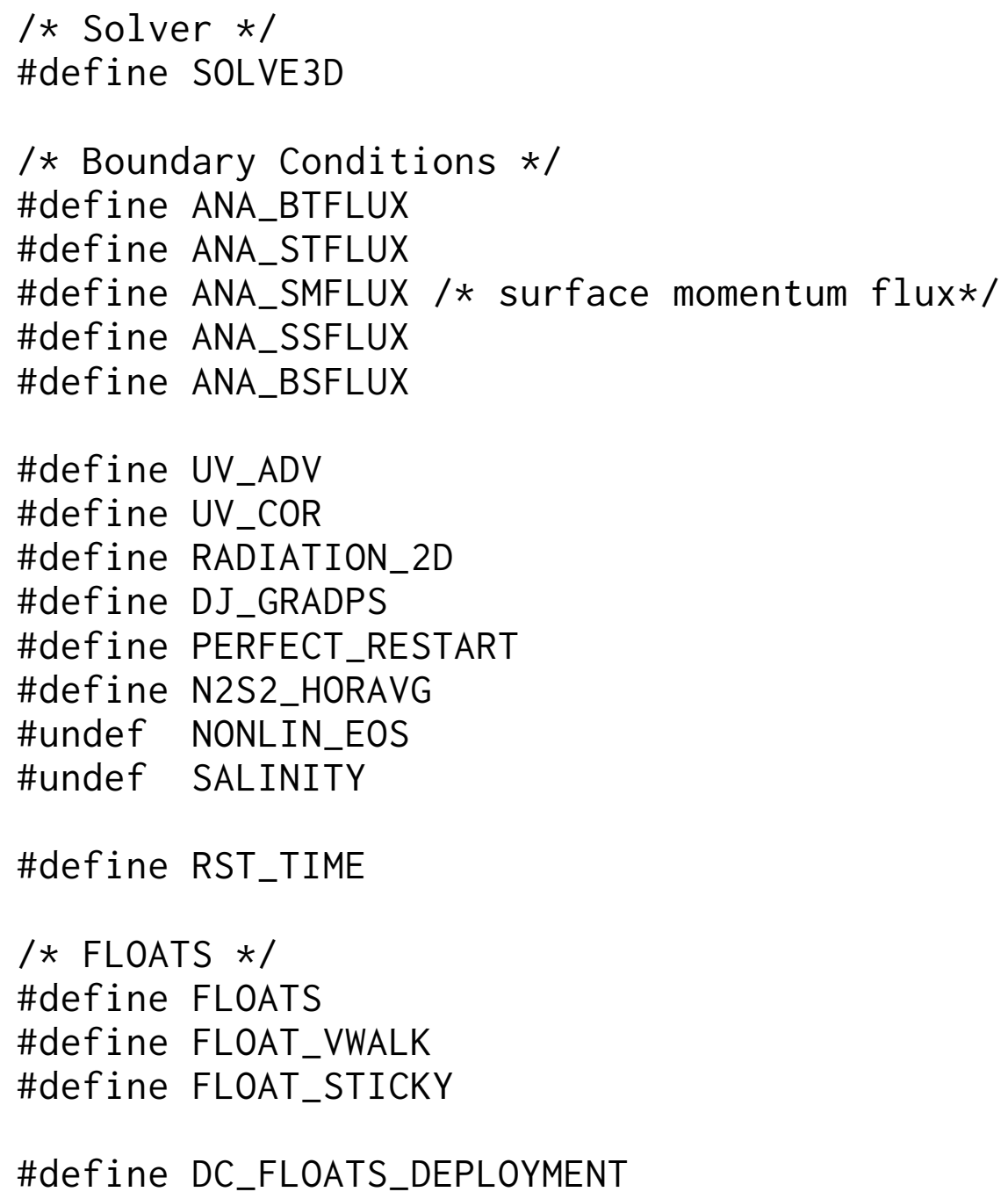




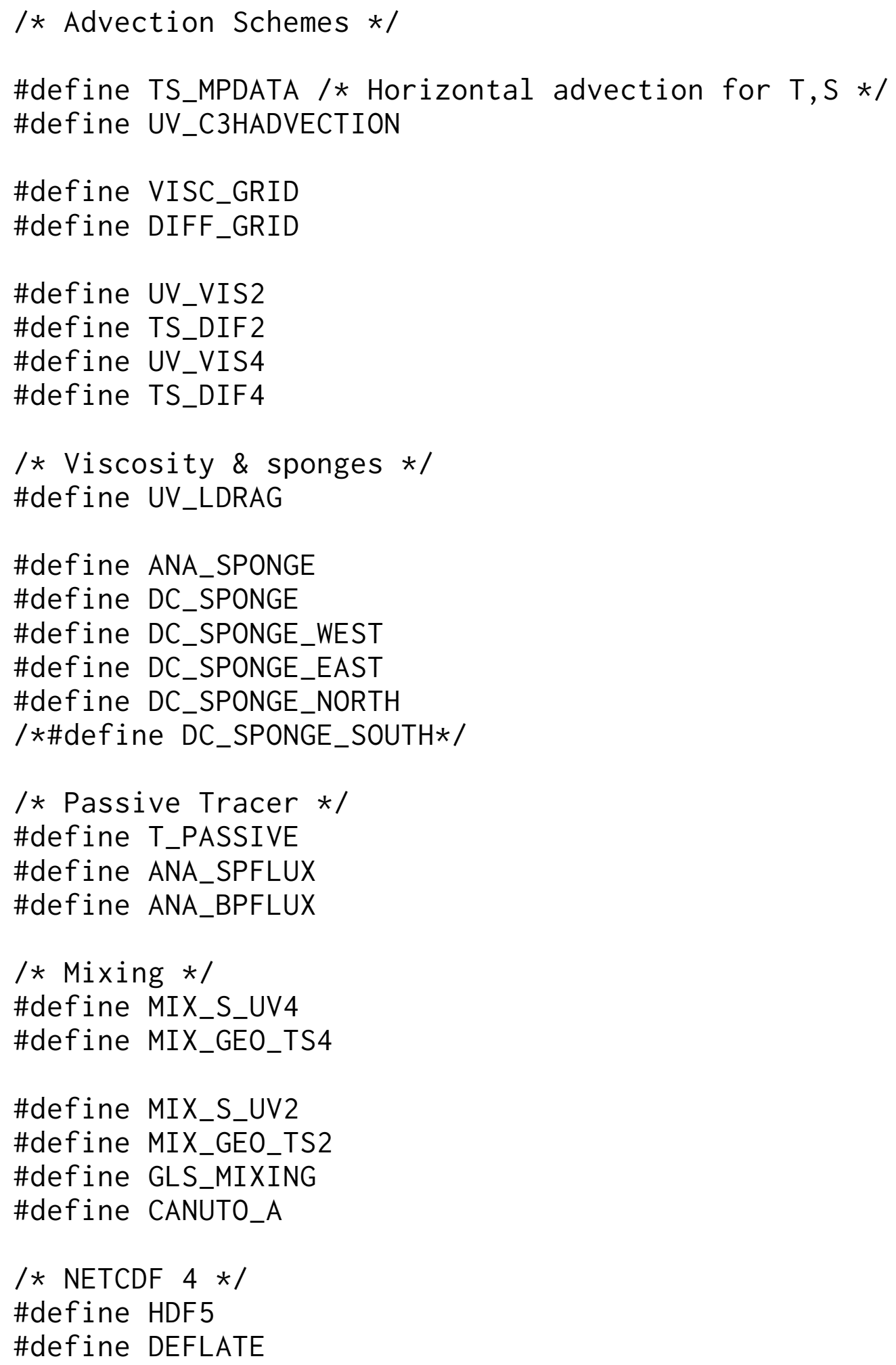




\section{References}

Andres, M., Cenedese, C., 2013. Laboratory experiments and observations of cyclonic and anticyclonic eddies impinging on an island. J. Geophys. Res. Ocean. 118 (2), 762-773.

Baker-Yeboah, S., Byrne, D. A., Watts, D. R., 2010. Observations of mesoscale eddies in the South Atlantic Cape Basin: Baroclinic and deep barotropic eddy variability. J. Geophys. Res. 115 (C12), C12069.

Beardsley, R. C., Chapman, D. C., Brink, K. H., Ramp, S. R., Schlitz, R. J., 1985. The Nantucket Shoals Flux Experiment (NSFE79). Part I: A Basic Description of the Current and Temperature Variability. J. Phys. Oceanogr. 15 (6), 713-748.

Beismann, J.-O., Käse, R. H., Lutjeharms, J. R. E., 1999. On the influence of submarine ridges on translation and stability of Agulhas rings. J. Geophys. Res. 104 (C4), 7897.

Bisagni, J. J., 1983. Lagrangian Current Measurements within the Eastern Margin of a Warm-Core Gulf Stream Ring. J. Phys. Oceanogr. 13 (4), 709-715.

Brink, K. H., 1998. Deep Sea Forcing and Exchange Processes. In: Brink, K. H., Robinson, A. R. (Eds.), Sea. Vol. 10. John Wiley \& Sons, Inc., Ch. 6, pp. 151-167.

Brink, K. H., 2012. Buoyancy Arrest and Shelf-Ocean Exchange. J. Phys. Oceanogr. $42(4), 644-658$.

Brink, K. H., Limeburner, R., Beardsley, R. C., 2003. Properties of flow and pressure over Georges Bank as observed with near-surface drifters. J. Geophys. Res. 108 (C11).

Brink, K. H., Seo, H., 2016. Continental Shelf Baroclinic Instability. Part II: Oscillating Wind Forcing. J. Phys. Oceanogr. 46 (2), 569-582.

Cenedese, C., Todd, R. E., Gawarkiewicz, G. G., Owens, W. B., Shcherbina, A. Y., 2013. Offshore Transport of Shelf Waters through Interaction of Vortices with a Shelfbreak Current. J. Phys. Oceanogr. 43 (5), 905-919. 
Chapman, D. C., Brink, K. H., 1987. Shelf and slope circulation induced by fluctuating offshore forcing. J. Geophys. Res. 92 (C11), 11741.

Chaudhuri, A. H., Bisagni, J. J., Gangopadhyay, A., 2009. Shelf water entrainment by Gulf Stream warm-core rings between $75^{\circ} \mathrm{W}$ and $50^{\circ} \mathrm{W}$ during $1978-1999$. Cont. Shelf Res. 29 (2), 393-406.

Chelton, D. B., Schlax, M. G., Samelson, R. M., 2011. Global observations of nonlinear mesoscale eddies. Prog. Oceanogr. 91 (2), 167-216.

Chen, K., He, R., Powell, B. S., Gawarkiewicz, G. G., Moore, A. M., Arango, H. G., 2014. Data assimilative modeling investigation of Gulf Stream Warm Core Ring interaction with continental shelf and slope circulation. J. Geophys. Res. Ocean. 119 (9), 5968-5991.

Churchill, J. H., Cornillon, P. C., Milkowski, G. W., 1986. A cyclonic eddy and shelfslope water exchange associated with a Gulf Stream warm-core ring. J. Geophys. Res. 91 (C8), 9615.

Churchill, J. H., Manning, J. P., Beardsley, R. C., 2003. Slope water intrusions onto Georges Bank. J. Geophys. Res. 108 (C11), 8012.

Cornillon, P. C., Weyer, R., Flierl, G. R., 1989. Translational Velocity of Warm Core Rings Relative to the Slope Water. J. Phys. Oceanogr. 19 (9), 1317-1332.

Csanady, G. T., 1978. The Arrested Topographic Wave. J. Phys. Oceanogr. 8 (1), 4762.

Dewar, W. K., Berloff, P., Hogg, A. M., 2011. Submesoscale generation by boundaries. J. Mar. Res. 69 (4), 501-522.

Dewar, W. K., Hogg, A. M., 2010. Topographic inviscid dissipation of balanced flow. Ocean Model. 32 (1-2), 1-13.

Early, J. J., Samelson, R. M., Chelton, D. B., 2011. The Evolution and Propagation of Quasigeostrophic Ocean Eddies. J. Phys. Oceanogr. 41 (8), 1535-1555.

Evans, R. H., Baker, K. S., Brown, O. B., Smith, R. C., 1985. Chronology of warm-core ring 82B. J. Geophys. Res. 90 (C5), 8803.

Ferrari, R., Wunsch, C., 2009. Ocean Circulation Kinetic Energy: Reservoirs, Sources, and Sinks. Annu. Rev. Fluid Mech. 41 (1), 253-282.

Flagg, C. N., 1987. Hydrographic Structure and Variability. In: Backus, R., Bourne, D. W. (Eds.), Georg. Bank. MIT Press, pp. 108-124.

Flierl, G. R., 1984. Rossby Wave Radiation from a Strongly Nonlinear Warm Eddy. J. Phys. Oceanogr. 14 (1), 47-58.

Flierl, G. R., 1987. Isolated Eddy Models in Geophysics. Annu. Rev. Fluid Mech. $19(1), 493-530$. 
Flierl, G. R., 1994. Rings: Semicoherent oceanic features. Chaos 4 (2), 355-367.

Flierl, G. R., Stern, M. E., Whitehead, J. A., 1983. The physical significance of modons: Laboratory experiments and general integral constraints. Dyn. Atmos. Ocean. 7 (4), 233-263.

Frolov, S. A., Sutyrin, G. G., Rowe, G. D., Rothstein, L. M., 2004. Loop Current Eddy Interaction with the Western Boundary in the Gulf of Mexico. J. Phys. Oceanogr. 34 (10), 2223-2237.

Garfield, N., Evans, D. L., 1987. Shelf water entrainment by Gulf Stream warm-core rings. J. Geophys. Res. 92 (C12), 13003.

Garvine, R. W., Wong, K.-C., Gawarkiewicz, G. G., 1989. Quantitative properties of shelfbreak eddies. J. Geophys. Res. 94 (C10), 14475.

Gawarkiewicz, G. G., Bahr, F., Beardsley, R. C., Brink, K. H., 2001. Interaction of a Slope Eddy with the Shelfbreak Front in the Middle Atlantic Bight*. J. Phys. Oceanogr. 31 (1987), 2783-2796.

Halliwell, G. R., Mooers, C. N. K., 1979. The space-time structure and variability of the shelf water-slope water and Gulf Stream surface temperature fronts and associated warm-core eddies. J. Geophys. Res. 84 (C12), 7707.

Holton, J. R., 1965. The influence of Viscous Boundary Layers on Transient Motions in a Stratified Rotating Fluid. Part I. J. Atmos. Sci. 22 (4), 402-411.

Houghton, R. W., Schlitz, R., Beardsley, R. C., Butman, B., Chamberlin, J. L., 1982. The Middle Atlantic Bight Cold Pool: Evolution of the Temperature Structure During Summer 1979. J. Phys. Oceanogr. 12 (10), 1019-1029.

Jacob, J. P., Chassignet, E. P., Dewar, W. K., 2002. Influence of Topography on the Propagation of Isolated Eddies. J. Phys. Oceanogr. 32 (10), 2848-2869.

Joyce, T. M., 1984. Velocity and Hydrographic Structure of a Gulf Stream WarmCore Ring. J. Phys. Oceanogr. 14 (5), 936-947.

Joyce, T. M., Bishop, J. K., Brown, O. B., 1992. Observations of offshore shelf-water transport induced by a warm-core ring. Deep Sea Res. Part A Oceanogr. Res. Pap. 39, S97-S113.

Joyce, T. M., Kennelly, M. A., 1985. Upper-ocean velocity structure of Gulf Stream warm-core ring 82B. J. Geophys. Res. 90 (C5), 8839.

Kamenkovich, V. M., Leonov, Y. P., Nechaev, D. A., Byrne, D. A., Gordon, A. L., 1996. On the Influence of Bottom Topography on the Agulhas Eddy. J. Phys. Oceanogr. $26(6), 892-912$.

Kelly, K. A., Chapman, D. C., 1988. The Response of Stratified Shelf and Slope Waters to Steady Offshore Forcing. J. Phys. Oceanogr. 18 (6), 906-925. 
Kennelly, M. A., Evans, R. H., Joyce, T. M., 1985. Small-scale cyclones on the periphery of a Gulf Stream warm-core ring. J. Geophys. Res. 90 (C5), 8845.

LaCasce, J. H., 1996. Baroclinic vortices over a sloping bottom. Ph.D. thesis, Massachusetts Institute of Technology and Woods Hole Oceanographic Institution, Woods Hole, MA.

LaCasce, J. H., 1998. A Geostrophic Vortex over a Slope. J. Phys. Oceanogr. 28 (12), 2362-2381.

Ladd, C., Mordy, C. W., Kachel, N. B., Stabeno, P. J., 2007. Northern Gulf of Alaska eddies and associated anomalies. Deep Sea Res. Part I Oceanogr. Res. Pap. 54 (4), 487-509.

Lee, C. M., Brink, K. H., 2010. Observations of storm-induced mixing and Gulf Stream Ring incursion over the southern flank of Georges Bank: Winter and summer 1997. J. Geophys. Res. 115 (C8), 1-19.

Lentz, S. J., 2008. Observations and a Model of the Mean Circulation over the Middle Atlantic Bight Continental Shelf. J. Phys. Oceanogr. 38 (6), 1203.

Lentz, S. J., 2010. The Mean Along-Isobath Heat and Salt Balances over the Middle Atlantic Bight Continental Shelf. J. Phys. Oceanogr. 40 (5), 934-948.

Linder, C. A., Gawarkiewicz, G. G., 1998. A climatology of the shelfbreak front in the Middle Atlantic Bight. J. Geophys. Res. 103 (C9), 18405.

Louis, J. P., Smith, P. C., 1982. The Development of the Barotropic Radiation Field of an Eddy over a Slope. J. Phys. Oceanogr. 12 (1), 56-73.

Marchesiello, P., McWilliams, J. C., Shchepetkin, A. F., 2001. Open boundary conditions for long-term integration of regional oceanic models. Ocean Model. 3 (1-2), $1-20$.

Mason, E., Molemaker, M. J., Shchepetkin, A. F., Colas, F., McWilliams, J. C., Sangrà, P., 2010. Procedures for offline grid nesting in regional ocean models. Ocean Model. 35 (1-2), 1-15.

McWilliams, J. C., Flierl, G. R., 1979. On the Evolution of Isolated, Nonlinear Vortices. J. Phys. Oceanogr. 9 (6), 1155-1182.

Mied, R. P., Lindemann, G. J., 1979. The Propagation and Evolution of Cyclonic Gulf Stream Rings. J. Phys. Oceanogr. 9 (6), 1183-1206.

Mizobata, K., Wang, J., Saitoh, S.-i., 2006. Eddy-induced cross-slope exchange maintaining summer high productivity of the Bering Sea shelf break. J. Geophys. Res. 111 (C10), C10017.

Morgan, C. W., Bishop, J. M. J., 1977. An Example of Gulf Stream Eddy-Induced Water Exchange in the Mid-Atlantic Bight. J. Phys. Oceanogr. 7 (3), 472-479. 
Mountain, D. G., Pastuszak, M., Busch, D. A., 1989. Slope Water Intrusion to the Great South Channel During Autumn, 1977-85. J. Northwest Atl. Fish. Sci. 9, 97102.

Nelson, D. M., Ducklow, H. W., Hitchcock, G. L., Brzezinski, M. A., Cowles, T. J., Garside, C., Gould, R. W., Joyce, T. M., Langdon, C., McCarthy, J. J., Yentsch, C. S., 1985. Distribution and composition of biogenic particulate matter in a Gulf Stream warm-core ring. Deep Sea Res. Part A Oceanogr. Res. Pap. 32 (11), 13471369.

Nof, D., 1983. On the migration of isolated eddies with application to Gulf Stream rings. J. Mar. Res. 41 (3), 399-425.

Nof, D., 1988. Eddy-wall interactions. J. Mar. Res. 46 (3), 527-555.

Nof, D., 1999. Strange encounters of eddies with walls. J. Mar. Res. 57 (5), 739-761.

Nycander, J., 2001. Drift Velocity of Radiating Quasigeostrophic Vortices. J. Phys. Oceanogr. 31 (8), 2178-2185.

Oey, L.-Y., Zhang, H., 2004. The generation of subsurface cyclones and jets through eddy-slope interaction. Cont. Shelf Res. 24 (18), 2109-2131.

Okkonen, S. R., Weingartner, T. J., Danielson, S., Musgrave, D., Schmidt, G., 2003. Satellite and hydrographic observations of eddy-induced shelf-slope exchange in the northwestern Gulf of Alaska. J. Geophys. Res. 108 (C2), 3033.

Olson, D. B., 1991. Rings in the Ocean. Annu. Rev. Earth Planet. Sci. 19 (1), 283-311.

Olson, D. B., Schmitt, R. W., Kennelly, M., Joyce, T. M., 1985. A two-layer diagnostic model of the long-term physical evolution of warm-core ring 82B. J. Geophys. Res. 90 (C5), 8813.

Peliz, Á., Santos, A. M. P., Oliveira, P. B., Dubert, J., 2004. Extreme cross-shelf transport induced by eddy interactions southwest of Iberia in winter 2001. Geophys. Res. Lett. 31 (8), $2-5$.

Ramp, S. R., Beardsley, R. C., Legeckis, R., 1983. An Observation of Frontal Wave Development on a Shelf-Slope/Warm Core Ring Front Near the Shelf Break South of New England. J. Phys. Oceanogr. 13 (5), 907-912.

Roberts, M. J., Ternon, J.-F., Morris, T., 2014. Interaction of dipole eddies with the western continental slope of the Mozambique Channel. Deep Sea Res. Part II Top. Stud. Oceanogr. 100, 54-67.

Schlitz, R. J., 2003. Interaction of shelf water with warm-core rings, focusing on th kinetics and statistics of shelf water entrained within streamers. NOAA Tech. Memo. NMFS-NE-170. 
Schlitz, R. J., Manning, J. P., Smith, K. W., 2001. Structure and transport of alongshelf currents across the southern flank of Georges Bank during late summer, 1982. Deep Sea Res. Part II Top. Stud. Oceanogr. 48 (1-3), 341-372.

Shapiro, G. I., Stanichny, S. V., Stanychna, R. R., 2010. Anatomy of shelf-deep sea exchanges by a mesoscale eddy in the North West Black Sea as derived from remotely sensed data. Remote Sens. Environ. 114 (4), 867-875.

Shaw, P.-T., Divakar, S., 1991. Generation of Topographic Waves over the Continental Margin. J. Phys. Oceanogr. 21 (7), 1032-1042.

Shchepetkin, A. F., McWilliams, J. C., 2003. A method for computing horizontal pressure-gradient force in an oceanic model with a nonaligned vertical coordinate. J. Geophys. Res. 108 (C3), 3090.

Shchepetkin, A. F., McWilliams, J. C., 2005. The regional oceanic modeling system (ROMS): a split-explicit, free-surface, topography-following-coordinate oceanic model. Ocean Model. 9 (4), 347-404.

Shi, C., Nof, D., 1993. The splitting of eddies along boundaries. J. Mar. Res. 51 (4), 771-795.

Shi, C., Nof, D., 1994. The Destruction of Lenses and Generation of Wodons. J. Phys. Oceanogr. 24 (6), 1120-1136.

Smith, D. C., O'Brien, J. J., 1983. The Interaction of a Two-Layer Isolated Mesoscale Eddy With Bottom Topography. J. Phys. Oceanogr. 13 (9), 1681-1697.

Smith, P. C., 1978. Low-frequency fluxes of momentum, heat, salt, and nutrients at the edge of the Scotian Shelf. J. Geophys. Res. 83 (C8), 4079.

Stewart, A. L., Thompson, A. F., 2015. Eddy-mediated transport of warm Circumpolar Deep Water across the Antarctic Shelf Break. Geophys. Res. Lett. 42 (2), 432-440.

Talley, L. D., Pickard, G. L., Emery, W. J., Swift, J. H., 2011. Descriptive Physical Oceanography. Academi.

Tang, C. L., Bennett, A. S., Lawrence, D. J., 1985. Thermohaline intrusions in the frontal zones of a warm-core ring observed by Batfish. J. Geophys. Res. 90 (C5), 8928.

Thierry, V., Morel, Y., 1999. Influence of a Strong Bottom Slope on the Evolution of a Surface-Intensified Vortex. J. Phys. Oceanogr. 29 (5), 911-924.

Trowbridge, J. H., Lentz, S. J., 1991. Asymmetric Behavior of an Oceanic Boundary Layer above a Sloping Bottom. J. Phys. Oceanogr. 21 (8), 1171-1185.

Ullman, D. S., Codiga, D. L., Pfeiffer-Herbert, A., Kincaid, C. R., 2014. An anomalous near-bottom cross-shelf intrusion of slope water on the southern New England continental shelf. J. Geophys. Res. Ocean. 119 (3), 1739-1753. 
Vukovich, F. M., Waddell, E., 1991. Interaction of a Warm Ring with the Western Slope in the Gulf of Mexico. J. Phys. Oceanogr. 21 (7), 1062-1074.

Wang, X., 1992. Interaction of an eddy with a continental slope. Ph.D. thesis, Massachusetts Institute of Technology.

Wei, J., Wang, D.-P., 2009. A three-dimensional model study of warm core ring interaction with continental shelf and slope. Cont. Shelf Res. 29 (13), 1635-1642.

Wei, J., Wang, D.-P., Flagg, C. N., 2008. Mapping Gulf Stream warm core rings from shipboard ADCP transects of the Oleander Project. J. Geophys. Res. 113 (C10), $1-12$.

Whitehead, J. A., 1985. The deflection of a baroclinic jet by a wall in a rotating fluid. J. Fluid Mech. 157, 79.

Zhang, W. G., Gawarkiewicz, G. G., 2015. Dynamics of the direct intrusion of Gulf Stream ring water onto the Mid-Atlantic Bight shelf. Geophys. Res. Lett. 42 (18), 7687-7695.

Zhang, Y., 2009. Slope / shelf Circulation and Cross-slope / shelf Transport out of a Bay driven by Eddies from the Open Ocean. Ph.D. thesis, Massachusetts Institute of Technology and Woods Hole Oceanographic Institution.

Zhang, Y., Pedlosky, J., Flierl, G. R., 2011. Shelf Circulation and Cross-Shelf Transport out of a Bay Driven by Eddies from an Open-Ocean Current. Part I: Interaction between a Barotropic Vortex and a Steplike Topography. J. Phys. Oceanogr. 41 (5), 889-910.

Zhou, F., Shapiro, G., Wobus, F., 2014. Cross-shelf exchange in the northwestern Black Sea. J. Geophys. Res. Ocean. 119 (4), 2143-2164. 